\author{
UNIVERSIDADE DE SÃO PAULO \\ ESCOLA DE ENGENHARIA DE SÃO CARLOS \\ DEPARTAMENTO DE ENGENHARIA DE ESTRUTURAS
}

WINSTON JUNIOR ZUMAETA MONCAYO

\title{
Comportamento residual do concreto leve com pérolas de EPS após situação de incêndio
}

SÃO CARLOS - SP 



\title{
Comportamento residual do concreto leve com pérolas de EPS após situação de incêndio
}

\author{
VERSÃO CORRIGIDA \\ A versão original encontra-se na Escola de Engenharia de São Carlos
}

Tese apresentada à Escola de Engenharia de São Carlos da Universidade de São Paulo como parte dos requisitos para obtenção do título de Doutor em Ciências, Programa de Engenharia Civil (Estruturas).

Área de concentração: Estruturas

Orientador: Prof. Dr. Libânio Miranda Pinheiro

SÃO CARLOS - SP 
AUTORIZO A REPRODUÇÃO TOTAL OU PARCIAL DESTE TRABALHO, POR QUALQUER MEIO CONVENCIONAL OU ELETRÔNICO, PARA FINS DE ESTUDO E PESQUISA, DESDE QUE CITADA A FONTE.

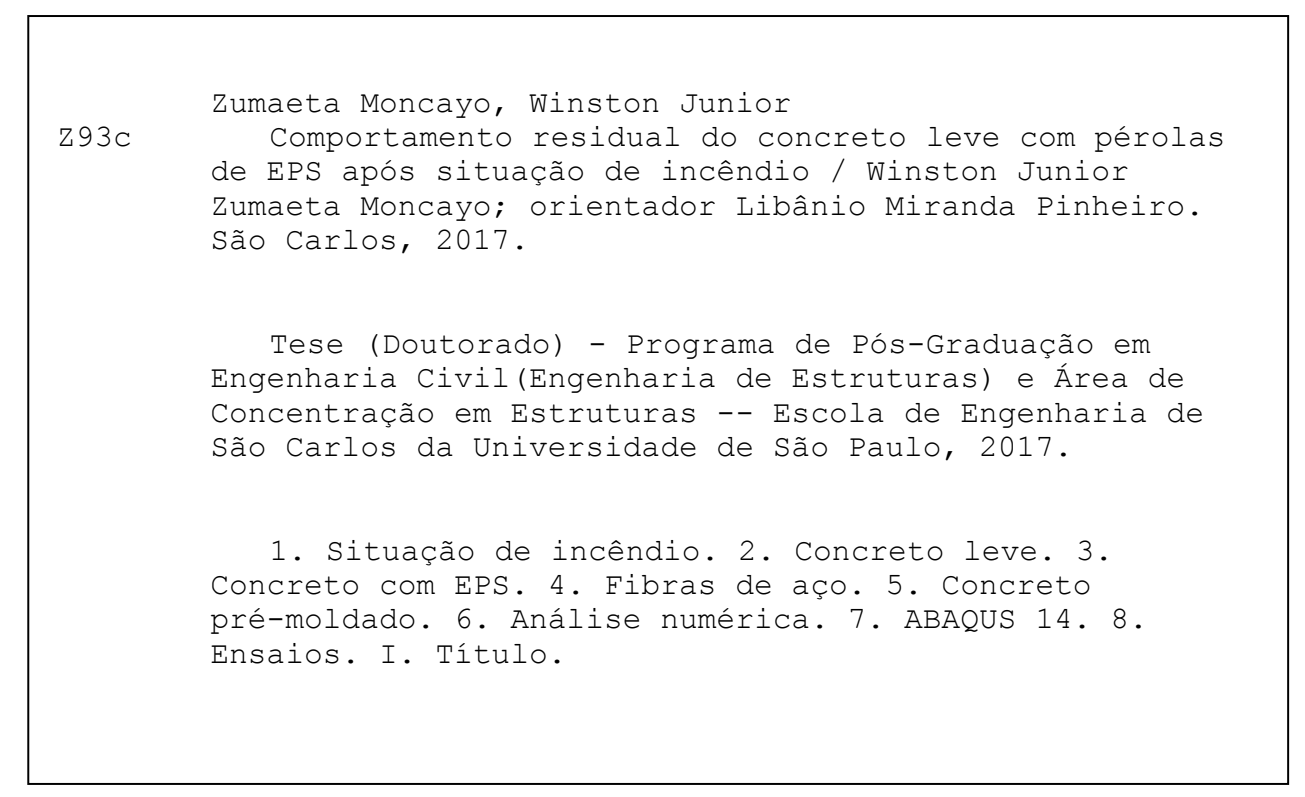




\section{FOLHA DE JULGAMENTO}

Candidato: Licenciado WINSTON JUNIOR ZUMAETA MONCAYO.

Título da tese: "Comportamento residual do concreto leve com pérolas de EPS após situação de incêndio".

Data da defesa: 15/02/2017.

\section{Comissão Julgadora:}

Prof. Dr. Libânio Miranda Pinheiro

(Orientador)

(Escola de Engenharia de São Carlos/EESC)

Prof. Associado Jorge Munaiar Neto

(Escola de Engenharia de São Carlos/EESC)

Prof. Dr. Armando Lopes Moreno Junior

(Universidade Estadual de Campinas/UNICAMP)

Prof. Dr. Geralldo Silveira Leite Junior

(Centro Universitário Adventista de São Paulo/UNASP)

Dra. Bruna Catoia

(Universidade Federal de São Carlos/UFSCar)
Resultado:

APROVADO
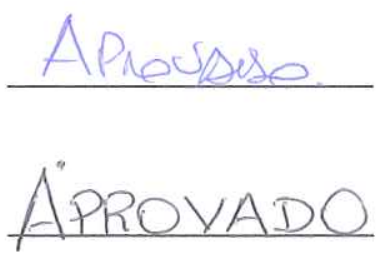

APROUADO

APROVADO

Coordenador do Programa de Pós-Graduação em Engenheira Civil (Engenharia de Estruturas):

Prof. Titular Humberto Breves Coda

Presidente da Comissão de Pós-Graduação:

Prof. Associado Luís Fernando Costa Alberto 

Aos meus pais, Winston e Martha. 



\section{AGRADECIMENTOS}

A Deus, meu pai e minha mãe, que foram muito importantes para esta conquista.

Ao prof. Libânio Miranda Pinheiro, por todos os ensinamentos, por sempre estar disposto a ajudar no que for necessário, pela amizade, e principalmente por ser um excelente professor e orientador.

À minha namorada Lídici Pomin de Simas, que me ajudou bastante em todas as etapas da realização desta tese. Obrigado por todo o amor e carinho que tem por mim.

Aos meus irmãos, Emerson, Gladys e Vivian, por todo apoio e incentivo, mesmo estando distantes.

À Universidade Federal do Amazonas, por ter concedido o afastamento de minhas atividades como docente, para a conclusão desta tese. E aos professores Elias Simão Assayag, Raimundo Pereira de Vasconcelos e Wagner Queiroz Silva, pelo apoio em todo o processo de solicitação deste afastamento.

Ao prof. Armando Lopes Moreno Junior, por todas as dicas e sugestões, principalmente por todo o apoio concedido para a realização da parte experimental no laboratório da Unicamp.

Ao prof. Jorge Munaiar Neto, pelas excelentes sugestões no exame de qualificação.

Ao técnico Luciano Passos, do laboratório de Concreto do Departamento de Estruturas da Faculdade de Engenharia Civil da UNICAMP.

Aos colegas e amigos Bianca Pereira Moreira Ozório, pela grande ajuda durante as concretagens, Gisele Cristina Antunes Martins, pela ajuda com o software Abaqus e pelas valiosas sugestões para a realização da parte experimental envolvendo altas temperaturas, e Fábio Martins Rocha, pela colaboração com o software Abaqus.

A todos os amigos que fiz durante o mestrado e o doutorado na EESC - USP.

Aos funcionários do laboratório do Departamento de Engenharia de Estruturas da Escola de Engenharia de São Carlos, os quais tiveram grande importância, pois sempre foram muito prestativos durante a realização dos ensaios para este trabalho.

Às funcionárias da secretaria do Departamento de Engenharia de Estruturas da Escola de Engenharia de São Carlos, sempre muito atenciosas. 



\section{RESUMO}

ZUMAETA MONCAYO, W. J. Comportamento residual do concreto leve com pérolas de EPS após situação de incêndio. 2016. 202 p. Tese (Doutorado em Engenharia de Estruturas) - Escola de Engenharia de São Carlos, Universidade de São Paulo, São Carlos, 2017.

O estudo do comportamento de estruturas em situação de incêndio tem se tornado cada vez mais importante devido às graves consequências de incêndios que têm ocorrido no Brasil e em outros países. Por esse motivo, este trabalho tem como objetivo estudar o comportamento residual do concreto com pérolas de EPS sob altas temperaturas, pois se pretende utilizar esse concreto em painéis e em lajes pré-moldadas para a construção de edifícios de pequeno e de médio porte, por ele ser um concreto muito leve, com massa específica em torno de $1170 \mathrm{~kg} / \mathrm{m}^{3}$, um pouco menos da metade da relativa ao concreto convencional. Para este estudo, foram utilizados corpos de prova cilíndricos e prismáticos, seguindo recomendações nacionais e internacionais. As análises foram realizadas para $200{ }^{\circ} \mathrm{C}, 400{ }^{\circ} \mathrm{C}$ e $600^{\circ} \mathrm{C}$, e foram avaliadas: massa específica, resistência à compressão, módulo de elasticidade estático, módulo de elasticidade dinâmico, resistência à tração por compressão diametral, resistência à tração na flexão e fator de tenacidade. Para esses dois últimos, foram utilizadas fibras de aço nas seguintes taxas: 0,3\%, 0,6\% e $0,9 \%$. Os resultados foram comparados com os de concreto com EPS em temperatura ambiente e com os de concreto convencional, que já tem alguns resultados disponíveis na literatura técnica. Também foi realizada uma análise térmica numérica, utilizando o software ABAQUS 14, para calibrar duas propriedades: calor específico e condutividade térmica. Para isso, foram utilizados resultados obtidos na análise experimental. Os resultados numéricos e experimentais foram coerentes com os esperados. Os experimentais apresentaram redução de valor à medida que a temperatura aumentava, e comportamento pior em comparação ao concreto convencional. A adição de fibras aumentou a resistência à tração na flexão e também a tenacidade, tanto em temperatura ambiente quanto em temperaturas elevadas.

Palavras-chave: Situação de incêndio. Concreto leve. Concreto com EPS. Fibras de aço. Concreto pré-moldado. Análise numérica. ABAQUS 14. Ensaios. 



\section{ABSTRACT}

ZUMAETA MONCAYO, W. J. Residual behavior of lightweight concrete with EPS beads after fire. 2016. 202 p. Thesis (Doctorate in Structural Engineering) - Escola de Engenharia de São Carlos, Universidade de São Paulo, São Carlos, 2017.

The study of the structures behavior in fire has become increasingly important due to the serious consequences of fires that have occurred in Brazil and in other countries. Therefore, this work aims to study the residual behavior of concrete with EPS beads under high temperatures, because it is intended to use it in panels and precast slabs for the construction of small and medium-sized buildings, for it is a very light concrete, with a density around $1170 \mathrm{~kg} / \mathrm{m}^{3}$, slightly less than half that of conventional concrete. For this study, cylindrical and prismatic specimens were used, following national and international standards. The analyses were carried out to $200{ }^{\circ} \mathrm{C}, 400{ }^{\circ} \mathrm{C}$ and $600{ }^{\circ} \mathrm{C}$, and were evaluated: density, compression strength, static modulus of elasticity, dynamic modulus of elasticity, splitting tensile strength, flexural tensile strength, and toughness factor. For the latter two, steel fibers were used at the following rates: $0.3 \%, 0.6 \%$ and $0.9 \%$. The results were compared with those of concrete with EPS at room temperature, and with conventional concrete which already has some results available in the technical literature. A numerical thermal analysis was also performed, using ABAQUS 14 software, to calibrate two properties: specific heat and thermal conductivity. For this, results obtained in the experimental analysis were used. The numerical and experimental results were consistent with those expected. The experimental results showed reduction of value as temperature increased, and worst behavior in comparison to ordinary concrete. The addition of fibers increased tensile strength in bending and also the toughness, both at room temperature and at elevated temperatures.

Keywords: Fire situation. Lightweight concrete. Concrete with EPS. Steel fibers. Precast concrete. Numerical analysis. ABAQUS 14. Tests. 



\section{LISTA DE FIGURAS}

Figura 2.1. (a) Concreto com agregados leves, (b) concreto celular e (c) concreto sem finos.

Figura 2.2. Embarcação construída com concreto leve. 40

Figura 2.3. (a) Lake Point, (b) Edifício da BMW, (c) Raymond-Hillard e (d) Standard Bank 40

Figura 2.4. Ponte da Baía de São Francisco - Oakland.........................................41

Figura 2.5. Estrutura interna do concreto leve estrutural com pérolas de EPS. .......42

Figura 2.6. Painel de concreto leve com EPS.

Figura 2.7. Peças de concreto leve com EPS: (a) Laje durante içamento;

(b) Painel PI 43

Figura 2.8. Painel de fechamento de concreto leve com EPS..............................44

Figura 2.9. Laje de concreto leve com EPS..................................................... 44

Figura 3.1. Efeitos de colapsos devidos a um incêndio........................................47

Figura 3.2. Colapso parcial do Ronan Point, em Londres - UK, 1968 ....................48

Figura 3.3. Colapso parcial da Katrantzos Sport em Atenas - Grécia, 1980 …........48

Figura 3.4. Colapso total da Biblioteca Municipal de Linköping - Suécia, 1996 .......49

Figura 3.5. Colapso total de um edifício residencial em São Petersburgo - Rússia,

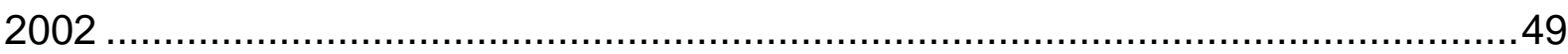

Figura 3.6. Colapso total de um edifício residencial no Cairo - Egito, 2004 .............49

Figura 3.7. Colapso localizado da laje de cobertura de um estacionamento subterrâneo em Gretzenbach - Suíça, 2004.

Figura 3.8. (a) Incêndio no edifício Andraus em 1972 e (b) edifício Joelma em 1974.

Figura 3.9. Colapso parcial do edifício Sede II da CESP em São Paulo - Brasil, 1987

Figura 3.10. Colapso total do depósito das lojas Zêlo, em Barueri (SP) - Brasil, 1995.

Figura 3.11. Danos nos elementos estruturais do Condomínio Edifício Cacique, em Porto Alegre - Brasil, 1996. 
Figura 3.12. Colapso total de um edifício em Nova Iguaçu, RJ - Brasil, 2000........ 53

Figura 3.13. Fluxo de Calor Convectivo.................................................. 54

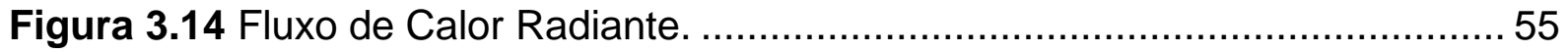

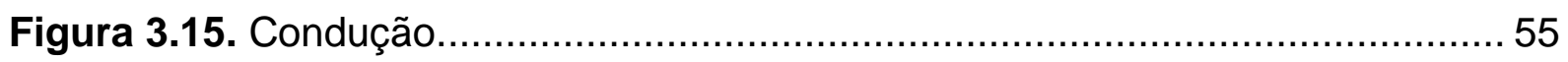

Figura 3.16. Curva tempo-temperatura típica de um incêndio real. ........................ 56

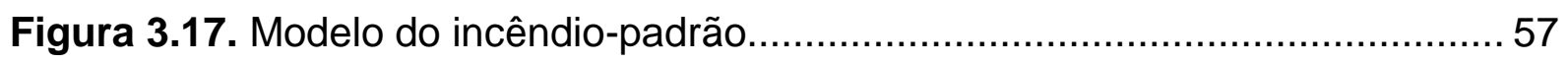

Figura 3.18. Curva Padrão - Temperatura x tempo (ISO 834:1999) …................... 59

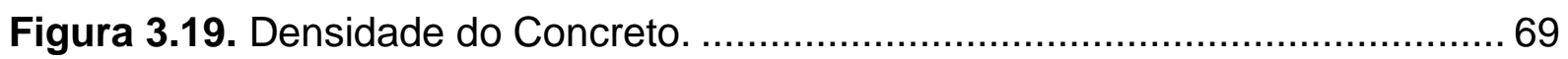

Figura 3.20. Calor específico do concreto....................................................... 71

Figura 3.21. Condutividade térmica do concreto......................................... 72

Figura 3.22. Alongamento específico do concreto. ............................................ 74

Figura 3.23. Fator de redução dos concretos em função da temperatura................ 75

Figura 3.24. Fator de redução da resistência do aço de armadura passiva em

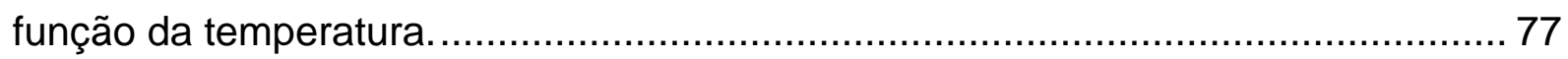

Figura 3.25. Armadura exposta após incêndio no Great Belt Tunnel, em 1994...... 79

Figura 3.26. Armadura exposta após incêndio no Channel Tunnel, em 1996..........80

Figura 3.27. Situação de lascamento após incêndio no Mont Blanc Tunnel, em 1999

Figura 3.28. Pilar apresentando lascamento do cobrimento após incêndio, em 1998.

Figura 3.29. Consequências do incêndio na Arena Pantanal - lascamento pilar/parede. 81

Figura 4.1. Esquema de concentração de tensões para um concreto sem fibras (a) e com fibras (b) - (Nunes, Tanesi, Figueiredo, 1997). 86

Figura 4.2. Curvas médias de carga versus deslocamento obtidas no ensaio de tração na flexão de concretos com $\mathrm{f}_{\mathrm{ck}}$ de $20 \mathrm{MPa}$ com a variação do consumo de fibras de aço (FIGUEIREDO, NUNES \& TANESI, 2000).

Figura 4.3. Ensaio de tração na flexão de compósitos reforçados com volume de fibras (VF) abaixo (A), acima (B) e igual (C) ao volume crítico (Figueiredo, 2000)...88 Figura 4.4. Relação entre os agregados graúdos e as fibras: (a) compatibilidade dimensional e (b) sem compatibilidade (Figueiredo, 2000). 90 
Figura 4.5. Esquema adotado no ensaio de dobramento da fibra de aço .92

Figura 4.6. Defeitos nas fibras: (a) Fibras emendadas pelo topo e (b) Fibras sem ancoragem correta (ABNT NBR 15530, 2007) ……..........................................

Figura 4.7. Esquema do ensaio de tração na flexão com o sistema "yoke" ..............94

Figura 4.8. Gráfico carga-deslocamento do ensaio de tensão na flexão ..................95

Figura 5.1. Laboratório de Estruturas e Materiais da UNICAMP..........................101

Figura 5.2. Forno fechado utilizado para o aquecimento dos corpos de prova......101

Figura 5.3. Lateral do forno utilizado para o aquecimento dos corpos de prova. ...102

Figura 5.4. Forno aberto utilizado para o aquecimento dos corpos de prova.........102

Figura 5.5. Painel eletrônico para controle de temperatura ..................................103

Figura 5.6. Termopar de controle dentro do forno ............................................104

Figura 5.7. Resistências para o aquecimento do forno ........................................104

Figura 5.8. Distância entre os corpos de prova e resistências ..............................105

Figura 5.9. Controle da temperatura do forno - aproximadamente $10 \mathrm{~h} 15 \mathrm{~m}$ da

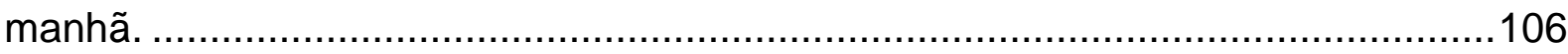

Figura 5.10. Controle da temperatura do forno - aproximadamente $13 \mathrm{~h} 15 \mathrm{~m}$.....106

Figura 5.11. Gráfico completo da temperatura do forno: aquecimento, constante

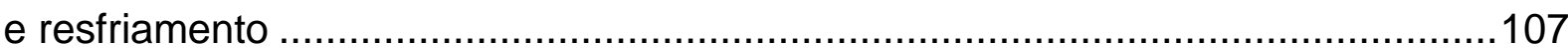

Figura 5.12. Disposição dos prismas dentro do forno. ......................................111

Figura 5.13. (a) Filme de PVC, (b) cilindro com o filme de PVC e (c) prisma com

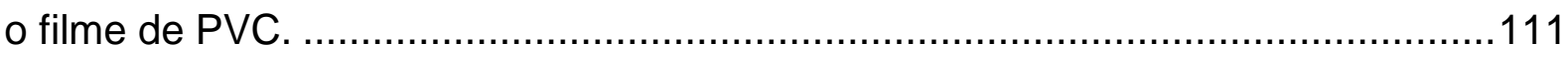

Figura 5.14. Tubo corrugado flexível colocado na parte superior do forno..............112

Figura 5.15. Lã de vidro: (a) rolo; (b) imagem ampliada.......................................113

Figura 5.16. Duto semidec $(76 \mathrm{~mm})$ semiflexível feito de alumínio. ........................114

Figura 5.17. Filtro de carvão ativado FXS Carbo..............................................114

Figura 5.18. Cimento utilizado - CP V-ARI FÁCIL. ............................................115

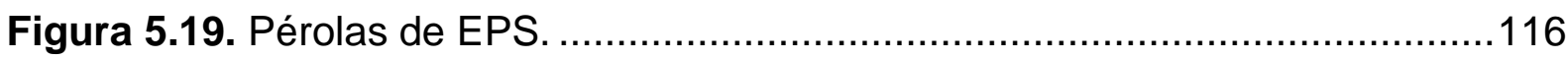

Figura 5.20. Superplastificante da marca Viapol .............................................117

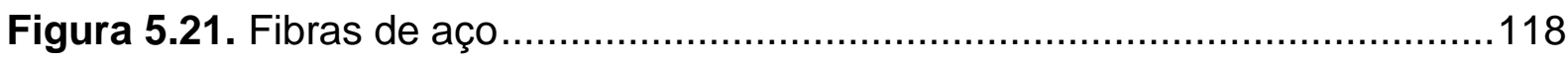

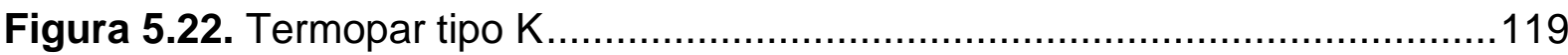


Figura 5.23. Máquina de solda e placa de cobre.

Figura 5.24. Posição dos termopares nos cilindros de concreto........................... 120

Figura 5.25. Posição dos termopares nos prismas de concreto. ........................... 120

Figura 5.26. Formas dos corpos de prova cilíndricos (a) com $10 \mathrm{~cm} \times 20 \mathrm{~cm}$ e (b) $\mathrm{com} 10 \mathrm{~cm} \times 30 \mathrm{~cm}$.

Figura 5.27. Formas dos corpos de prova prismáticos com $15 \mathrm{~cm} \times 15 \mathrm{~cm} \times 50 \mathrm{~cm}$. 121

Figura 5.28. Misturador de 350 litros. 122

Figura 5.29. (a) Ensaio do tronco de cone e (b) caso em que se avaliou o espalhamento.

Figura 6.1. Fator de redução da massa específica em função da temperatura. .... 129

Figura 6.2. Corpo de prova cilíndrico, instrumentado, sendo ensaiado na máquina INSTRON.

Figura 6.3. Corpo de prova cilíndrico após a ruptura no ensaio de resistência à compressão (temperatura ambiente).

Figura 6.4. Gráfico de tensão versus deformação do ensaio de resistência à compressão dos corpos de prova relativos à temperatura ambiente.

Figura 6.5. Corpo de prova cilíndrico após ruptura no ensaio de resistência à compressão $\left(200^{\circ} \mathrm{C}\right)$.

Figura 6.6. Gráfico de tensão versus deformação do ensaio de resistência à compressão dos corpos de prova aquecidos a $200{ }^{\circ} \mathrm{C}$.

Figura 6.7. Corpo de prova cilíndrico após ruptura no ensaio de resistência à compressão $\left(400^{\circ} \mathrm{C}\right)$.

Figura 6.8. Gráfico de tensão versus deformação do ensaio de resistência à compressão dos corpos de prova aquecidos a $400 \stackrel{\circ}{ } \mathrm{C}$.

Figura 6.9. Corpo de prova cilíndrico após ruptura no ensaio de resistência à compressão $\left(600^{\circ} \mathrm{C}\right)$. 136

Figura 6.10. Gráfico de tensão versus deformação do ensaio de resistência à compressão dos corpos de prova aquecidos a $600^{\circ} \mathrm{C}$.

Figura 6.11. Resistência à compressão em função da temperatura. 138

Figura 6.12. Fator de redução da resistência à compressão em função da temperatura. 
Figura 6.13. Módulo de elasticidade estático $\left(E_{c}\right)$ em função da temperatura

Figura 6.14. Fator de redução do módulo de elasticidade estático $\left(E_{c}\right)$ em função da temperatura.

Figura 6.15. Equipamento Sonelastic $\AA$

Figura 6.16. Módulo de elasticidade dinâmico $\left(E_{d}\right)$ em função da temperatura......148

Figura 6.17. Fator de redução do módulo de elasticidade dinâmico $\left(E_{d}\right)$ em função da temperatura.

Figura 6.18. Ensaio de resistência à tração por compressão diametral.

Figura 6.19. Resistência à tração por compressão diametral $\left(f_{c t, s p}\right)$ em função da temperatura.

Figura 6.20. Fator de redução da resistência à tração por compressão diametral $\left(f_{c t, s p}\right)$ em função da temperatura.

Figura 6.21. Corpo de prova prismático, instrumentado, sendo ensaiado na máquina INSTRON.

Figura 6.22. Corpo de prova prismático, sem fibras, após a ruptura no ensaio de resistência à tração na flexão (temperatura ambiente).

Figura 6.23. Gráfico carga versus deslocamento do ensaio de resistência à tração na flexão dos corpos de prova com o traço padrão, em temperatura ambiente.

Figura 6.24. Corpo de prova prismático, sem fibras, após a ruptura no ensaio de resistência à tração na flexão $(200 \stackrel{\circ}{\mathrm{C}})$.

Figura 6.25. Gráfico carga versus deslocamento do ensaio de resistência à tração na flexão dos corpos de prova com o traço padrão, aquecidos a $200{ }^{\circ} \mathrm{C} \ldots . .157$

Figura 6.26. Gráfico carga versus deslocamento do ensaio de resistência à tração na flexão dos corpos de prova com o traço padrão, aquecidos a $600{ }^{\circ} \mathrm{C} . . . .158$

Figura 6.27. Corpo de prova prismático com $0,3 \%$ de fibras, após a ruptura no ensaio de resistência à tração na flexão (temperatura ambiente).

Figura 6.28. Gráfico carga versus deslocamento do ensaio de resistência à tração na flexão dos corpos de prova com $0,3 \%$ de fibras de aço, para temperatura ambiente.

Figura 6.29. Corpo de prova prismático com $0,3 \%$ de fibras, após a ruptura no ensaio de resistência à tração na flexão $\left(200^{\circ} \mathrm{C}\right)$. 
Figura 6.30. Gráfico carga versus deslocamento do ensaio de resistência à tração na flexão dos corpos de prova com $0,3 \%$ de fibras de aço, aquecidos a $200 \stackrel{\circ}{\circ}$ 162

Figura 6.31. Gráfico carga versus deslocamento do ensaio de resistência à tração na flexão dos corpos de prova com $0,3 \%$ de fibras de aço, aquecidos a $600 \stackrel{\circ}{\circ}$. 163

Figura 6.32. Corpo de prova prismático com $0,6 \%$ de fibras, após a ruptura no ensaio de resistência à tração na flexão (temperatura ambiente). 165

Figura 6.33. Gráfico carga versus deslocamento do ensaio de resistência à tração na flexão dos corpos de prova com $0,6 \%$ de fibras de aço, para temperatura ambiente. 165

Figura 6.34. Gráfico carga versus deslocamento do ensaio de resistência à tração na flexão dos corpos de prova com $0,6 \%$ de fibras de aço, aquecidos a $200 \stackrel{\circ}{\circ}$. 167

Figura 6.35. Gráfico carga versus deslocamento do ensaio de resistência à tração na flexão dos corpos de prova com $0,6 \%$ de fibras de aço, aquecidos a $600 \stackrel{\circ}{\circ}$. 168

Figura 6.36. Corpo de prova prismático com $0,9 \%$ de fibras, após a ruptura no ensaio de resistência à tração na flexão (temperatura ambiente). 169

Figura 6.37. Gráfico carga versus deslocamento do ensaio de resistência à tração na flexão dos corpos de prova com $0,9 \%$ de fibras de aço, para temperatura ambiente.

Figura 6.38. Corpo de prova prismático com $0,9 \%$ de fibras, após a ruptura no ensaio de resistência à tração na flexão (200 $\left.{ }^{\circ} \mathrm{C}\right)$.

Figura 6.39. Gráfico carga versus deslocamento do ensaio de resistência à tração na flexão dos corpos de prova com $0,9 \%$ de fibras de aço, aquecidos a $200 \stackrel{\circ}{\circ}$. 172

Figura 6.40. Gráfico carga versus deslocamento do ensaio de resistência à tração na flexão dos corpos de prova com $0,9 \%$ de fibras de aço, aquecidos a $600 \stackrel{\circ}{\mathrm{C}}$. 173

Figura 6.41. Comparativo da resistência à tração na flexão em função da temperatura.

Figura 6.42. Comparativo da resistência à tração na flexão em função da taxa de fibras. 
Figura 6.43. Comparativo da resistência à tração na flexão em função da taxa de fibras, retirando os pontos referentes a $0,6 \%$ de fibras. 176

Figura 6.44. Comparativo do fator de tenacidade em função da temperatura. 177

Figura 6.45. Comparativo do fator de tenacidade em função da taxa de fibras 177

Figura 6.46. Comparativo do fator de tenacidade em função da taxa de fibras, retirando os pontos referentes a $0,6 \%$ de fibras. 178

Figura 7.1. Modelo numérico dos corpos de prova (a) cilíndricos e (b) prismáticos 179

Figura 7.2. Variação do calor no cilindro 182

Figura 7.3. Variação do calor no prisma 182

Figura 7.4. Gráfico comparativo entre o resultado experimental e o numérico para o cilindro. 183

Figura 7.5. Gráfico comparativo entre o resultado experimental e o numérico para o prisma. 184

Figura 7.6. Condutividade térmica versus temperatura 185

Figura 8.1. Comparativo entre as características estudadas com os corpos de prova cilíndricos 188 



\section{LISTA DE TABELAS}

Tabela 3.1. Tempos requeridos de resistência ao fogo (TRRF), em minutos. 60

Tabela 3.2. Classificação das edificações quanto à sua ocupação. 61

Tabela 3.3. Valores das cargas de incêndio específicas .65

Tabela 3.4. Fatores de ponderação das medidas de segurança contra incêndio 67

Tabela 3.5. Valores de $\gamma s 2$ em função do risco de ativação do incêndio (r) 68

Tabela 3.6. Valores de $\mathrm{k}_{\mathrm{c}, \theta}$ para concretos de massa específica normal $\left(2000 \mathrm{~kg} / \mathrm{m}^{3}\right.$ a $\left.2800 \mathrm{~kg} / \mathrm{m}^{3}\right)$ preparados com agregados predominantemente silicosos e calcários, respectivamente. 75

Tabela 4.1. Classificação de acordo com a geometria das fibras de aço 84

Tabela 4.2. Limite de resistência à tração das fibras de aço .91

Tabela 4.3. Fator de forma mínimo para as fibras de aço 93

Tabela 5.1. Taxa máxima recomendada de aquecimento e resfriamento de corpos de prova cilíndricos, segundo a RILEM. 100

Tabela 5.2. Esquema de corpos de prova para ensaios de $f_{c}$, $E_{c}$ e $E_{d}$ 108

Tabela 5.3. Esquema de corpos de prova para ensaios de $\mathrm{f}_{\mathrm{ct}, \mathrm{sp}}$ 109

Tabela 5.4. Esquema geral para ensaios com os corpos de prova prismáticos .....110

Tabela 5.5. Características físicas e químicas do cimento CP V-ARI. 115

Tabela 5.6. Granulometria da areia média. 116

Tabela 5.7. Granulometria das pérolas de EPS. 117

Tabela 5.8. Propriedades físicas e mecânicas das fibras FS8 Wirand. 118

Tabela 5.9. Propriedades dos traços estudados nesta pesquisa 123

Tabela 5.10. Carga máxima (C.M) e resistência $(R)$ do traço padrão, aos 28 e 100 dias.

Tabela 5.11. Carga máxima (C.M) e resistência $(R)$ do traço com $0,3 \%$ de fibra, aos 28 e 100 dias. 124

Tabela 5.12. Carga máxima (C.M) e resistência $(R)$ do traço com $0,6 \%$ de fibra, aos 28 e 100 dias. 
Tabela 5.13. Carga máxima (C.M) e resistência (R) do traço com $0,9 \%$ de fibra, aos 28 e 100 dias.

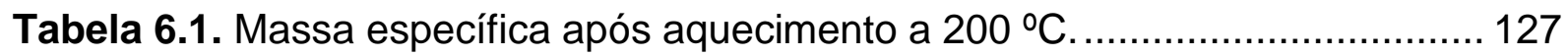

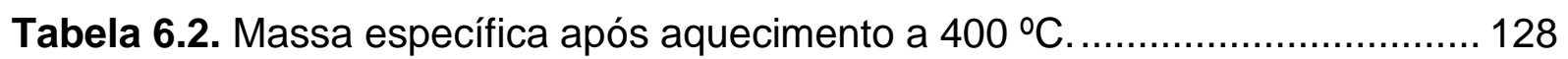

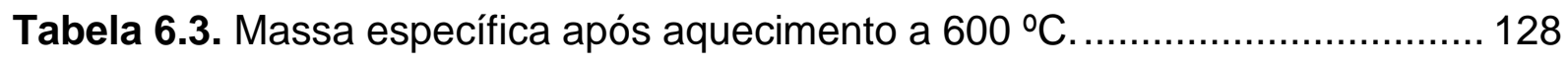

Tabela 6.4. Resistência à compressão dos corpos de prova relativos à temperatura ambiente.

Tabela 6.5. Resistência à compressão dos corpos de prova aquecidos a $200 \stackrel{\circ}{\circ} \mathrm{C} .134$

Tabela 6.6. Resistência à compressão dos corpos de prova aquecidos a $400^{\circ} \mathrm{C} .136$

Tabela 6.7. Resistência à compressão dos corpos de prova aquecidos a $600 \stackrel{\circ}{\circ} \mathrm{C} .138$

Tabela 6.8. Módulo de elasticidade estático $\left(E_{c}\right)$ dos corpos de prova em temperatura ambiente.

Tabela 6.9. Módulo de elasticidade estático $\left(E_{c}\right)$ dos corpos de prova aquecidos a $200 \stackrel{\circ}{\circ}$

Tabela 6.10. Módulo de elasticidade estático $\left(E_{c}\right)$ dos corpos de prova aquecidos a $400 \stackrel{\circ}{\circ}$.

Tabela 6.11. Módulo de elasticidade estático $\left(E_{c}\right)$ dos corpos de prova aquecidos a $600 \stackrel{\circ}{ } \mathrm{C}$.

Tabela 6.12. Módulo de elasticidade dinâmico $\left(E_{d}\right)$ dos corpos de prova em temperatura ambiente.

Tabela 6.13. Módulo de elasticidade dinâmico $\left(E_{d}\right)$ dos corpos de prova aquecidos a $200{ }^{\circ} \mathrm{C}$.

Tabela 6.14. Módulo de elasticidade dinâmico $\left(E_{d}\right)$ dos corpos de prova aquecidos a $400 \stackrel{\circ}{\circ}$.

Tabela 6.15. Módulo de elasticidade dinâmico $\left(E_{d}\right)$ dos corpos de prova aquecidos a $600 \stackrel{\circ}{\circ}$.

Tabela 6.16. Resistência à tração por compressão diametral ( $\left.f_{c t, s p}\right)$ para os corpos de prova em temperatura ambiente.

Tabela 6.17. Resistência à tração por compressão diametral ( $\left.f_{c t, s p}\right)$ dos corpos de prova aquecidos a $200 \stackrel{\circ}{ } \mathrm{C}$

Tabela 6.18. Resistência à tração por compressão diametral ( $\left.f_{c t, s p}\right)$ dos corpos de prova aquecidos a $400^{\circ} \mathrm{C}$ 
Tabela 6.19. Resistência à tração por compressão diametral ( $\left.f_{c t, s p}\right)$ dos corpos de prova aquecidos a $600 \stackrel{\circ}{\mathrm{C}}$.

Tabela 6.20. Resistência à tração na flexão $\left(f_{c t, f}\right)$ e fator de tenacidade (FT) dos corpos de prova com o traço padrão, mantidos em temperatura ambiente.

Tabela 6.21. Resistência à tração na flexão $\left(f_{c t, f}\right)$ e fator de tenacidade (FT) dos

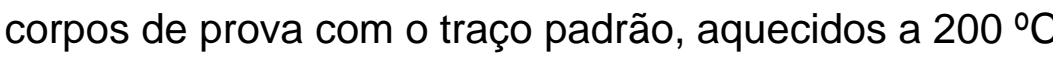

Tabela 6.22. Resistência à tração na flexão $\left(f_{c t, f}\right)$ e fator de tenacidade (FT) dos corpos de prova com o traço padrão, aquecidos a $600{ }^{\circ} \mathrm{C}$

Tabela 6.23. Resistência à tração na flexão $\left(f_{c t, f}\right)$ e fator de tenacidade (FT) dos corpos de prova com $0,3 \%$ de fibras de aço, para temperatura ambiente.

Tabela 6.24. Resistência à tração na flexão $\left(f_{c t, f}\right)$ e fator de tenacidade (FT) dos corpos de prova com $0,3 \%$ de fibras de aço, aquecidos a $200 \stackrel{\circ}{\circ}$.

Tabela 6.25. Resistência à tração na flexão $\left(f_{c t, f}\right)$ e fator de tenacidade $(F T)$ dos corpos de prova com $0,3 \%$ de fibras de aço, aquecidos a $600 \stackrel{\circ}{\circ}$.

Tabela 6.26. Resistência à tração na flexão $\left(f_{c t, f}\right)$ e fator de tenacidade (FT) dos corpos de prova com $0,6 \%$ de fibras de aço, para temperatura ambiente.

Tabela 6.27. Resistência à tração na flexão $\left(f_{c t, f}\right)$ e fator de tenacidade (FT) dos corpos de prova com $0,6 \%$ de fibras de aço, aquecidos a $200 \stackrel{\circ}{\circ}$.

Tabela 6.28. Resistência à tração na flexão $\left(f_{c t, f}\right)$ e fator de tenacidade (FT) dos corpos de prova com $0,6 \%$ de fibras de aço, aquecidos a $600 \stackrel{\circ}{\circ}$.

Tabela 6.29. Resistência à tração na flexão $\left(f_{c t, f}\right)$ e fator de tenacidade (FT) dos corpos de prova com $0,9 \%$ de fibras de aço, para temperatura ambiente.

Tabela 6.30. Resistência à tração na flexão $\left(f_{c t, f}\right)$ e fator de tenacidade $(F T)$ dos corpos de prova com $0,9 \%$ de fibras de aço, aquecidos a $200{ }^{\circ} \mathrm{C}$........................172

Tabela 6.31. Resistência à tração na flexão $\left(f_{c t, f}\right)$ e fator de tenacidade (FT) dos corpos de prova com $0,9 \%$ de fibras de aço, aquecidos a $600 \stackrel{\circ}{\circ}$.

Tabela 7.1. Calor específico e massa especifica utilizados na análise numérica ...181

Tabela 7.2. Resultados de condutividade térmica $\left(W / \mathrm{m}^{\circ} \mathrm{C}\right)$ 



\title{
LISTA DE SIGLAS
}

\author{
ABNT Associação Brasileira de Normas Técnicas \\ $\mathrm{ACl} \quad$ American Concrete Institute \\ ASTM American Society for Testing and Materials \\ CP Corpo de prova \\ EPS Poliestireno Expandido (Expanded Polystyrene) \\ EUA Estados Unidos da América \\ FT Fator de Tenacidade \\ $\mathrm{GPa} \quad$ Gigapascal \\ ISO International Organization for Standardization \\ JSCE Japan Society of Civil Engineers \\ LVDT Linear Variable Differential Transformer \\ MPa Megapascal \\ PVC Polyvinyl Chloride ou Policloreto de Vinil \\ TP Traço Padrão \\ TRRF Tempo Requerido de Resistência ao Fogo \\ UNICAMP Universidade Estadual de Campinas \\ USP Universidade de São Paulo
}





\section{LISTA DE SÍMBOLOS}

$\theta_{1}(\mathrm{t}) \quad$ Temperatura na face exposta ao calor

$\theta_{2}(\mathrm{t}) \quad$ Temperatura na face oposta ao calor

$\theta_{\text {máx }} \quad$ Temperatura máxima

$t_{e} \quad$ Tempo equivalente

$\mathrm{C}_{\mathrm{p}, \theta} \quad$ Calor específico em função da temperatura

$\mathrm{f}_{\mathrm{c}, \theta}$ Resistência à compressão em função da temperatura

$\mathrm{T}_{\mathrm{b}} \quad$ Medida de tenacidade

N.mm Newton vezes milímetro

${ }^{\circ} \mathrm{C} \quad$ Grau Celsius

${ }^{\circ} \mathrm{C} / \mathrm{min}$ Grau Celsius por minuto

$\rho \quad$ Massa específica

$f_{c} \quad$ Resistência à compressão axial

$\mathrm{E}_{\mathrm{c}} \quad$ Módulo de elasticidade estático

$E_{d} \quad$ Módulo de elasticidade dinâmico

$\mathrm{fct}_{\mathrm{ct}, \mathrm{sp}}$ Resistência à tração por compressão diametral

$\mathrm{fct}_{\mathrm{ct}, \mathrm{f}} \quad$ Resistência à tração na flexão

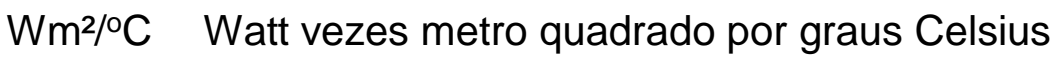

$\mathrm{J} / \mathrm{kg}{ }^{\circ} \mathrm{C} \quad$ Joule por quilograma vezes graus Celsius

$\mathrm{kg} / \mathrm{m}^{3} \quad$ Quilograma por metro cúbico

$\mathrm{W} / \mathrm{m}{ }^{\circ} \mathrm{C} \quad$ Watt por metro vezes graus Celsius 



\section{SUMÁRIO}

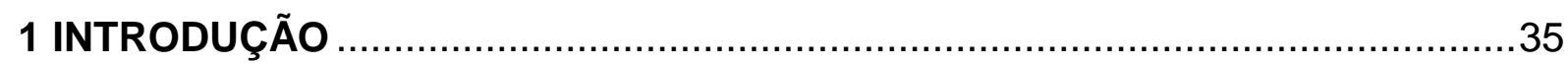

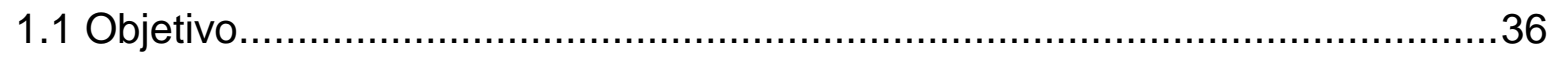

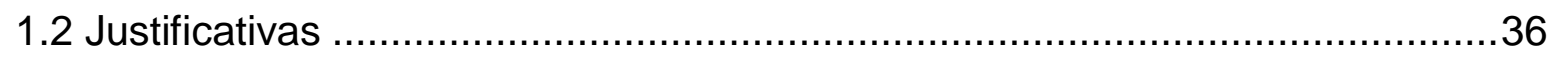

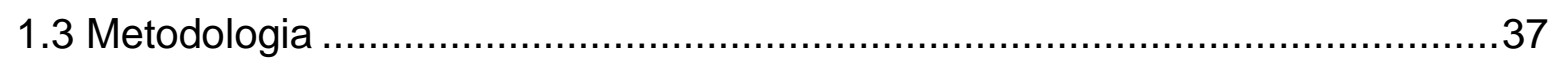

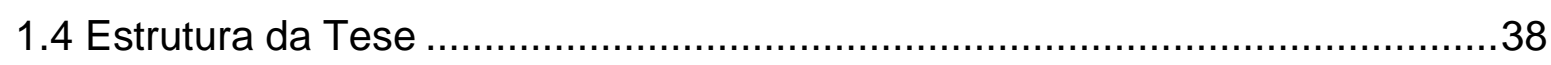

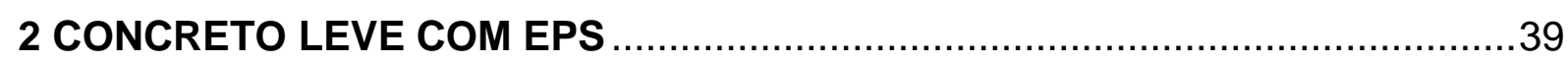

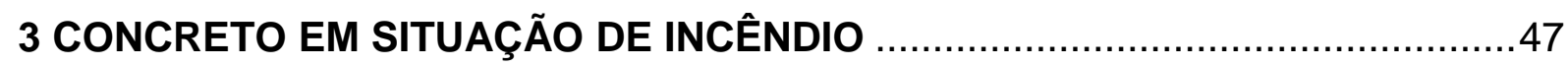

3.1 Ação térmica em situação de incêndio ……………...................................53

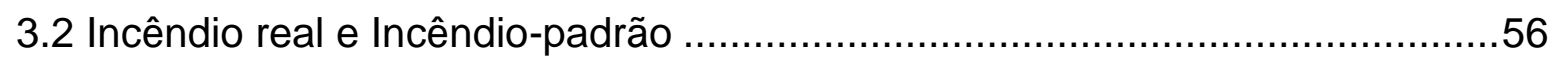

3.3 Tempo requerido de resistência ao fogo (TRRF) ........................................58

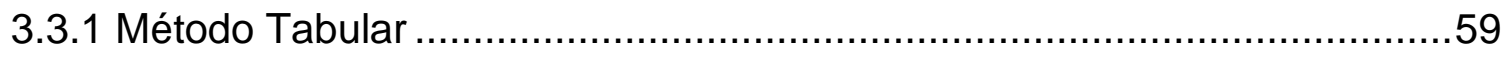

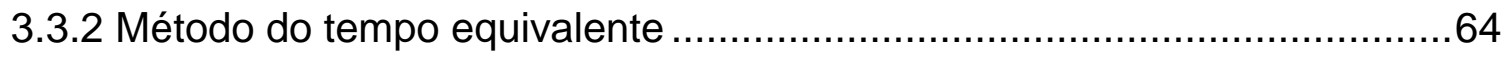

3.4 Comportamento do concreto e do aço submetidos a elevadas temperaturas. 68

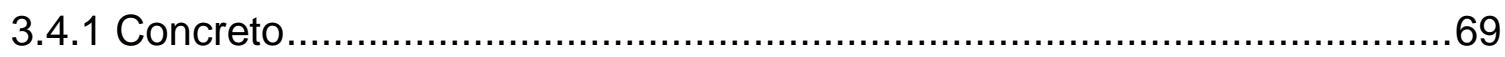

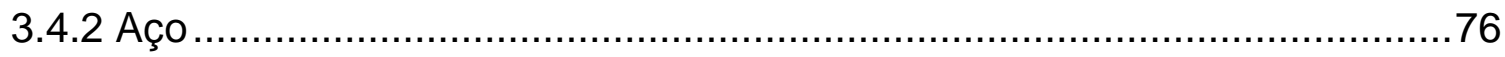

3.5 Comportamento do Poliestireno Expandido (EPS) ao fogo .............................77

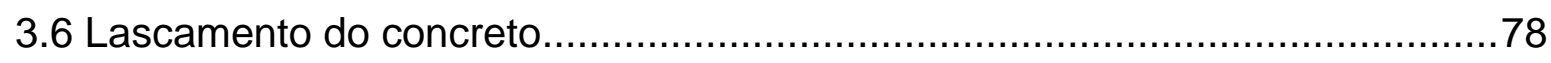

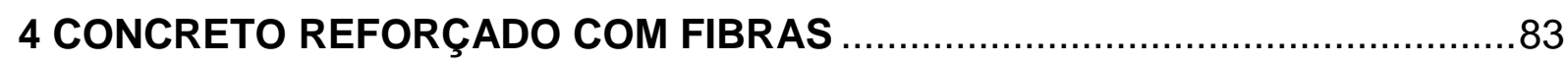

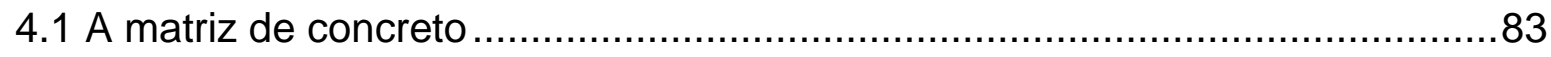

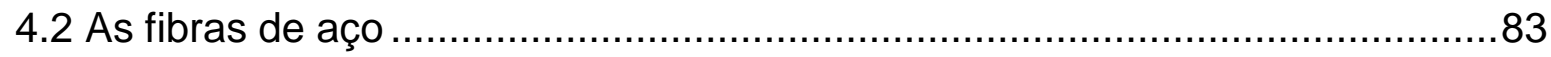

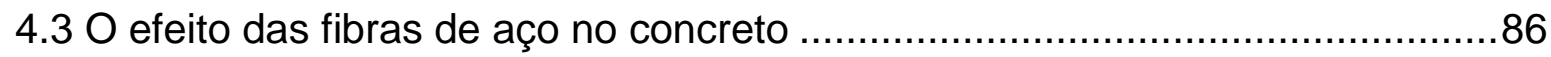

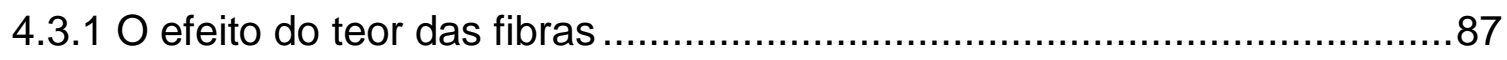

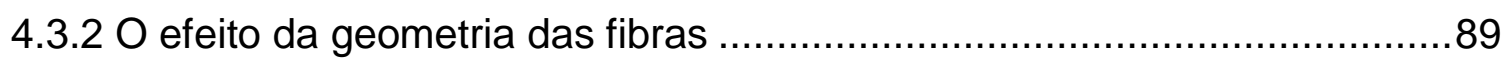

4.3.3 O efeito da resistência das fibras ........................................................90 
4.3.4 O efeito da resistência da matriz ........................................................... 91

4.3.5 Outras considerações normativas a respeito das fibras .......................... 92

4.4 Controle do concreto com fibras - Tenacidade ........................................... 93

4.5 Dosagem do concreto com fibras............................................................. 96

4.6 Estudos sobre o concreto reforçado com fibras de aço ..................................96

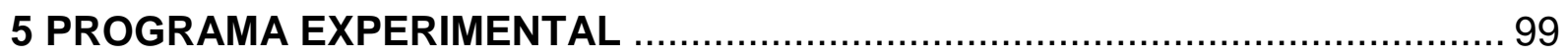

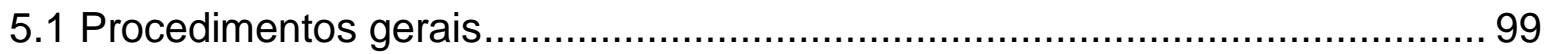

5.2 Características dos materiais utilizados .................................................. 114

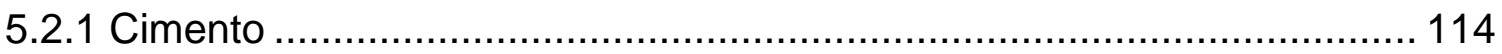

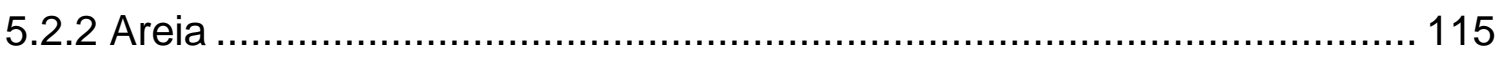

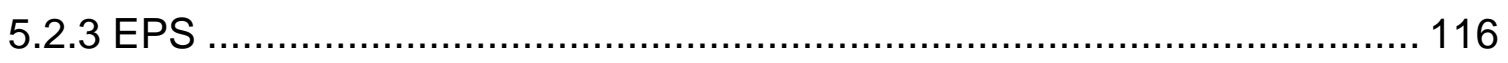

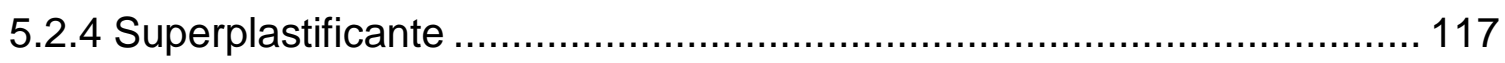

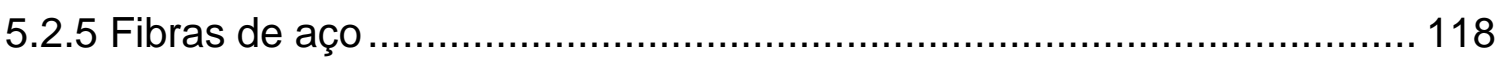

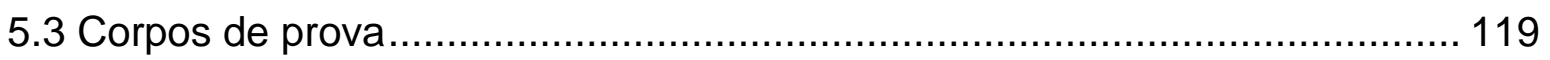

5.3.1 Produção dos corpos de prova cilíndricos e prismáticos ........................ 121

5.3.2 Transporte dos corpos de prova para Unicamp.................................... 125

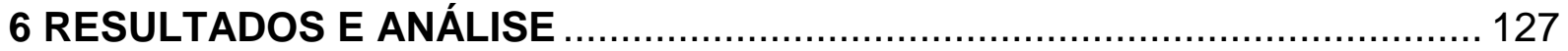

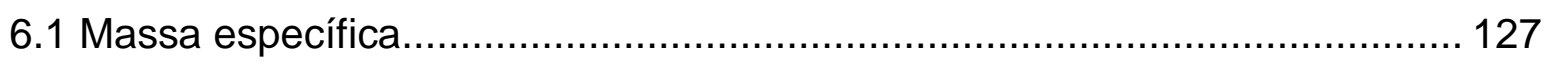

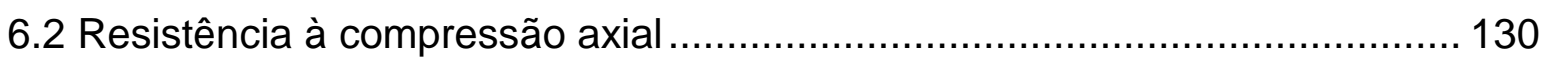

6.2.1 Temperatura ambiente .............................................................. 130

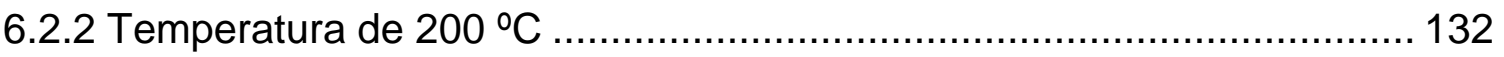

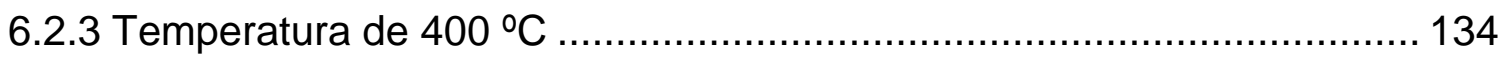

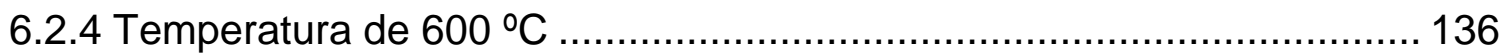

6.2.5 Resistência à compressão axial versus Temperatura ............................ 138

6.3 Módulo de elasticidade estático ……………..................................... 140

6.3.1 Temperatura ambiente ............................................................. 140 


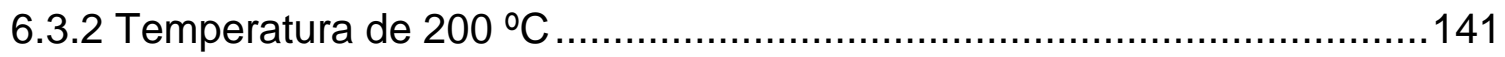

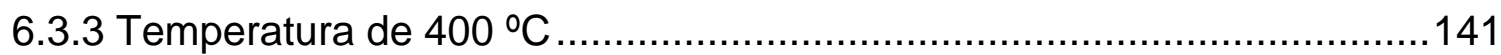

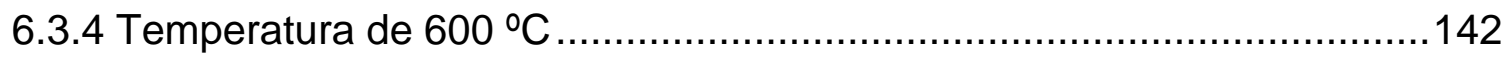

6.3.5 Módulo de elasticidade estático versus Temperatura ............................142

6.4 Módulo de elasticidade dinâmico .............................................................144

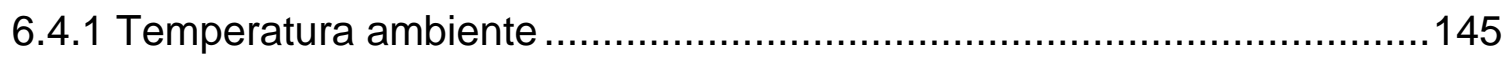

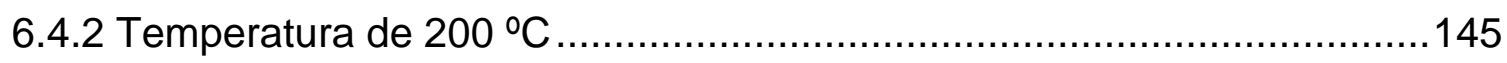

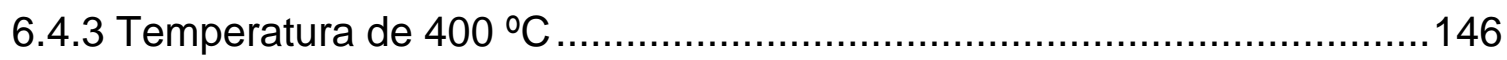

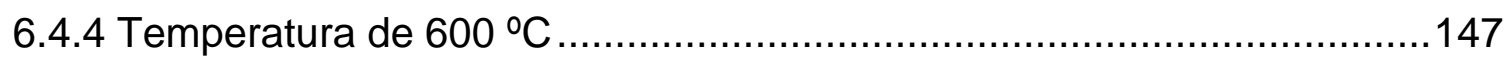

6.4.5 Módulo de elasticidade dinâmico versus Temperatura ..........................147

6.5 Resistência à tração por compressão diametral .........................................149

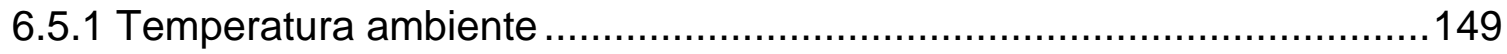

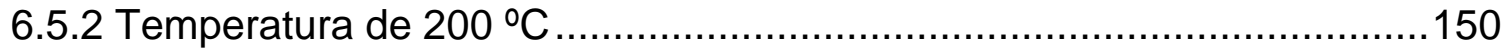

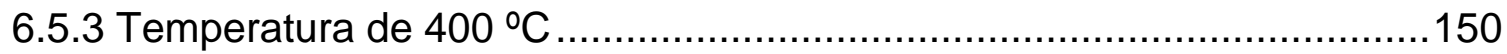

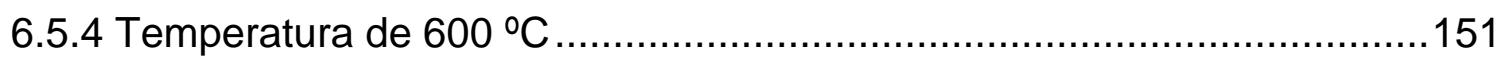

6.5.5 Resistência à tração por compressão diametral versus Temperatura.....152

6.7 Resistência à tração na flexão e tenacidade .............................................153

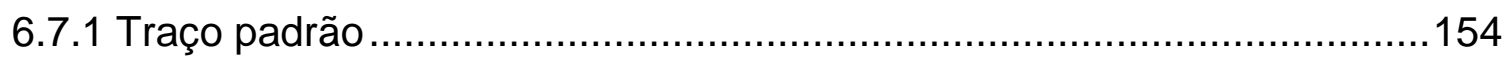

6.7.2 Traço padrão com 0,3\% de fibras de aço............................................159

6.7.3 Casos com 0,6\% de fibras de aço ......................................................164

6.7.4 Casos com 0,9\% de fibras de aço ..................................................169

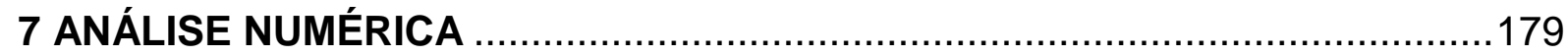

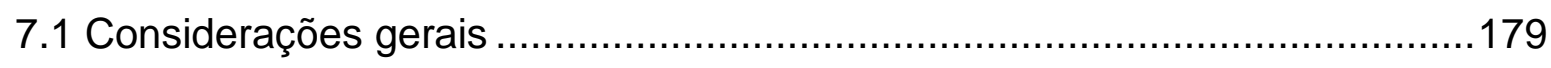

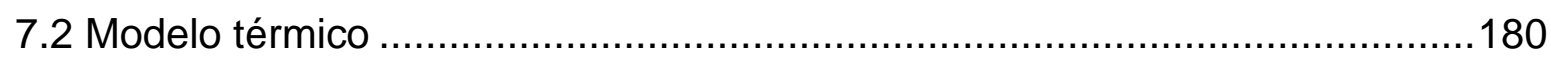

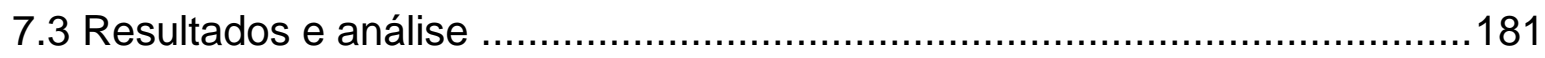


8.1 Análise experimental dos corpos de prova cilíndricos ................................ 187

8.2 Análise experimental dos corpos de prova prismáticos................................ 188

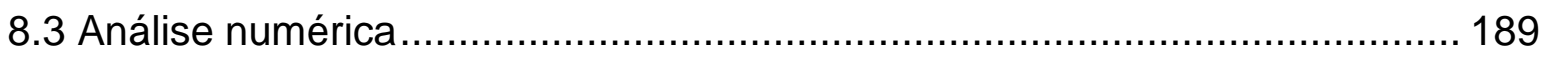

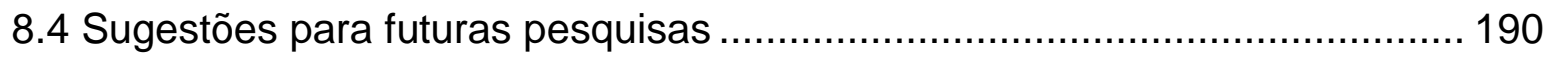

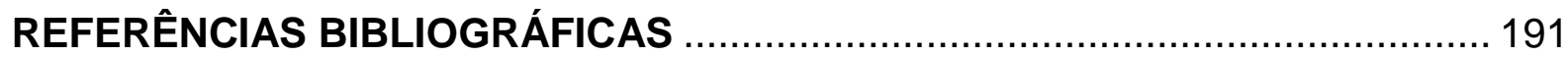

APÊNDICE A - Roteiro da análise numérica ................................................ 199 


\section{INTRODUÇÃO}

Nos dias atuais, a competitividade entre as empresas da construção civil está acirrada. Sendo assim, há necessidade do aumento da produção, com rapidez de execução e redução de custos. Contudo, esse ramo ainda se encontra defasado em relação aos demais setores industriais. Isso se deve a inúmeros fatores, dentre eles: o desperdício de materiais, a baixa produtividade, o baixo controle de qualidade, a escassez e a má qualidade da mão de obra disponível.

Por conta dessas desvantagens, muitas vezes, o sistema convencional vem sendo substituído por elementos pré-moldados, visto que essa tecnologia apresenta soluções que atendem as exigências das empresas. No entanto, o elevado peso para o transporte caracteriza-se como um inconveniente.

Para resolver esse problema, o concreto leve possibilita, com sua menor massa específica, a diminuição da armadura e do volume total de concreto, diminuindo a energia utilizada no transporte e no processo construtivo (ROSSIGNOLO e AGNESINI, 2005).

Por outro lado, a intensa industrialização e o crescimento populacional implicaram no agravamento de problemas relacionados à disposição de resíduos industriais. Como na maioria das cidades brasileiras não há áreas apropriadas para a destinação adequada desses resíduos, aliado ao fato de serem constituídos por materiais com elevado potencial de reciclagem (evitando impactos na exploração de novas jazidas), cabe o estudo de soluções técnicas para resolver tal problema.

Dentre esses resíduos, encontra-se o poliestireno expandido, conhecido como EPS (SIQUEIRA et al., 2004). De acordo com Anbio (2008) apud Ferreira e Ribeiro (2008), o Brasil gera cerca de 15 mil toneladas de resíduos de EPS por ano que têm como destino final, na maioria das vezes, aterros sanitários e lixões, sendo que o poliestireno expandido não é biodegradável, mas é reciclável. O grande problema é que o número de estabelecimentos que reciclam EPS no país é muito baixo, pois o custo é muito alto, e não vale a pena se for realizada por pequenas indústrias.

Sendo assim, uma maneira de reduzir esses resíduos no meio ambiente é produzir concreto leve, substituindo parte dos compósitos convencionais por EPS, 
podendo, dessa maneira, usufruir das propriedades de baixa massa específica desses materiais para produção de Concreto Leve com EPS, também denominado Concreto Ultraleve ${ }^{\circledR}$ ou Concreflex ${ }^{\circledR}$.

Pretende-se verificar se esse concreto é adequado para uso, por exemplo, em painéis e em lajes pré-moldadas para a construção de edifícios de pequeno e de médio porte, por ele ser um concreto muito leve, com massa específica em torno de $1170 \mathrm{~kg} / \mathrm{m}^{3}$, um pouco menos da metade da relativa ao concreto convencional.

\subsection{Objetivo}

O principal objetivo deste trabalho é estudar o comportamento residual do concreto leve com pérolas de EPS após ser submetido a altas temperaturas, considerando resfriamento lento, assim como, também, dar continuidade às pesquisas envolvendo o concreto leve com EPS no Departamento de Engenharia de Estruturas da Escola de Engenharia de São Carlos (EESC/USP).

\subsection{Justificativas}

As vantagens da utilização de concretos leves, segundo Neville (1997), é a redução de esforços na estrutura e na infraestrutura das edificações, uma economia em formas e cimbramento e a diminuição dos custos com transporte e montagem de peças pré-fabricadas, além do aumento da produtividade. Tudo isso, graças aos benefícios promovidos pela diminuição da massa específica.

Em complemento, a importância da análise do comportamento do concreto em situação de incêndio vem crescendo a cada dia. Isso se deve aos sinistros que vem ocorrendo pelo mundo, casos como o Incêndio do Edifício Sede II da CESP em São Paulo, em 1987, o colapso total de um edifício residencial no Cairo (Egito) e parcial do edifício Herm Stoltz da Eletrobrás no Rio de Janeiro, ambos em 2004, e o incêndio na torre Windsor em Madri, em 2005, a qual possuía estrutura mista de aço 
e concreto. Esses são alguns dos inúmeros exemplos em que houve danos estruturais e até de efeitos destrutivos que um incêndio pode ocasionar.

Sendo assim, faz-se necessário um estudo mais detalhado do concreto leve com EPS, objetivando reduzir esses efeitos destrutivos causados pelo incêndio. Como prova disso, Neville (1997) estudou a utilização de concretos preparados com agregados leves para a proteção de estruturas metálicas, e seu desempenho perante o fogo apresentou boa resistência.

Com tudo isso, a utilização de resíduos de EPS como compósito na produção do Concreto Ultraleve ${ }^{\circledR}$, além de apresentar vantagens do ponto de vista técnico (desempenho acústico, térmico e leveza) e econômico (por não despender recursos significativos para produção de agregados leves), pode representar uma alternativa ambiental viável, amenizando impactos negativos causados por esse produto em aterros sanitários e lixões.

\subsection{Metodologia}

Inicialmente, será apresentada uma revisão bibliográfica sobre estruturas em situação de incêndio, com ênfase nas estruturas de concreto, concreto com fibras de aço e também sobre o concreto leve convencional e o com EPS.

Em seguida, serão mostrados ensaios para concreto com EPS após situação de incêndio. Para a simulação de incêndio, foi utilizado o forno da UNICAMP, que foi escolhido pelo fato de o forno da Escola de Engenharia de São Carlos ser muito grande para realizar os ensaios desta pesquisa, o que geraria custos desnecessários. O traço do concreto utilizado neste trabalho foi obtido por Ozório (2016). Nos ensaios foram utilizados corpos de prova cilíndricos de $10 \mathrm{~cm} \times 20 \mathrm{~cm}$ e $10 \mathrm{~cm} \times 30 \mathrm{~cm}$ e corpos de prova prismáticos de $15 \mathrm{~cm} \times 15 \mathrm{~cm} \times 50 \mathrm{~cm}$.

$\mathrm{Na}$ análise experimental, foram estudadas as seguintes propriedades do concreto: massa específica, resistência à compressão axial, módulo de elasticidade estático, módulo de elasticidade dinâmico, resistência à tração por compressão diametral, resistência à tração na flexão e fator de tenacidade. Foram feitas comparações com relação ao concreto convencional e ao próprio concreto com EPS à temperatura ambiente. 
Também foi realizada uma análise térmica numérica, via elementos finitos, utilizando o software ABAQUS 14, com a qual se tentou calibrar duas propriedades térmicas: o calor específico e a condutividade térmica. Para isso foram utilizados resultados obtidos nos ensaios em laboratório.

O software citado está disponível no Departamento de Engenharia de Estruturas da Escola de Engenharia de São Carlos (EESC/USP).

\subsection{Estrutura da Tese}

Capítulo 1: apresentação do trabalho, mostrando os objetivos, as justificativas e a metodologia utilizada.

Capítulo 2: revisão bibliográfica sobre o concreto leve convencional e o concreto pré-moldado com pérolas de EPS (Concreto Ultraleve ${ }^{\circledR}$ ).

Capítulo 3: revisão bibliográfica sobre concreto em situação de incêndio.

Capítulo 4: revisão bibliográfica sobre concreto reforçado com fibras.

Capítulo 5: detalhes do programa experimental.

Capítulo 6: resultados da parte experimental e análise.

Capítulo 7: análise numérica dos corpos de prova e análise dos resultados.

Capítulo 8: conclusões e sugestões para novas pesquisas. 


\section{CONCRETO LEVE COM EPS}

O concreto leve é caracterizado por uma diminuição na sua massa específica. Segundo Metha e Monteiro (2008), essa massa específica é de aproximadamente dois terços da relativa ao concreto convencional, o que se deve ao uso de um agregado leve celular na confecção da mistura.

De acordo com o ACl 213R-87 (1999), esse tipo de concreto deve apresentar, aos 28 dias, resistência à compressão superior a $17 \mathrm{MPa}$ e massa específica menor ou igual a $1850 \mathrm{~kg} / \mathrm{m}^{3}$. Já para a ASTM C330, a resistência mínima à compressão e a massa específica máxima devem ser de $28 \mathrm{MPa}$ e $1760 \mathrm{~kg} / \mathrm{m}^{3}$, respectivamente. Além disso, a ASTM C330 especifica a necessidade de que os agregados leves miúdos e graúdos não excedam, na devida ordem, 1120 kg/m³ e $880 \mathrm{~kg} / \mathrm{m}^{3}$.

Os concretos leves tradicionais podem ser classificados em: concretos com agregados leves, concretos celulares e concreto sem finos (Figura 2.1). O concreto leve com EPS constitui uma inovação, principalmente para aplicações estruturais, como em lajes e painéis pré-moldados.
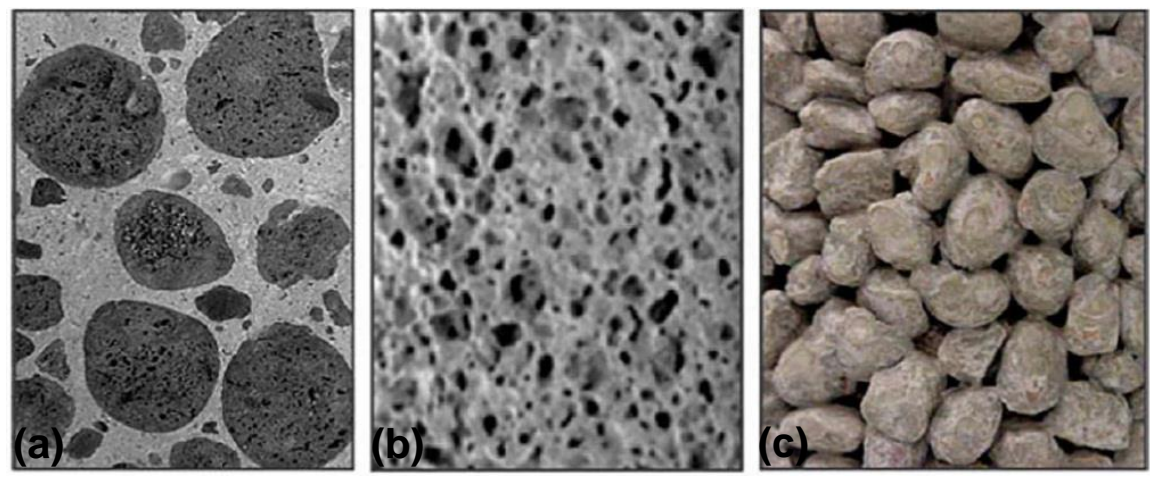

Figura 2.1. (a) Concreto com agregados leves, (b) concreto celular e (c) concreto sem finos.

(ROSSIGNOLO E AGNESINI, 2005)

As primeiras aplicações de concreto leve datam de aproximadamente 3000 anos, época em que, no México, elementos estruturais foram construídos com a mistura de pedra-pomes, adicionando um ligante à base de cinzas vulcânicas e cal. 
No entanto, a utilização do concreto leve na forma como é conhecido hoje ocorreu durante a Primeira Guerra Mundial, com a construção de embarcações, como mostra a Figura 2.2 (ROSSIGNOLO E AGNESINI, 2005).

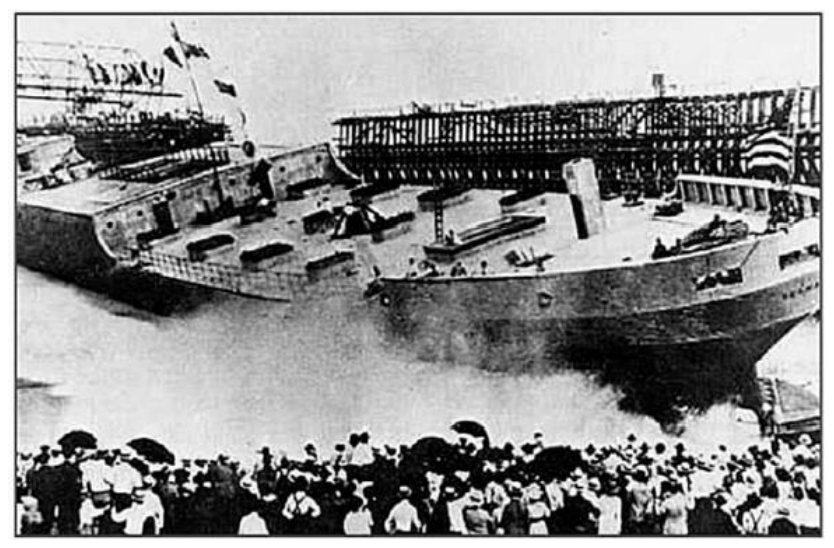

Figura 2.2. Embarcação construída com concreto leve. (ROSSIGNOLO E AGNESINI, 2005)

Entretanto, foi após a Segunda Guerra Mundial que os estudos e aplicações do concreto leve estrutural aumentaram. A partir dos anos 1960, importantes edifícios (Figura 2.3) foram executados com o concreto leve, como: (a) Lake Point (Chicago, EUA, 75 pavimentos, 1968), (b) Edifício administrativo da BMW (Munique, Alemanha, 1972), (c) Raymond-Hillard (Chicago, EUA, 1974) e (d) Standard Bank (Johanesburgo, África do Sul, 1974) (ROSSIGNOLO E AGNESINI, 2005).

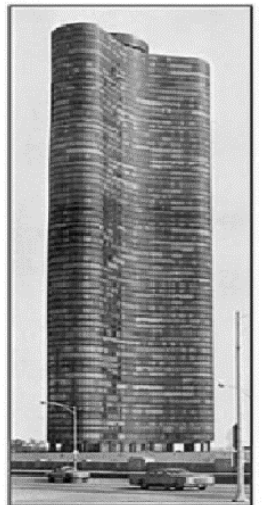

(a)

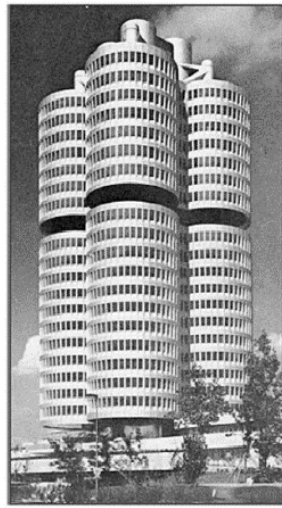

(b)

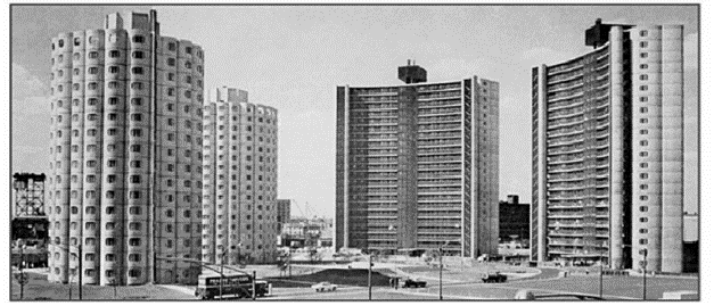

(c)

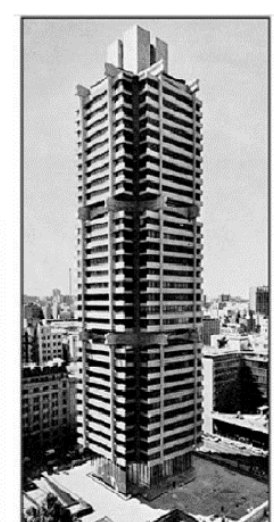

(d)

Figura 2.3. (a) Lake Point, (b) Edifício da BMW, (c) Raymond-Hillard e (d) Standard Bank. (ROSSIGNOLO E AGNESINI, 2005) 
Já no Brasil, a maioria das aplicações dos concretos leves no ramo da construção civil ocorre em elementos estruturais pré-fabricados e em estruturas de edificações de múltiplos pavimentos moldadas in loco, em especial nas lajes, e praticamente se restringe à utilização de argila expandida.

Entre as aplicações se destacam: a ampliação do Rio Centro, no Rio de Janeiro, e o pavilhão de exposições do Anhembi, o edifício da Faculdade de Economia, Administração e Contabilidade da USP e o Hotel Grand Hyatt, os três em São Paulo (CATOIA, 2012).

De acordo com o ACl 213R-87, o uso do concreto leve, normalmente, resulta em custos mais baixos. Embora o preço do concreto leve por metro cúbico seja superior ao do convencional, a estrutura pode custar menos devido à redução do peso próprio. Um exemplo disso foi a construção do tabuleiro de concreto leve para a Ponte da Baía de São Francisco - Oakland, nos EUA (Figura 2.4), em 1936, que resultou em uma economia de aproximadamente US\$ 3 milhões (WILSON, 1981, apud METHA e MONTEIRO, 2008).

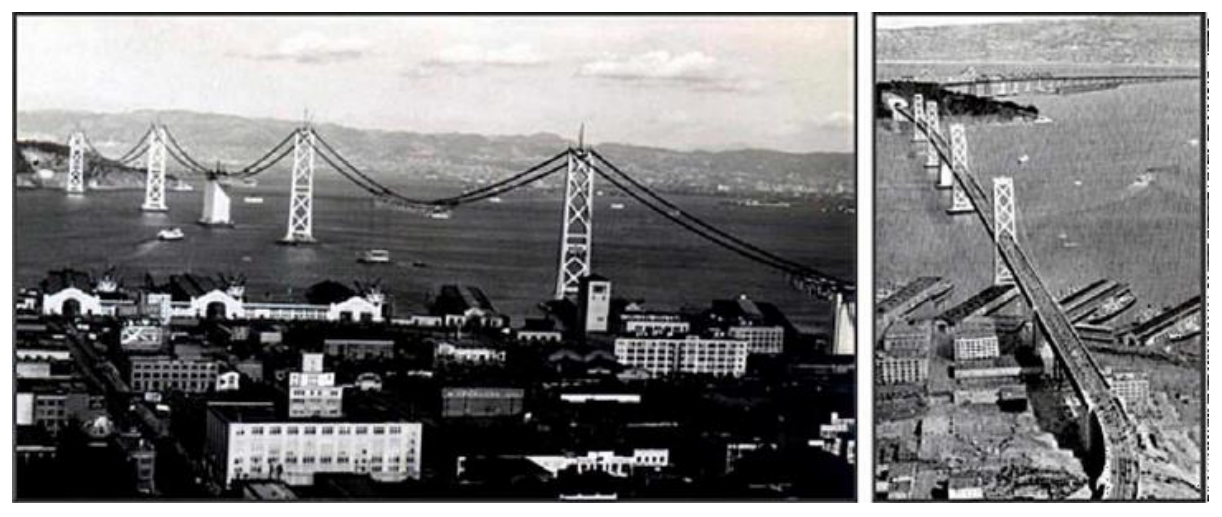

Figura 2.4. Ponte da Baía de São Francisco - Oakland.

(ROSSIGNOLO E AGNESINI, 2005)

Dentre os diversos tipos de concreto leve, destaca-se o concreto leve com EPS. Também denominado de Concreto Ultraleve ${ }^{\circledR}$ ou Concreflex ${ }^{\circledR}$, é um concreto que contém Poliestireno Expandido (EPS) atuando como agregado leve, com massa específica variando entre $400 \mathrm{~kg} / \mathrm{m}^{3}$ e $1300 \mathrm{~kg} / \mathrm{m}^{3}$ (KERBAUY, 2010, apud CATOIA, 2012). Mais recentemente, pelo fato de não atuar como material resistente, o EPS é considerado como agente incorporador de vazios. 
O concreto leve com EPS pode ser composto pelos mesmos materiais que os demais concretos leves, com exceção do Poliestireno Expandido (EPS), que, geralmente, substitui o agregado graúdo e parte do miúdo.

As pérolas de EPS servem como elementos de enchimento e devem ser incorporadas a elementos de maior peso, para que se obtenha um concreto com resistência adequada. A Figura 2.5 mostra a estrutura interna desse tipo de material.

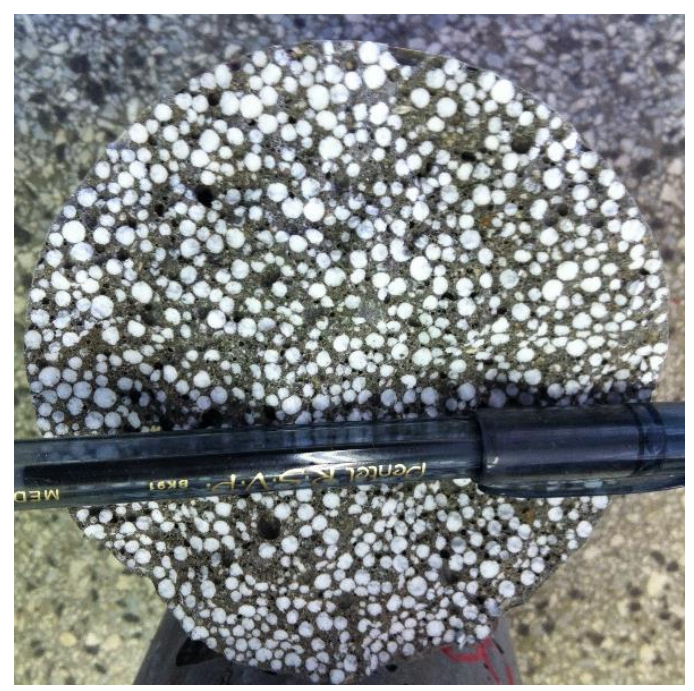

Figura 2.5. Estrutura interna do concreto leve estrutural com pérolas de EPS.

Segundo Stocco et al. (2009), o concreto leve com EPS começou a ser desenvolvido em 1957, na Alemanha, pela empresa BASF. Devido ao alto custo da matéria-prima, seus estudos foram interrompidos e somente em 1968 foram retomados, em virtude da redução do custo do EPS e da previsão de que poderia ocupar, em longo prazo, um lugar importante no setor de construção civil, por apresentar uma série de vantagens sobre o concreto convencional.

O concreto leve com EPS pode ser usado em diversos tipos de aplicações, tais como: pré-fabricados, elementos de vedação internos, isolante térmico e acústico, elementos resistentes à propagação do fogo, casas pré-fabricadas, tijolos, blocos, entre outras.

Alguns testes de aplicação do material em estudo já foram realizados, como os exemplificados a seguir.

Souza et al. (2006), após pesquisas, desenvolveram uma unidade habitacional utilizando painéis de concreto leve constituído por EPS (Figura 2.6), elaborando estudos de resistência mecânica, conforto térmico e acústico. 


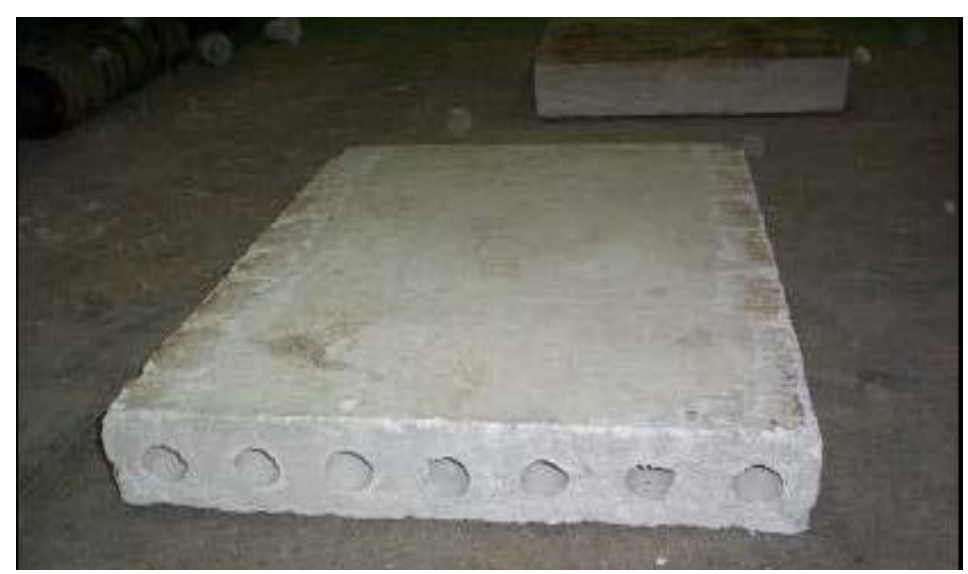

Figura 2.6. Painel de concreto leve com EPS.

(SOUZA et al., 2006)

Kerbauy (2011), apud Catoia (2012), realizou experimentos com o Concreto Leve com EPS, em forma de laje (Figura 2.7a). Pode-se notar que ela apresenta acabamento semelhante ao de peças de concreto pré-moldado comum. Além disso, foi feito um painel PI (Figura 2.7b), que também ilustra as boas condições obtidas.

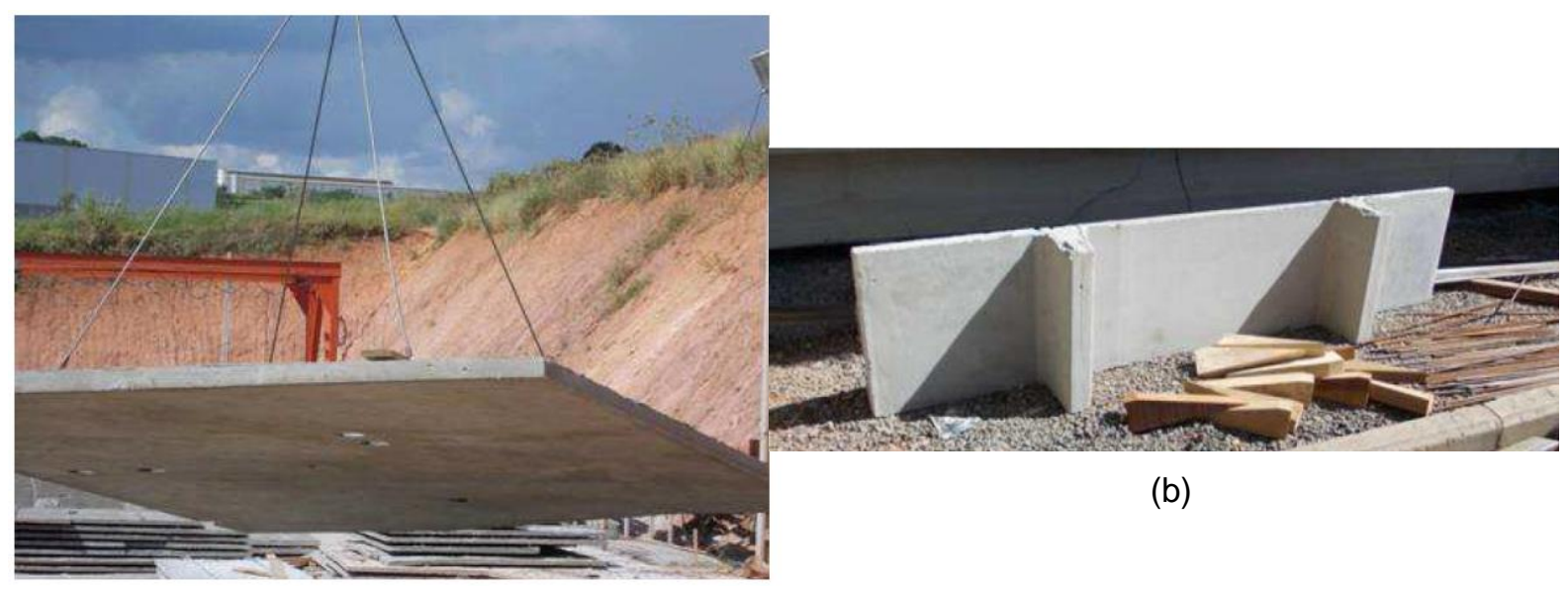

(a)

Figura 2.7. Peças de concreto leve com EPS: (a) Laje durante içamento; (b) Painel PI. (KERBAUY, 2011, apud CATOIA, 2012)

A Figura 2.8 mostra uma foto, tirada pelo orientador deste trabalho, em 2012, de ensaio realizado por Kerbauy, com painel de fechamento moldado verticalmente, com dimensões em metros $0,15 \times 1,25 \times 10$, que apresentou bom acabamento superficial e boa textura. 


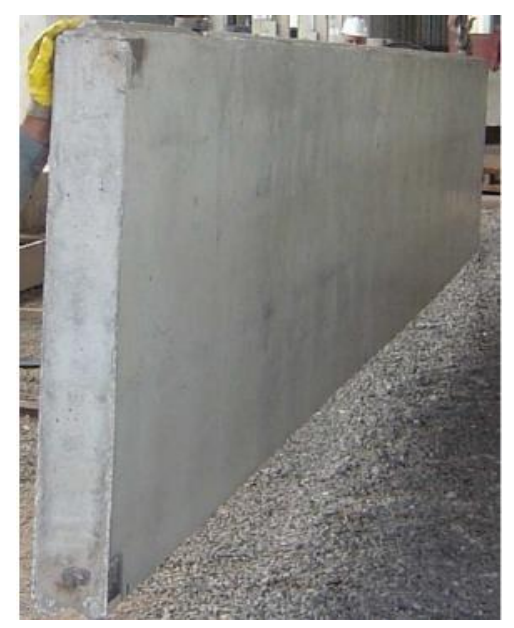

Figura 2.8. Painel de fechamento de concreto leve com EPS.

(Arquivo pessoal do orientador deste trabalho, em 2012)

Catoia (2012) realizou um estudo sobre o comportamento de lajes produzidas com o Concreto Ultraleve ${ }^{\circledR}$ (Figura 2.9), no qual, dentre os resultados mais expressivos, tem-se:

(a) o estudo de deformabilidade apresentou resultados coerentes com as propriedades dos materiais e com a literatura técnica, e valores satisfatórios para aplicação do material em elementos estruturais;

(b) para a análise da resistência, como era de se esperar, o resultado foi inferior para o Concreto Leve com EPS em relação ao concreto convencional, entretanto, foi constatada uma vida útil maior em relação à do concreto comum, com base em ensaios de carbonatação.

Sendo assim, concluiu-se que o concreto estudado, com aproximadamente metade da massa específica dos concretos convencionais, apresenta valores de resistência mecânica e outras características compatíveis com a produção e a aplicação comercial de lajes maciças, principalmente pré-moldadas, e de outros tipos de peças submetidas a moderadas tensões de compressão.

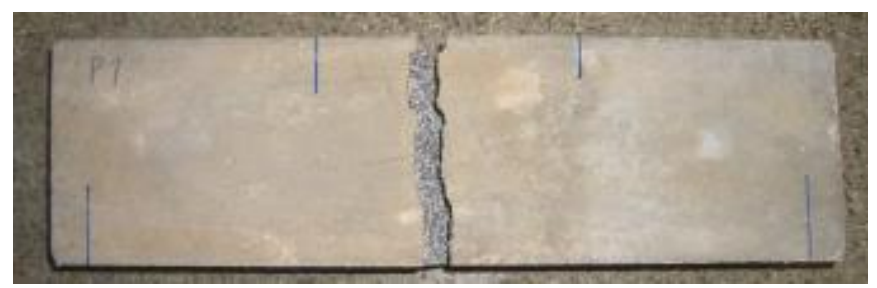

Figura 2.9. Laje de concreto leve com EPS.

(CATOIA, 2012) 
Na preparação desse concreto, por ser o EPS um material que tem densidade absoluta muito baixa, deve ser levado em consideração que ele tende a flutuar durante a mistura, dificultando a homogeneização do concreto. Para evitar isso, ele deve ser, inicialmente, misturado com areia e parte da água. Depois, podem ser colocados os outros componentes. Vale lembrar que nesse concreto não é necessário misturar nenhum tipo de cola ou resina, para garantir a homogeneização do EPS.

Conforme Bauer e Toledo (1973), o processo de produção do concreto leve com EPS apresenta como vantagem a possibilidade de preparação no canteiro de obra, no mesmo patamar que a de um concreto convencional. 



\section{CONCRETO EM SITUAÇÃO DE INCÊNDIO}

O principal objetivo de proteção de uma estrutura contra incêndio é a de proteger a vida humana. Entretanto, a proteção da edificação também requer atenção, principalmente em se tratando do ramo comercial, em que, com a sua paralisação, devido a danos estruturais resultantes do incidente, pode afetar o setor financeiro da empresa.

O colapso de uma estrutura de concreto armado ocasionada por um incêndio, segundo Costa (2008), pode ser local, parcial ou global. Quando ocorre um colapso local, há a falência estrutural de elementos isolados, entretanto, sem o comprometimento da estabilidade global. No colapso parcial ocorrem problemas em alguns dos elementos estruturais, levando esta parte a desabar, isso porque a estabilidade de parte da edificação fica comprometida. Já o colapso global se caracteriza pela falência progressiva dos elementos da estrutura.

A ruptura localizada de apenas um elemento da estrutura pode ocasionar diferentes riscos à estabilidade da edificação. Como Costa (2008) mostra na Figura 3.1, o colapso de um pilar pode levar parte da edificação acima deste a desabar, assim como, se uma viga perder a capacidade de suporte, as lajes que se apoiam nela podem ceder sobre os pavimentos inferiores.

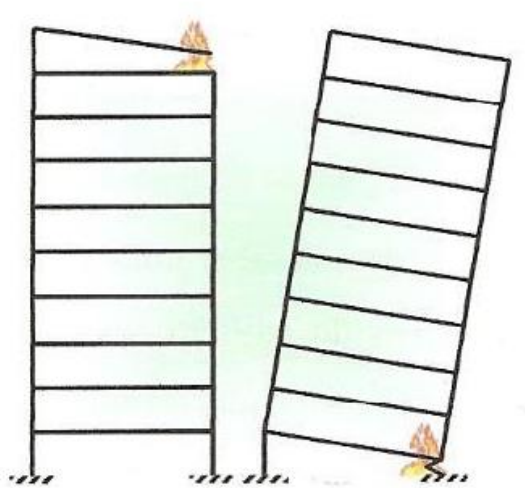

Ruptura de pilares

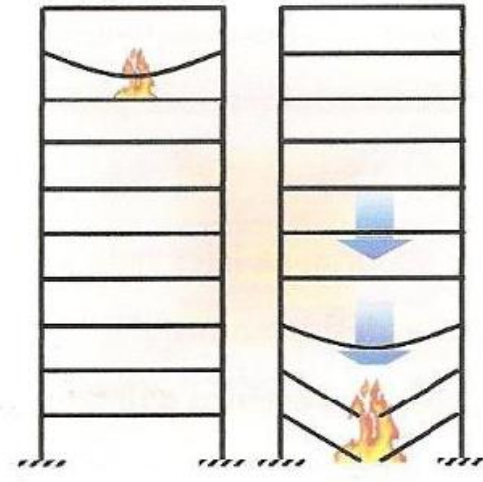

Ruptura de lajes

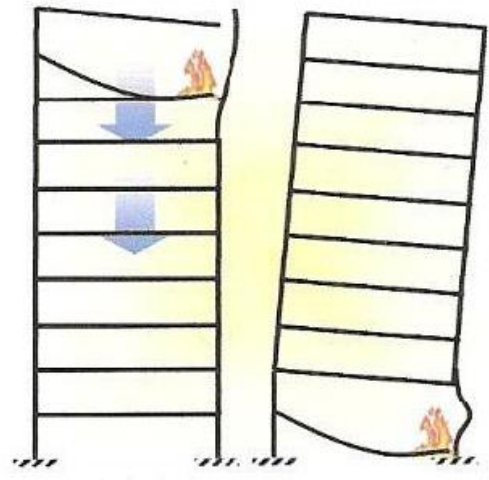

Ruptura de lajes ou vigas essenciais para o travamento horizontal

Figura 3.1. Efeitos de colapsos devidos a um incêndio.

(COSTA, 2008) 
São inúmeros os casos de colapso estrutural relacionados a incêndios que ocorreram no mundo. A literatura técnica e jornais proveem registros de edificações de concreto que sofreram colapso estrutural parcial ou total, além de vitimar centenas de pessoas (Figura 3.2 a 3.6).

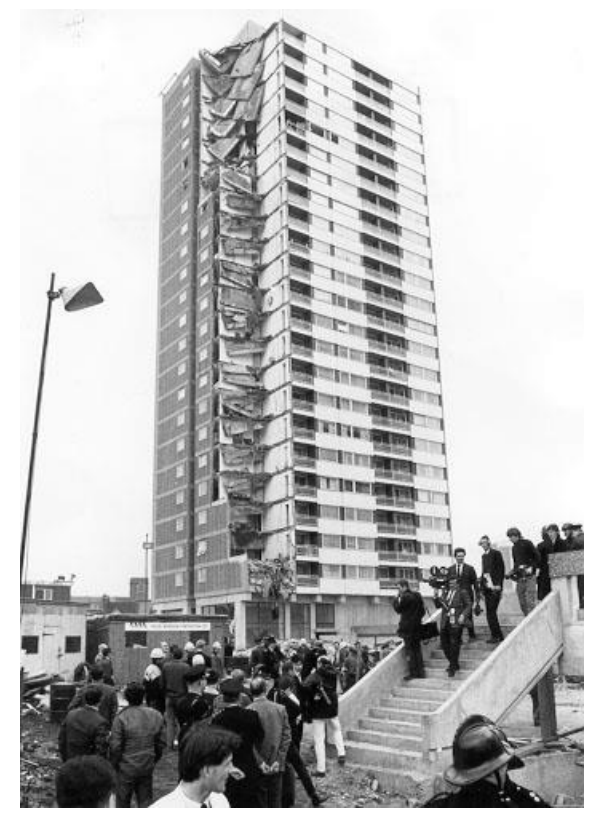

Figura 3.2. Colapso parcial do Ronan Point, em Londres - UK, 1968 (LARANJEIRAS, 2011).

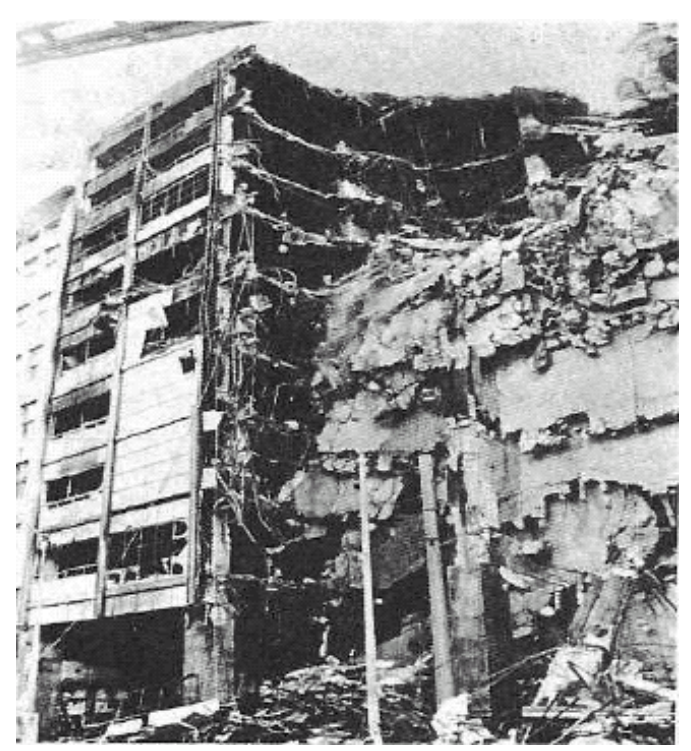

Figura 3.3. Colapso parcial da Katrantzos Sport em Atenas - Grécia, 1980 (SILVA, 2010) 


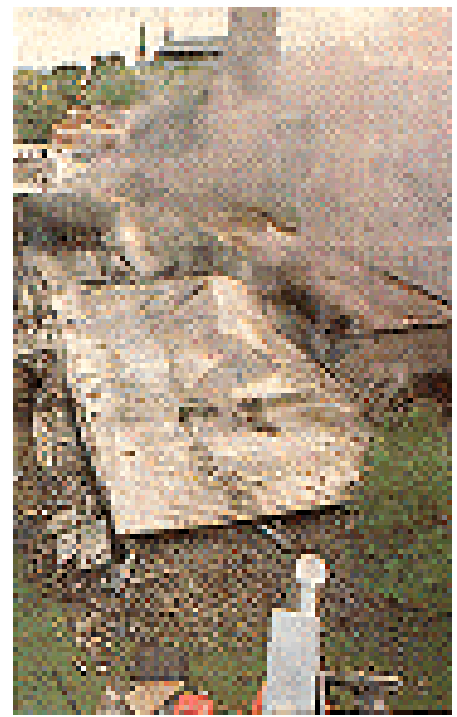

Figura 3.4. Colapso total da Biblioteca Municipal de Linköping - Suécia, 1996 (ANDERSSON, 1996)

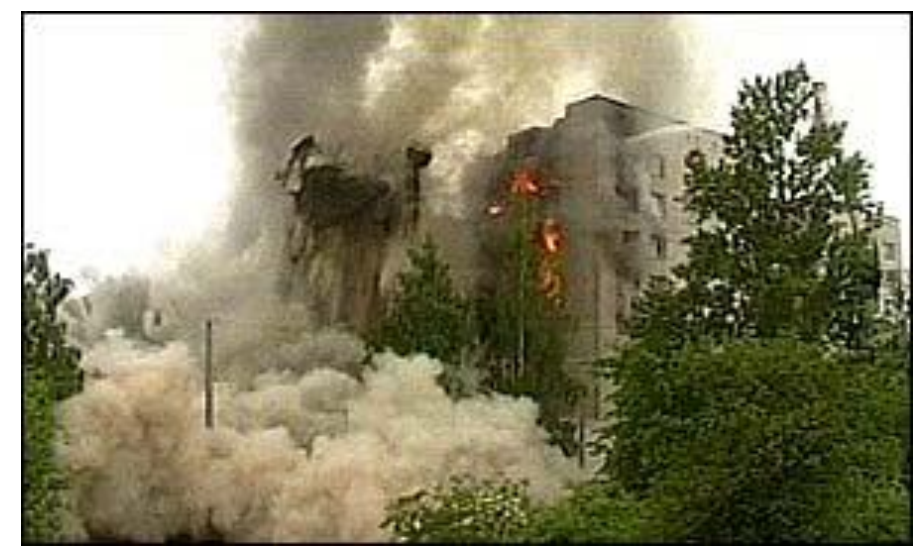

Figura 3.5. Colapso total de um edifício residencial em São Petersburgo - Rússia, 2002 (BBC News, 2002)

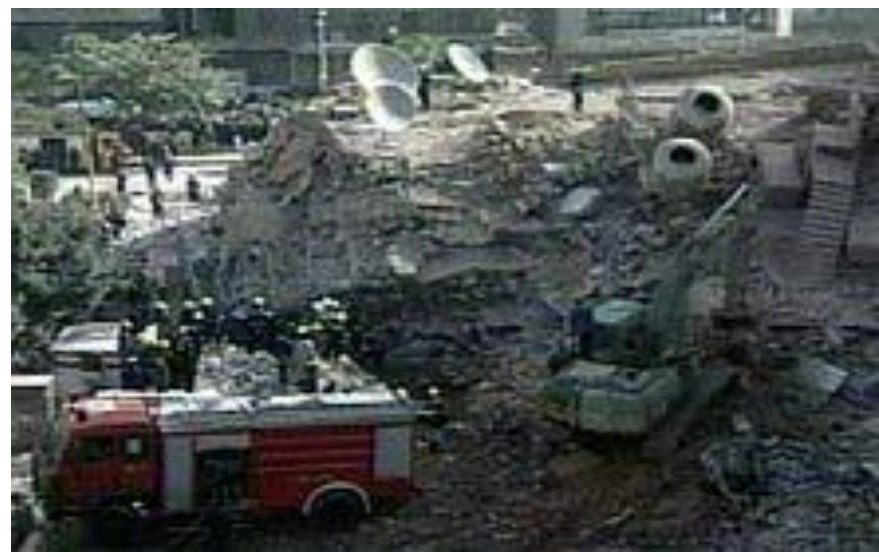

Figura 3.6. Colapso total de um edifício residencial no Cairo - Egito, 2004 (CHINAdaily.com.cn, 2004) 
Em 2004, um colapso ocorreu em um estacionamento subterrâneo em Gretzenbach, na Suíça. Segundo Ruiz et al. (2010), noventa minutos após o início de um incêndio no interior do parque, ocorreu o puncionamento em volta de um pilar que, de imediato, se alastrou a vários, levando ao desmoronamento de grande parte da estrutura, como pode ser visto na Figura 3.7. As principais causas do acidente estão associadas à sobrecarga da estrutura, colocação de uma camada de solo superior à esperada, e uma abordagem grosseira da verificação da capacidade resistente ao puncionamento.

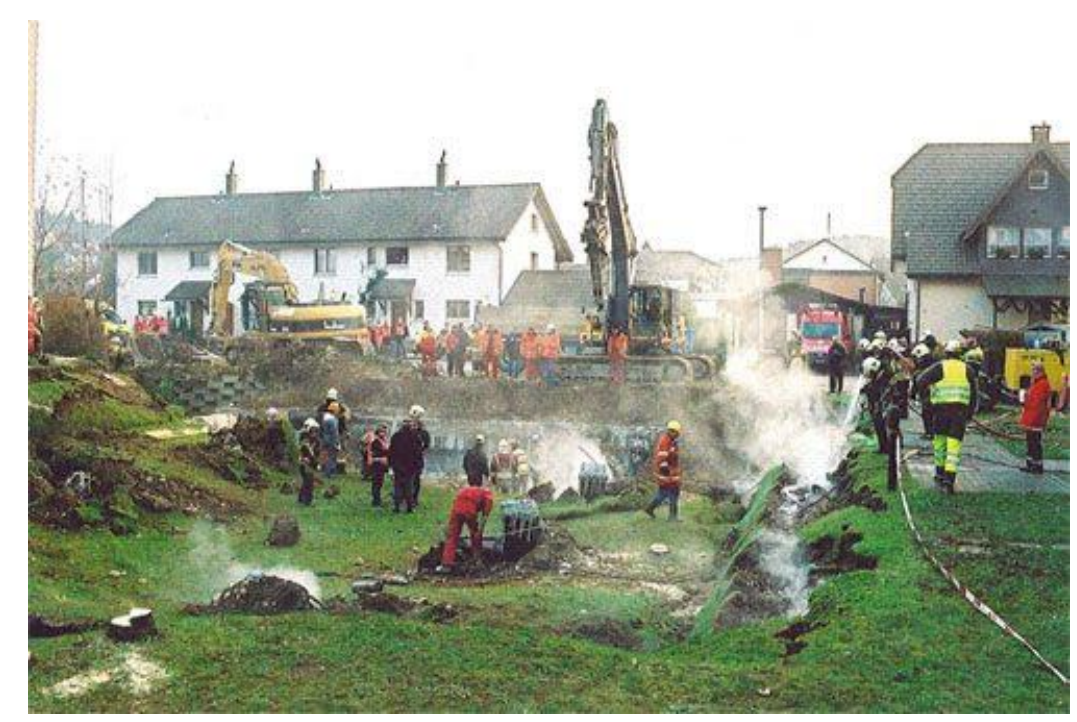

Figura 3.7. Colapso localizado da laje de cobertura de um estacionamento subterrâneo em Gretzenbach - Suíça, 2004.

(FEUERWEHRVEREIN HINWIL, 2004)

Embora uma das primeiras normas para ensaios de resistência ao fogo tenha surgido em 1911 (ASTM E-119 "Standard Test Methods for Fire Tests of Building Construction and Materials"), no Brasil, a consideração do desempenho estrutural no âmbito da segurança contra o incêndio das edificações é recente. A regulamentação só teve incentivo a partir da década de 1970, com a publicação da norma ABNT NB 503 de 1977 (BACARJI, 1993), devido a algumas catástrofes relacionadas ao assunto, como foi o caso dos incêndios dos edifícios Andraus, em 1972, e Joelma, em 1974 (Figura 3.8), ambos em São Paulo. 


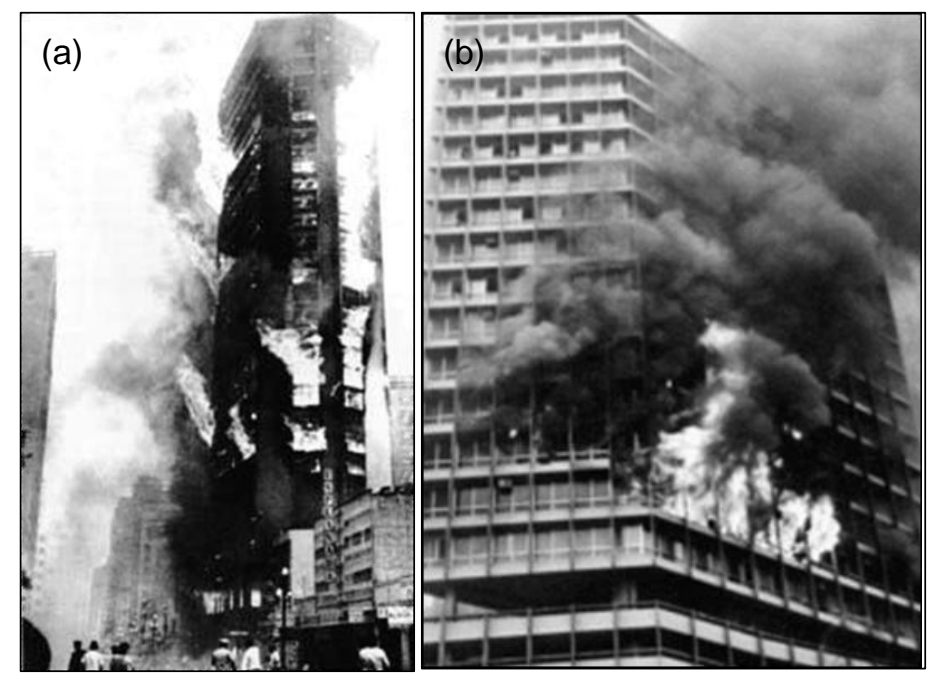

Figura 3.8. (a) Incêndio no edifício Andraus em 1972 e (b) edifício Joelma em 1974.

(BLOG MEMÓRIA VIVA, 2011)

Em 1987, um incêndio nos edifícios da CESP (Figura 3.9) atingiu praticamente todos os andares dos edifícios "Sede I" e "Sede II" da companhia. Durante o incêndio, a parte central da "Sede 2" ruiu e desabou, ocasionando uma morte.

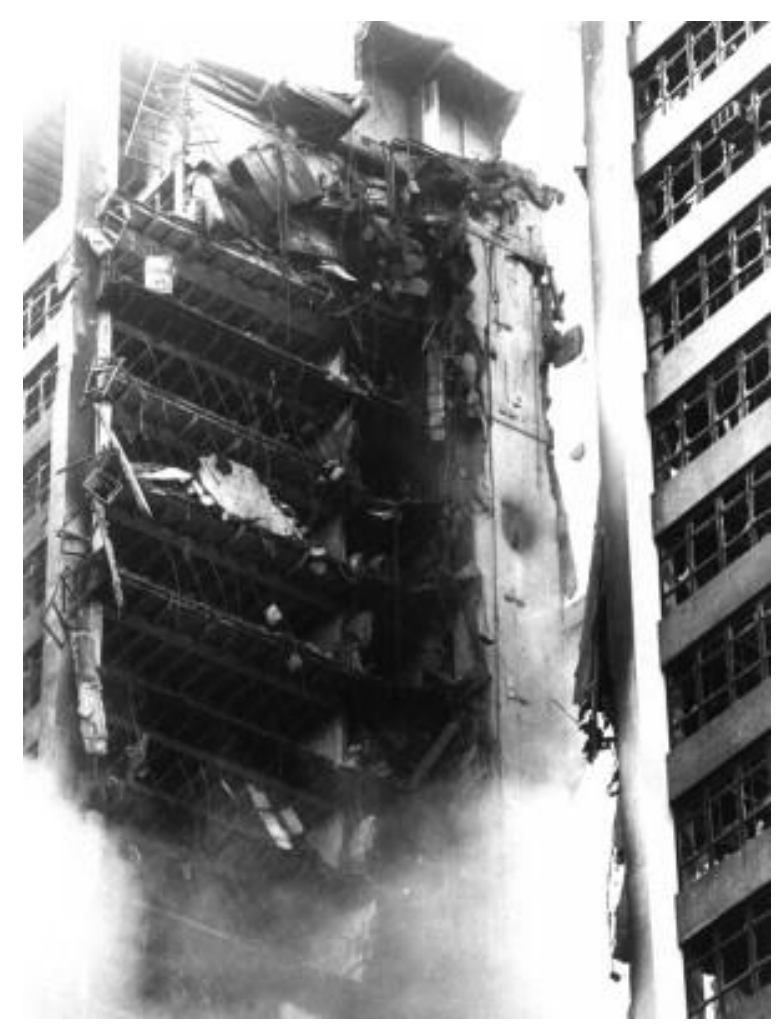

Figura 3.9. Colapso parcial do edifício Sede II da CESP em São Paulo - Brasil, 1987 (JORNAL ESTADO DE SÃO PAULO, 2010) 
Devido ao reconhecimento tardio de que as estruturas necessitavam de verificações para situações de incêndio, há diversos exemplos de acidentes, tais como os apresentados nas Figuras 3.10 a 3.12 .

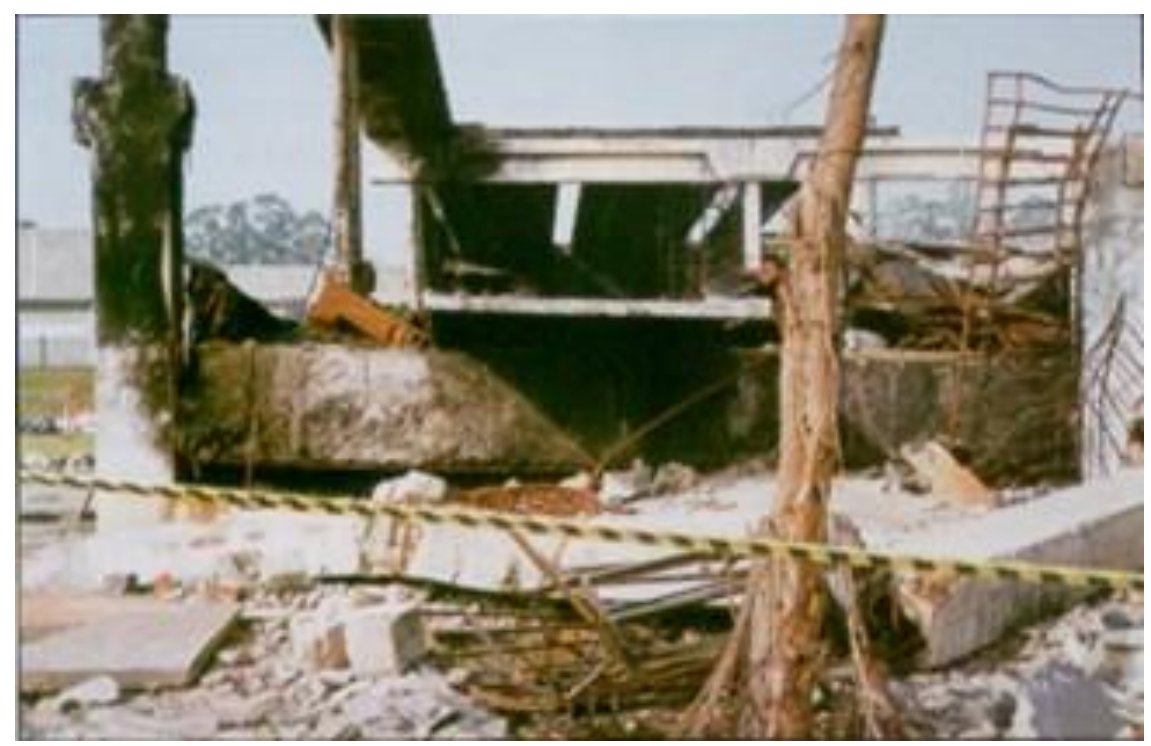

Figura 3.10. Colapso total do depósito das lojas Zêlo, em Barueri (SP) - Brasil, 1995.

(SILVA, 2010)

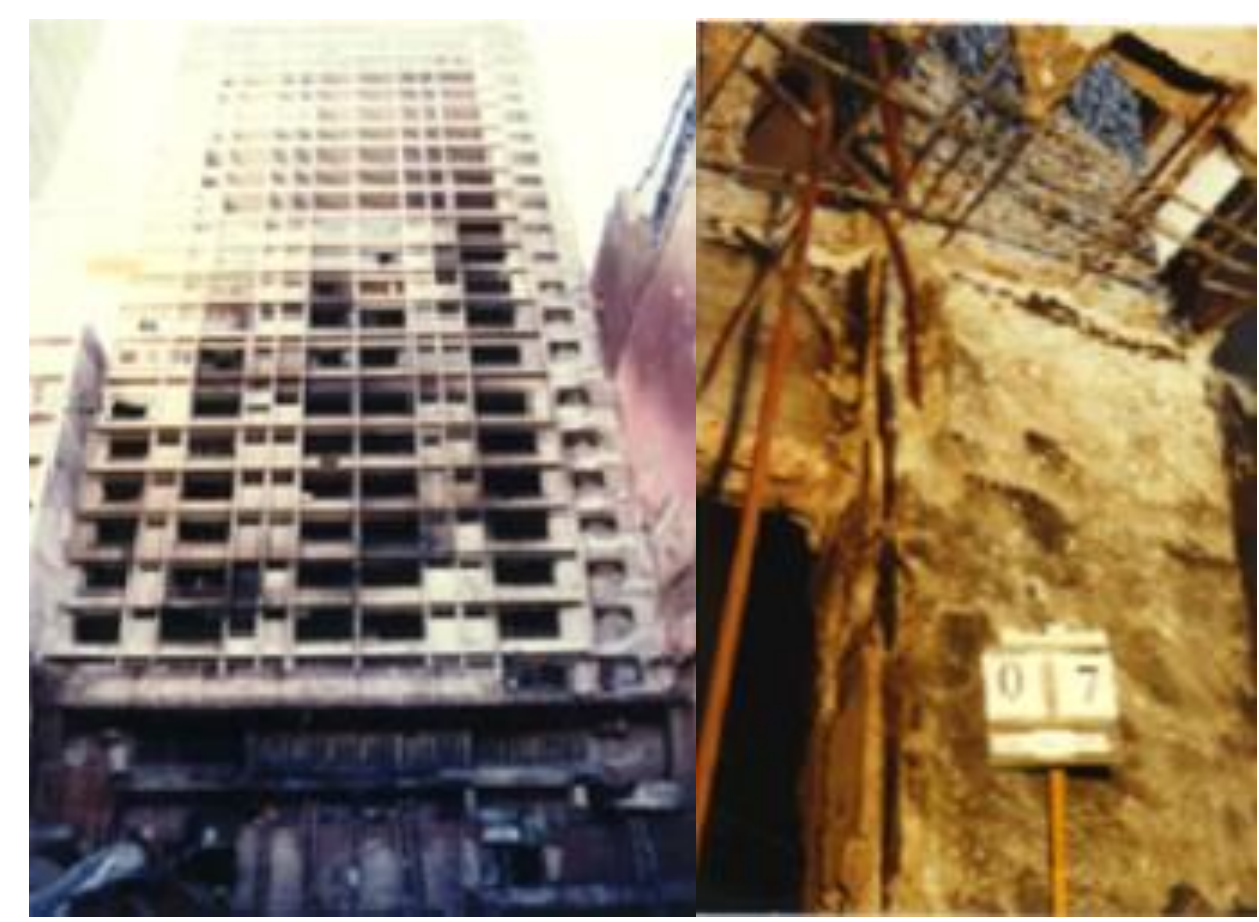

Figura 3.11. Danos nos elementos estruturais do Condomínio Edifício Cacique, em Porto Alegre Brasil, 1996.

(SILVA, 2010) 


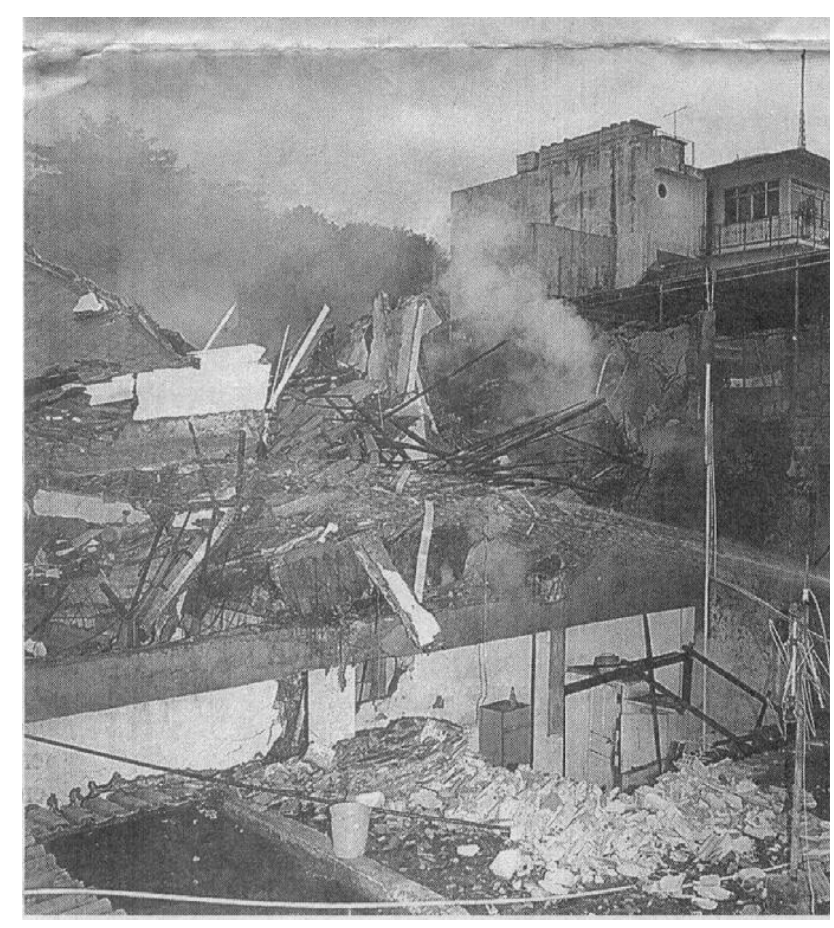

Figura 3.12. Colapso total de um edifício em Nova Iguaçu, RJ - Brasil, 2000.

(SILVA, 2010)

Atualmente, novas exigências para o projeto de estruturas em situação de incêndio estão em vigor. As normas ABNT NBR 14323:2013 (Projeto de estruturas de aço e de estruturas mistas de aço e concreto de edifícios em situação de incêndio), ABNT NBR 14432:2001 (Exigências de resistência ao fogo de elementos construtivos de edificações - Procedimento) e ABNT NBR 15200:2012 (Projeto de estruturas de concreto em situação de incêndio) apresentam parâmetros para que as edificações sejam mais seguras caso ocorra o sinistro.

\subsection{Ação térmica em situação de incêndio}

A diferença de temperatura entre os gases quentes e a estrutura, em um ambiente em chamas, gera uma ação térmica sobre os elementos estruturais. Essa ação é proveniente de um fluxo de calor por radiação e convecção. Dentre as consequências do aumento dessa temperatura em elementos estruturais destacamse a redução da sua resistência e rigidez (SILVA, 2012). 
O fluxo de calor por convecção (Figura 3.13) ocorre devido à diferença de densidade entre os gases no ambiente em chamas. As massas de gases quentes -menos densos- tendem a subir, enquanto os gases frios -mais densos- tendem a ocupar a atmosfera inferior do ambiente. Em uma situação de incêndio, esse processo é livre, pois o movimento dos fluidos ocorre de forma natural, exclusivamente pela atuação do gradiente térmico.

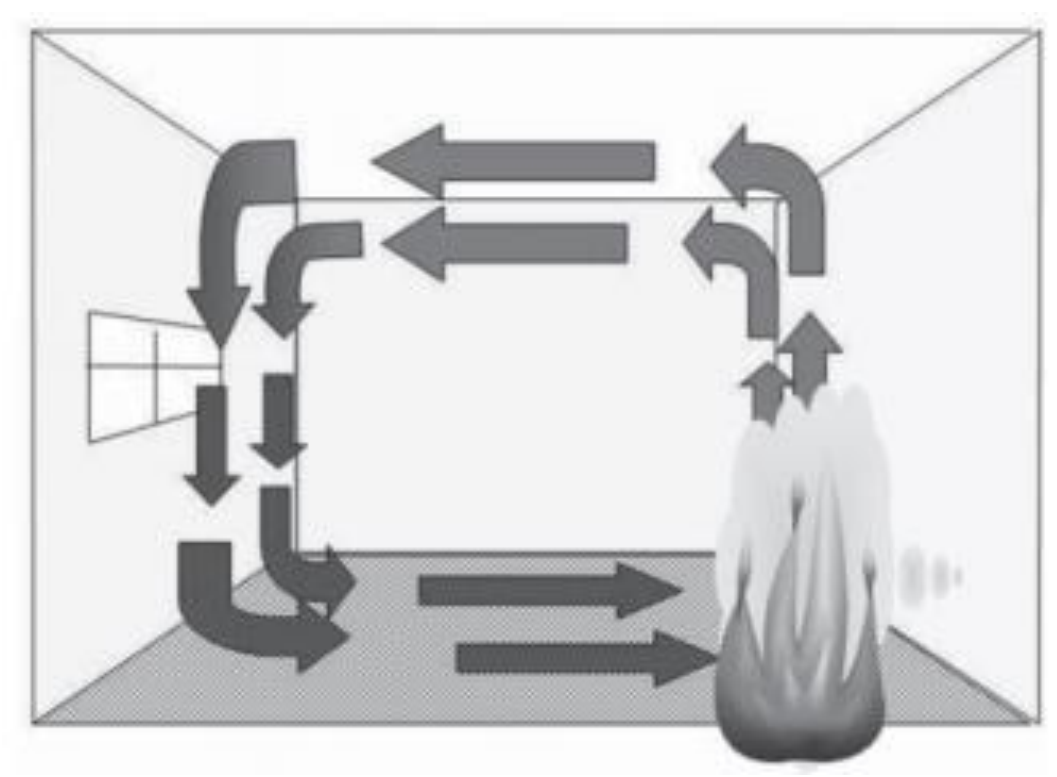

Figura 3.13. Fluxo de Calor Convectivo.

(SILVA, 2012)

Já o fluxo de calor por radiação (Figura 3.14), de acordo com a Teoria do Eletromagnetismo, é o processo pelo qual o calor flui por meio de ondas eletromagnéticas, conhecidas também por ondas caloríficas ou calor radiante, de um corpo sob alta temperatura para um corpo de baixa temperatura, devido ao alto grau de agitação das partículas. Quando o calor radiante incide num determinado corpo, uma parte pode ser absorvida ou refletida pela superfície, e o restante, transmitido pelo meio. 


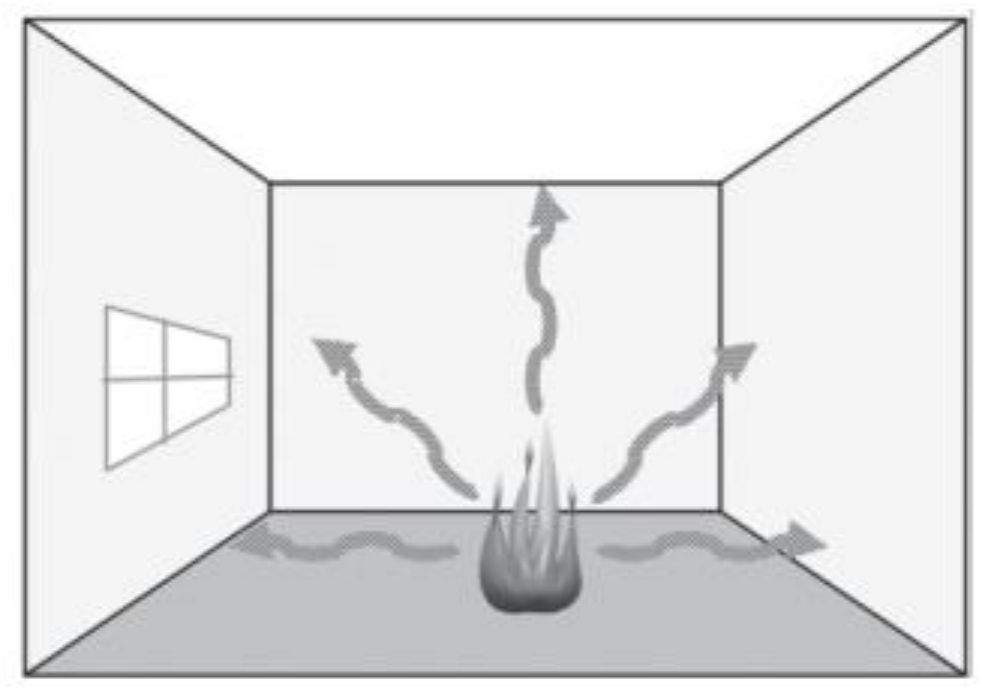

Figura 3.14 Fluxo de Calor Radiante.

(SILVA, 2012)

Na estrutura, o calor é conduzido de molécula a molécula (Figura 3.15). No concreto, o calor se propaga, elevando a temperatura gradualmente ao longo da seção do elemento e originando elevados gradientes térmicos. No aço, o calor se propaga mais rápido, e a temperatura elevada tende a se uniformizar ao longo da pequena seção das barras das armaduras.

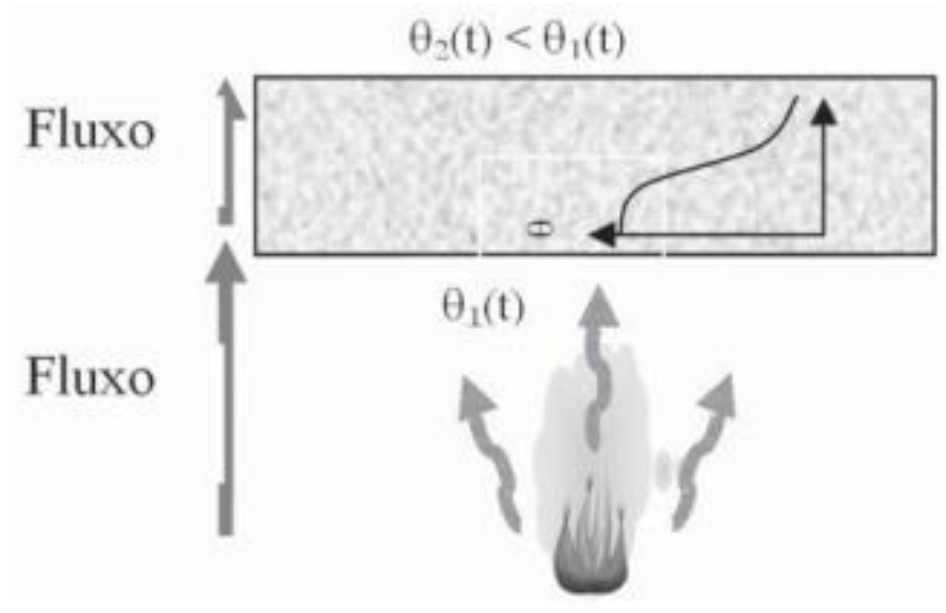

Figura 3.15. Condução.

(SILVA, 2012) 


\subsection{Incêndio real e Incêndio-padrão}

Para obter a máxima temperatura atingida por um elemento estrutural, e consequentemente sua resistência ao incêndio, é utilizada a curva tempotemperatura, que fornece a temperatura dos gases em função do tempo de incêndio. A Figura 3.16 mostra uma curva típica de um edifício em situação real de incêndio.

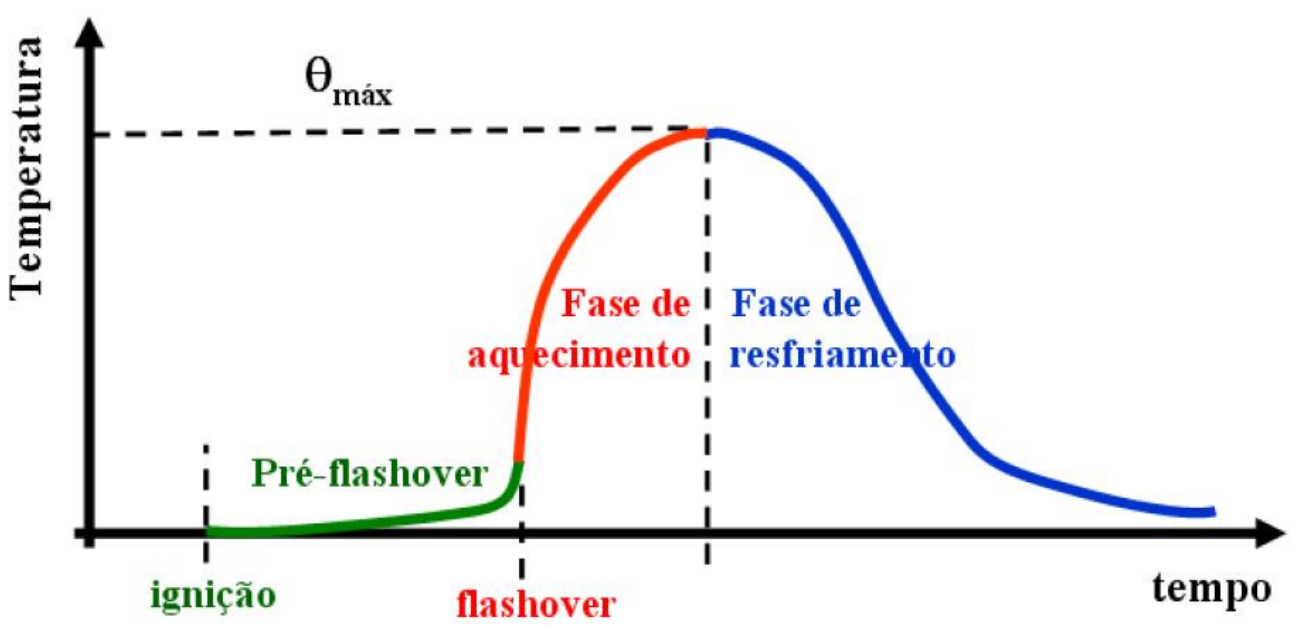

Figura 3.16. Curva tempo-temperatura típica de um incêndio real.

(Adaptado de SILVA, 2012)

De acordo com essa curva, o trecho inicial não representa perigo à estrutura. Entretanto, nesse período o risco está relacionado à vida humana. Sendo assim, é nessa fase que os projetos de arquitetura e instalações devem prever uma desocupação rápida da edificação, para evitar danos à vida. A etapa pré-flashover é importante no desenvolvimento do incêndio: quanto mais longa for, maiores serão as chances de controlar esse incêndio. Uma opção muito interessante seria incluir medidas de proteção ativa no interior da edificação, como, por exemplo: extintores, hidrantes, sprinklers (pequenos chuveiros presos no teto) e alarmes de incêndio.

Após esse período, caso o incêndio não seja extinto, há um aumento brusco na temperatura, chamado de flashover, tendo início no instante em que o fogo se espalha, resultando em um incêndio generalizado de todo o compartimento. A partir desse instante, as temperaturas dos gases sobem rapidamente, caracterizando a 
fase de aquecimento, alcançando a temperatura máxima, até todo material combustível começar a extinguir-se, dando início, então, à fase de resfriamento.

Segundo Silva (2012), para a análise da estrutura, é usual considerar que a temperatura do ambiente em chamas atinja seu valor máximo ( $\left.\theta_{\text {máx }}\right)$.

Os modelos dessas curvas são construídos a partir de análises experimentais ou computacionais que procuram simular a situação real de um compartimento em situação de incêndio. Ou seja, cada compartimento de uma edificação deveria ser projetado utilizando um tipo de curva específico para aquela situação, isso porque, geralmente, os parâmetros que influenciam a gravidade de um incêndio natural em um compartimento de uma edificação são diversos: carga de incêndio, condições de ventilação, propriedades físico-térmicas das paredes do compartimento, tipo de combustível predominante (celulósico, hidrocarbonetos, etc.), entre outros (SILVA, 2012).

Sendo assim, devido à enorme dificuldade de se estabelecer uma curva tempo-temperatura típica de um incêndio real, dificuldade essa justificada pela grande sensibilidade dessa curva às diversas variáveis mencionadas, as principais normas sobre o assunto adotam curvas padronizadas, denominadas de curvas de incêndio-padrão (Figura 3.17). Essas curvas possuem apenas um ramo ascendente, admitindo, portanto, que a temperatura é sempre crescente com o tempo e, além disso, independente da carga de incêndio e das características do ambiente.

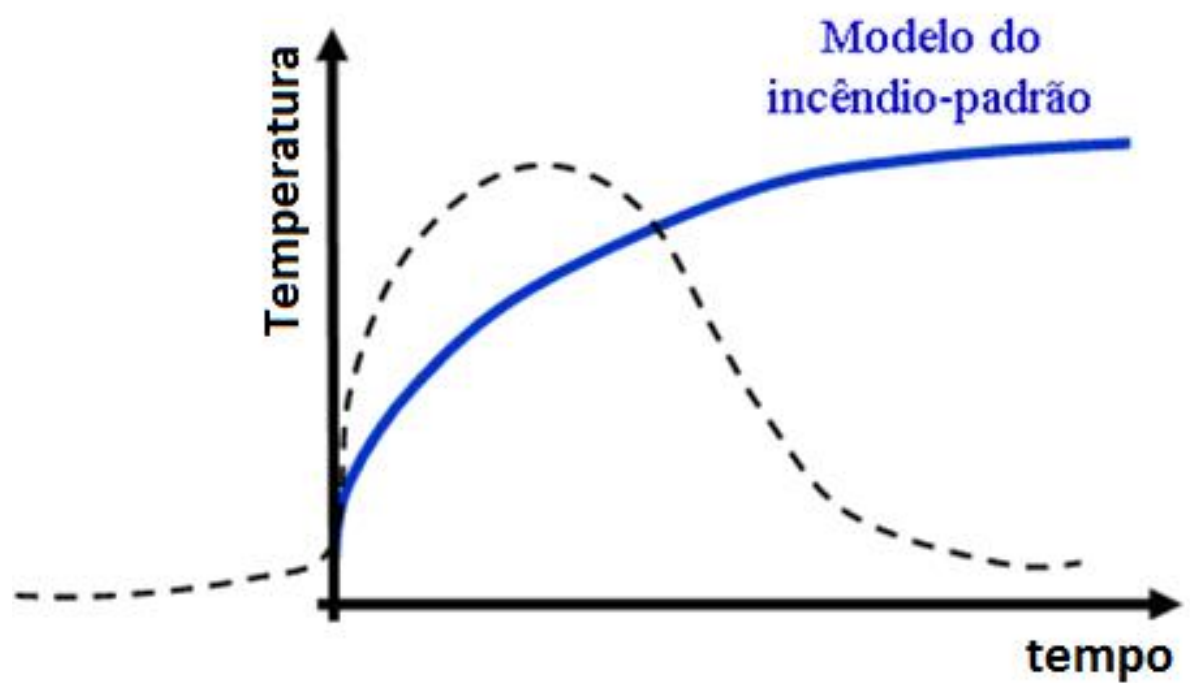

Figura 3.17. Modelo do incêndio-padrão.

(Adaptado de SILVA, 2012) 
O meio técnico adota a curva de incêndio-padrão e mede a resistência do material ao fogo, em função de um tempo. Esse tempo é chamado de Tempo Requerido de Resistência ao Fogo (TRRF).

\subsection{Tempo requerido de resistência ao fogo (TRRF)}

Um elemento construtivo, quando sujeito à curva do incêndio-padrão, apresenta um tempo mínimo de resistência ao fogo. Esse intervalo de tempo, chamado de Tempo Requerido de Resistência ao Fogo (TRRF), é definido a partir das características da construção e do seu uso; portanto, não representa o tempo de desocupação ou o tempo de duração do incêndio.

O calor transmitido à estrutura nesse intervalo de tempo gera em cada elemento estrutural uma distribuição de temperatura, que resulta na redução da resistência dos materiais e da capacidade portante dos elementos estruturais. Vale ressaltar que esses intervalos referem-se ao tempo em que a estrutura deve se comportar satisfatoriamente, ou seja, os elementos estruturais não devem sofrer colapso e não pode haver fissuras que permitam que o fogo se propague para um compartimento adjacente, para que assim possibilitem o cumprimento dos objetivos descritos no art. $2^{\circ}$ do decreto estadual $n^{\circ} 46.076 / 01$ que diz:

Artigo $2^{\circ}$ - Os objetivos deste Regulamento são:

I - proteger a vida dos ocupantes das edificações e áreas de risco, em caso de incêndio;

II - dificultar a propagação do incêndio, reduzindo danos ao meio ambiente e ao patrimônio;

III - proporcionar meios de controle e extinção do incêndio; e

IV - dar condições de acesso para as operações do Corpo de Bombeiros.

O TRRF é encontrado em normas e trata-se de um valor que é determinado em função do risco de incêndio e das consequências provenientes de um colapso estrutural. Os valores são padronizados e variam entre 30, 60, 90 e 120 minutos.

Segundo Silva (2012), o TRRF pode ser obtido pelo método tabular, contido na ABNT NBR 14432:2001, ou pelo método do tempo equivalente, que apresenta um método baseado no conceito do TRRF para o incêndio da Curva Padrão da ISO 834:1999 (Figura 3.18). 


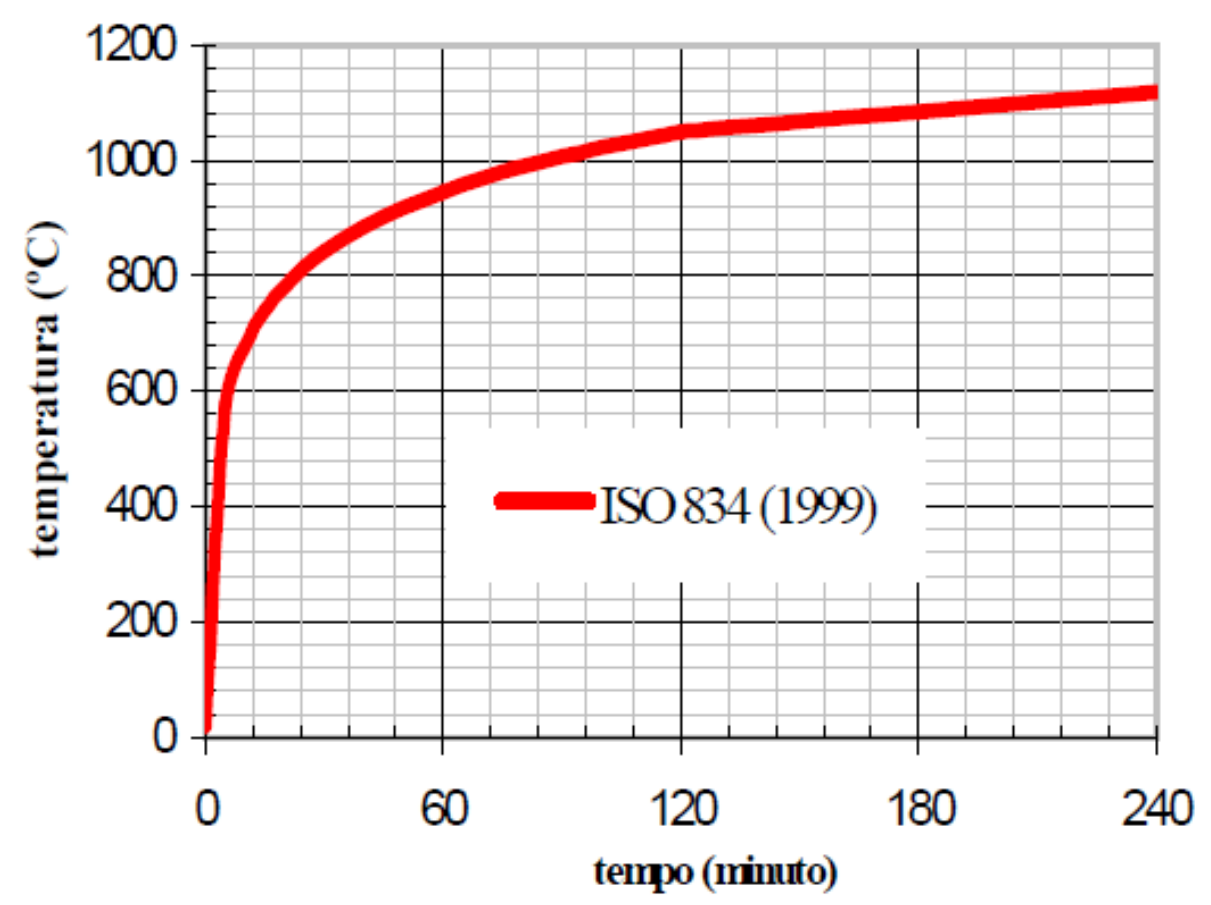

Figura 3.18. Curva Padrão - Temperatura x tempo (ISO 834:1999)

(SOUZA, 2005)

\subsubsection{Método Tabular}

O método tabular da ABNT NBR 14432: 2001 é prático e pode ser aplicado de forma direta para o dimensionamento, ou seja, sem o auxílio de programas computacionais ou ensaios experimentais. Além disso, não há necessidade de verificação, basta atender às dimensões mínimas apresentadas nas tabelas da referida norma.

Para se determinar o TRRF dos elementos construtivos, usa-se a Tabela 3.1, que estabelece o TRRF em função do tipo de ocupação da edificação, e a Tabela 3.2, que organiza as edificações em classes, também em função da ocupação. $\mathrm{Na}$ Tabela 3.1, hs é a profundidade do subsolo e h é a altura da edificação. 
Tabela 3.1. Tempos requeridos de resistência ao fogo (TRRF), em minutos.

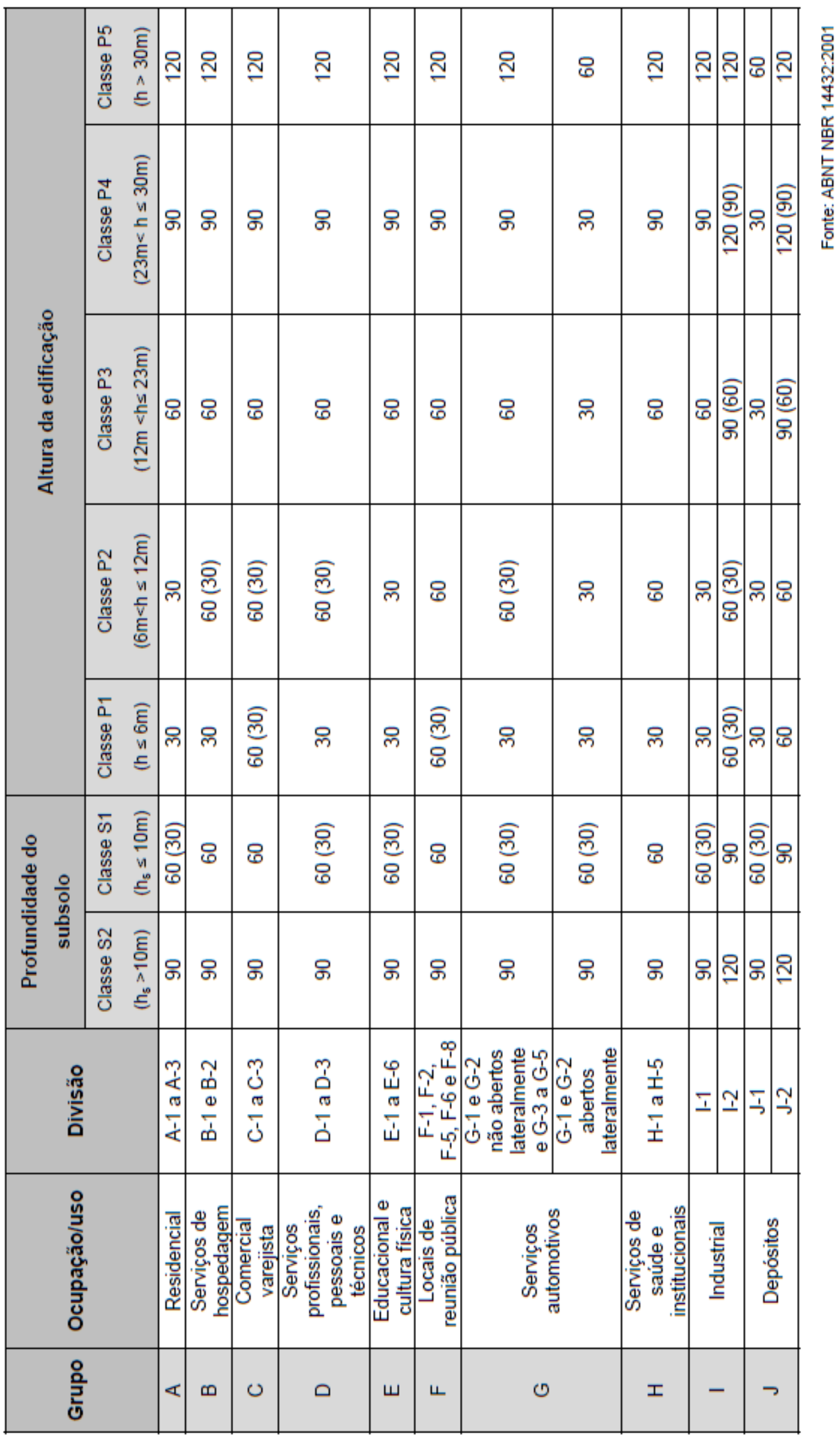


Tabela 3.2. Classificação das edificações quanto à sua ocupação.

\begin{tabular}{|c|c|c|c|c|c|c|c|c|c|c|c|c|c|c|}
\hline 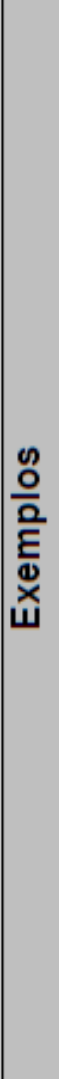 & 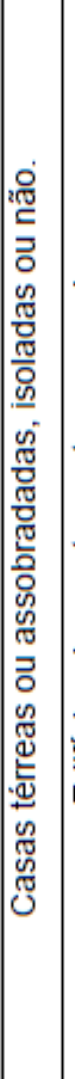 & 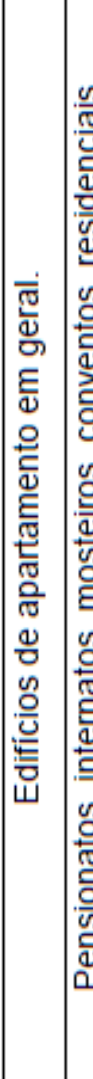 & 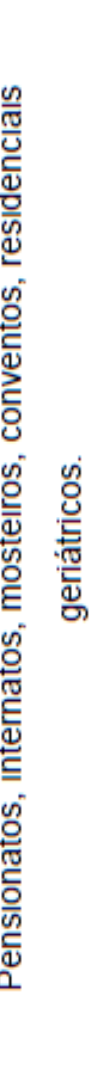 & 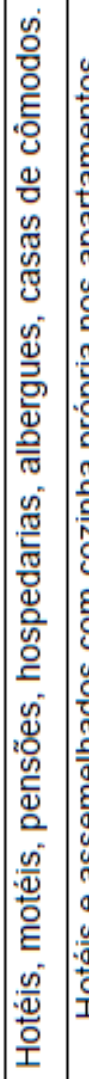 & 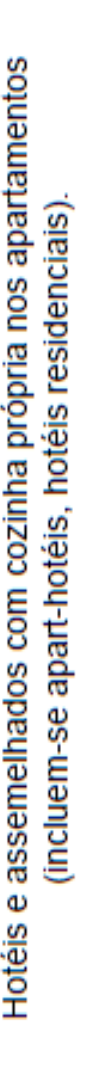 & 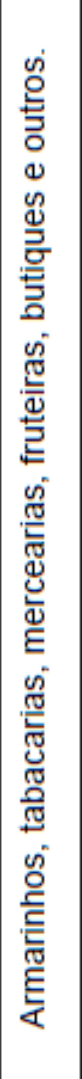 & 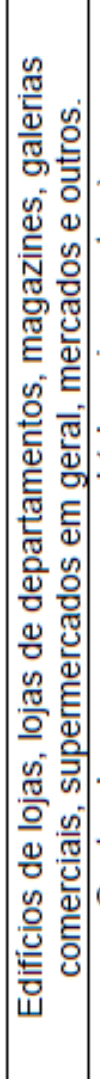 & 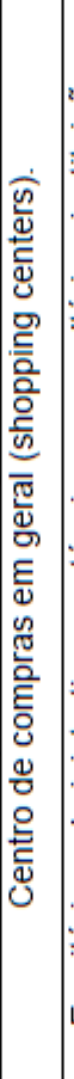 & 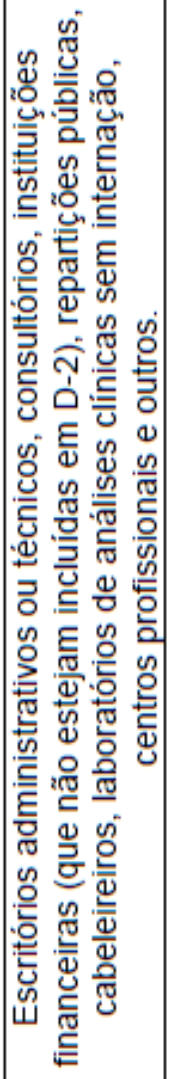 & 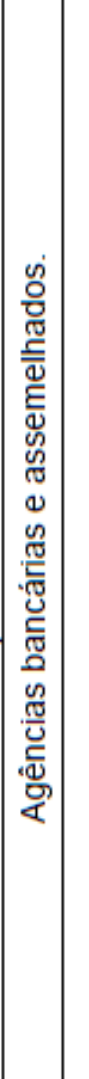 & 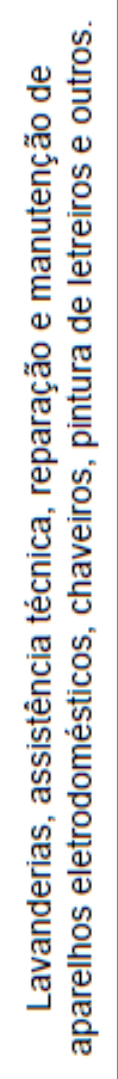 & 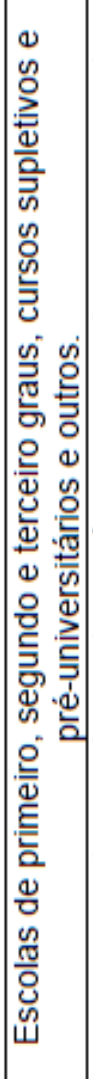 & 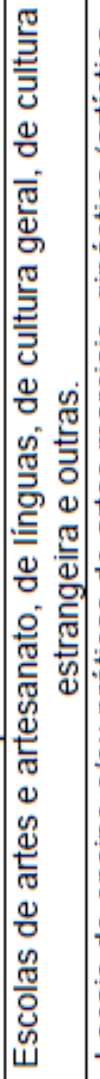 & 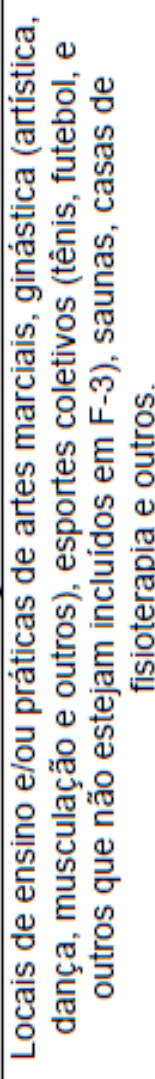 \\
\hline 产 & 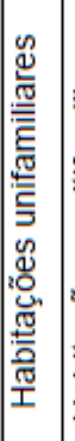 & 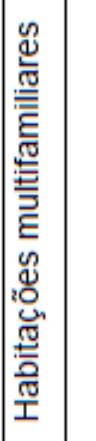 & 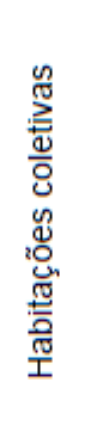 & 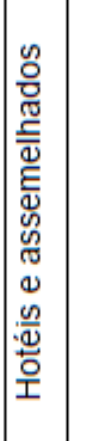 & 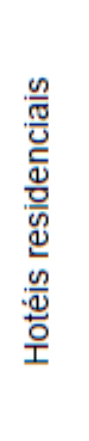 & 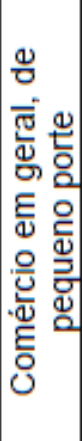 & 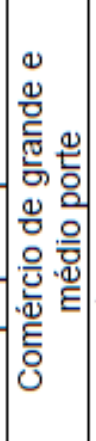 & 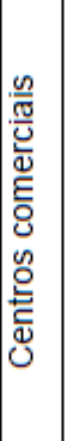 & 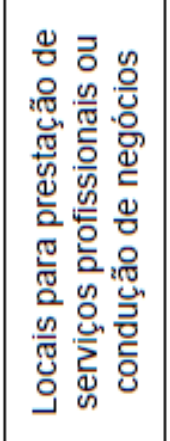 & 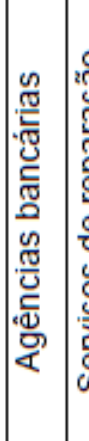 & 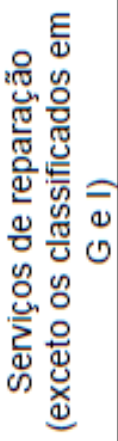 & 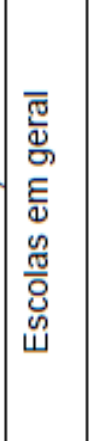 & 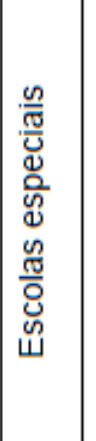 & 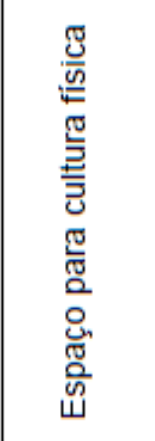 \\
\hline 禺 & $\bar{\alpha}$ & $\frac{N}{4}$ & $\frac{m}{4}$ & $\bar{\omega}$ & ஸ̃ & $\bar{j}$ & j & o & $\bar{o}$ & ڤִ & p̧ & ய் & ஸ் & 竞 \\
\hline 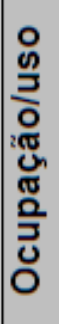 & & 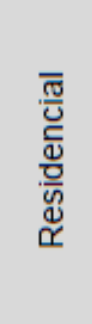 & & & 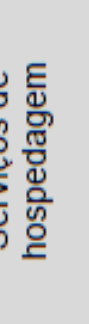 & & 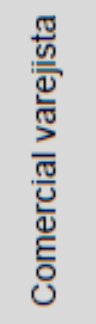 & & & 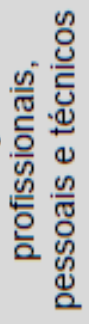 & & & 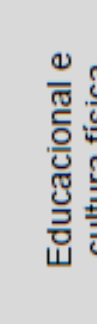 & \\
\hline$\frac{2}{2}$ & & $\varangle$ & & $\oplus$ & D & & 0 & & & ט & & & Ш & \\
\hline
\end{tabular}


Tabela 3.2. Classificação das edificações quanto à sua ocupação. (continuação)

\begin{tabular}{|c|c|c|c|c|c|c|c|c|c|c|c|c|c|c|c|c|}
\hline 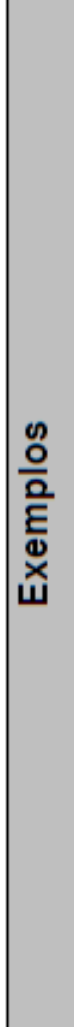 & 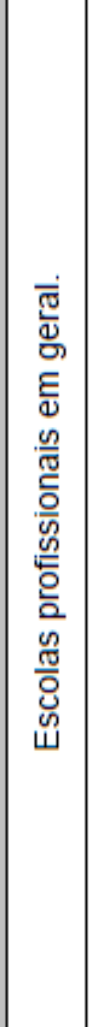 & 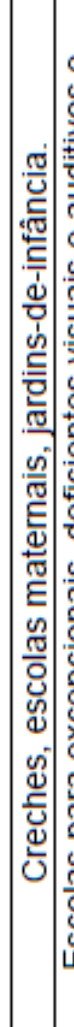 & 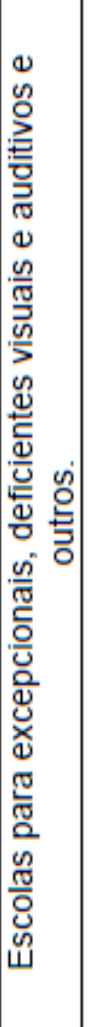 & 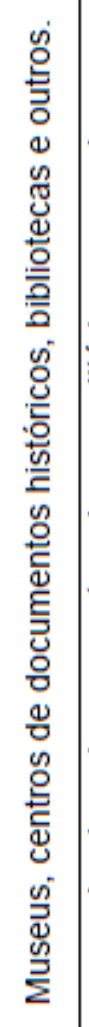 & 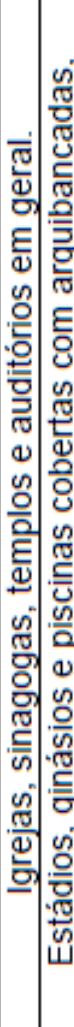 & 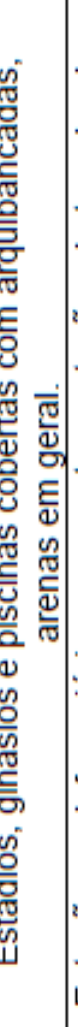 & 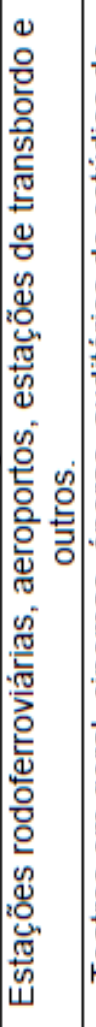 & 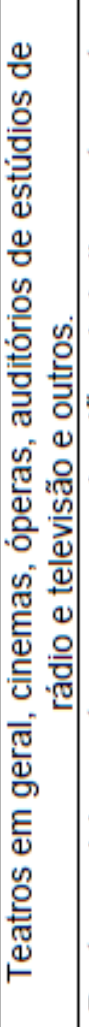 & 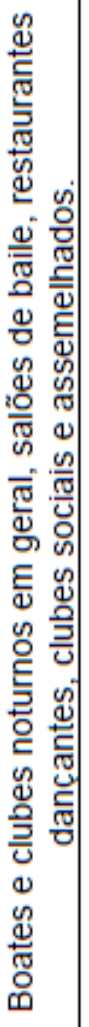 & 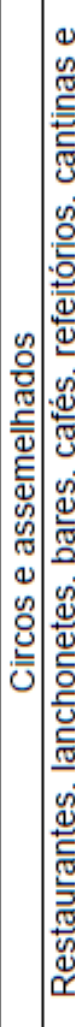 & 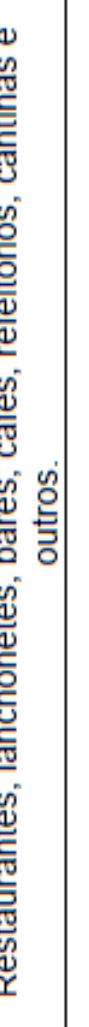 & 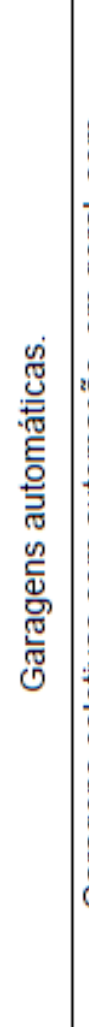 & 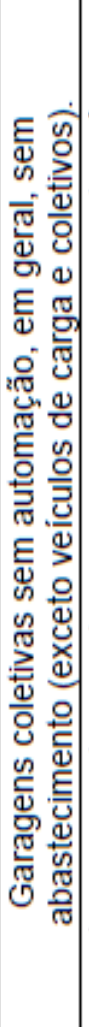 & 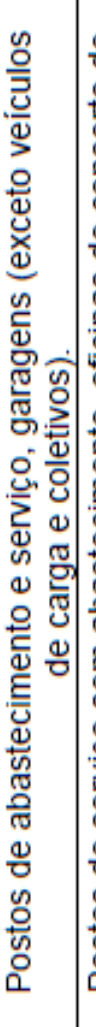 & 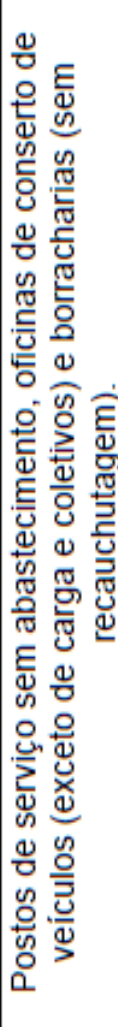 & 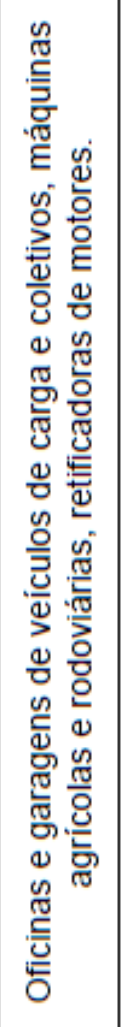 \\
\hline 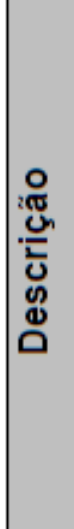 & 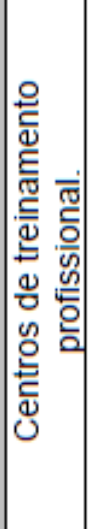 & 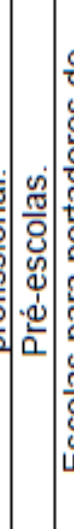 & 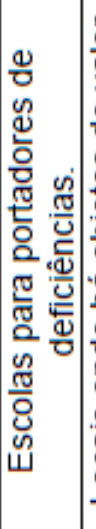 & 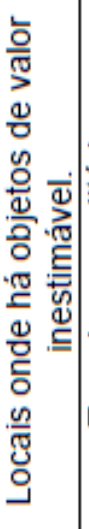 & 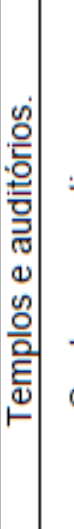 & 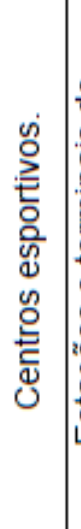 & 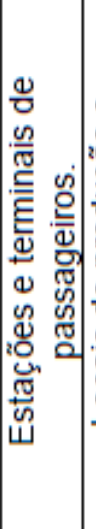 & 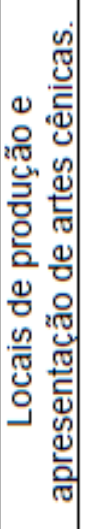 & 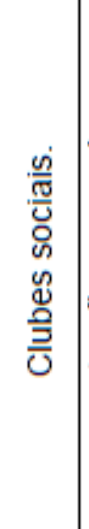 & 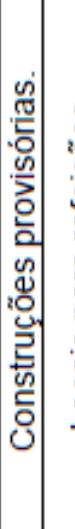 & 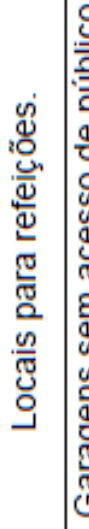 & 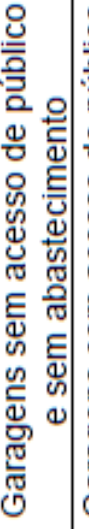 & 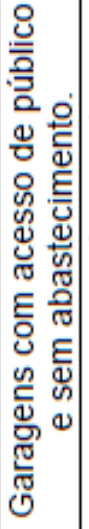 & 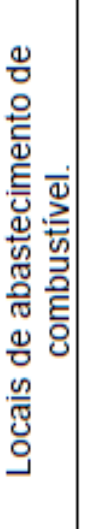 & 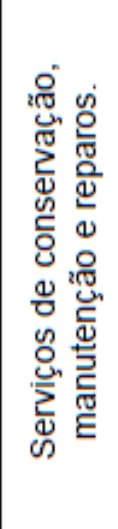 & 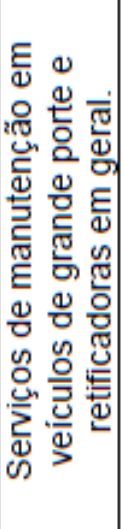 \\
\hline 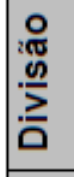 & 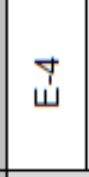 & 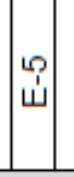 & $\begin{array}{l}\varphi \\
\dot{U}\end{array}$ & $\bar{\leftarrow}$ & $\begin{array}{l}\stackrel{T}{\leftarrow} \\
\stackrel{1}{*}\end{array}$ & $\begin{array}{l}\text { ? } \\
\ddot{1}\end{array}$ & $\underset{\leftarrow}{\forall}$ & $\begin{array}{l}\stackrel{p}{\varphi} \\
\stackrel{1}{4}\end{array}$ & $\begin{array}{l}\varphi \\
\stackrel{1}{\leftarrow}\end{array}$ & $\begin{array}{l}\hat{1} \\
\dot{1}\end{array}$ & $\begin{array}{l}\infty \\
\perp^{\prime}\end{array}$ & $\overline{0}$ & ஸे & ? & ఫ̇ & 号 \\
\hline 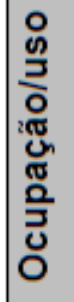 & & 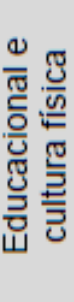 & & & & & 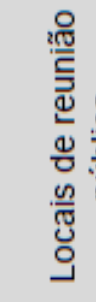 & 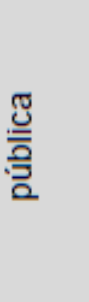 & & & & & & & 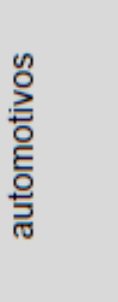 & \\
\hline 을 & & ш & & & & & ᄂ & - & & & & & & () & D & \\
\hline
\end{tabular}


Tabela 3.2. Classificação das edificações quanto à sua ocupação. (continuação)

\begin{tabular}{|c|c|c|c|c|c|c|c|c|c|}
\hline 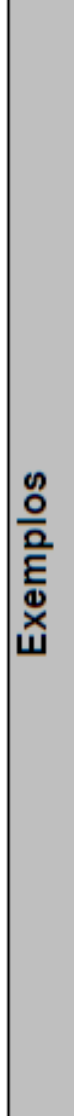 & 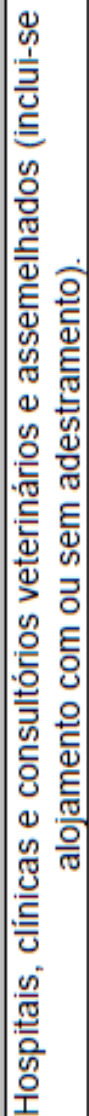 & 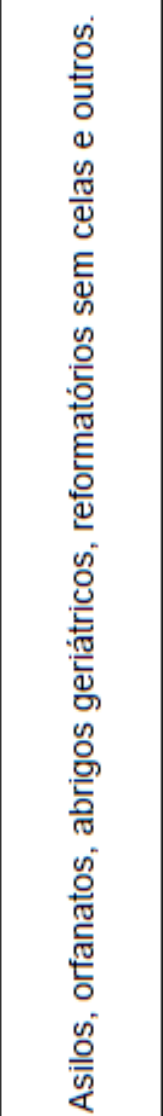 & 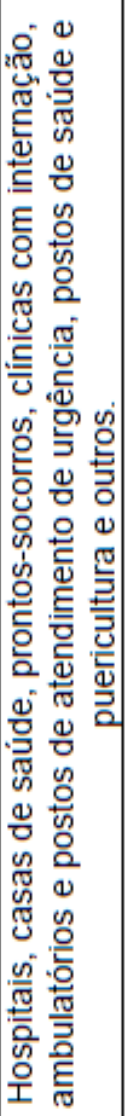 & 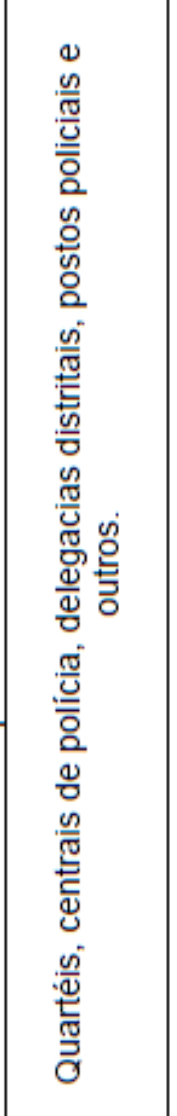 & 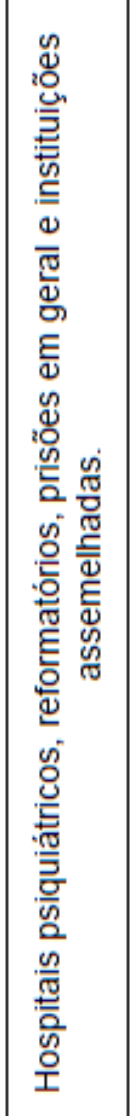 & 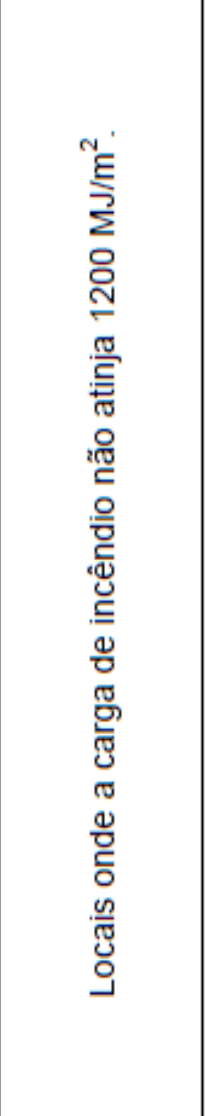 & 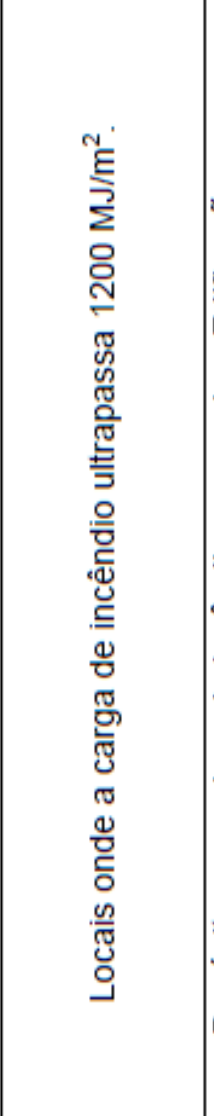 & 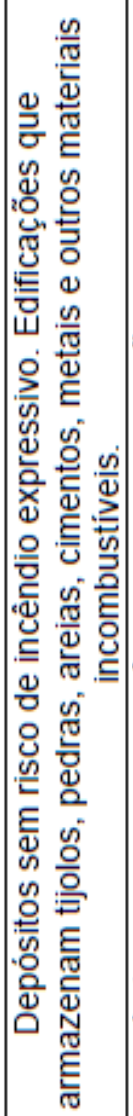 & 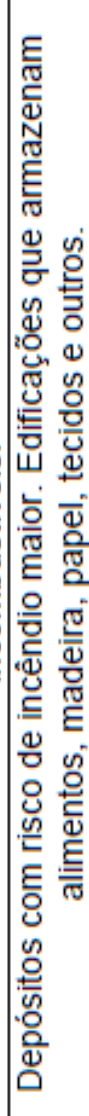 \\
\hline 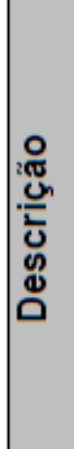 & 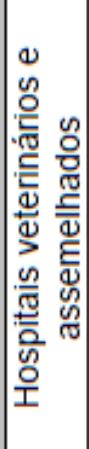 & 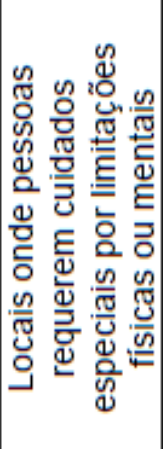 & 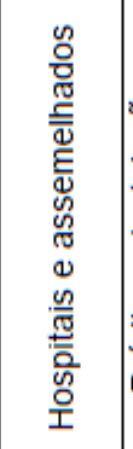 & 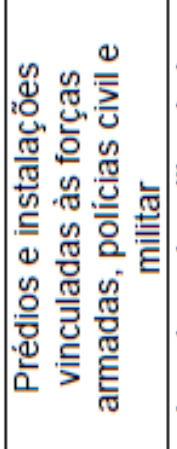 & 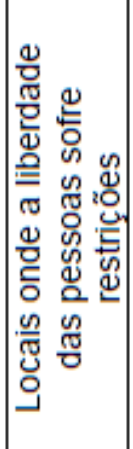 & 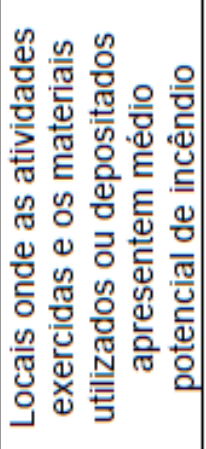 & 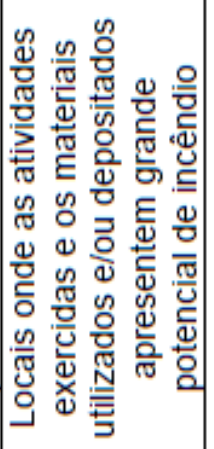 & 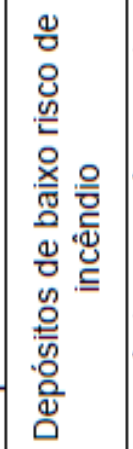 & 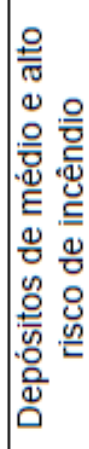 \\
\hline 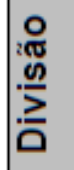 & $\stackrel{\bar{I}}{\bar{I}}$ & $\underset{\text { I }}{\stackrel{Y}{I}}$ & $\begin{array}{l}p \\
\text { I }\end{array}$ & $\stackrel{⿱ 亠}{I}$ & $\stackrel{\varphi}{\underline{1}}$ & $I$ & $\stackrel{\Upsilon}{\perp}$ & 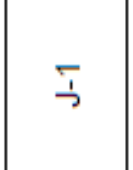 & $\stackrel{\Upsilon}{\zeta}$ \\
\hline 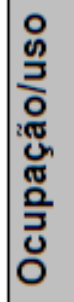 & \multicolumn{5}{|c|}{ 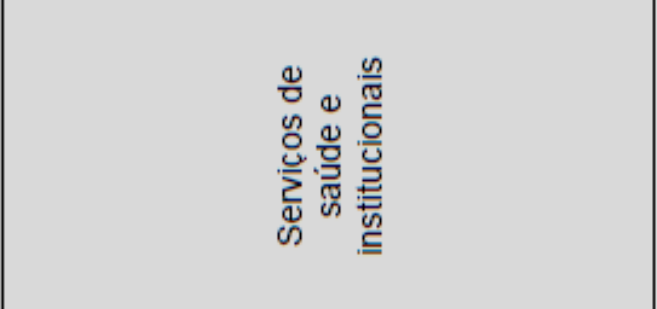 } & \multicolumn{2}{|c|}{ 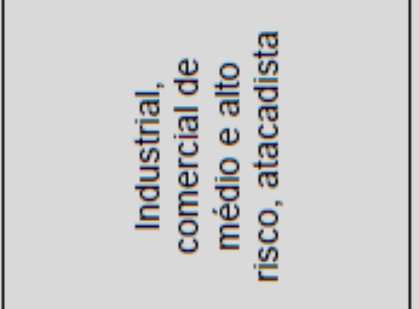 } & \multicolumn{2}{|l|}{ 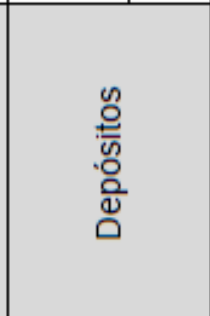 } \\
\hline 을 & \multicolumn{5}{|c|}{ I } & \multicolumn{2}{|c|}{-} & \multicolumn{2}{|l|}{$\neg$} \\
\hline
\end{tabular}


De acordo com Silva (2012), apesar de esse método ser uma simplificação, essa teoria é aceita pela comunidade científica internacional, pois se admite que a segurança estrutural dos elementos estruturais estará garantida.

\subsubsection{Método do tempo equivalente}

É um método em que o tempo requerido de resistência ao fogo (TRRF) de elementos estruturais de concreto armado poderá ser reduzido em até 30 minutos, mas não poderá ser inferior a 15 minutos. Esse tempo é determinado pela Equação 3.1.

$$
\mathrm{t}_{\mathrm{e}}=0,07 \mathrm{q}_{\mathrm{fi}, \mathrm{k}} \mathrm{W} \gamma_{\mathrm{n}} \gamma_{\mathrm{s}}
$$

- $\mathrm{q}_{\mathrm{fi}, \mathrm{k}}$ é o valor característico da carga de incêndio específica do compartimento, em $\mathrm{MJ} / \mathrm{m}^{2}$ - Valores apresentados na Tabela 3.3.

- W é um fator que considera a influência da ventilação e da altura do compartimento, conforme a Equação 3.2, em que $A_{v}$ é a área de ventilação vertical para o ambiente externo do compartimento, admitindo-se que os vidros das janelas se quebrarão durante $\mathrm{o}$ incêndio, $\mathrm{A}_{\mathrm{f}}$ é a área do piso do compartimento em metros quadrados e $\mathrm{H}$ é a altura do compartimento (distância do piso ao teto), em metros. Na Equação 3.2, $\mathrm{A}_{\mathrm{v}} / \mathrm{A}_{\mathrm{f}}$ deve ser menor ou igual a 0,30. Já para $A_{v} / A_{f}$ maior do que 0,30, deve-se tomar $A_{v} / A_{f}$ igual a 0,30. Em ambos os casos, $A_{v} / A_{f}$ deve ser maior ou igual a 0,025.

$$
W=\left(\frac{6}{H}\right)^{0,3}\left\{0,62+90\left(0,4-\frac{A_{v}}{A_{f}}\right)^{4}\right\} \geq 0,5
$$

- $\gamma_{\mathrm{n}}$ é um fator de ponderação determinado por $\gamma_{\mathrm{n}}=\gamma_{\mathrm{n} 1} \cdot \gamma_{\mathrm{n} 2} \cdot \gamma_{\mathrm{n} 3}$, conforme a Tabela 3.4. Na ausência de algum meio de proteção, adotar $\gamma_{\mathrm{n}}=1$.

- $\gamma_{\mathrm{s}}$ é um fator de ponderação determinado por $\gamma_{\mathrm{s}}=\gamma_{\mathrm{s} 1} \cdot \gamma_{\mathrm{s} 2}$, em que: 
$\gamma_{\mathrm{s} 1}$ é um fator de segurança determinado pela Equação 3.3, que depende da área do piso do compartimento $\left(\mathrm{A}_{\mathrm{f}}\right)$, em metros quadrados, e h é a altura do piso habitável mais elevado da edificação, em metros. Para $\gamma_{\mathrm{s} 1}<1$, deve ser adotado $\gamma_{\mathrm{s} 1}=1$, e para $\gamma_{\mathrm{s} 1}>3$, pode-se adotar $\gamma_{\mathrm{s} 1}=3$.

$\gamma_{\mathrm{s} 1}=1+\frac{\mathrm{A}_{\mathrm{f}} \cdot(\mathrm{h}+3)}{10^{5}}$

$\gamma_{\mathrm{s} 2}$ é um fator que depende do risco do incêndio (Tabela 3.5).

Tabela 3.3. Valores das cargas de incêndio específicas

\begin{tabular}{|c|c|c|c|}
\hline Ocupação/uso & Descrição & Divisão & $\begin{array}{c}\text { Carga de } \\
\text { incêndio } \\
\mathrm{MJ} / \mathrm{m}^{2}\end{array}$ \\
\hline Residencial & $\begin{array}{l}\text { Alojamentos estudantis } \\
\text { Apartamentos } \\
\text { Casas térreas ou sobrados } \\
\text { Pensionatos }\end{array}$ & $\begin{array}{l}\text { A-1 } \\
\text { A-2 } \\
\text { A-1 } \\
\text { A-3 }\end{array}$ & $\begin{array}{l}300 \\
300 \\
300 \\
300\end{array}$ \\
\hline $\begin{array}{l}\text { Serviços de } \\
\text { hospedagem }\end{array}$ & $\begin{array}{l}\text { Hotéis } \\
\text { Motéis } \\
\text { Apart-hotéis }\end{array}$ & $\begin{array}{l}\text { B-1 } \\
\text { B-1 } \\
\text { B-2 }\end{array}$ & $\begin{array}{l}500 \\
500 \\
300\end{array}$ \\
\hline $\begin{array}{l}\text { Comercial } \\
\text { varejista }\end{array}$ & $\begin{array}{l}\text { Açougues } \\
\text { Antiguidades } \\
\text { Aparelhos domésticos } \\
\text { Artigos de bijuteria, metal ou vidro } \\
\text { Artigos de couro, borracha, esportivos } \\
\text { Automóveis } \\
\text { Bebidas destiladas } \\
\text { Brinquedos } \\
\text { Cabeleireiro } \\
\text { Calçados } \\
\text { Drogarias (incluindo depósitos) } \\
\text { Ferragens } \\
\text { Floricultura } \\
\text { Galeria de quadros } \\
\text { Livrarias } \\
\text { Lojas de departamento ou centro de compras } \\
\text { Máquinas de costura ou de escritório } \\
\text { Materiais fotográficos } \\
\text { Móveis } \\
\text { Papelarias } \\
\text { Perfumarias } \\
\text { Produtos têxteis } \\
\text { Relojoarias } \\
\text { Supermercados } \\
\text { Tapetes } \\
\text { Tintas } \\
\text { Verduras } \\
\text { Vinhos } \\
\text { Vulcanização }\end{array}$ & $\begin{array}{l}\mathrm{C}-1 / \mathrm{C}-2 \\
\mathrm{C}-1 / \mathrm{C}-2 \\
\mathrm{C}-1 / \mathrm{C}-2 \\
\mathrm{C}-1 / \mathrm{C}-2 \\
\mathrm{C}-1 / \mathrm{C}-2 \\
\mathrm{C}-1 / \mathrm{C}-2 \\
\mathrm{C}-1 / \mathrm{C}-2 \\
\mathrm{C}-1 / \mathrm{C}-2 \\
\mathrm{C}-1 / \mathrm{C}-2 \\
\mathrm{C}-1 / \mathrm{C}-2 \\
\mathrm{C}-1 / \mathrm{C}-2 \\
\mathrm{C}-1 / \mathrm{C}-2 \\
\mathrm{C}-1 / \mathrm{C}-2 \\
\mathrm{C}-1 / \mathrm{C}-2 \\
\mathrm{C}-1 / \mathrm{C}-2 \\
\mathrm{C}-2 \\
\mathrm{C}-1 / \mathrm{C}-2 \\
\mathrm{C}-1 / \mathrm{C}-2 \\
\mathrm{C}-1 / \mathrm{C}-2 \\
\mathrm{C}-1 / \mathrm{C}-2 \\
\mathrm{C}-1 / \mathrm{C}-2 \\
\mathrm{C}-1 / \mathrm{C}-2 \\
\mathrm{C}-1 / \mathrm{C}-2 \\
\mathrm{C}-2 \\
\mathrm{C}-1 / \mathrm{C}-2 \\
\mathrm{C}-1 / \mathrm{C}-2 \\
\mathrm{C}-1 / \mathrm{C}-2 \\
\mathrm{C}-1 / \mathrm{C}-2 \\
\mathrm{C}-1 / \mathrm{C}-2\end{array}$ & $\begin{array}{c}40 \\
700 \\
500 \\
300 \\
800 \\
200 \\
700 \\
500 \\
300 \\
500 \\
1000 \\
300 \\
80 \\
200 \\
1000 \\
600 \\
300 \\
300 \\
500 \\
700 \\
400 \\
600 \\
300 \\
400 \\
800 \\
1000 \\
200 \\
200 \\
1000\end{array}$ \\
\hline
\end{tabular}




\begin{tabular}{|c|c|c|c|}
\hline Ocupação/uso & Descrição & Divisão & $\begin{array}{l}\text { Carga de } \\
\text { incêndio } \\
\mathrm{MJ} / \mathrm{m}^{2}\end{array}$ \\
\hline $\begin{array}{l}\text { Serviços } \\
\text { profissionais, } \\
\text { pessoais e } \\
\text { técnicos }\end{array}$ & $\begin{array}{l}\text { Agências bancárias } \\
\text { Agências de correios } \\
\text { Centrais telefônicas } \\
\text { Consultórios médicos ou odontológicos } \\
\text { Copiadora } \\
\text { Encadernadoras } \\
\text { Escritórios } \\
\text { Estúdios de rádio ou de televisão ou de fotografia } \\
\text { Lavanderias } \\
\text { Oficinas elétricas } \\
\text { Oficinas hidráulicas ou mecânicas } \\
\text { Pinturas } \\
\text { Processamentos de dados }\end{array}$ & $\begin{array}{l}\text { D-2 } \\
\text { D-1 } \\
\text { D-1 } \\
\text { D-1 } \\
\text { D-3 } \\
\text { D-3 } \\
\text { D-1 } \\
\text { D-1 } \\
\text { D-1 } \\
\text { D-3 } \\
\text { D-3 } \\
\text { D-3 } \\
\text { D-1 }\end{array}$ & $\begin{array}{c}300 \\
400 \\
100 \\
200 \\
400 \\
1000 \\
700 \\
300 \\
300 \\
600 \\
200 \\
500 \\
400\end{array}$ \\
\hline $\begin{array}{l}\text { Educacional e } \\
\text { cultura física }\end{array}$ & $\begin{array}{l}\text { Academias } \\
\text { Creches } \\
\text { Escolas }\end{array}$ & $\begin{array}{c}E-3 \\
E-5 \\
E-1 / E-2 / E-4 \\
\end{array}$ & $\begin{array}{l}300 \\
400 \\
300\end{array}$ \\
\hline $\begin{array}{l}\text { Locais de } \\
\text { reunião pública }\end{array}$ & $\begin{array}{l}\text { Bibliotecas } \\
\text { Cinemas ou teatros } \\
\text { Igrejas } \\
\text { Museus } \\
\text { Restaurantes }\end{array}$ & $\begin{array}{l}\text { F-1 } \\
\text { F-5 } \\
\text { F-2 } \\
\text { F-1 } \\
\text { F-8 }\end{array}$ & $\begin{array}{l}2000 \\
600 \\
200 \\
300 \\
300\end{array}$ \\
\hline $\begin{array}{c}\text { Serviços } \\
\text { automotivos }\end{array}$ & $\begin{array}{l}\text { Estacionamentos } \\
\text { Oficinas de conserto de veículos }\end{array}$ & $\begin{array}{c}\mathrm{G}-1 / \mathrm{G}-2 \\
\mathrm{G}-4\end{array}$ & $\begin{array}{l}200 \\
300\end{array}$ \\
\hline $\begin{array}{l}\text { Serviços de } \\
\text { saúde e } \\
\text { institucionais }\end{array}$ & $\begin{array}{l}\text { Asilos } \\
\text { Hospitais }\end{array}$ & $\begin{array}{l}\mathrm{H}-2 \\
\mathrm{H}-1\end{array}$ & $\begin{array}{l}350 \\
300 \\
\end{array}$ \\
\hline Industrial & $\begin{array}{l}\text { Geladeiras } \\
\text { Gelatinas } \\
\text { Gesso } \\
\text { Gorduras comestíveis } \\
\text { Gráficas (empacotamento) } \\
\text { Gráficas (produção) } \\
\text { Guarda-chuvas } \\
\text { Hangares } \\
\text { Instrumentos musicais } \\
\text { Janelas e portas de madeira } \\
\text { Joias } \\
\text { Laboratórios farmacêuticos } \\
\text { Laboratórios químicos } \\
\text { Lápis } \\
\text { Lâmpadas } \\
\text { Laticínios } \\
\text { Malharias } \\
\text { Máquinas de lavar, de costura ou de escritório } \\
\text { Massas alimentícias } \\
\text { Mastiques } \\
\text { Materiais sintéticos ou plásticos } \\
\text { Metalurgia } \\
\text { Montagens de automóveis } \\
\text { Motocicletas } \\
\text { Motores elétricos } \\
\text { Móveis } \\
\text { Óleos comestíveis } \\
\text { Padarias } \\
\text { Papéis (acabamento) } \\
\text { Papéis (preparo da celulose) } \\
\text { Papéis (processamento) } \\
\text { Papelões betuminados }\end{array}$ & 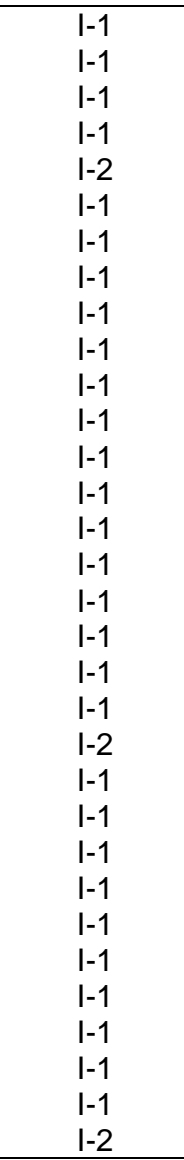 & $\begin{array}{c}1000 \\
800 \\
80 \\
1000 \\
2000 \\
400 \\
300 \\
200 \\
600 \\
800 \\
200 \\
300 \\
500 \\
600 \\
40 \\
200 \\
300 \\
300 \\
1000 \\
1000 \\
2000 \\
200 \\
300 \\
300 \\
300 \\
600 \\
1000 \\
1000 \\
500 \\
80 \\
800 \\
2000 \\
\end{array}$ \\
\hline
\end{tabular}




\begin{tabular}{|c|c|c|c|}
\hline Ocupação/uso & Descrição & Divisão & $\begin{array}{c}\text { Carga de } \\
\text { incêndio } \\
\mathrm{MJ} / \mathrm{m}^{2}\end{array}$ \\
\hline Industrial & $\begin{array}{l}\text { Papelões ondulados } \\
\text { Pedras } \\
\text { Perfumes } \\
\text { Pneus } \\
\text { Produtos adesivos } \\
\text { Produtos de adubo químico } \\
\text { Produtos alimentícios (expedição) } \\
\text { Produtos com ácido acético } \\
\text { Produtos com ácido carbônico } \\
\text { Produtos com ácido inorgânico } \\
\text { Produtos com albumina } \\
\text { Produtos com alcatrão } \\
\text { Produtos com amido } \\
\text { Produtos com soda } \\
\text { Produtos de limpeza } \\
\text { Produtos graxos } \\
\text { Produtos refratários } \\
\text { Rações } \\
\text { Relógios } \\
\text { Resinas } \\
\text { Roupas } \\
\text { Sabões } \\
\text { Sacos de papel } \\
\text { Sacos de juta } \\
\text { Sorvetes } \\
\text { Sucos de fruta } \\
\text { Têxteis em geral } \\
\text { Tintas e solventes } \\
\text { Tintas látex } \\
\text { Tintas não inflamáveis } \\
\text { Transformadores } \\
\text { Tratamento de madeira } \\
\text { Tratores } \\
\text { Vagões } \\
\text { Vassouras ou escovas } \\
\text { Velas } \\
\text { Verduras desidratadas } \\
\text { Vidros ou espelhos } \\
\text { Vinagres }\end{array}$ & $\begin{array}{l}\mid-1 \\
\mid-1 \\
\mid-1 \\
\mid-1 \\
\mid-1 \\
\mid-1 \\
\mid-1 \\
\mid-1 \\
\mid-1 \\
\mid-1 \\
\mid-2 \\
\mid-1 \\
\mid-2 \\
\mid-1 \\
\mid-2 \\
\mid-1 \\
\mid-1 \\
\mid-2 \\
\mid-1 \\
\mid-2 \\
\mid-1 \\
\mid-1 \\
\mid-1 \\
\mid-1 \\
\mid-1 \\
\mid-1 \\
\mid-1 \\
\mid-2 \\
\mid-1 \\
\mid-1 \\
\mid-1 \\
\mid-2 \\
\mid-1 \\
\mid-1 \\
\mid-1 \\
\mid-1 \\
\mid-1 \\
\mid-1 \\
\mid-1\end{array}$ & $\begin{array}{c}800 \\
40 \\
300 \\
700 \\
1000 \\
200 \\
1000 \\
200 \\
40 \\
80 \\
2000 \\
800 \\
2000 \\
40 \\
2000 \\
1000 \\
200 \\
2000 \\
300 \\
3000 \\
500 \\
300 \\
800 \\
500 \\
80 \\
200 \\
700 \\
4000 \\
800 \\
200 \\
200 \\
3000 \\
300 \\
200 \\
700 \\
1000 \\
1000 \\
200 \\
80\end{array}$ \\
\hline
\end{tabular}

Fonte: ABNT NBR 14432:2001 (Tabela C1)

Tabela 3.4. Fatores de ponderação das medidas de segurança contra incêndio

\begin{tabular}{|c|c|c|}
\hline \multicolumn{3}{|c|}{ Valores de $\boldsymbol{\gamma}_{\mathbf{n i}}$} \\
\hline Chuveiros automáticos & Brigada contra incêndio & Detecção automática \\
\hline$\gamma_{\mathrm{n} 1}=0,60$ & $\gamma_{\mathrm{n} 2}=0,90$ & $\gamma_{\mathrm{n} 3}=0,90$ \\
\hline
\end{tabular}

Fonte: ABNT NBR 15200:2012 (Tabela A1) 
Tabela 3.5. Valores de $\gamma_{\mathrm{s} 2}$ em função do risco de ativação do incêndio (r)

\begin{tabular}{|c|c|l|}
\hline$\gamma_{\mathbf{s} 2}$ & $\mathbf{r}$ & \multicolumn{1}{c|}{ Exemplos de ocupação } \\
\hline 0,85 & Pequena & Escola, galeria de arte, parque aquático, igreja, museu. \\
\hline 1,0 & Normal & $\begin{array}{l}\text { Biblioteca, cinema, correio, consultório médico, escritório, farmácia, frigorífico, } \\
\text { hotel, livraria, hospital, laboratório fotográfico, indústria de papel, oficina } \\
\text { elétrica ou mecânica, residência, restaurante, supermercado, teatro, depósitos } \\
\text { (produtos farmacêuticos, bebidas alcoólicas, venda de acessórios de } \\
\text { automóveis) e depósitos em geral. }\end{array}$ \\
\hline 1,2 & Média & Montagem de automóveis, hangar, indústria mecânica. \\
\hline 1,5 & Alta & Laboratório químico, oficina de pintura de automóveis. \\
\hline
\end{tabular}

Fonte: ABNT NBR 15200:2012 (Tabela A2)

A norma ABNT NBR 15200:2012 também faz as seguintes limitações:

- $\mathrm{Na}$ Equação 3.1, $\mathrm{q}_{\mathrm{fi}, \mathrm{k}} \gamma_{\mathrm{n}} \gamma_{\mathrm{s}}$ não pode ser inferior a $300 \mathrm{MJ} / \mathrm{m}^{2}$.

- O valor de TRRF poderá ser substituído pelo valor de te, determinado pela Equação 3.1, se (TRRF - $30 \mathrm{~min}$ ) $<t_{e} \leq \mathrm{TRRF}$. Se $t_{e} \leq$ (TRRF - $30 \mathrm{~min}$ ), então o valor do TRRF poderá ser substituído por TRRF $-30 \mathrm{~min}$.

\subsection{Comportamento do concreto e do aço submetidos a elevadas temperaturas}

A exposição do aço e do concreto a altas temperaturas faz com que suas características físicas e químicas se degenerem, causando alterações em suas propriedades.

O concreto endurecido começa a perder sua capacidade resistente a partir dos $100{ }^{\circ} \mathrm{C}$ (KHOURY, 2000). No caso de concretos preparados com agregados leves, o desempenho perante o fogo apresenta boa resistência, sendo indicados para proteção de estruturas metálicas, segundo Neville (1997).

Já em relação ao aço, segundo Landi (1986), os problemas mais graves de uma estrutura de concreto armado ocorrem quando a sua armadura atinge temperaturas entre $500^{\circ} \mathrm{C}$ e $600^{\circ} \mathrm{C}$, intervalo em que o aço perde sua resistência à tração, comprometendo a estrutura como um todo. 


\subsubsection{Concreto}

a) Densidade

A densidade do concreto submetido a temperaturas elevadas é influenciada, primariamente, pela evaporação da água livre e, secundariamente, pelo aumento do volume devido à expansão térmica. Essa variação pode ser considerada, segundo Silva (2012), conforme as Equações 3.4, ou analisada de acordo com o gráfico da Figura 3.19.

$$
\begin{array}{ll}
\rho(\theta)=\rho_{c} & \rightarrow \text { se } 20^{\circ} \mathrm{C} \leq \theta \leq 115^{\circ} \mathrm{C} \\
\rho(\theta)=\rho_{c} \cdot\left(1-0,02 \cdot\left(\frac{\theta-115}{85}\right)\right) & \rightarrow \text { se } 115^{\circ} \mathrm{C}<\theta \leq 200^{\circ} \mathrm{C} \\
\rho(\theta)=\rho_{c} \cdot\left(0,98-0,03 \cdot\left(\frac{\theta-200}{200}\right)\right) & \rightarrow \text { se } 200^{\circ} \mathrm{C}<\theta \leq 400^{\circ} \mathrm{C} \\
\rho(\theta)=\rho_{c} \cdot\left(0,95-0,07 \cdot\left(\frac{\theta-400}{800}\right)\right) & \rightarrow \text { se } 400^{\circ} \mathrm{C}<\theta \leq 1200^{\circ} \mathrm{C}
\end{array}
$$

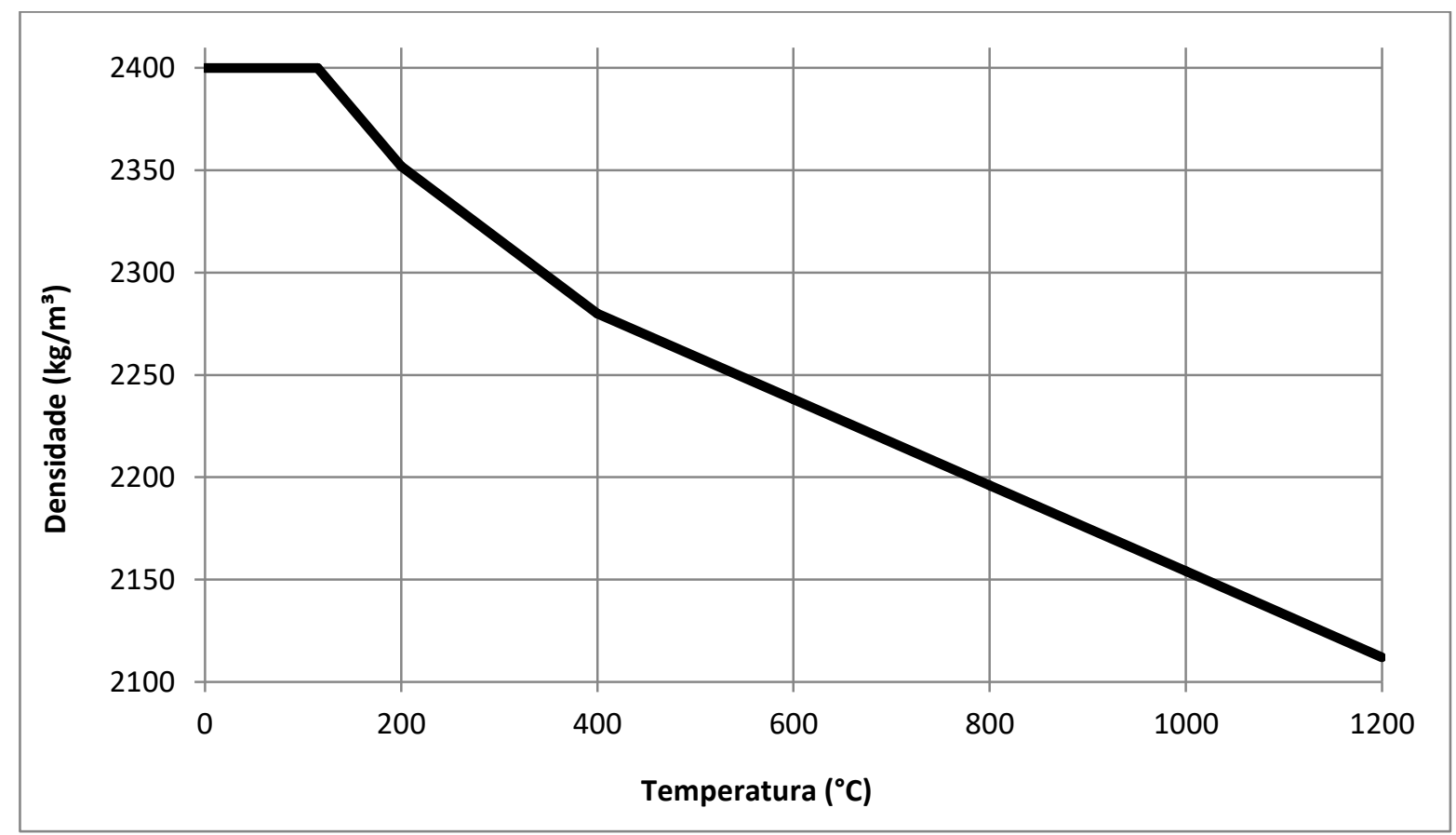

Figura 3.19. Densidade do Concreto.

(Adaptado de SILVA, 2012) 
Para o projeto de estruturas de concreto à temperatura ambiente, a ABNT NBR 6120:1980 e a ABNT NBR 6118:2014 recomendam os valores da massa específica $\rho_{c}=2400 \mathrm{~kg} / \mathrm{m}^{3}$ e $\rho_{c}=2500 \mathrm{~kg} / \mathrm{m}^{3}$, respectivos ao concreto simples e ao concreto armado.

A massa específica $\rho_{c}=2400 \mathrm{~kg} / \mathrm{m}^{3}$ é recomendada para as análises térmicas das seções dos elementos de concreto, em que somente as propriedades térmicas são relevantes, enquanto que $\rho_{c}=2500 \mathrm{~kg} / \mathrm{m}^{3}$ é própria para o cálculo do peso próprio dos elementos de concreto de seção com armaduras, nos quais a ação gravitacional sobre os elementos é relevante.

As Equações 3.4 vêm sendo questionadas pelo exagero de até $12 \%$ da redução da massa específica do concreto de densidade normal aquecido em situação de incêndio, pois, na prática, essa redução está em torno de $100 \mathrm{~kg} / \mathrm{m}^{3}$. Sendo assim, alguns autores consideram a massa específica independente da temperatura elevada, ou seja, com o mesmo valor à temperatura ambiente (COSTA, 2008, apud FIP-CEB Bulletins N¹45 (1982), N 174 (1987) e No 208 (1991); SCHLEICH, 2005).

b) Calor específico

$\mathrm{Na}$ ausência de dados experimentais, pode-se modelar a função do calor específico (Equação 3.5) considerando o valor de pico constante entre $100^{\circ} \mathrm{C} \mathrm{e}$

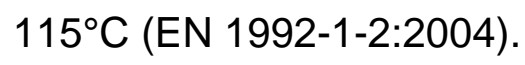

$\mathrm{C}_{\mathrm{p}, \theta}=900$

$\mathrm{C}_{\mathrm{p}, \theta}=\mathrm{C}_{\mathrm{p}, \mathrm{top}}$

$C_{p, \theta}=C_{p, t o p}-\left(\frac{C_{p, t o p}-1000}{85}\right) \cdot(\theta-115)$

$C_{p, \theta}=1000+\left(\frac{\theta-200}{2}\right)$

$\mathrm{C}_{\mathrm{p}, \theta}=1100$ $\rightarrow \quad$ se $20^{\circ} \mathrm{C} \leq \theta \leq 100^{\circ} \mathrm{C}$

$\rightarrow \quad$ se $100^{\circ} \mathrm{C}<\theta \leq 115^{\circ} \mathrm{C}$

$\rightarrow \quad$ se $115^{\circ} \mathrm{C}<\theta \leq 200^{\circ} \mathrm{C}$

$\rightarrow \quad$ se $200^{\circ} \mathrm{C}<\theta \leq 400^{\circ} \mathrm{C}$

$\rightarrow \quad$ se $400{ }^{\circ} \mathrm{C}<\theta \leq 1200^{\circ} \mathrm{C}$

$\mathrm{C}_{\mathrm{p}, \theta}$ é o calor específico por unidade de massa do concreto de densidade normal em função da temperatura $\theta\left(\mathrm{J} / \mathrm{kg} /{ }^{\circ} \mathrm{C}\right)$; 


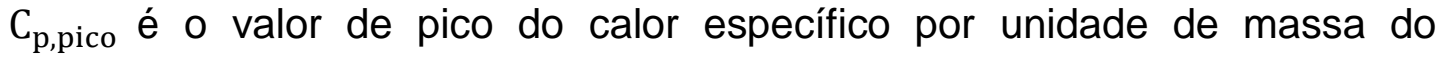
concreto, em função da umidade de equilíbrio do concreto e da temperatura $\theta\left(\mathrm{J} / \mathrm{kg} /{ }^{\circ} \mathrm{C}\right)$ :

$$
\begin{aligned}
& \mathrm{C}_{\text {p,top }}=900 \frac{\mathrm{J}}{\mathrm{kg}}{ }^{\circ} \mathrm{C}, \text { para umidade zero } \\
& \mathrm{C}_{\text {p,top }}=1470 \frac{\mathrm{J}}{\mathrm{kg}}{ }^{\circ} \mathrm{C}, \text { para umidade de } 1,5 \% \text { em peso } \\
& \mathrm{C}_{\text {p,top }}=2020 \frac{\mathrm{J}}{\mathrm{kg}}{ }^{\circ} \mathrm{C} \text {, para umidade de } 3,0 \% \text { em peso }
\end{aligned}
$$

De maneira simplificada, pode-se considerar constante a relação entre o calor específico do concreto e a temperatura, valor que é igual a $1000 \mathrm{~J} . \mathrm{kg} /{ }^{\circ} \mathrm{C}$.

A variação do calor específico do concreto com a temperatura também pode ser vista na Figura 3.20.

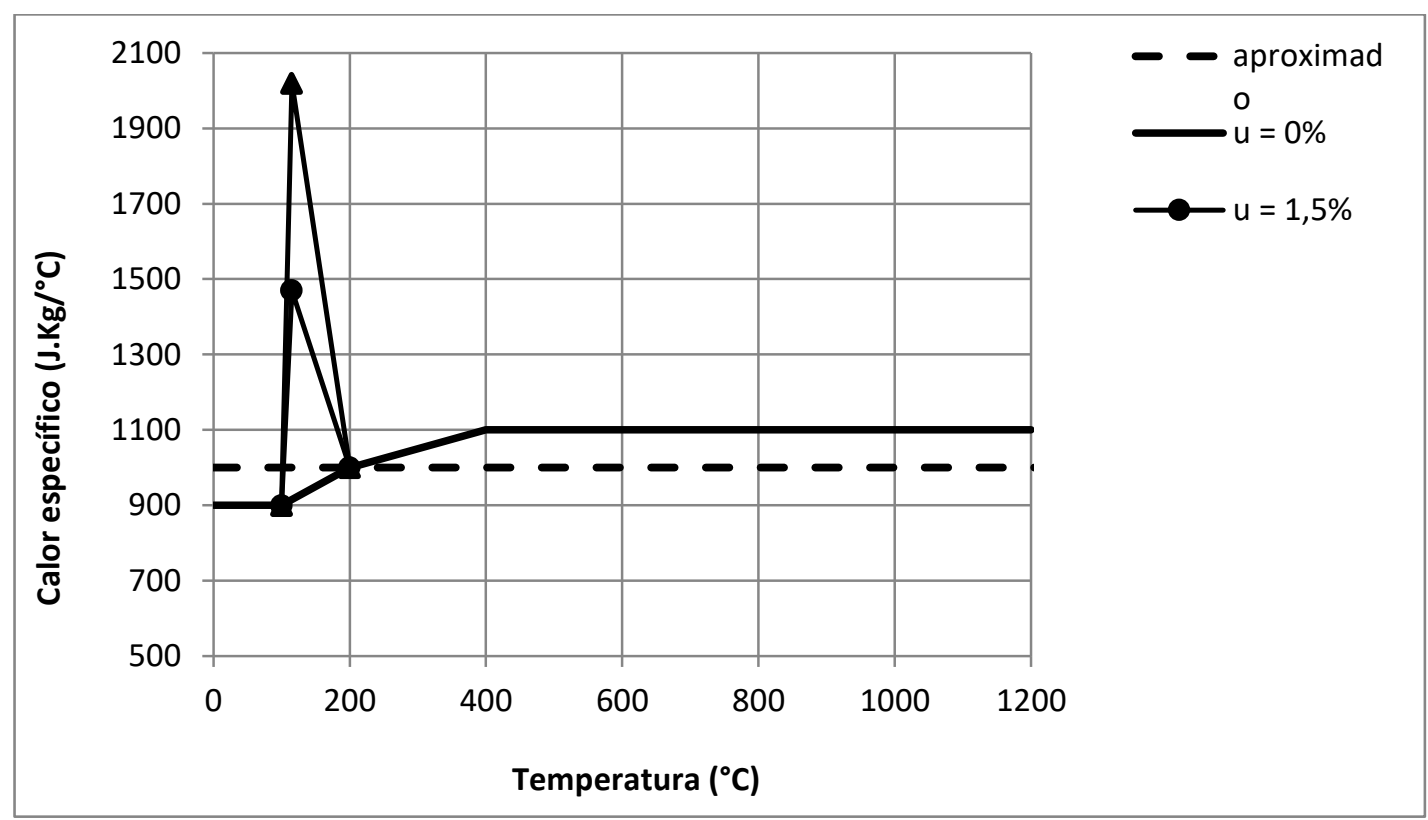

Figura 3.20. Calor específico do concreto.

(Adaptado de SILVA, 2012)

c) Condutividade térmica

A condutividade térmica do concreto diminui conforme a temperatura aumenta. Ela está diretamente relacionada aos tipos de agregados e, também, é influenciada pela porosidade da pasta de cimento (NEVILLE, A. M, 1997). 
A ABNT NBR 15200 (2012) fornece equações para determinar a condutividade térmica, em watt por metro e por grau Celsius $\left[\left(\mathrm{W} /\left(\mathrm{m} .{ }^{\circ} \mathrm{C}\right)\right]\right.$, para o intervalo $20^{\circ} \mathrm{C} \leq \theta \leq 1200^{\circ} \mathrm{C}$, para valor mínimo (Equação 3.6), adequado a estruturas de concreto, e valor máximo (Equação 3.7), adequado para estruturas mistas de aço e concreto.

$\lambda=1,36-0,136 \cdot \frac{\theta_{c}}{100}+0,0057\left(\frac{\theta_{c}}{100}\right)^{2}$

$\lambda=2-0,2451 \cdot \frac{\theta_{c}}{100}+0,0107\left(\frac{\theta_{c}}{100}\right)^{2}$

$\theta_{c}$ é a temperatura do concreto, em graus Celsius.

De maneira simplificada, pode-se considerar constante a relação entre a condutividade térmica do concreto e a temperatura, sendo esse valor igual a $1,3 \mathrm{~W} /\left(\mathrm{m} .{ }^{\circ} \mathrm{C}\right)$.

A variação da condutividade do concreto (valor mínimo) com a temperatura também pode ser vista na Figura 3.21.

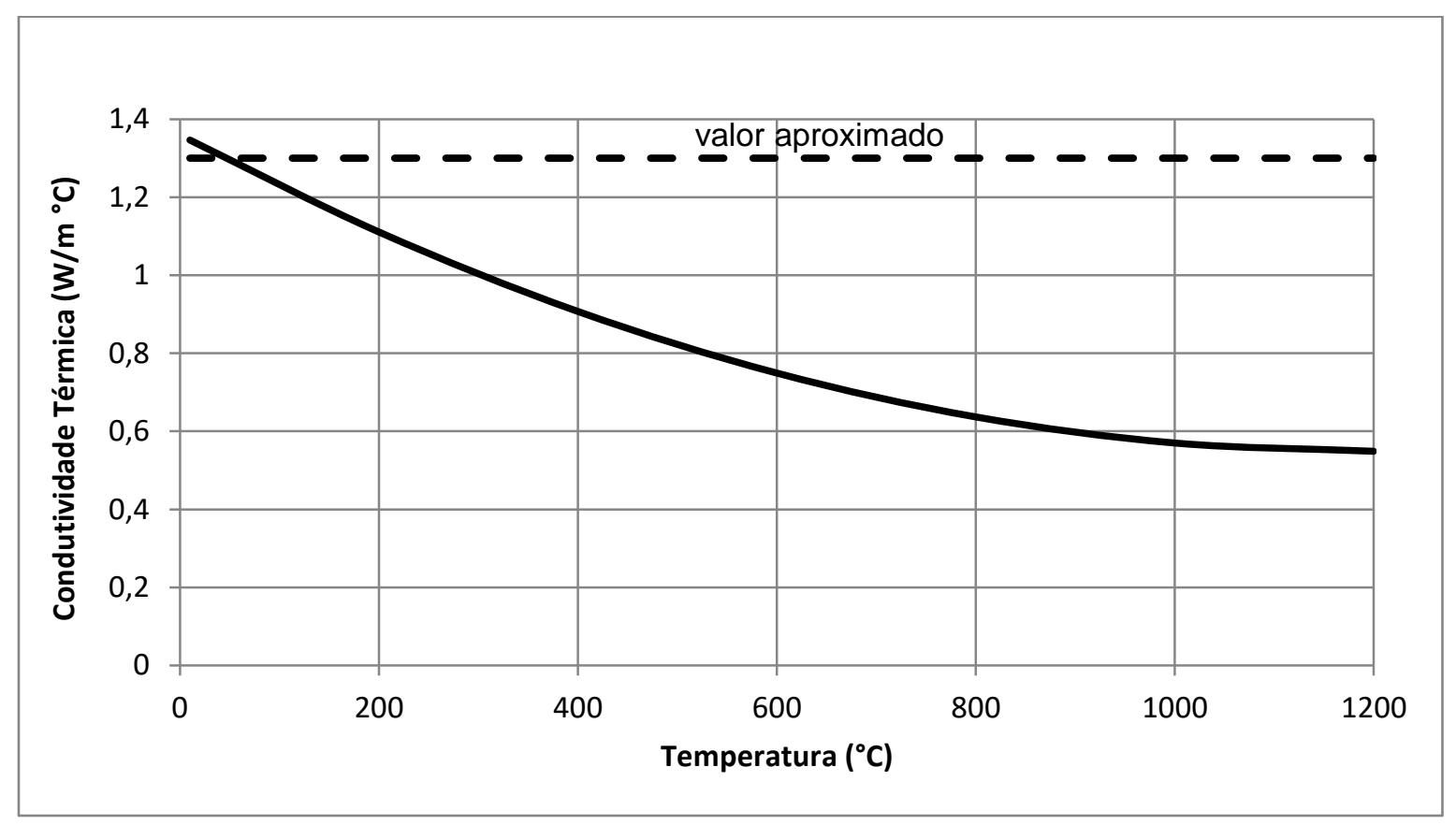

Figura 3.21. Condutividade térmica do concreto.

(Adaptado de SILVA, 2012) 
d) Alongamento

O alongamento (ou expansão) térmico do concreto de agregados silicosos é calculado pela Equação 3.8.

(Eq. 3.8)

$$
\begin{array}{ll}
\frac{\Delta \mathrm{l}}{\mathrm{l}}=1,8 \times 10^{-4}+9 \times 10^{-6} \cdot \theta_{\mathrm{c}}+2,3 \times 10^{-11} \cdot \theta_{\mathrm{c}}{ }^{3} & \rightarrow \text { se } 20^{\circ} \mathrm{C}<\theta_{\mathrm{c}} \leq 700^{\circ} \mathrm{C} \\
\frac{\Delta \mathrm{l}}{\mathrm{l}}=14 \times 10^{-3} & \rightarrow \text { se } 700^{\circ} \mathrm{C}<\theta_{\mathrm{c}} \leq 1200^{\circ} \mathrm{C}
\end{array}
$$

l é o comprimento da peça de concreto a $20^{\circ} \mathrm{C}$;

$\Delta l$ é o alongamento do elemento de concreto, provocado pela temperatura;

$\theta_{c}$ é a temperatura do concreto, em graus Celsius.

Já o alongamento específico do concreto com agregado calcário é calculado pela Equação 3.9 .

(Eq. 3.9)

$$
\begin{array}{ll}
\frac{\Delta \mathrm{l}}{\mathrm{l}}=-1,2 \times 10^{-4}+6 \times 10^{-6} \cdot \theta_{\mathrm{c}}+1,4 \times 10^{-11} \cdot \theta_{\mathrm{c}}^{3} & \rightarrow \text { se } 20^{\circ} \mathrm{C}<\theta_{\mathrm{c}} \leq 700^{\circ} \mathrm{C} \\
\frac{\Delta \mathrm{l}}{\mathrm{l}}=12 \times 10^{-3} & \rightarrow \text { se } 700^{\circ} \mathrm{C}<\theta_{\mathrm{c}} \leq 1200^{\circ} \mathrm{C}
\end{array}
$$

A Figura 3.22 mostra a variação do alongamento específico do concreto com a temperatura.

Para modelos de cálculo simples, o alongamento térmico do concreto pode ser simplificado por uma única função linear (Equação 3.10), para $20^{\circ} \mathrm{C} \leq \theta \leq 1200^{\circ} \mathrm{C}$ :

$$
\frac{\Delta \mathrm{l}}{\mathrm{l}}=18 \times 10^{-3} \cdot(\theta-20)
$$




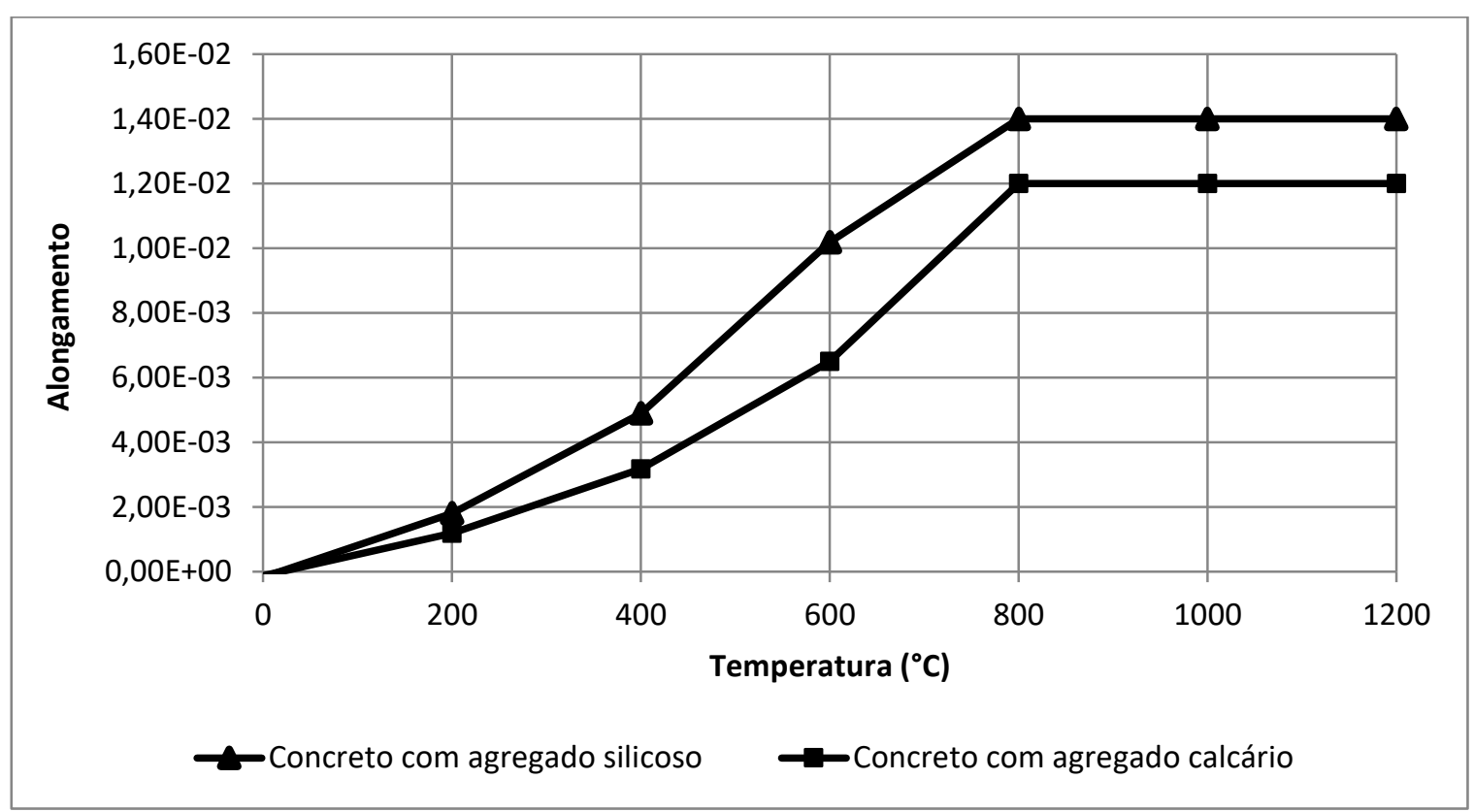

Figura 3.22. Alongamento específico do concreto.

(Adaptado de SILVA, 2012)

e) Resistência à compressão em função da temperatura

A resistência característica do concreto à compressão em situação de incêndio diminui com o aumento da temperatura, podendo ser obtida pela Equação 3.11.

$\mathrm{f}_{\mathrm{c}, \theta}=\mathrm{k}_{\mathrm{c}, \theta} \cdot \mathrm{f}_{\mathrm{ck}}$

$\mathrm{f}_{\mathrm{c}, \theta}$ é a resistência característica do concreto à compressão à temperatura $\theta$;

$\mathrm{f}_{\mathrm{ck}}$ é a resistência característica do concreto à compressão em temperatura ambiente;

$\mathrm{k}_{\mathrm{c}, \theta}$ é o fator de redução da resistência do concreto na temperatura $\theta$.

Na Tabela 3.6 são apresentados, segundo as especificações do EUROCODE 2 (prEN 1992-1-2:2003), os valores de redução com a elevação da temperatura, das propriedades mecânicas do concreto de acordo com o tipo de agregado utilizado. $\mathrm{Na}$ Figura 3.23, esses valores são representados graficamente. 
Tabela 3.6. Valores de $\mathrm{k}_{\mathrm{c}, \theta}$ para concretos de massa específica normal $\left(2000 \mathrm{~kg} / \mathrm{m}^{3}\right.$ a $\left.2800 \mathrm{~kg} / \mathrm{m}^{3}\right)$ preparados com agregados predominantemente silicosos e calcários, respectivamente.

\begin{tabular}{|c|c|c|}
\hline \multirow{2}{*}{$\begin{array}{c}\text { Temperatura do } \\
\text { Concreto }\left({ }^{\circ} \mathbf{C}\right)\end{array}$} & $\mathbf{k}_{\mathbf{c}, \boldsymbol{\theta}}=\mathbf{f}_{\mathbf{c}, \boldsymbol{\theta}} / \mathbf{f}_{\mathbf{c k}}$ \\
\hline 20 & Agregados silicosos & Agregados calcários \\
\hline 100 & 1,00 & 1,00 \\
\hline 200 & 1,00 & 1,00 \\
\hline 300 & 0,95 & 0,97 \\
\hline 400 & 0,85 & 0,91 \\
\hline 500 & 0,75 & 0,85 \\
\hline 600 & 0,60 & 0,74 \\
\hline 700 & 0,45 & 0,60 \\
\hline 800 & 0,30 & 0,43 \\
\hline 900 & 0,15 & 0,27 \\
\hline 1000 & 0,08 & 0,15 \\
\hline 1100 & 0,04 & 0,06 \\
\hline 1200 & 0,01 & 0,02 \\
\hline
\end{tabular}

Fonte: ABNT NBR 15200:2012 e Eurocode 2 parte 1-2 (2004)

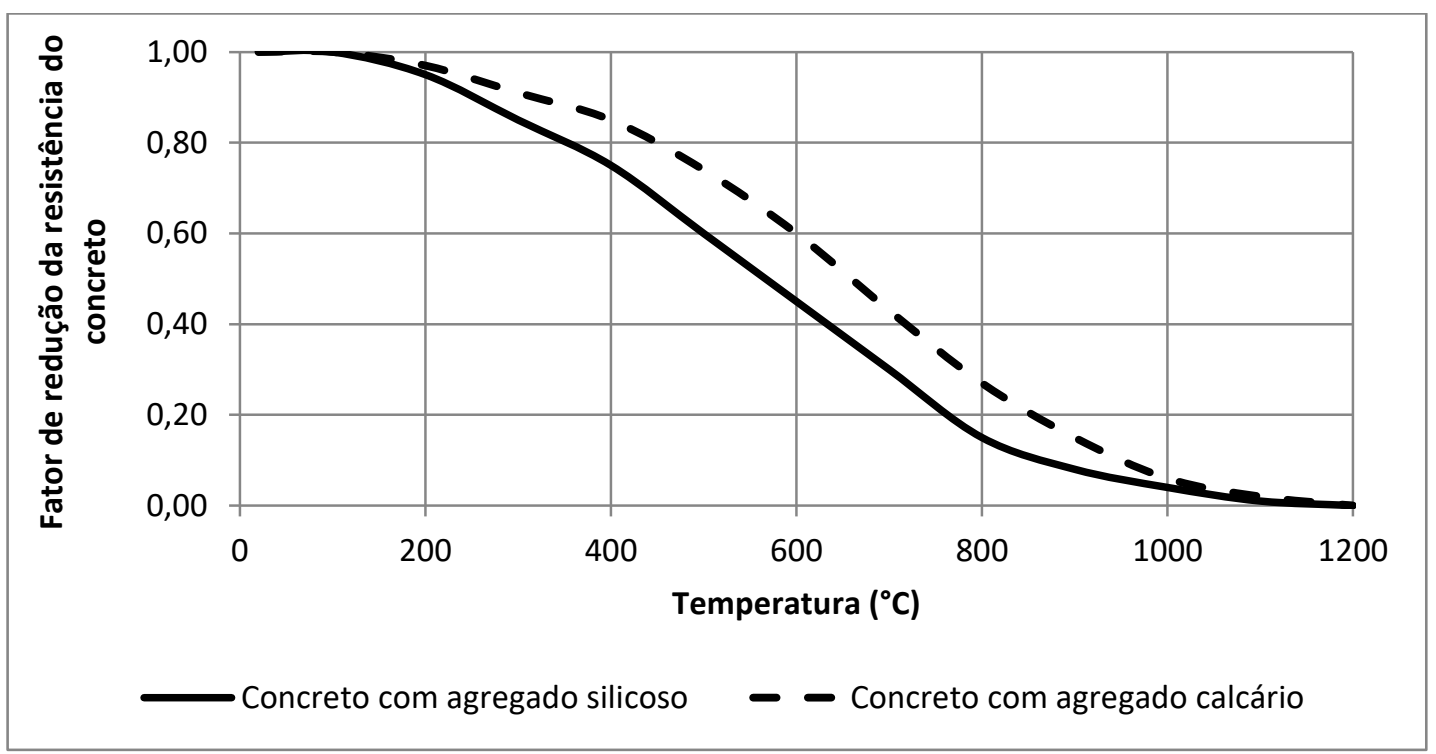

Figura 3.23. Fator de redução dos concretos em função da temperatura.

(Adaptado de SILVA, 2012)

Vale ressaltar que os valores de redução apresentados na Tabela 3.6 são aplicáveis somente aos concretos com resistência característica à compressão inferior ou igual a $50 \mathrm{MPa}$. 


\subsubsection{Aço}

A resistência da armadura passiva ao escoamento, em situação de incêndio, decresce com o aumento da temperatura, e pode ser obtida pela Equação 12.

$\mathrm{f}_{\mathrm{y}, \theta}=\mathrm{k}_{\mathrm{s}, \theta} \cdot \mathrm{f}_{\mathrm{yk}}$

$\mathrm{f}_{\mathrm{y}, \theta}$ é a resistência característica do aço à temperatura $\theta$;

$\mathrm{f}_{\mathrm{yk}}$ é a resistência característica do aço em temperatura ambiente;

$\mathrm{k}_{\mathrm{c}, \theta}$ é o fator de redução da resistência do aço na temperatura $\theta$.

A Tabela 3.7 fornece os fatores de redução da resistência aplicáveis quando a deformação específica do aço no escoamento ( $\left.\varepsilon_{y i}\right)$ é maior ou igual a $2 \%$ -usualmente armaduras tracionadas de vigas, lajes ou tirantes- ou quando $\varepsilon y i$ é menor que $2 \%$-geralmente armaduras comprimidas de pilares, vigas ou lajes. $\mathrm{Na}$ Figura 3.24, esses valores são representados graficamente.

Tabela 3.7. Valores de $\mathrm{ks}, \theta$ para aços de armadura passiva.

\begin{tabular}{|c|c|c|c|}
\hline \multirow{2}{*}{$\begin{array}{c}\text { Temperatura do } \\
\text { Aço }\left({ }^{\circ} \mathbf{C}\right)\end{array}$} & \multicolumn{3}{|c|}{$\mathbf{k}_{\mathbf{s}, \boldsymbol{\theta}}=\mathbf{f}_{\mathbf{y}, \mathbf{\theta}} / \mathbf{f}_{\mathbf{y k}}$} \\
\cline { 2 - 4 } & Tração & Compressão \\
\hline 20 & 1,00 & CA-60 & CA-50 ou CA-60 \\
\hline 100 & 1,00 & 1,00 & 1,00 \\
\hline 200 & 1,00 & 1,00 & 1,00 \\
\hline 300 & 1,00 & 1,00 & 0,89 \\
\hline 400 & 1,00 & 0,94 & 0,78 \\
\hline 500 & 0,78 & 0,67 & 0,67 \\
\hline 600 & 0,47 & 0,40 & 0,56 \\
\hline 700 & 0,23 & 0,12 & 0,33 \\
\hline 800 & 0,11 & 0,11 & 0,10 \\
\hline 900 & 0,06 & 0,08 & 0,06 \\
\hline 1000 & 0,04 & 0,05 & 0,04 \\
\hline 1100 & 0,02 & 0,03 & 0,02 \\
\hline 1200 & 0,00 & 0,00 & 0,00 \\
\hline \multicolumn{3}{|c|}{ Fonte: ABNT NBR 15200:2012 } \\
\hline
\end{tabular}




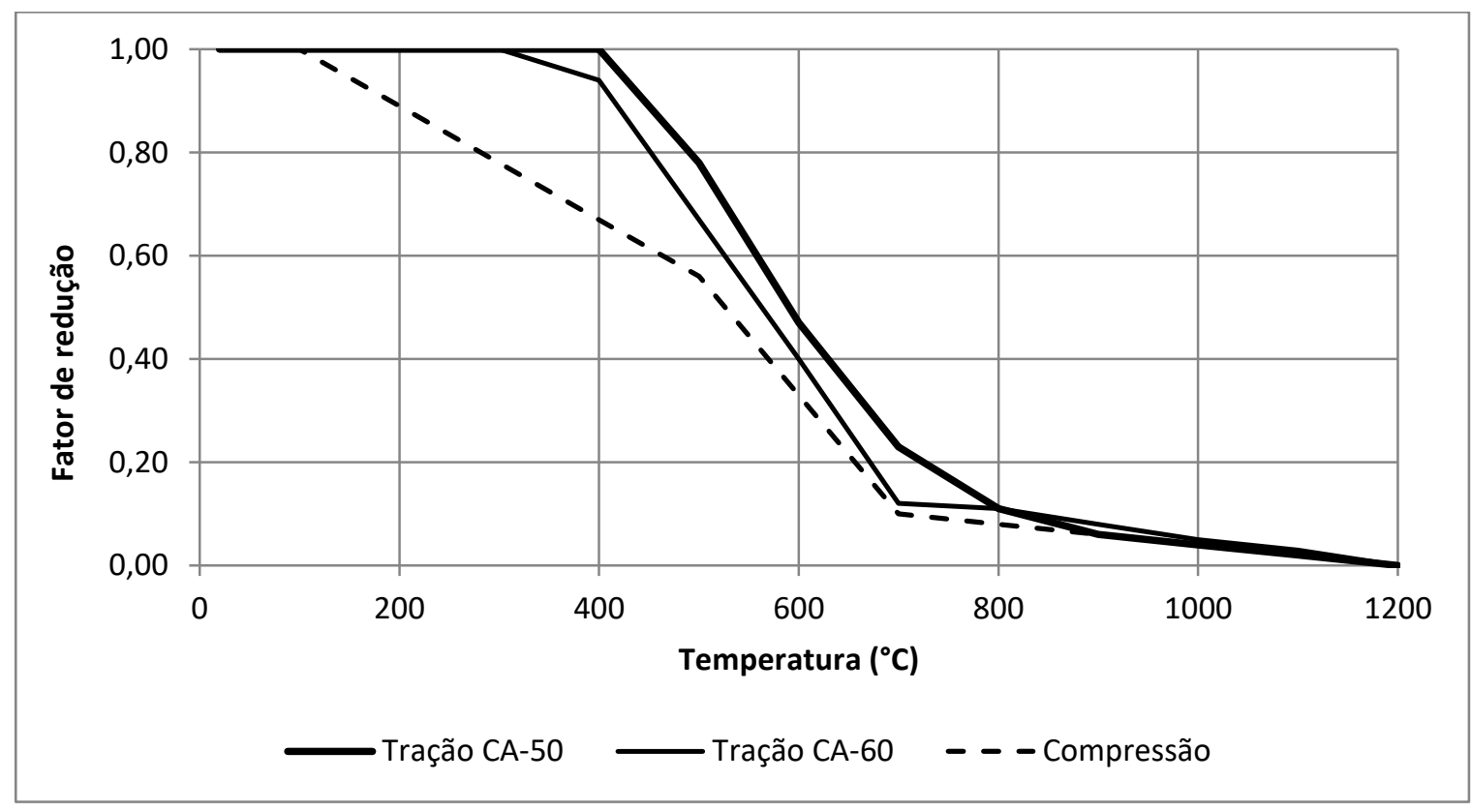

Figura 3.24. Fator de redução da resistência do aço de armadura passiva em função da temperatura. (Adaptado de SILVA, 2012)

\subsection{Comportamento do Poliestireno Expandido (EPS) ao fogo}

Isoféres (2012) fez um estudo do comportamento do EPS quando submetido ao fogo, sendo utilizado como material de construção. Levou em consideração a liberação do calor, propagação da chama, produção e toxicidade da fumaça e sua contribuição para propagação de um incêndio.

O EPS é classificado em dois tipos, o tipo P (Padrão) e o tipo F (Flame), com retardante de chama, o qual será utilizado neste trabalho. Quando submetido ao fogo, amolece e se contrai progressivamente a partir dos $100 \stackrel{\circ}{\circ}$ a $120 \stackrel{\circ}{\circ}(110 \stackrel{\circ}{\circ}$ a $120 \stackrel{\circ}{\circ}$ para o tipo F). Quando atingem temperaturas em torno de $230 \stackrel{\circ}{\circ}$ e $260 \stackrel{\circ}{\circ}$, os dois tipos liberam gases combustíveis.

Da pesquisa realizada, Isoféres (2012) chegou às seguintes conclusões:

> Para a segurança contra o incêndio, o ideal é estudar os elementos construtivos em suas condições de uso, e não somente os seus componentes de forma isolada;

O EPS produz mais fumaça por unidade de massa que outros materiais, porém deve-se considerar que o EPS contém em torno de $2 \%$ de matéria sólida, quantidade muito menor que outros materiais combustíveis; 
Os gases e fumaça liberados pelo EPS (tipo P e F) durante o incêndio são menos tóxicos do que aqueles liberados por outros materiais, como, por exemplo, cortiça, lã, madeira, linho e a maioria dos plásticos.

Isoféres (2012) destaca que o EPS quando utilizado de maneira correta na construção civil não representa risco de incêndio, não representa risco de aumento significativo na densidade da fumaça e nem riscos de toxicidade.

\subsection{Lascamento do concreto}

Quando uma estrutura está submetida a uma situação de incêndio, efeitos como o lascamento podem ocorrer de modo a causar patologias na estrutura.

Esse fenômeno, conhecido também como spalling, consiste, basicamente, segundo Hertz (2003), no desprendimento de camadas superficiais do concreto, que ocorre devido a uma acentuada liberação de energia, além de alterações físicoquímicas do material, aliados a um conjunto de carregamentos na estrutura. Para Kalifa et al. (2000), esse acontecimento tem maior incidência a temperaturas entre $250^{\circ} \mathrm{C}$ e $400{ }^{\circ} \mathrm{C}$.

A ocorrência de lascamentos ainda não apresenta controle total confiável, isso porque há uma série de fatores que podem causar um comportamento imprevisível do concreto (PHAN \& CARINO, 1998). Conforme Buchanan (2001), em alguns casos esse fenômeno é consequência da natureza mineralógica dos agregados, ou até mesmo de concentrações de tensões térmicas que ocorrem durante o aquecimento da estrutura.

Segundo Purkiss (1996), há duas formas de apresentação do lascamento: (a) a delaminação gradual (sloughing), que é a perda de material de maneira progressiva, em que há o desprendimento de uma porção de concreto numa grande extensão de superfície, e (b) o lascamento explosivo (explosivespalling), no qual a perda do material ocorre de maneira parcial, instantânea e violenta, com uma alta liberação de energia, formando grandes cavidades, na primeira meia hora do incêndio. 
Alguns agregados leves podem causar lascamentos explosivos, embora não sejam comuns nesse tipo de material quando apresentam resistências usuais (HARMATHY, 1993). Quando o concreto leve apresenta susceptibilidade a esse tipo de lascamento, o Eurocode 2 (2001) sugere ensaios para que se possa determinar, dentro das medidas de segurança, dimensões mínimas de elementos estruturais. Vale ressaltar que o concreto leve com EPS estudado nesta pesquisa não apresentou nenhum tipo de lascamento explosivo.

Relatos de situações de lascamentos de diferentes tipos, devido a uma situação de incêndio, comprometendo a segurança dos elementos ou, até mesmo, da própria estrutura, ocorreram por todo o mundo. Costa et al. (2002) fizeram um levantamento desse tipo de acontecimento, em nível internacional, dos quais se destacam alguns a seguir.

(a) Em 1994, na Dinamarca, um incêndio no Great Belt Tunnel ocasionou lascamentos que reduziram a espessura das peças estruturais de concreto de alta resistência (Figura 3.25).

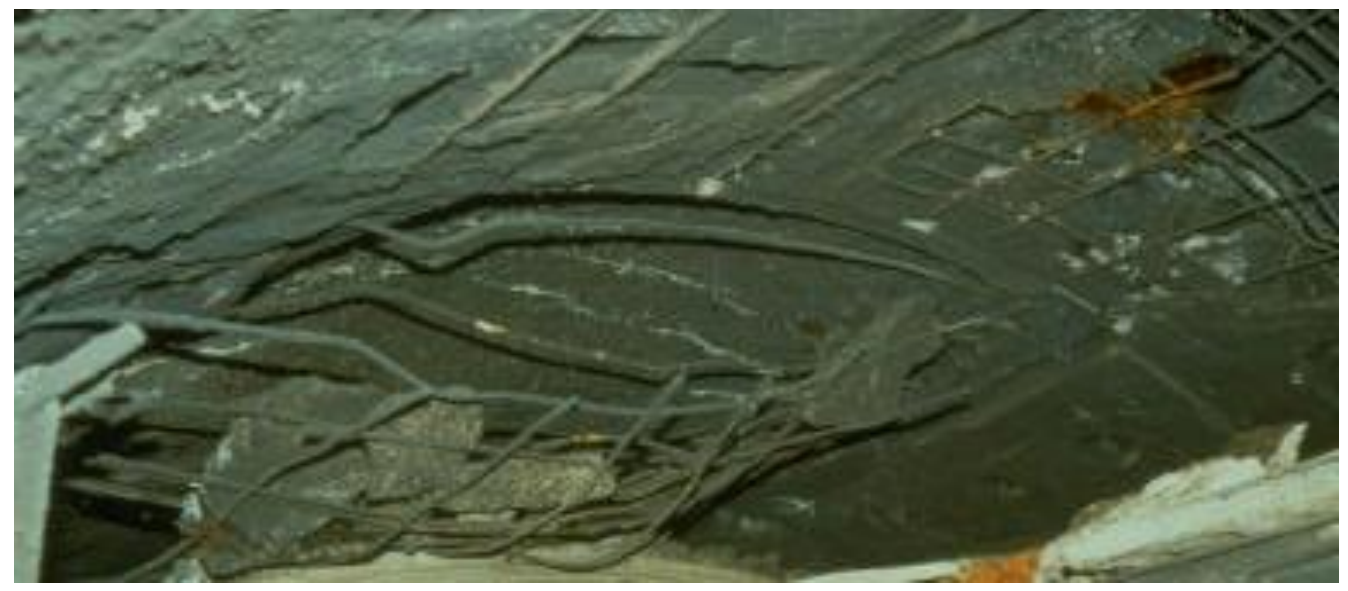

Figura 3.25. Armadura exposta após incêndio no Great Belt Tunnel, em 1994.

(GALSKJ/ER (2001) apud COSTA et al., 2002)

(b) Em 1996, o Channel Tunnel, entre a França e a Inglaterra, lascamentos explosivos, ocasionados por um incêndio de temperatura de $1000^{\circ} \mathrm{C}$, destruíram partes das estruturas de concreto, deixando uma profundidade entre $5 \mathrm{~mm}$ e $40 \mathrm{~mm}$ de lascamento (Figura 3.26). 

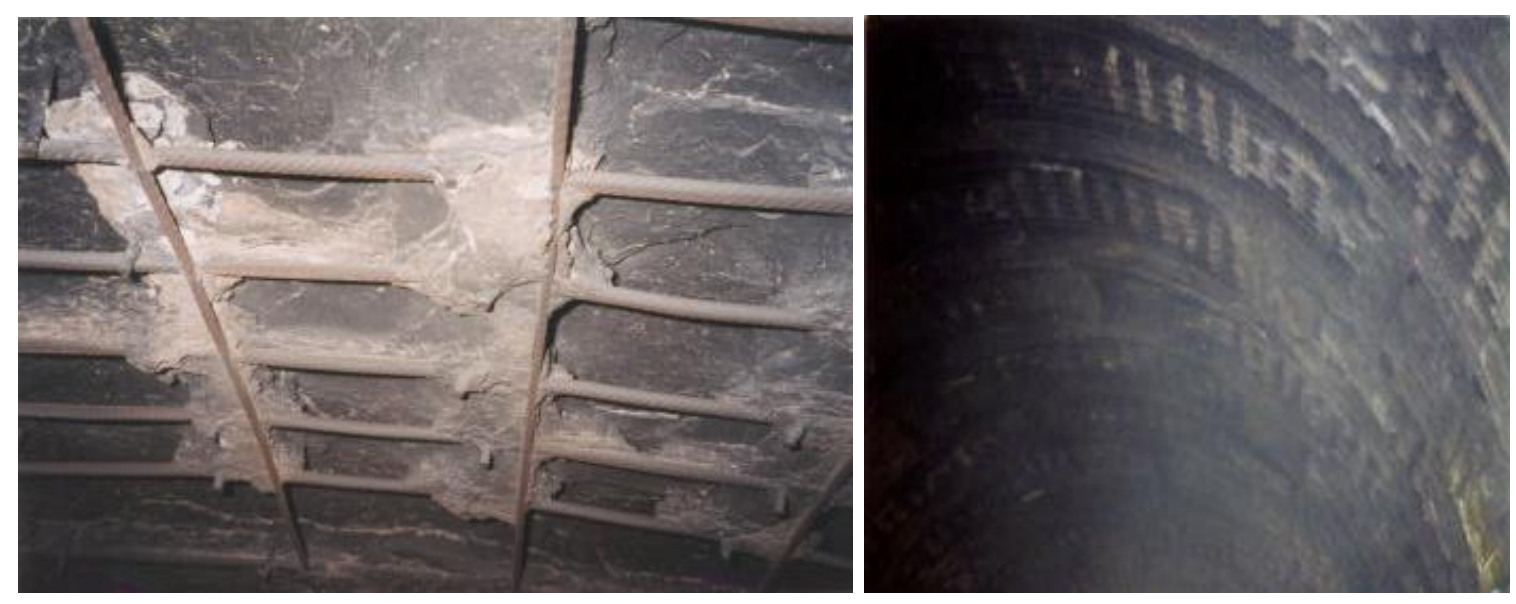

Figura 3.26. Armadura exposta após incêndio no Channel Tunnel, em 1996.

(ULM, 2000, apud COSTA et al., 2002)

(c) Em 1999, outro túnel, agora entre a França e a Itália (Mont Blanc Tunnel), sofreu um incêndio de grandes proporções que durou dois dias, ocorrendo um lascamento instantâneo que comprometeu a resistência do concreto de alto desempenho (Figura 3.27).

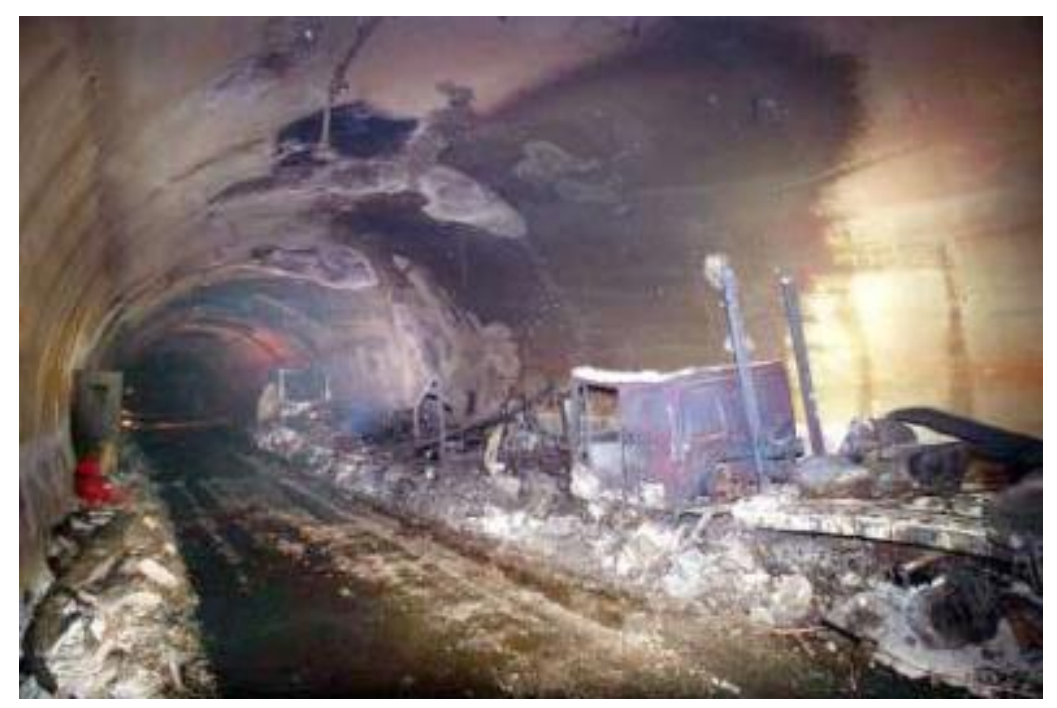

Figura 3.27. Situação de lascamento após incêndio no Mont Blanc Tunnel, em 1999.

(ULM, 2000, apud COSTA et al., 2002)

No Brasil, dentre os casos de lascamento do concreto devido à situação de incêndio, pode-se citar o que ocorreu no terminal principal de passageiros do Aeroporto Santos Dumont, no Rio de Janeiro, onde a estrutura de concreto armado foi seriamente danificada por um incêndio em 1998, que se estendeu por oito horas. 
O incêndio chegou a uma temperatura de, aproximadamente, $900^{\circ} \mathrm{C}$, sendo que vários pilares apresentaram lascamentos, e parte do cobrimento das lajes foi destruída (Figura 3.28).
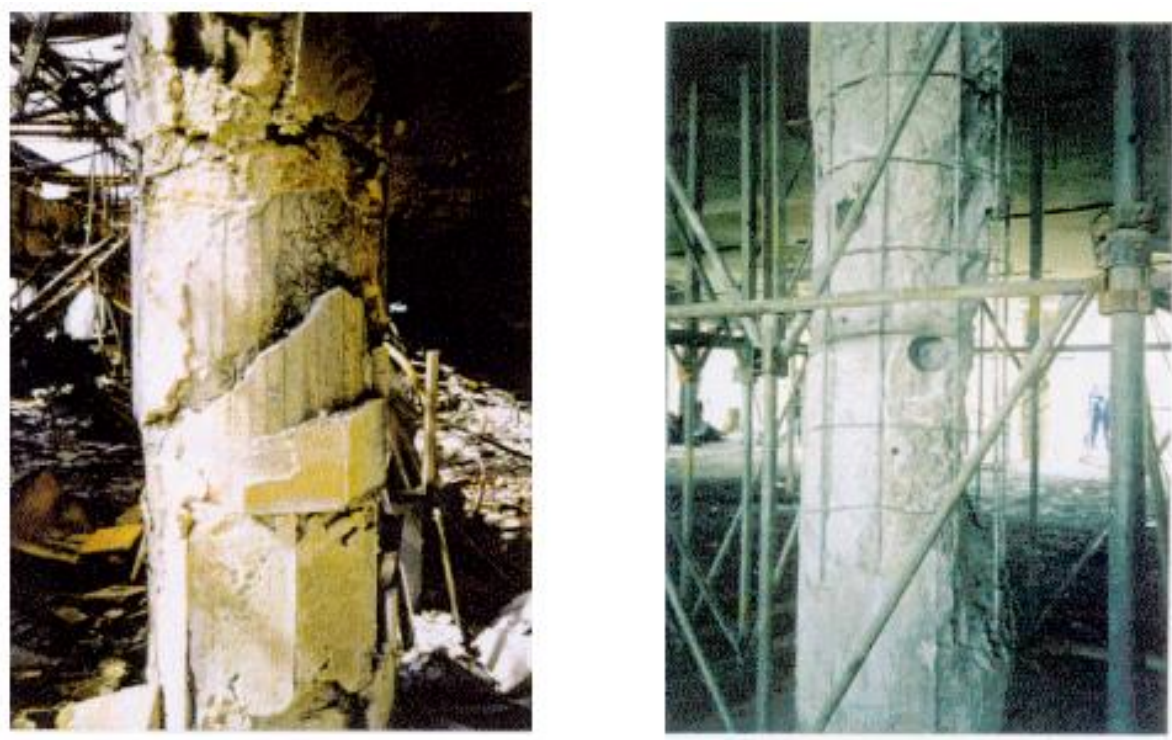

Figura 3.28. Pilar apresentando lascamento do cobrimento após incêndio, em 1998.

(BATTISTA, 2002)

Mais recente, em 2013, um incêndio que ocorreu no subsolo de uma das duas principais arquibancadas do estádio de futebol Arena Pantanal, em Cuiabá, deixou consequências. Segundo o relatório apresentado pela perícia, em um dos trechos cita-se que no "pilar/parede danificado pelo incêndio, houve lascamento do concreto" (Figura 3.29).

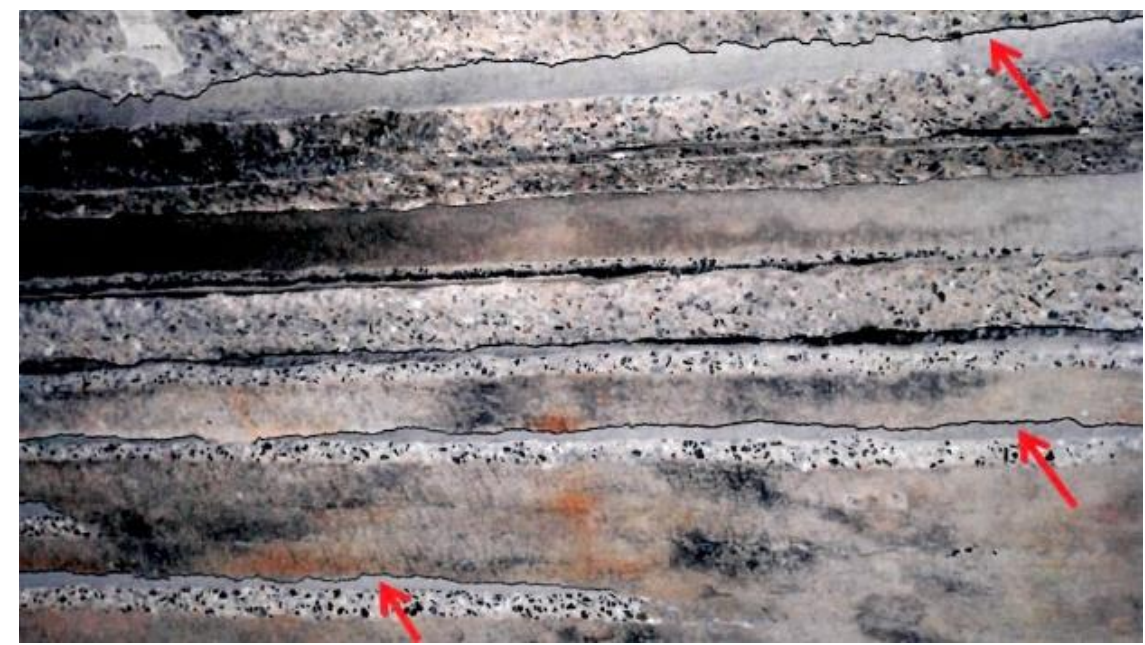

Figura 3.29. Consequências do incêndio na Arena Pantanal - lascamento pilar/parede.

(REUTERS, 2014) 
Estudos sobre o lascamento em estruturas de concreto ainda são poucos, entretanto, algumas pesquisas relevantes para o assunto deste trabalho são explanadas a seguir.

Para Purkiss (1996), o lascamento é mais plausível de acontecer em concretos de alta resistência, por apresentarem uma permeabilidade mais baixa, e em concretos com teor de umidade mais elevado.

Nince (2006) observou que as variáveis mais relevantes à ocorrência de lascamento foram a relação água/cimento e a umidade ambiente, concluindo que o cenário mais propício para acontecer esse fenômeno envolve uma relação a/c reduzida e uma elevada umidade ambiente. Sendo assim, a suscetibilidade do concreto ao lascamento está relacionada com a qualidade da sua microestrutura e com o nível de saturação dos seus poros. Além disso, constatou, também, que a inserção de fibras de polipropileno é eficaz no combate ao lascamento, e que quanto maior for a susceptibilidade do concreto ao lascamento, maior será o teor de fibras exigido para eliminar o fenômeno.

Souza (2010) verificou que o tipo de agregado graúdo utilizado na mistura é um fator de extrema importância, pois sua porosidade e mineralogia influenciam no comportamento do concreto. Em complemento, a citada autora constatou que concretos preparados com agregados basálticos apresentam maior resistência em situação de incêndio, comparados com os que utilizam agregado de calcário que, devido à sua expansão, aumenta o lascamento superficial do elemento aquecido.

Kirchhof (2010) fez um estudo teórico-experimental da influência do teor de umidade no fenômeno do lascamento em concretos com resistências acima de $40 \mathrm{MPa}$ e grau de saturação em torno de ou superior a $90 \%$, e concluiu que é fundamental considerar a possibilidade de lascamentos explosivos em estruturas suscetíveis a tal fenômeno, pois a ocorrência dele reduz substancialmente o tempo de resistência ao fogo (TRRF), devido à diminuição da resistência dos elementos estruturais e da aceleração dos danos. 


\section{CONCRETO REFORÇADO COM FIBRAS}

Sabe-se que o concreto simples, quando submetido a esforços de tração, é um material com baixa capacidade de deformação antes da ruptura (MEHTA; MONTEIRO, 2008). Sendo assim, surgiram alternativas tecnológicas para resolver este problema, como foi o caso do concreto armado.

Mesmo após a efetivação do concreto armado na construção civil, vários estudos foram realizados para mostrar outras alternativas de se reforçar esse compósito, como foi o caso da inserção de fibras de aço no concreto.

\subsection{A matriz de concreto}

O concreto de cimento Portland é um compósito que apresenta uma grande variação de suas propriedades, em função dos tipos de componentes e suas proporções, tanto para as condições de aplicação quanto para seu comportamento no estado endurecido. Sendo assim, as opções disponíveis desse material são vastas, inclusive na possibilidade de modificação do seu comportamento com a adição de fibras (FIGUEIREDO, 2011).

É importante ressaltar que o acréscimo de fibras reforça o material e proporciona uma resistência à propagação de fissuras que possam surgir na matriz, porém, eleva o custo unitário do compósito e pode dificultar sua trabalhabilidade.

\subsection{As fibras de aço}

As fibras são elementos lamelares em que o comprimento, variando de $25 \mathrm{~mm}$ (fibras curtas) a $60 \mathrm{~mm}$ (fibras longas), é superior às duas dimensões da seção transversal. As fibras são caracterizadas por alta resistência à tração em sua direção longitudinal (MORRISON; BOYD, 2002). 
As fibras de aço para reforço estrutural do concreto são conhecidas como macrofibras e, normalmente, possuem extremidades na forma de gancho, garantindo, assim, uma melhor ancoragem na mistura (FIGUEIREDO, 2011).

No Brasil, a norma que rege a utilização desse tipo de material é a ABNT NBR 15530:2007, intitulada "Fibras de aço para concreto - Especificação", que traz informações sobre o material no que diz respeito à geometria das fibras, a resistência do aço com que são fabricadas, dentre outras.

De acordo com essa norma, podem-se adotar três tipos básicos de fibras, classificadas quanto a suas conformações geométricas: (a) fibra de aço com ancoragens nas extremidades - Tipo A; (b) fibra de aço corrugada - Tipo C; e (c) fibra de aço reta - Tipo R.

É importante salientar que essa classificação não leva em consideração o tipo e a dimensão da seção transversal. Essa característica é modificada conforme o tipo de aço com que a fibra é produzida, podendo ser em aço laminado ou trefilado. Sendo assim, a norma brasileira divide as fibras de aço em três classes: Classe I (fibras oriundas de arame trefilado a frio), Classe II (fibras oriundas de chapas laminadas cortadas a frio) e Classe III (fibras oriundas de arame trefilado e escarificado).

Em resumo das classificações apresentadas até aqui, a Tabela 4.1 mostra os tipos de fibras, suas classes e geometria.

Tabela 4.1. Classificação de acordo com a geometria das fibras de aço

(Figueiredo et al., 2008)

\begin{tabular}{|c|c|c|c|}
\hline Tipo & Classe & Geometria \\
\hline \multirow{4}{*}{ A } & I & II & \\
\cline { 2 - 4 } & & & \\
\hline
\end{tabular}




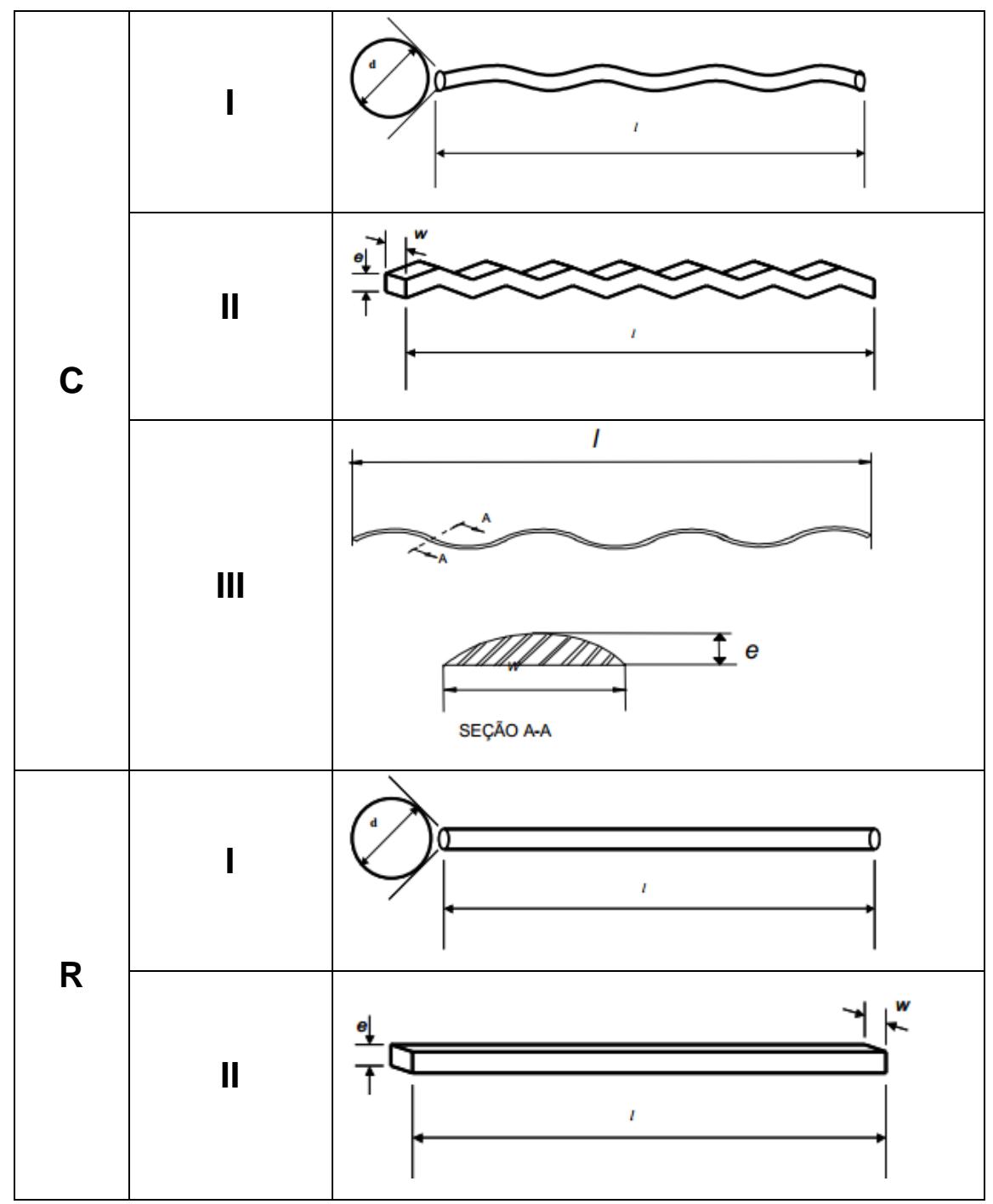

Segundo Figueiredo (2011), atualmente, no Brasil, a utilização desse tipo de fibra é feita de forma aleatória, não existindo procedimentos de controle da qualidade do compósito. No geral, a utilização das fibras de aço no concreto é feita com uma dosagem de múltiplos de $5 \mathrm{~kg}$ a cada metro cúbico de material.

No primeiro semestre de 2010 foi constatado que a utilização de fibras para reforço em concreto estava centralizada na aplicação de pavimentos industriais, apontando, aproximadamente, $74 \%$ do total das fibras utilizadas. Ficava em segundo plano o concreto projetado e os pré-fabricados, com $20 \%$ e $3 \%$, respectivamente (FIGUEIREDO, 2011). 


\subsection{O efeito das fibras de aço no concreto}

Consoante Figueiredo (2005), para um concreto simples, uma fissura representa um impedimento para a propagação de tensões de tração, implicando em uma concentração de tensões nas extremidades da fissura (Figura 4.1a) e, caso essa tensão seja superior à tensão crítica, acontecerá a ruptura do material.

Já quando se adicionam fibras ao concreto, com resistência, módulo de elasticidade e teor adequados, esse material deixa de se caracterizar como frágil. Isso porque as fibras atuam como ponte de transferência de tensões pelas fissuras, diminuindo, então, a concentração de tensões em suas extremidades (Figura 4.1b).
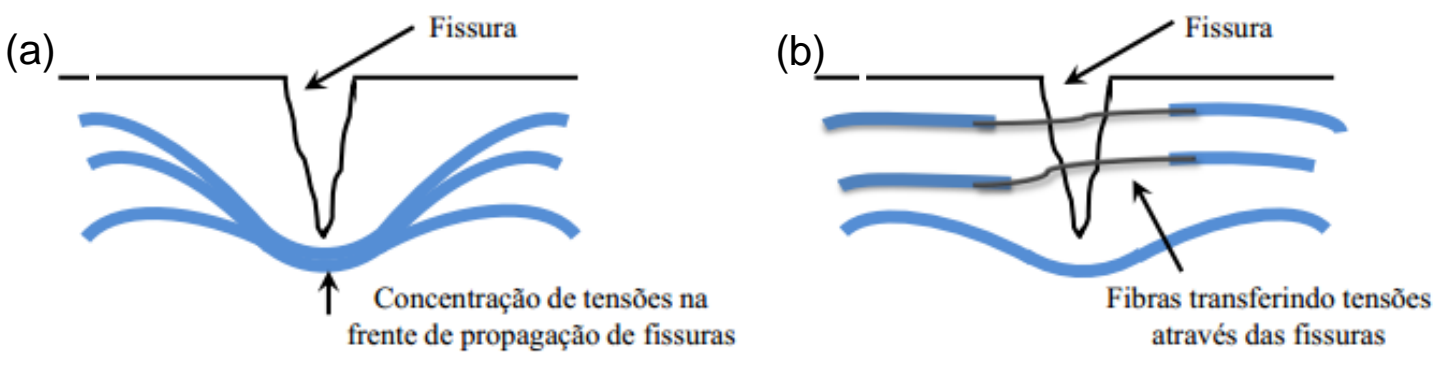

Figura 4.1. Esquema de concentração de tensões para um concreto sem fibras (a) e com fibras (b) (Nunes, Tanesi, Figueiredo, 1997).

Então, com o acréscimo de fibras ao concreto, tem-se uma redução da velocidade de propagação e da abertura das fissuras, e o material passa a ter um comportamento não frágil, ou seja, apresenta determinada capacidade resistente pós-fissuração, fazendo com que o compósito suporte maiores deformações. Sendo assim, com a utilização de fibras, o compósito terá maior tenacidade (RAMOS, 2002). 


\subsubsection{O efeito do teor das fibras}

Segundo Figueiredo (2011), quanto maior for o teor de fibras, maior será o número de fibras atuando como ponte de transferência de tensão ao longo da fissura, aumentando, assim, o reforço pós-fissuração do concreto.

A influência do teor de fibras de aço na mistura foi demonstrada em um estudo realizado por Figueiredo, Nunes \& Tanesi (2000), no qual, em um ensaio de tração na flexão com deslocamento controlado, houve uma comparação do teor de fibras (Figura 4.2).

Observa-se que quanto maior o consumo de fibras na mistura, maior é a carga resistida após a fissuração da matriz, ou seja, o consumo de fibras de $40 \mathrm{~kg} / \mathrm{m}^{3}$ indica uma resistência residual pós-fissuração mais elevada que o consumo de $30 \mathrm{~kg} / \mathrm{m}^{3}$, o que também se verifica para o consumo de $30 \mathrm{~kg} / \mathrm{m}^{3}$ em relação ao de $20 \mathrm{~kg} / \mathrm{m}^{3}$.

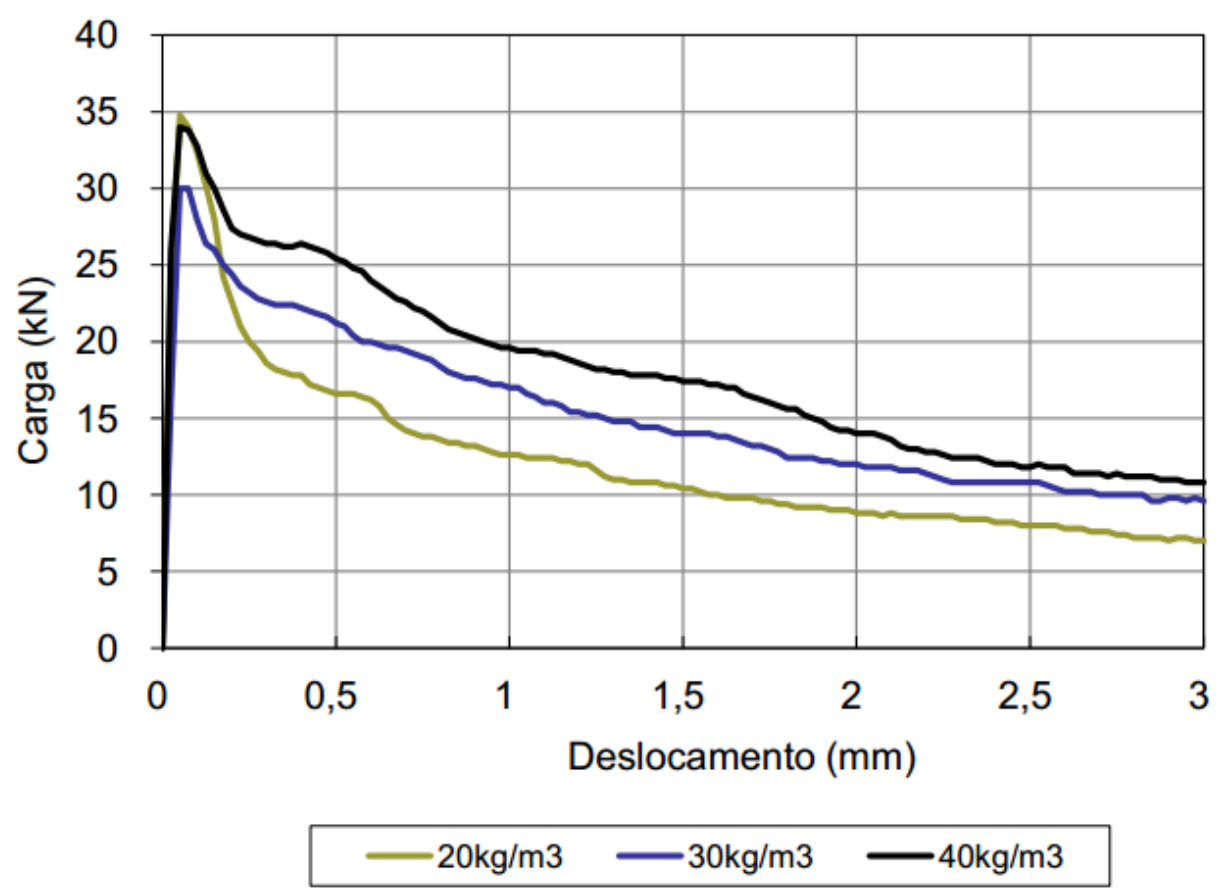

Figura 4.2. Curvas médias de carga versus deslocamento obtidas no ensaio de tração na flexão de concretos com $f_{c k}$ de $20 \mathrm{MPa}$ com a variação do consumo de fibras de aço (FIGUEIREDO, NUNES \& TANESI, 2000).

Em complemento, Naaman (2008) indica que a principal via de classificação dos compósitos de cimento reforçados com fibras deve ser guiada pelo seu 
desempenho. Essa classificação baseia-se no conceito de volume crítico de fibras, que corresponde ao teor de fibras que permanece com a mesma capacidade resistente no compósito após a ruptura da matriz.

Sendo assim, abaixo do volume crítico ocorre o comportamento chamado de strain-softening, em que haveria, no compósito, uma perda de capacidade resistente progressiva após a fissuração da matriz. Se o teor de fibras estiver acima do volume crítico, o compósito apresenta comportamento strain-hardening, para o qual o compósito apresenta ganho da sua capacidade resistente mesmo depois da fissuração da matriz.

Figueiredo (2000) realizou um estudo comparando os comportamentos descritos anteriormente. No gráfico da Figura 4.3, apresentam-se curvas com dados de deslocamento em função da carga, obtidas em ensaios de tração na flexão de prismas de concretos com fibras, em que se ensaiaram matrizes com volume de fibras igual ao volume crítico, inferior e superior a esse valor. Nesse gráfico, verificase um trecho elástico linear inicial em todas as situações, correspondente ao estágio de trabalho elástico da matriz do compósito. No outro trecho, análogo a um patamar de escoamento, observa-se a influência do teor de fibras no comportamento do concreto.

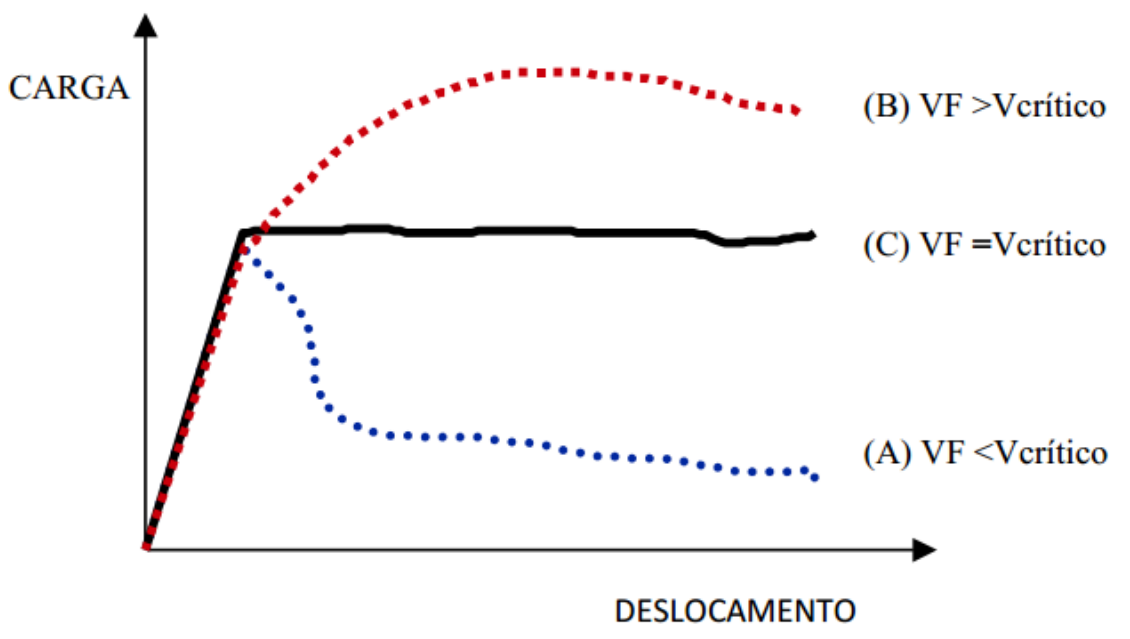

Figura 4.3. Ensaio de tração na flexão de compósitos reforçados com volume de fibras (VF) abaixo (A), acima (B) e igual (C) ao volume crítico (Figueiredo, 2000). 


\subsubsection{O efeito da geometria das fibras}

Segundo Figueiredo (2011), além do teor de fibras, sua geometria é um fator preponderante no desempenho do compósito pós-fissuração.

Associado à eficiência das fibras está seu comprimento crítico $\left(L_{c}\right)$, que é aquele em que a fibra atinge uma tensão no seu centro igual à sua tensão de ruptura, quando a fissura ocorre perpendicular à fibra.

Quando a fibra apresenta um comprimento menor que o comprimento crítico, a carga de arrancamento não é suficiente para produzir tensões que superem a resistência da fibra. Com isso, com o aumento da deformação e da abertura da fissura, a fibra que está servindo de ponte de transferência de tensões será arrancada do lado que apresentar o menor comprimento embutido.

Diante disso, Figueiredo (2011) concluiu que quanto maior o comprimento da fibra, maior será seu embutimento e, por consequência, maior será sua capacidade de resistência após a fissuração. Entretanto, quanto maior o tamanho da fibra, maior será a dificuldade na trabalhabilidade da mistura do compósito, assim como, a chance dessa fibra se romper.

Segundo Maidl (1991), deve haver uma compatibilidade dimensional entre os agregados e as fibras da mistura, isso porque a fissura se propaga, especialmente na região de interface do agregado graúdo com a pasta. Com isso, a atuação da fibra serve como reforço do concreto e não da argamassa. Desta forma, é recomendável a utilização de fibras com comprimento igual ou superior ao dobro da dimensão máxima característica do agregado. Na Figura 4.4 é demonstrada a relação citada, sendo que na parte (a) tem-se a compatibilização entre o agregado e a fibra, e na parte (b) isso não ocorre, fazendo com que poucas fibras trabalhem como ponte de transferência de tensões na fissura. 


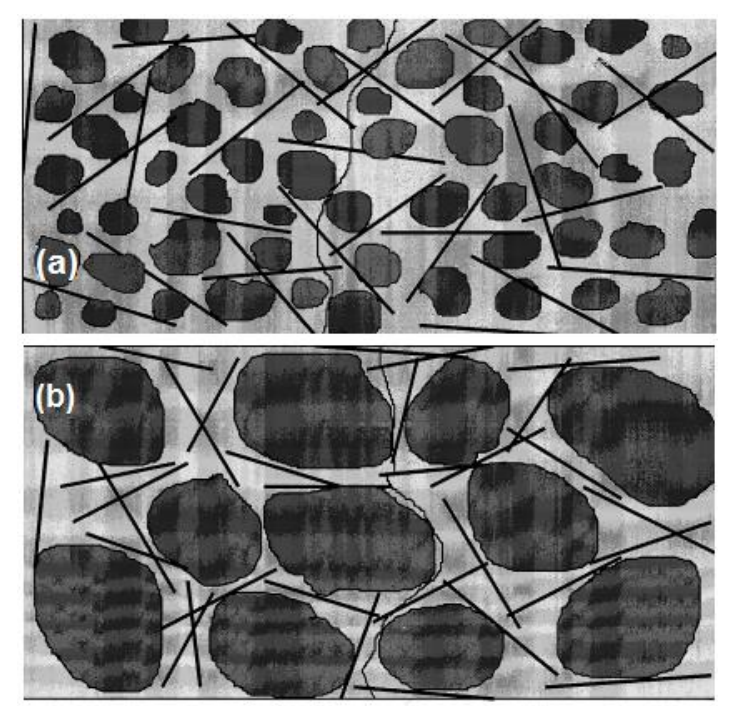

Figura 4.4. Relação entre os agregados graúdos e as fibras: (a) compatibilidade dimensional e (b) sem compatibilidade (Figueiredo, 2000).

Outro fator geométrico que influencia no comportamento pós-fissuração do compósito é a seção transversal da fibra. Quanto menor a seção transversal, menor a área de contato entre a fibra e a matriz. Sendo assim, o arrancamento da fibra se dará por um carregamento menor (FIGUEIREDO, 2011).

Por fim, Figueiredo e Torneri (2006) estudaram o comportamento pósfissuração de fibras com e sem ancoragem em gancho em suas extremidades. Ensaiaram materiais com fibras de mesmo comprimento e mesma seção transversal, modificando apenas a situação de ancoragem das fibras, chegando à conclusão de que a fibra reta proporciona uma maior força de arrancamento, sendo assim, uma maior resistência residual do compósito para maiores aberturas de fissuras.

\subsubsection{O efeito da resistência das fibras}

Outro fator importante na definição do comportamento da fibra de aço no concreto reforçado é a resistência do aço utilizado na sua produção, sendo esta característica mais expressiva em concreto de maior resistência mecânica.

De acordo com a ABNT NBR 15530:2007, a resistência mínima do aço, em função da classe da fibra, é dada pela Tabela 4.2. Observa-se que o menor valor estipulado pela norma brasileira é de $500 \mathrm{MPa}$, diferentemente da normalização 
internacional, como a ASTM A820, que especifica o valor mínimo de resistência de $345 \mathrm{MPa}$ (FIGUEIREDO, 2011).

Tabela 4.2. Limite de resistência à tração das fibras de aço

(ABNT NBR 15530:2007)

\begin{tabular}{|c|c|}
\hline Fibra & $\begin{array}{c}\text { Limite de resistência à } \\
\left.\text { tração do aço fu (MPa) } \text { ( }^{*}\right)\end{array}$ \\
\hline A I & 1000 \\
\hline A II & 500 \\
\hline C I & 800 \\
\hline C II & 500 \\
\hline C III & 800 \\
\hline R I & 1000 \\
\hline R II & 500 \\
\hline \multicolumn{2}{|c|}{} \\
$\begin{array}{c}\left.{ }^{*}\right) \text { Esta determinação deve ser feita } \\
\text { no aço, no diâmetro equivalente final, } \\
\text { imediatamente antes do corte. }\end{array}$ \\
\hline
\end{tabular}

Em estudos realizados por Figueiredo (2011), admitiu-se que não há necessidade de se utilizar fibras mais resistentes, quando se trabalha com fibras curtas abaixo do comprimento crítico, dado que o principal mecanismo de arrancamento das fibras curtas é o escorregamento.

\subsubsection{O efeito da resistência da matriz}

O módulo de elasticidade do compósito está diretamente relacionado ao teor critico de fibras. Esse parâmetro é uma combinação entre o módulo da matriz e o da fibra, e quanto maior o módulo de elasticidade da matriz, maior será o teor de fibras necessário para garantir o comportamento próximo ao do elastoplástico perfeito (FIGUEIREDO, 2011). 


\subsubsection{Outras considerações normativas a respeito das fibras}

Outras especificações a respeito das fibras de aço preconizadas pela ABNT NBR 15530:2007 são: (a) ductilidade da fibra; (b) variabilidade do fator de forma e (c) defeitos nas fibras.

Para se evitar a fragilização do compósito, segundo Figueiredo (2005), é necessária uma ductilidade mínima para a fibra de aço. Para isto, é estabelecido pela norma brasileira o ensaio de dobramento da fibra, no qual, sobre um pino de $3,2 \mathrm{~mm}$ de diâmetro, a uma temperatura de $16^{\circ} \mathrm{C}$, deve-se dobrar manualmente a fibra até formar um ângulo de $90^{\circ}$, inclinação em que não pode ocorrer a quebra dos exemplares (Figura 4.5).

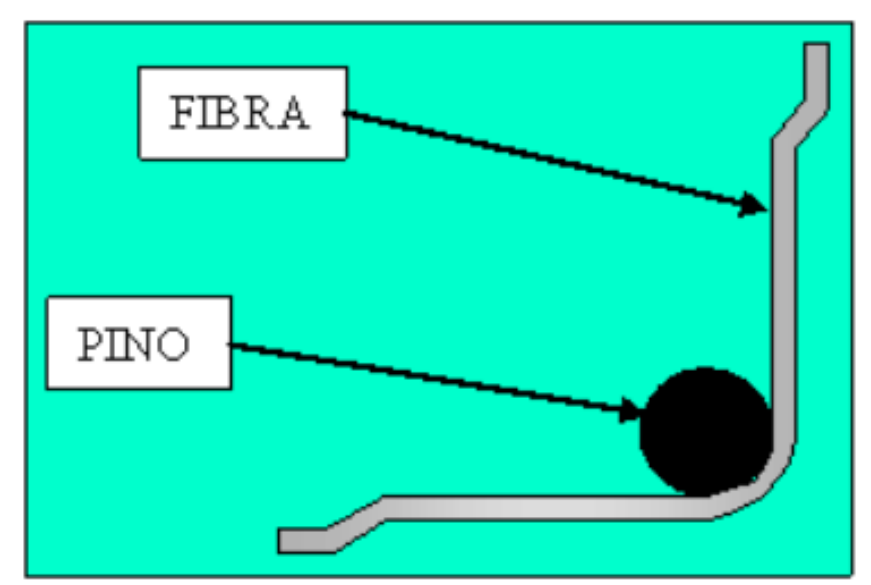

Figura 4.5. Esquema adotado no ensaio de dobramento da fibra de aço (Figueiredo, 2011).

Outra preocupação da Norma, de acordo com Figueiredo (2008), é de se evitar uma variação exagerada do desempenho do concreto reforçado com as fibras, provocada pela variabilidade do fator de forma da fibra $(\lambda)$. Esse fator relaciona o comprimento da fibra, não alongada, com o diâmetro do círculo com área equivalente à de sua seção transversal (diâmetro equivalente). A limitação normativa pode ser vista na Tabela 4.3, que leva em consideração a classe da fibra e o tipo de aço. 
Tabela 4.3. Fator de forma mínimo para as fibras de aço

(ABNT NBR 15530:2007)

\begin{tabular}{|c|c|c|}
\hline $\begin{array}{c}\text { Classe da } \\
\text { fibra }\end{array}$ & Tipo de aço & $\begin{array}{c}\text { Fator de forma } \\
\text { mínimo }(\boldsymbol{\lambda})\end{array}$ \\
\hline I & Fio de aço trefilado & 40 \\
\hline II & Chapa de aço cortada & 30 \\
\hline III & Fio de aço trefilado e escarificado & 30 \\
\hline
\end{tabular}

A Norma preconiza uma limitação de defeitos em um lote de fibras, e para cada lote utilizado, deve-se separar no mínimo 200 gramas do material, e nessa quantidade deve apresentar no máximo $5 \%$ da massa total com defeitos.

Alguns dos defeitos previstos pela Norma podem ser visualizados na Figura 4.6: (a) emenda das fibras pelo topo, podendo ser prejudicial quando a fibra é utilizada em concretos projetados, e (b) corte da ancoragem nas fibras tipo A, podendo prejudicar a tenacidade do concreto, por reduzir o seu fator de forma real.

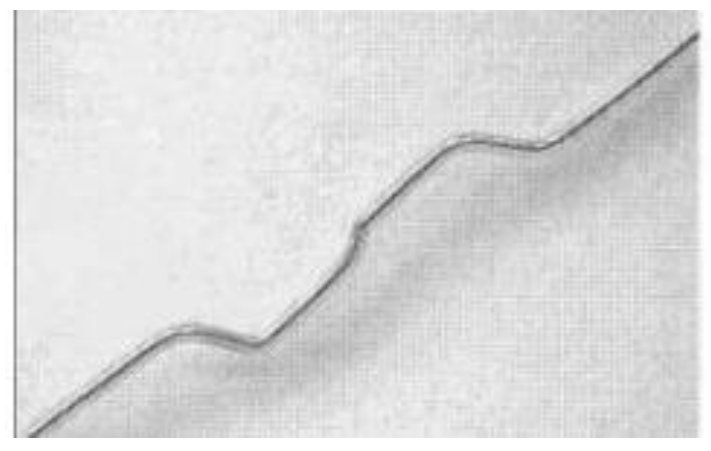

(a)

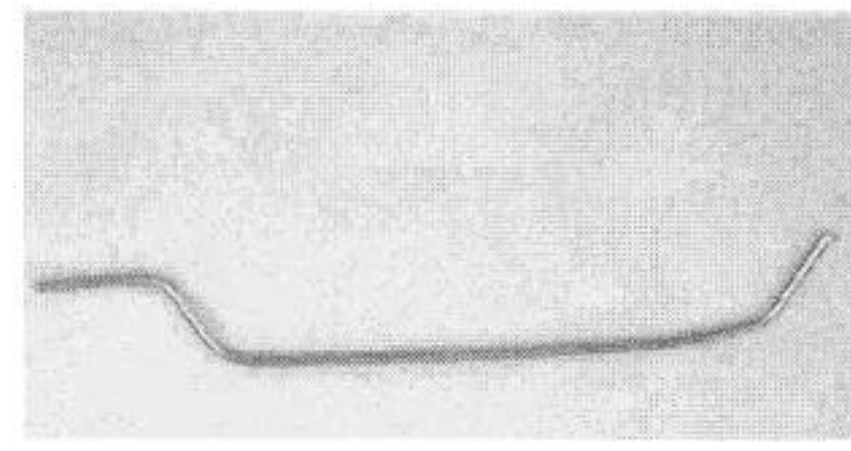

(b)

Figura 4.6. Defeitos nas fibras: (a) Fibras emendadas pelo topo e (b) Fibras sem ancoragem correta (ABNT NBR 15530, 2007).

\subsection{Controle do concreto com fibras - Tenacidade}

Grande parte dos ensaios para estudar o comportamento da interação da fibra de aço com a matriz procura avaliar a tenacidade do compósito. Atualmente, a definição desse parâmetro, quando o assunto é concreto reforçado com fibras, é de que a tenacidade é a energia absorvida pelo compósito quando carregado, compreendendo a energia absorvida antes e depois da fissuração da matriz, quando, efetivamente, as fibras passam a trabalhar (FIGUEIREDO, 2011). O método 
utilizado, no Brasil, para determinar a tenacidade é o ensaio indicado pela Japan Society os Civil Engineers (JSCE-SF4, 1984).

Segundo Carnio (1998), o papel principal das fibras acontece após a fissuração da matriz, pois elas criam mecanismos de absorção de energia associados com o alongamento das fibras existentes nas zonas fissuradas, com a ruptura da aderência fibra-matriz, aumentando, assim, a tenacidade do compósito.

Convencionou-se indicar a tenacidade do concreto reforçado com fibras como sendo a área contida sob a curva carga-deslocamento, que simboliza o trabalho dissipado do material. Esse valor depende diretamente das dimensões dos corpos de prova utilizados nos ensaios, assim como do sistema de aplicação dos esforços.

A recomendação da norma japonesa JSCE-SF4 (1984) baseia-se na flexão de corpos de prova prismáticos sem entalhe, de dimensões de $10 \mathrm{~cm} \times 10 \mathrm{~cm} \times 40 \mathrm{~cm}$ ou de $15 \mathrm{~cm} \times 15 \mathrm{~cm} \times 50 \mathrm{~cm}$, com vãos de $30 \mathrm{~cm}$ ou de $45 \mathrm{~cm}$, respectivamente.

A dimensão do corpo de prova será definida conforme o tamanho da fibra utilizada no concreto. Recomenda-se que a menor dimensão do prisma seja, no mínimo, três vezes maior que o comprimento da fibra utilizada (FIGUEIREDO, 2011).

O suporte para apoio dos corpos de prova e para a aplicação de carga contém dois cutelos cilíndricos com livre rotação sobre seus eixos. Além disso, dois transdutores do tipo LVDT são utilizados para leitura do deslocamento vertical do corpo de prova, centralizados em cada face lateral do prisma, utilizando-se, para isto, um yoke (Figura 4.7).

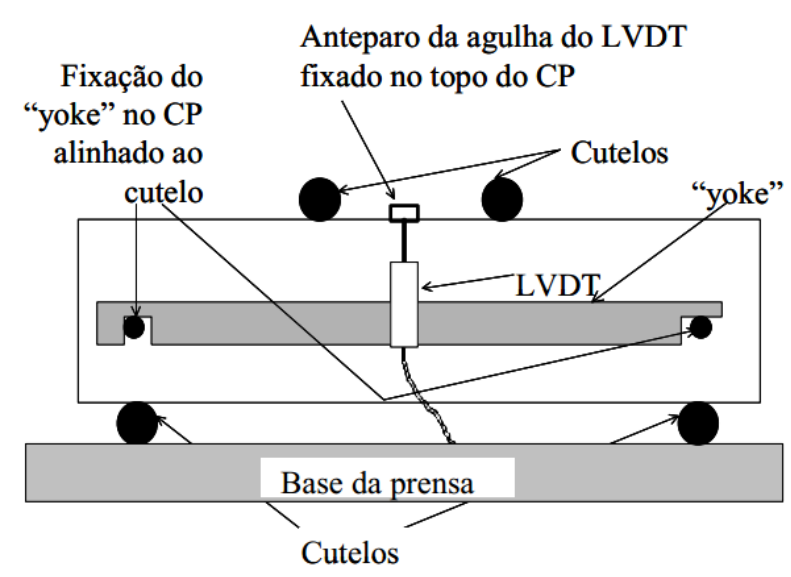

Figura 4.7. Esquema do ensaio de tração na flexão com o sistema "yoke"

(Figueiredo, 1999). 
O carregamento é realizado até que o deslocamento vertical mínimo atinja o valor de L/150 mm, em que $L$ é o vão de $30 \mathrm{~cm}$ ou $45 \mathrm{~cm}$. O rompimento deve ocorrer em seu terço central. Caso isso não ocorra, o ensaio deve ser descartado. Então, a medida da tenacidade ( $\mathrm{T}_{\mathrm{b}}$ ) é obtida a partir da curva carga-deslocamento, que é definida pela área total do diagrama, em Joules ou kgf.cm (Figura 4.8). Para encontrar o valor do fator de tenacidade (FT), basta utilizar a Equação 4.1.

Essencialmente, o valor de $\mathrm{T}_{\mathrm{b}}$ dividido por $\delta_{\mathrm{tb}}$ irá fornecer a carga média que o compósito resistiu durante o ensaio até determinado grau de deslocamento. Ou seja, é o valor médio de carga resistida após a fissuração da matriz.

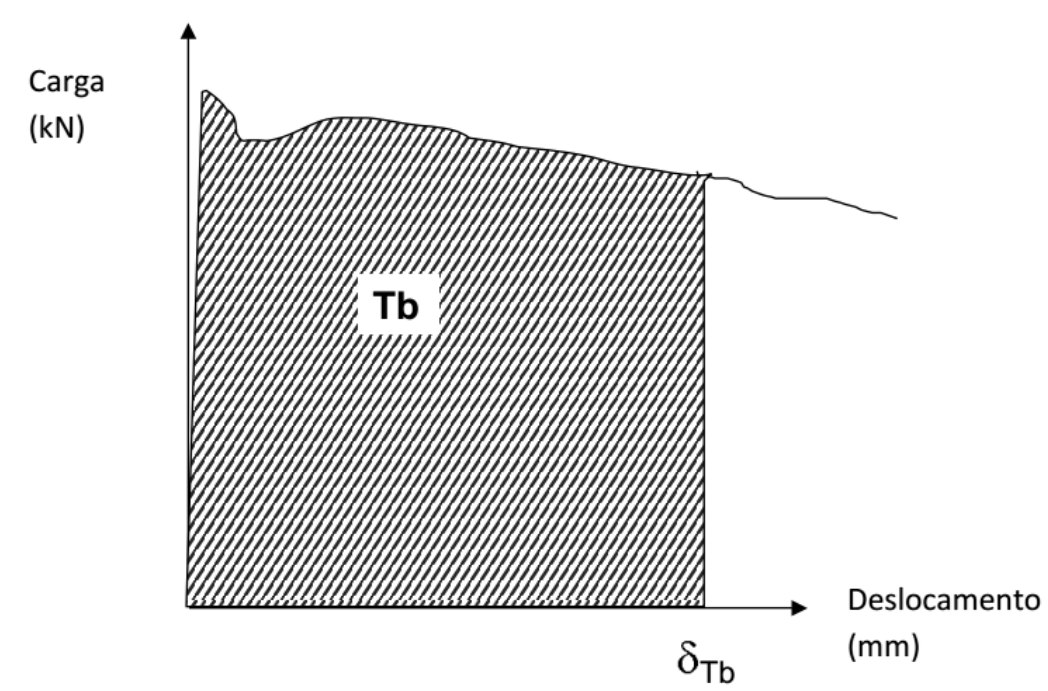

Figura 4.8. Gráfico carga-deslocamento do ensaio de tensão na flexão (Figueiredo, 1999).

$\boldsymbol{F T}=\frac{T_{b}}{\delta_{t b}} \cdot \frac{\boldsymbol{L}}{b \cdot h^{2}} \quad$ (Equação 4.1)

$\mathrm{FT}=$ Fator de tenacidade na flexão (MPa);

$\mathrm{T}_{\mathrm{b}}=$ Tenacidade na flexão (J) ou (N.mm);

$\delta_{\mathrm{tb}}=$ Deslocamento equivalente a $\mathrm{L} / 150(\mathrm{~cm})$;

$\mathrm{b}=$ Largura do corpo de prova $(\mathrm{cm})$;

$\mathrm{h}=$ Altura do corpo de prova $(\mathrm{cm})$;

$L=$ Vão do corpo de prova durante o ensaio $(\mathrm{cm})$. 


\subsection{Dosagem do concreto com fibras}

O consumo de fibras de aço tem grande influência no custo final do concreto. Consumo regular, na ordem de $40 \mathrm{~kg} / \mathrm{m}^{3}$, praticamente duplica o custo unitário do metro cúbico do concreto (FIGUEIREDO, 2011).

Ainda que seja verdade, são raras as metodologias para a otimização de um traço de concreto contendo fibras. Atualmente, os processos de dosagem utilizados para os concretos com fibras são procedimentos experimentais, que complementam os métodos utilizados no concreto convencional.

Conforme Figueiredo (2011), a metodologia para dosagem do compósito tem foco especial na determinação do teor ótimo de fibras, em que o alvo é atender aos requisitos especificados para a tenacidade, não podendo deixar de levar em consideração as características da matriz, tanto no que se refere à sua trabalhabilidade como à sua resistência mecânica.

Para se definir o teor de fibras, deve-se avaliar o volume crítico, a relação entre a resistência da matriz e o ganho de tenacidade requerido. Como já foi mencionado, quanto maior a quantidade de fibras, maior o ganho da tenacidade. Já a escolha do tipo de fibra está condicionada à aplicação do concreto reforçado. Para uma maior tenacidade, em geral, deve-se priorizar a utilização de fibras mais longas e com melhor ancoragem mecânica. Além disso, o comprimento da fibra deve ser igual ou superior ao dobro da dimensão máxima característica do agregado.

\subsection{Estudos sobre o concreto reforçado com fibras de aço}

As fibras de aço têm sido amplamente utilizadas em substituição às telas soldadas em pisos, pavimentos, revestimentos de túneis e obras de infraestrutura, como as de saneamento básico (ACI, 2002; FIGUEIREDO, 2011).

Segundo Bentur \& Mindess (2007), o reforço com fibras é particularmente interessante em elementos de baixa espessura ou elementos sujeitos a grandes cargas ou deformações localizadas. 
Nesse contexto, Carnio (1998) fez uma análise em regime plástico sobre pisos e pavimentos de concreto reforçado com fibras de aço sobre base elástica. Nesse trabalho o autor analisou teorias plásticas segundo modelos propostos por Losberg e por Meyerhof, introduzindo algumas adaptações, uma vez que essas teorias foram desenvolvidas para aplicações com uso somente de armadura convencional. Os resultados encontrados identificaram a possibilidade da substituição das armaduras convencionais por fibras de aço.

Em programa experimental, Nunes (2006) analisou a construção de pistas de concreto reforçado com fibras de aço, variando o consumo das fibras e avaliando a fissuração por retração na superfície através da medida da abertura e do comprimento das fissuras. Dentre as conclusões do autor nesse estudo, destacamse: (a) a adição de fibras, juntamente com a cura úmida ou limitação no consumo de cimento da matriz, é um procedimento eficiente para o controle da fissuração por retração em elementos de superfície; (b) as pistas confeccionadas com fibras de fator de forma menor apresentaram aberturas e áreas de fissuras maiores; (c) para teores de fibras inferiores a $40 \mathrm{~kg} / \mathrm{m}^{3}$, a variação da abertura de fissura em função do teor de fibra segue uma predisposição linear; (d) para a garantia de fissuras menores que $0,3 \mathrm{~mm}$, o consumo médio de fibras deve ser superior a $40 \mathrm{~kg} / \mathrm{m}^{3}$.

Além disso, com o intuito de contribuir para o estudo da utilização da infraestrutura de saneamento, pesquisas da inserção de fibras de aço em tubos de concreto vêm acontecendo há algum tempo, como foi o caso do estudo de Ramos (2002), em que o autor avaliou o comportamento de tubos de concreto reforçado com fibras de aço frente aos tubos de concreto simples e de concreto armado.

Foi constatado por Ramos (2002) que: (a) a incorporação de baixos teores de fibras proporciona a redução de dados acidentais que podem ocorrer durante a fabricação, armazenamento, transporte e instalação dos tubos; (b) a utilização de fibras com comprimentos maiores do que a espessura da parede dos tubos aumenta a capacidade de reforço da peça e (c) que, pelo tubo apresentar-se como uma estrutura hiperestática, pode-se aproveitar a capacidade de redistribuição de esforços proporcionada pelas fibras de aço. 
Além disso, os resultados desse trabalho também indicaram que na determinação da resistência à compressão axial, o ideal seria através da extração de corpos de prova dos próprios tubos, devido às características de compactação do elemento, assim como nos ensaios de tração na flexão, em que, através da utilização de prismas, não é possível garantir a condição de compactação e de distribuição das fibras que acontece nos tubos.

Contudo, Ramos (2002) conclui que a inserção de fibras de aço ocasiona um comportamento dúctil aos tubos, mantendo a mesma capacidade de suporte, com ganhos significativos de durabilidade.

Escariz (2012), em um estudo comparativo sobre a inserção de fibras de aço e fibras poliméricas em tubos de concreto, concluiu que a inserção de fibras de aço apresentou um desempenho mecânico marcadamente superior ao das fibras poliméricas, principalmente referente à capacidade resistente pós-fissuração, apresentando o dobro da capacidade resistente residual em relação às macrofibras poliméricas, para um mesmo teor em volume.

Outro estudo com a inserção de fibras foi realizado por Oliveira Junior (2012), que utilizou fibras de aço no concreto para desenvolver uma ligação viga-pilar capaz de resistir a ações cíclicas e dinâmicas. A inserção de $2 \%$ do material no traço indicou um aumento de 34\% na resistência à tração na flexão, 16\% na resistência à compressão e $33 \%$ na tenacidade. 


\section{PROGRAMA EXPERIMENTAL}

Neste capítulo serão descritos todos os procedimentos relacionados à análise experimental.

\subsection{Procedimentos gerais}

Para analisar o comportamento residual do concreto leve com EPS sob elevadas temperaturas, avaliaram-se as seguintes propriedades:

- Massa específica $(\rho)$

- Resistência à compressão axial $\left(\mathrm{f}_{\mathrm{c}}\right)$

- Módulo de elasticidade estático $\left(E_{c}\right)$

- Módulo de elasticidade dinâmico $\left(E_{d}\right)$

- Resistência à tração por compressão diametral $\left(f_{c t, s p}\right)$

- Resistência à tração na flexão $\left(\mathrm{f}_{\mathrm{ct}, \mathrm{f}}\right)$

- Fator de tenacidade (FT)

Para as cinco primeiras propriedades, foram utilizados corpos de prova cilíndricos de $10 \mathrm{~cm}$ x $30 \mathrm{~cm}$, dimensões recomendadas pela RILEM TC 200-HTC e RILEM TC 129-MHT, para as quais a altura deve ser pelo menos igual a três vezes o diâmetro. O traço utilizado para avaliação dessas propriedades foi 1:1:1,5:0,28 (cimento CPV-ARI: areia média: EPS: água), com a adição de $1 \%$ de superplastificante. Esse traço, chamado padrão (TP), foi obtido em um estudo de dosagem e de características mecânicas realizado por Ozório (2016).

Para as duas últimas propriedades, foram utilizados corpos de prova prismáticos com dimensões $15 \mathrm{~cm} \times 15 \mathrm{~cm} \times 50 \mathrm{~cm}$, de acordo com a ABNT NBR 12142:2010. Nesses casos foi utilizado o mesmo traço padrão, porém com adição de fibras e $1,1 \%$ de superplastificante. Para a realização do estudo com fibras, optou-se por utilizar as seguintes taxas: $0,3 \%, 0,6 \%$ e $0,9 \%$ (equivalentes a $23,55 \mathrm{~kg} / \mathrm{m}^{3}, 47,1 \mathrm{~kg} / \mathrm{m}^{3}$ e $70,65 \mathrm{~kg} / \mathrm{m}^{3}$, respectivamente). Esses valores foram escolhidos pelo fato de taxas em torno das duas primeiras serem usualmente 
empregadas em estudos de traços com fibras de aço, mesmo sabendo que as duas últimas taxas são valores elevados considerando-se a viabilidade econômica, porém nesse estudo pretendeu-se, apenas, avaliar a eficiência das fibras no concreto com EPS. Para todos os traços estudados neste trabalho, avaliaram-se as resistências aos 28 e aos 100 dias, usando os corpos de prova com $10 \mathrm{~cm} \times 20 \mathrm{~cm}$.

Os corpos de prova cilíndricos e prismáticos foram ensaiados à temperatura ambiente para se obter o valor de referência, conforme será visto mais adiante, nas tabelas 5.2, 5.3 e 5.4 .

Depois, seguindo as recomendações da RILEM, conforme a tabela 5.1, os corpos de prova cilíndricos foram aquecidos e resfriados lentamente a uma taxa de $1 \stackrel{\circ}{\circ} / \mathrm{min}$, mantendo-se constante por 60 minutos a temperatura em estudo.

Tabela 5.1. Taxa máxima recomendada de aquecimento e resfriamento de corpos de prova cilíndricos, segundo a RILEM.

\begin{tabular}{c|c}
\hline $\begin{array}{c}\text { Diâmetro máximo do } \\
\text { corpo de prova } \\
\text { cilíndrico }(\mathbf{m m})\end{array}$ & $\begin{array}{c}\text { Taxa de aquecimento e } \\
\text { resfriamento }\left({ }^{\circ} \mathrm{C} / \mathrm{min}\right)\end{array}$ \\
\hline 150 & 0,50 \\
\hline 100 & 1,00 \\
\hline 80 & 2,00 \\
\hline 60 & 4,00 \\
\hline
\end{tabular}

Não há recomendações para os prismas, porém como eles têm dimensões de $150 \mathrm{~mm} \times 150 \mathrm{~mm} \times 500 \mathrm{~mm}$, adotou-se a mesma taxa recomendada para os corpos de prova cilíndricos com $150 \mathrm{~mm}$ de diâmetro, ou seja, 0,5 드. $\mathrm{min}$. E nesse caso, também se manteve constante por 60 minutos a temperatura em estudo. Lembra-se que o corpo de prova cilíndrico com $15 \mathrm{~cm}$ de diâmetro, seguindo as recomendações da RILEM, deveria ter pelo menos $45 \mathrm{~cm}$ de altura.

Para o aquecimento dos corpos de prova, foi utilizado o forno disponível no Laboratório de Estruturas e Materiais da UNICAMP, conforme mostrado nas figuras 5.1, 5.2, 5.3 e 5.4. Esse forno foi fabricado para fazer ensaios em vigas, por isso ele possui uma abertura retangular na superfície em aço inox, que pode ser vista na figura 5.2. Ele foi adaptado para realizar os ensaios com os corpos de prova. 


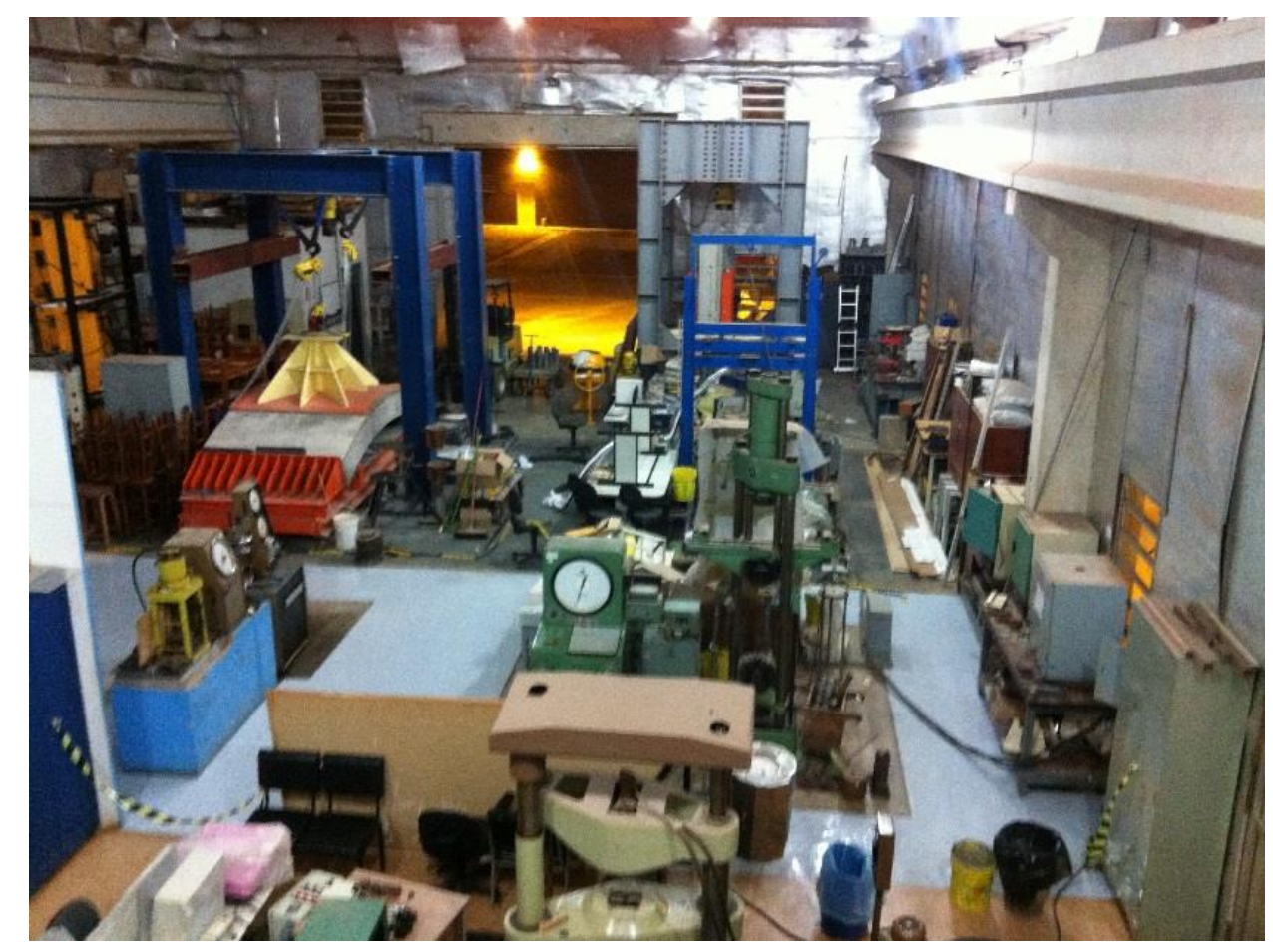

Figura 5.1. Laboratório de Estruturas e Materiais da UNICAMP.

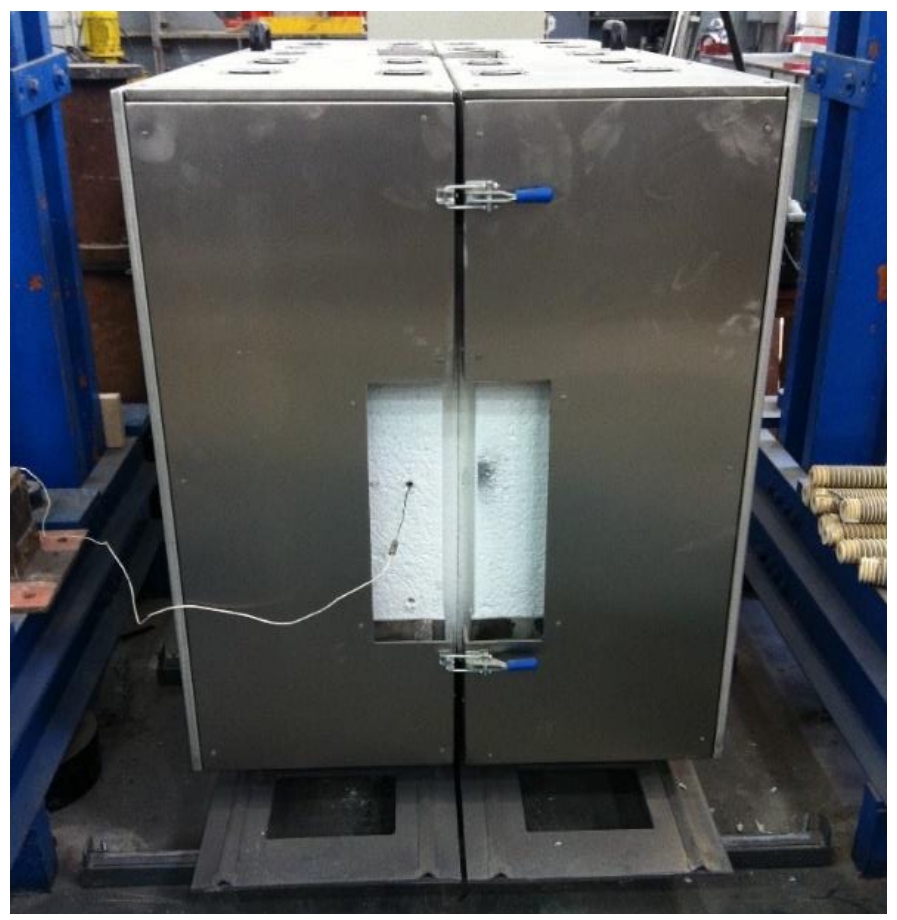

Figura 5.2. Forno fechado utilizado para o aquecimento dos corpos de prova. 


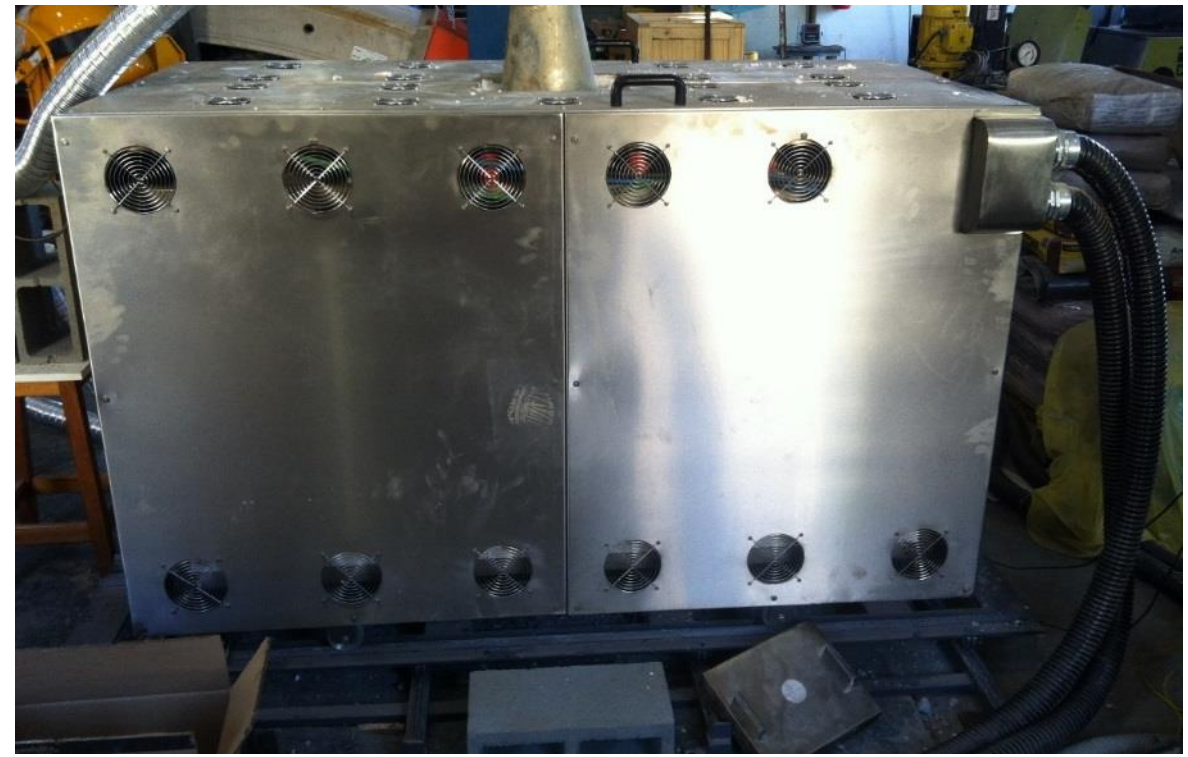

Figura 5.3. Lateral do forno utilizado para o aquecimento dos corpos de prova.

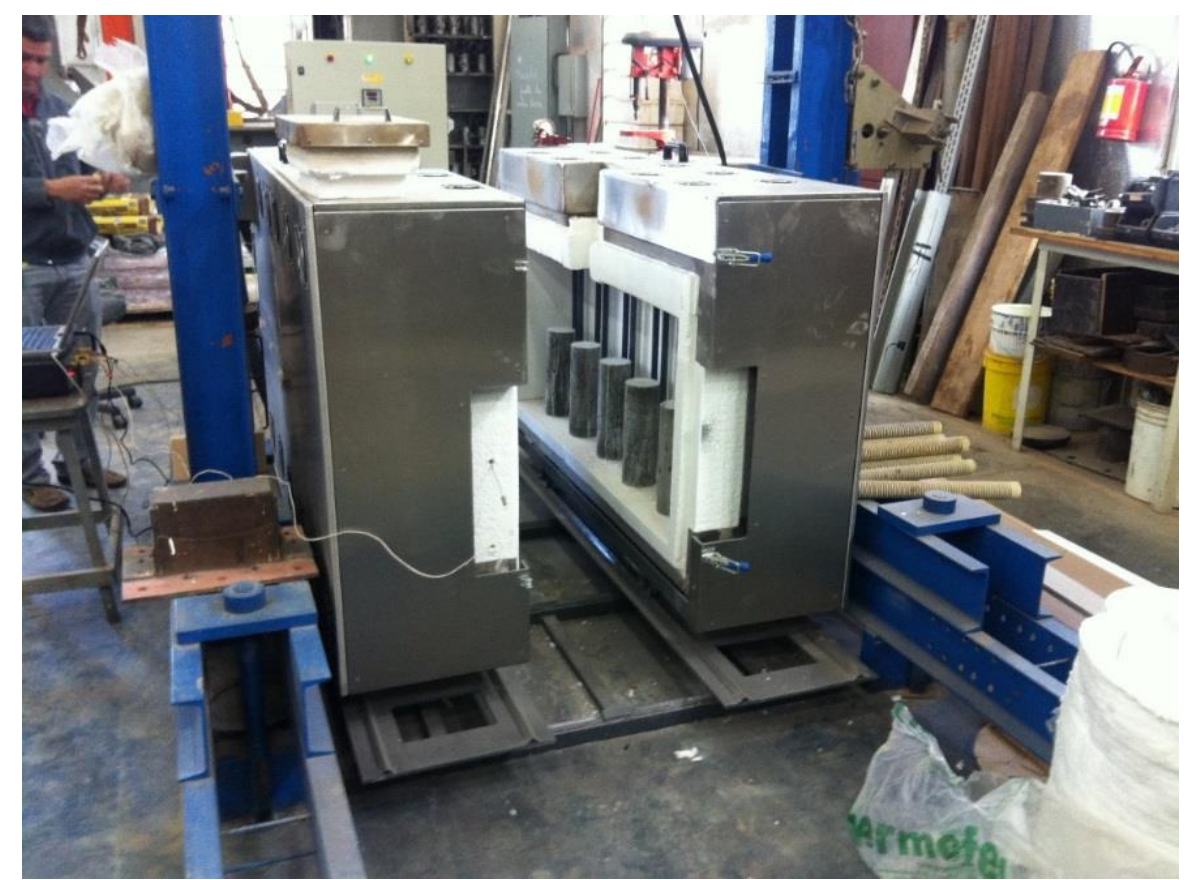

Figura 5.4. Forno aberto utilizado para o aquecimento dos corpos de prova.

O forno fechado possui as seguintes dimensões externas: $85 \mathrm{~cm}$ de largura, $102,6 \mathrm{~cm}$ de altura e $172,2 \mathrm{~cm}$ de comprimento (direção em que os corpos de prova foram distribuídos, conforme mostrado na figura 5.4). Os corpos de prova ficam a $21,6 \mathrm{~cm}$ do piso. A abertura na parte da frente, utilizada para a passagem de vigas, tem as seguintes dimensões: $19,8 \mathrm{~cm}$ na horizontal e 41,5 cm na vertical. Quando o forno está aberto, a dimensão de 19,8 cm pode chegar até a 63,8 cm. 
Todo o interior do forno é vedado com fibra de vidro (parte branca), que é excelente isolante térmico, e que também pode ser visto na figura 5.4.

O forno possui as seguintes características técnicas:

$>$ Temperatura máxima $1100^{\circ} \mathrm{C}$;

$>$ Tensão $220 \mathrm{~V}$;

$>$ Corrente $118 \mathrm{~A}$;

> Potência $45000 \mathrm{~W}$.

A taxa de aquecimento e resfriamento é controlada pelo painel eletrônico, mostrado na figura 5.5 .

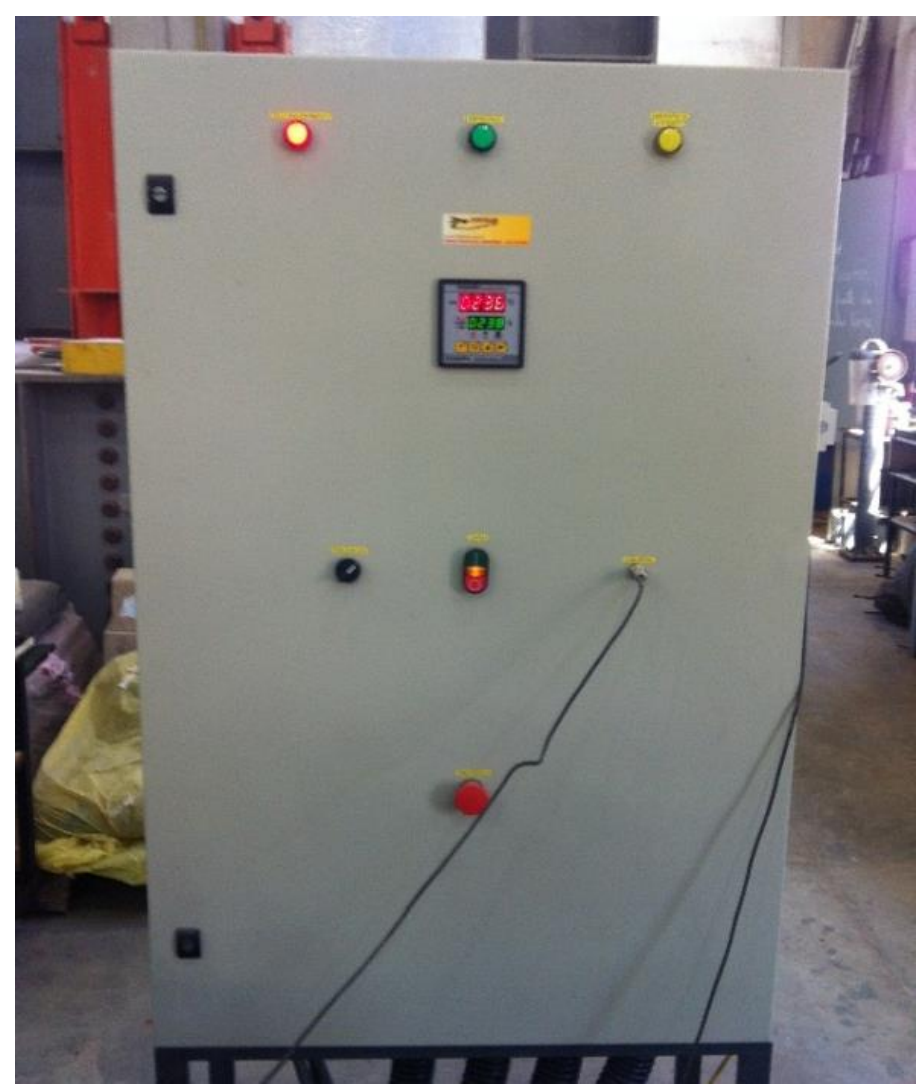

Figura 5.5. Painel eletrônico para controle de temperatura

A temperatura interna é captada pelo termopar de controle que fica na parte central do forno, conforme pode ser visto na figura 5.6.

$\mathrm{O}$ aquecimento acontece por meio das resistências (barras paralelas) na cor preta, mostradas na figura 5.7 , as quais ficam espaçadas $15 \mathrm{~cm}$ uma da outra. São 12 resistências no total, seis de cada lado do forno. 


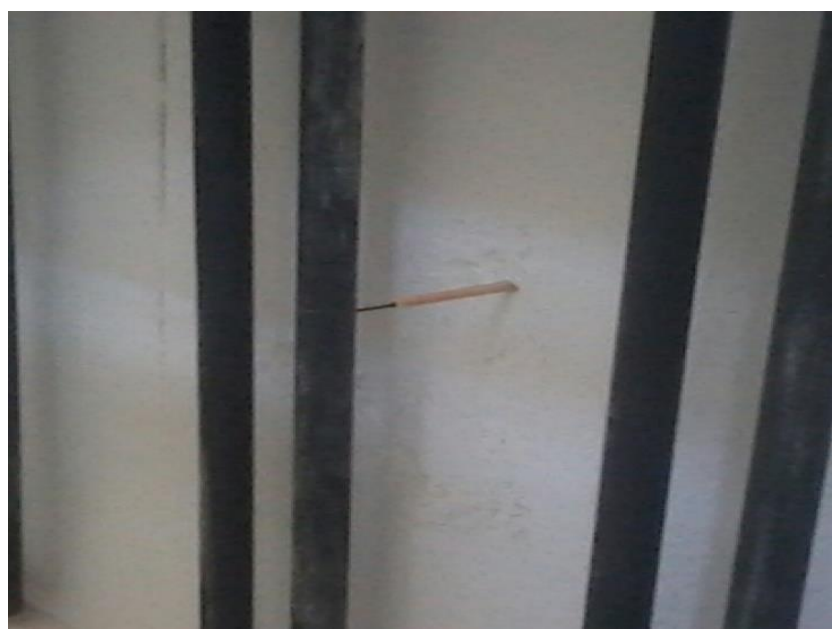

Figura 5.6. Termopar de controle dentro do forno

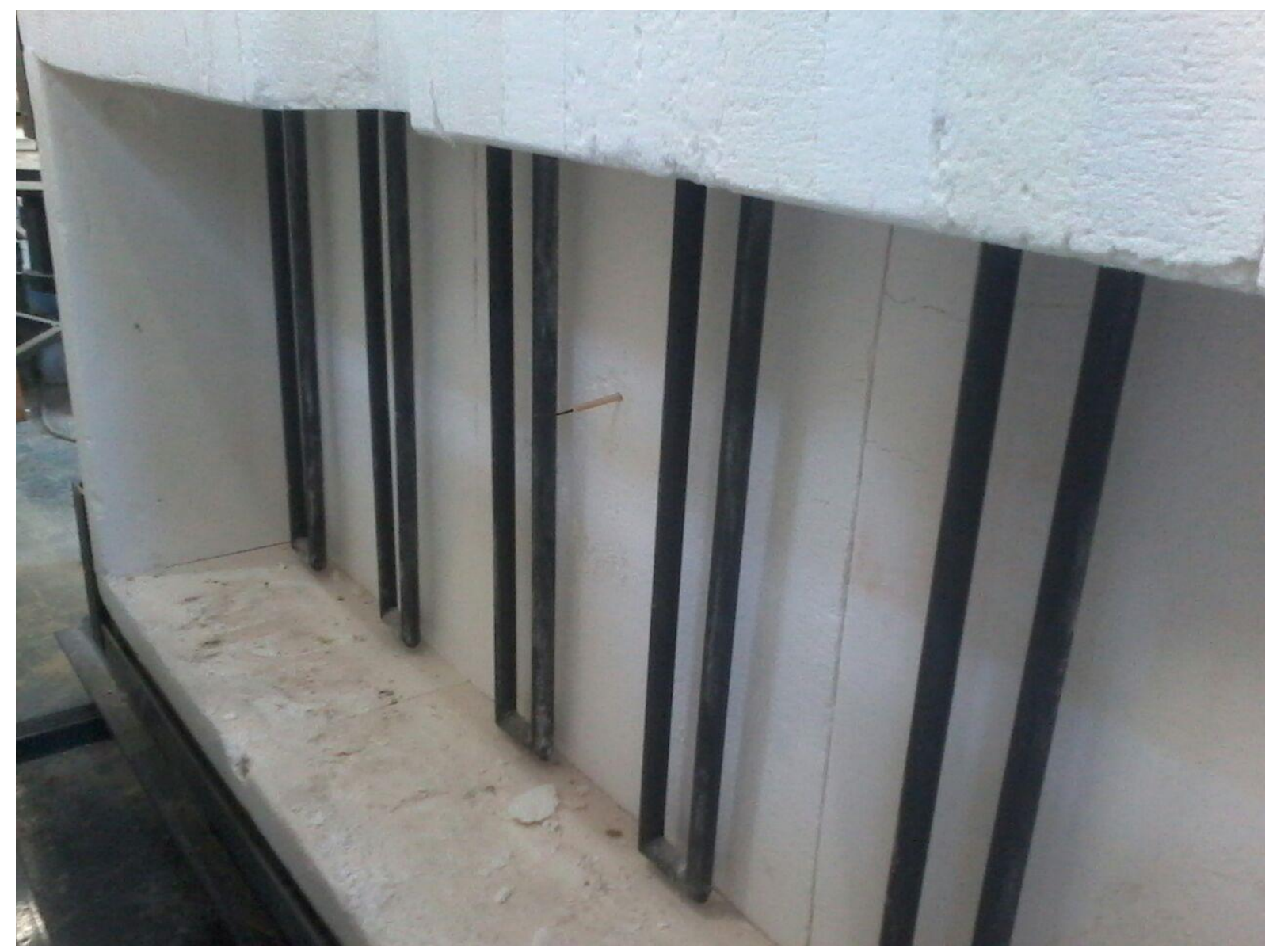

Figura 5.7. Resistências para o aquecimento do forno

Os corpos de prova foram posicionados entre as resistências, tanto os cilíndricos (figura 5.8) como os prismáticos, com uma distância aproximada de $10 \mathrm{~cm}$ entre o corpo de prova e a resistência. 


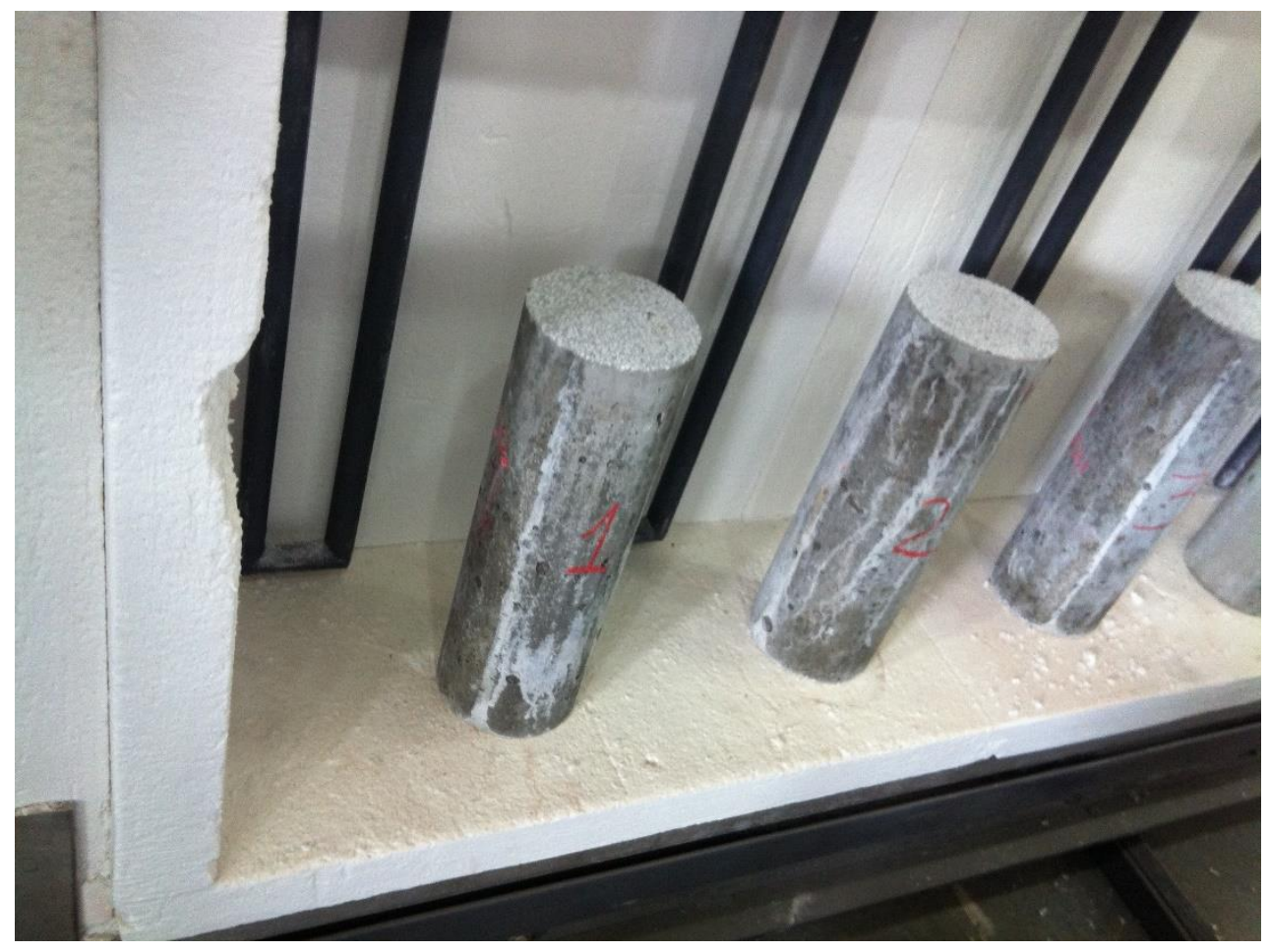

Figura 5.8. Distância entre os corpos de prova e resistências

Pode-se acompanhar o aquecimento pelo software flexlab, como indicado na figura 5.9, na qual se mostra o gráfico da taxa de aquecimento que foi programada (em azul), o gráfico da temperatura interna no forno (em vermelho - canal 1), a temperatura ambiente (em verde - canal 2) e o alarme de segurança (em marrom).

Destaca-se a precisão de aquecimento do forno, no qual a temperatura interna aumenta seguindo exatamente a taxa programada.

Pode-se observar na figura 5.10 que aproximadamente três horas depois do horário registrado na figura 5.9, a temperatura interna ainda acompanhava com extrema precisão a taxa programada (em azul). 


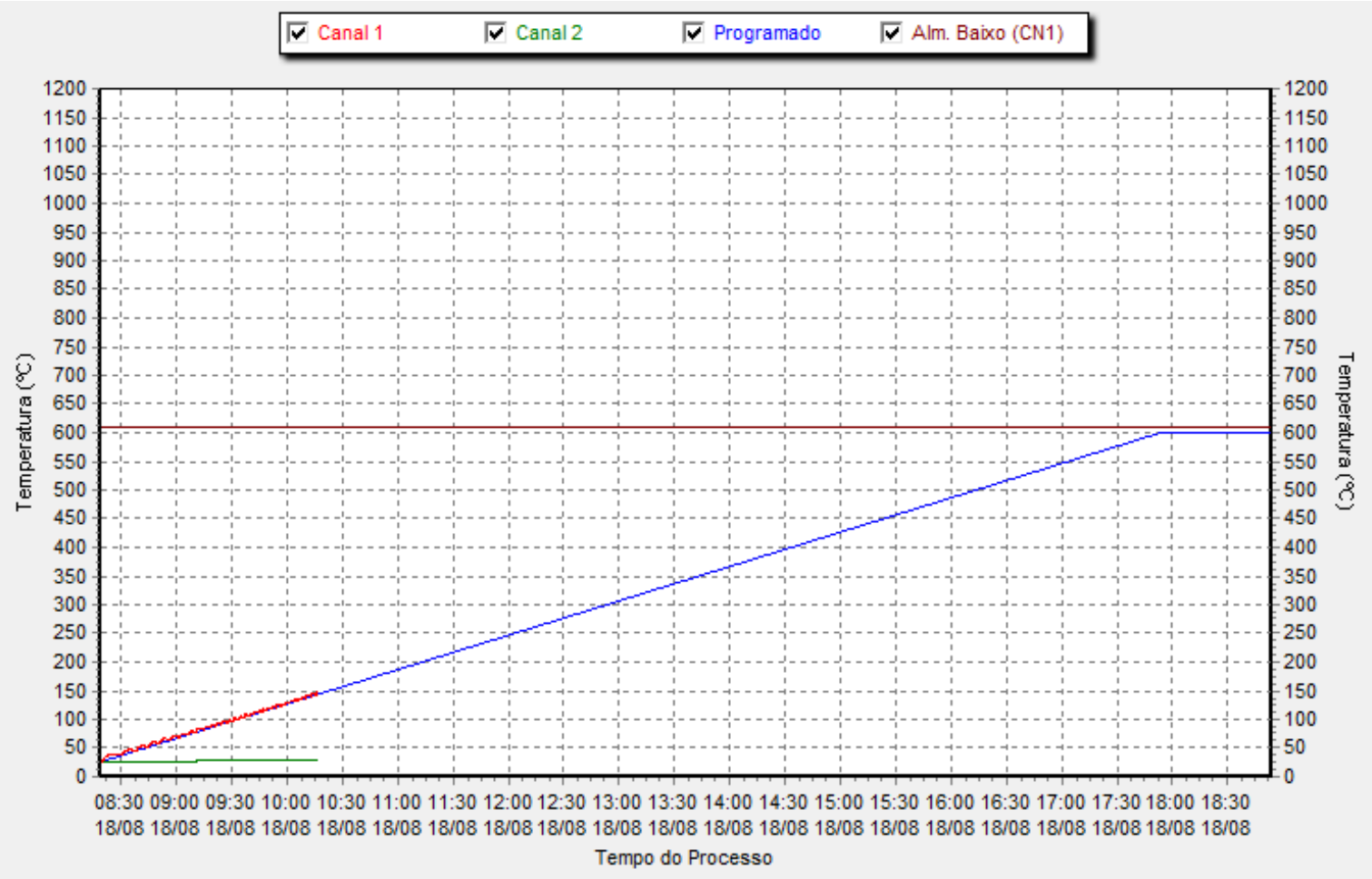

Figura 5.9. Controle da temperatura do forno - aproximadamente $10 \mathrm{~h} 15 \mathrm{~m}$ da manhã.

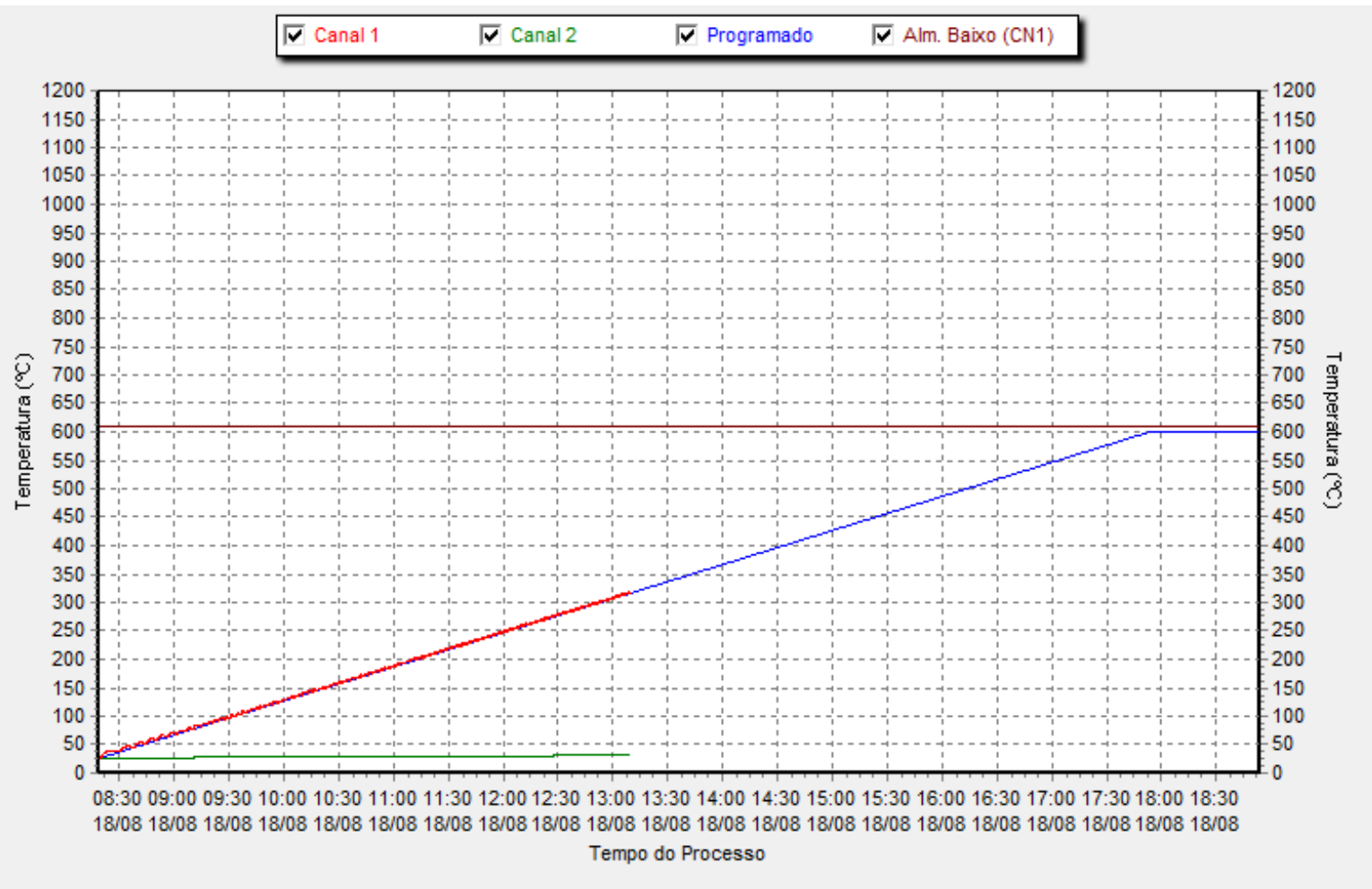

Figura 5.10. Controle da temperatura do forno - aproximadamente $13 \mathrm{~h} 15 \mathrm{~m}$. 
Na figura 5.11 tem-se o gráfico completo da taxa programada, com as três partes: de aquecimento, de temperatura constante por 60 minutos e de resfriamento.

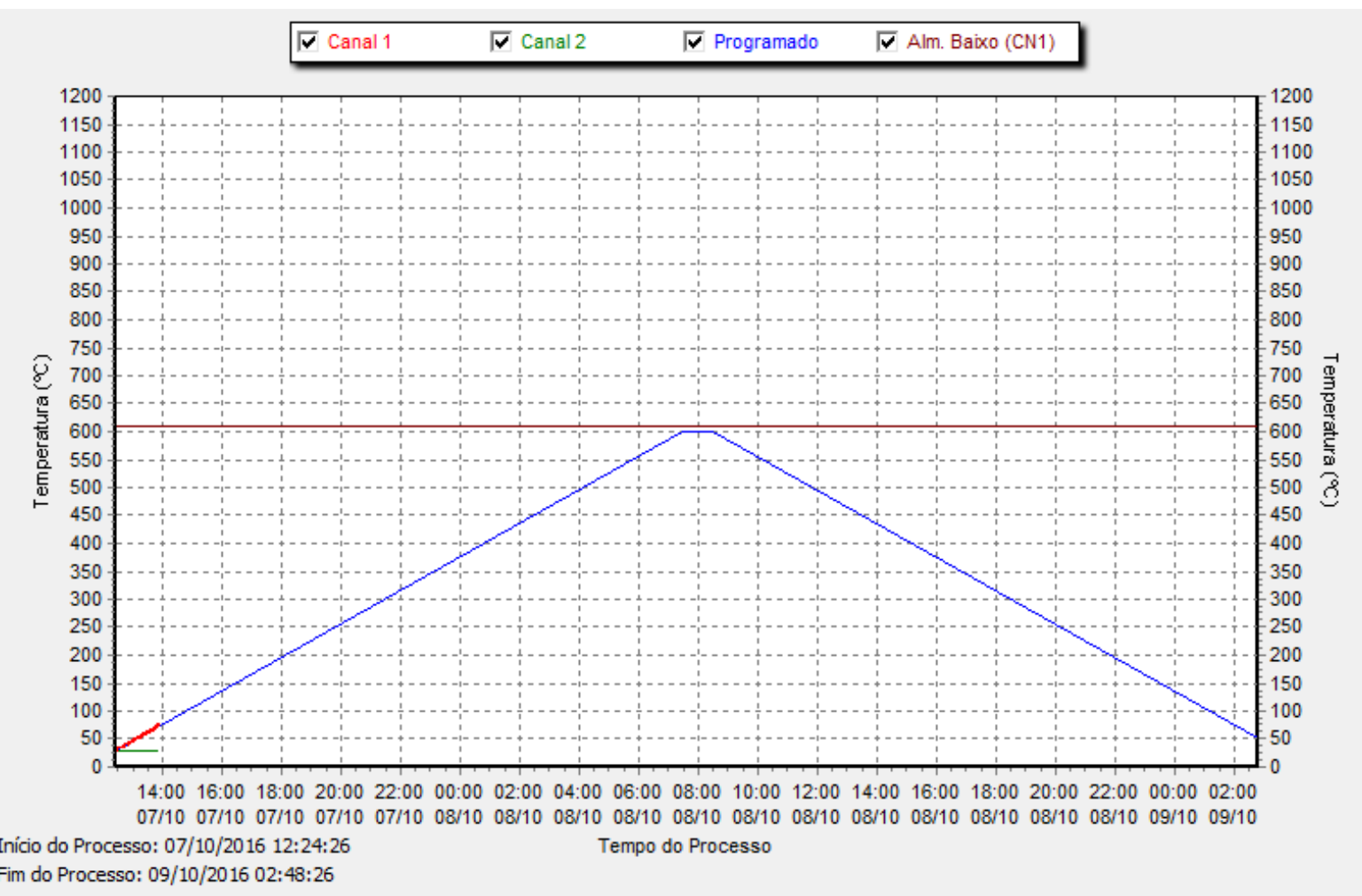

Figura 5.11. Gráfico completo da temperatura do forno: aquecimento, constante e resfriamento

Para o estudo da massa específica $(\rho)$, foram utilizados os corpos de prova indicados nas tabelas 5.2 e 5.3 .

Para o estudo da resistência à compressão $\left(\mathrm{f}_{\mathrm{c}}\right)$, do módulo de elasticidade estático $\left(E_{c}\right)$ e do módulo de elasticidade dinâmico $\left(E_{d}\right)$, foram utilizados os mesmos corpos de prova mostrados na tabela 5.2. Quatro corpos de prova foram ensaiados à temperatura ambiente e grupos de quatro corpos de prova foram ensaiados após serem submetidos a cada temperatura de $200^{\circ} \mathrm{C}, 400^{\circ} \mathrm{C}$ e $600^{\circ} \mathrm{C}$.

No ensaio de $200^{\circ} \mathrm{C}$, os corpos de prova cilíndricos ficaram aproximadamente sete horas dentro forno, já contando o ciclo completo (aquecimento, período de 60 minutos com temperatura constante e resfriamento). No ensaio de $400 \stackrel{\circ}{\mathrm{C}}$, ficaram aproximadamente 13 horas, e no ensaio de $600 \stackrel{\circ}{ }$, ficaram aproximadamente 20 horas. 
Tabela 5.2. Esquema de corpos de prova para ensaios de $f_{c}, E_{c}$ e $E_{d}$

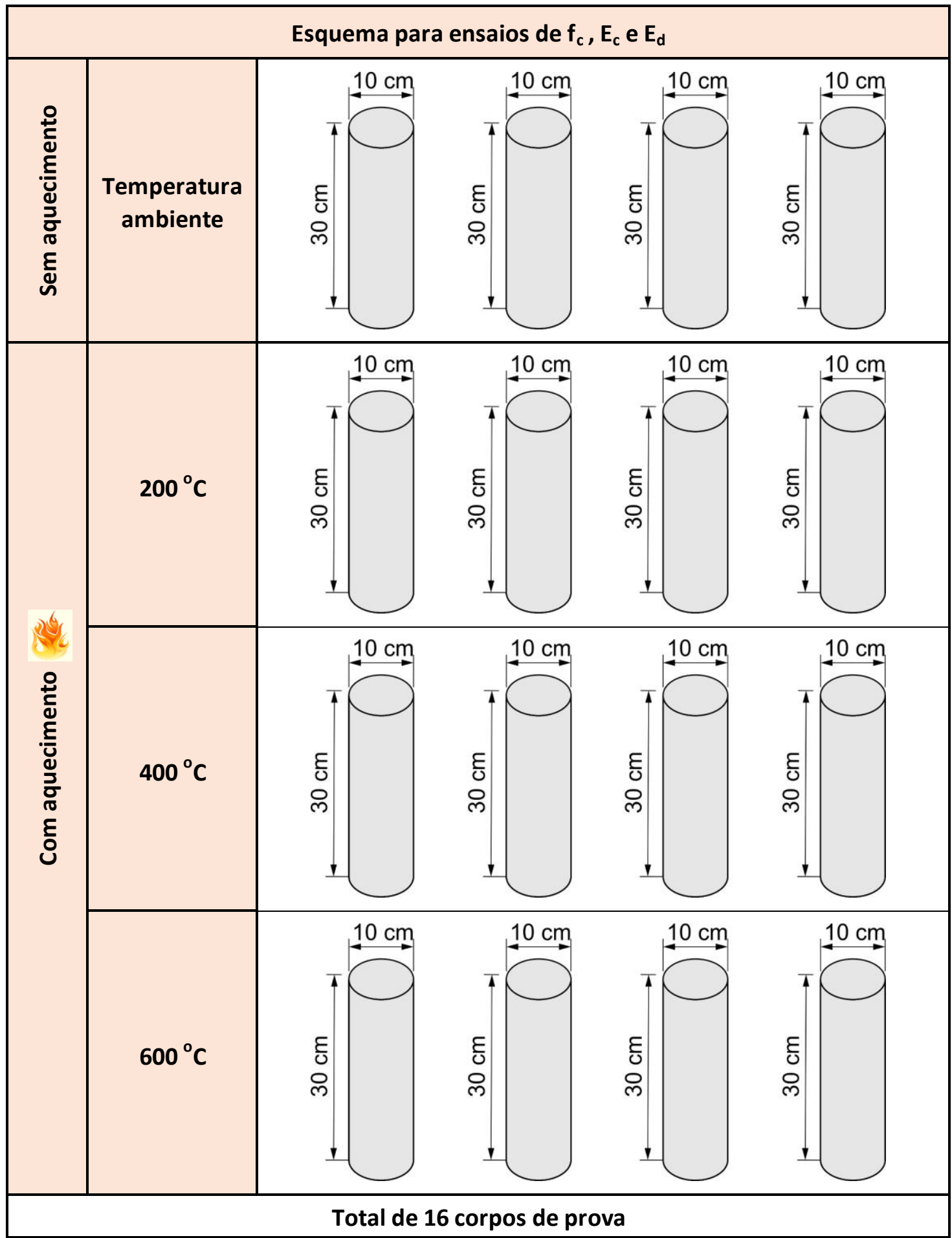

Para o estudo da resistência à tração por compressão diametral ( $\left.\mathfrak{f}_{\mathrm{ct}, \mathrm{sp}}\right)$, foram utilizados os corpos de prova indicados na tabela 5.3, seguindo o mesmo padrão de aquecimento mostrado na tabela 5.2. 
Tabela 5.3. Esquema de corpos de prova para ensaios de $\mathrm{fct}_{\mathrm{sp}}$

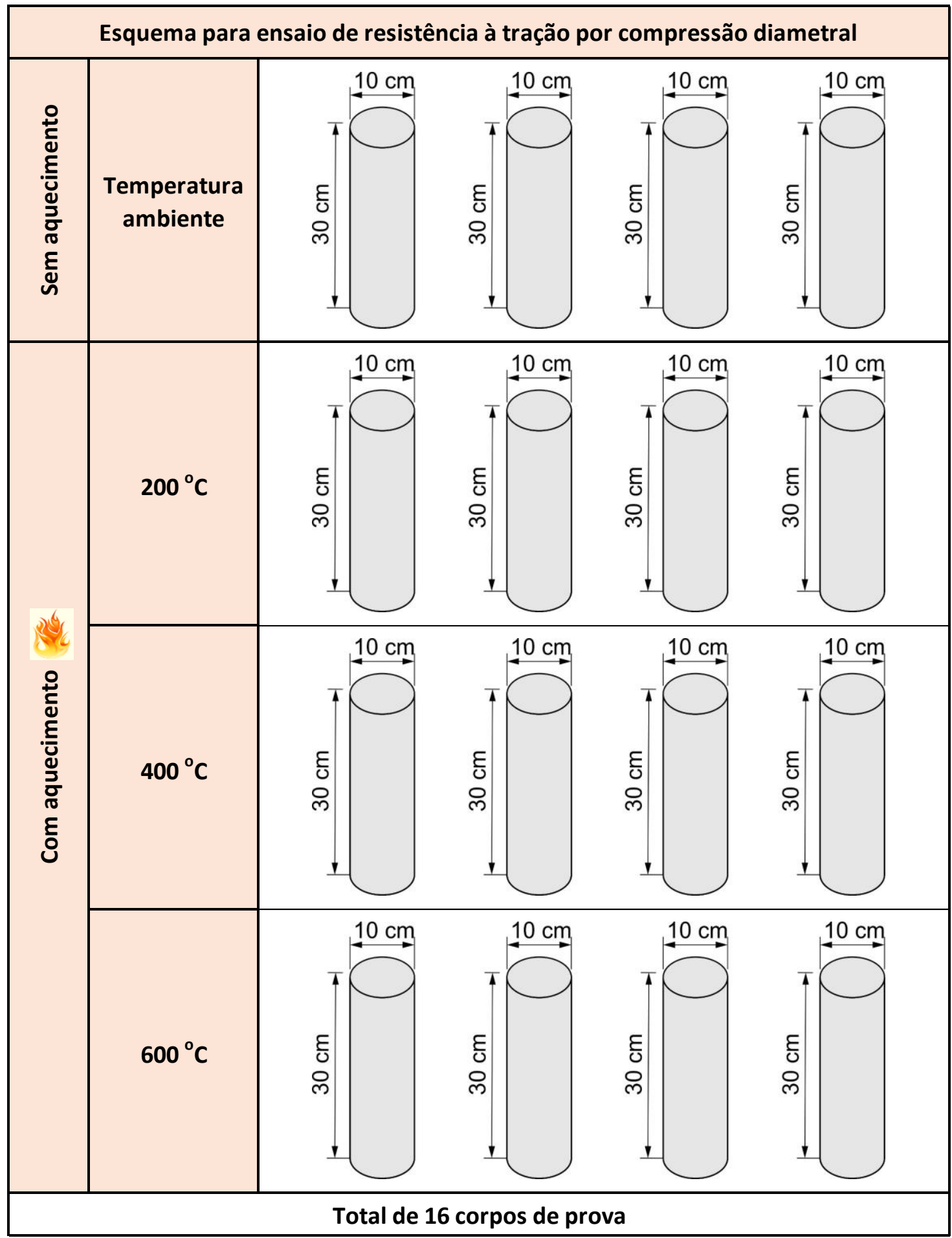

Para o estudo da resistência à tração na flexão e do fator de tenacidade, foram utilizados corpos de prova prismáticos sem fibras de aço e com fibras de aço, considerando as taxas de $0,3 \%, 0,6 \%$ e $0,9 \%$. 
Para cada um dos quatro grupos considerou-se o esquema de corpos de prova mostrado na tabela 5.4 , em que três foram ensaiados à temperatura ambiente e três após serem submetidos às temperaturas de $200{ }^{\circ} \mathrm{C}$ e $600{ }^{\circ} \mathrm{C}$. Aqui não foi considerada a temperatura de $400{ }^{\circ} \mathrm{C}$, devido à grande quantidade de prismas a mais que deveriam ser concretados, o que dificultaria o transporte para a Unicamp.

No ensaio de $200 \stackrel{\circ}{\circ}$, os corpos de prova prismáticos ficaram aproximadamente 13 horas dentro forno, e no ensaio de $600 \stackrel{\circ}{\circ}$, aproximadamente 40 horas. Vale destacar que os corpos de prova prismáticos ficaram aproximadamente o dobro do tempo dentro do forno, porque a taxa de aquecimento e resfriamento é igual à metade da utilizada para os corpos de prova cilíndricos.

Tabela 5.4. Esquema geral para ensaios com os corpos de prova prismáticos

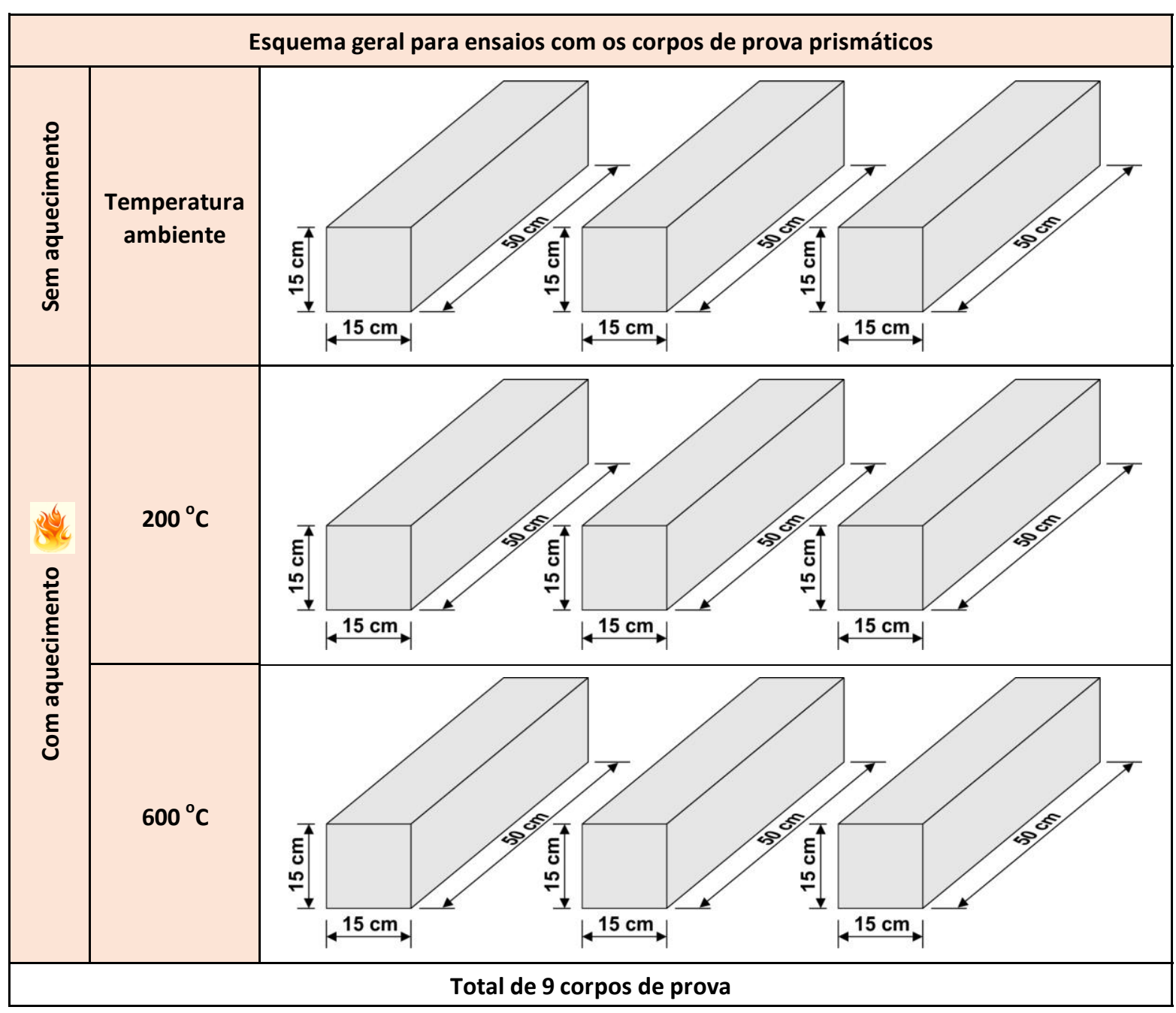

Os corpos de prova prismáticos ficaram dentro do forno na posição vertical, conforme é mostrado na figura 5.12 . 


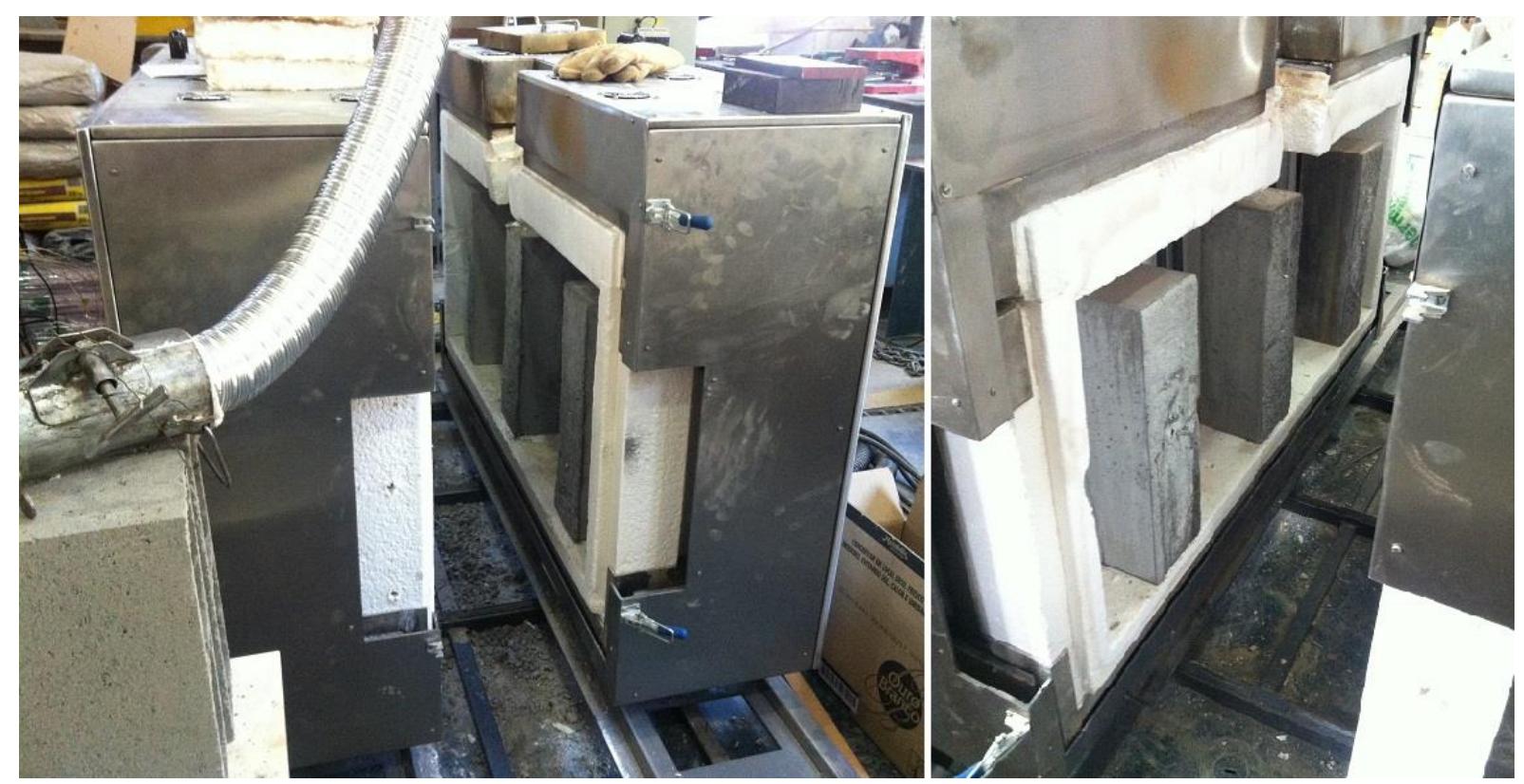

Figura 5.12. Disposição dos prismas dentro do forno.

Após a retirada dos corpos de prova do forno, todos foram embalados com filme de PVC (figura 5.13-a), para evitar absorção de umidade do ambiente e ter qualquer alteração em suas propriedades pós-aquecimento, prejudicando o objetivo desta pesquisa. Os corpos de prova embalados com o filme de PVC podem ser vistos nas figuras 5.13-b e 5.13-c.

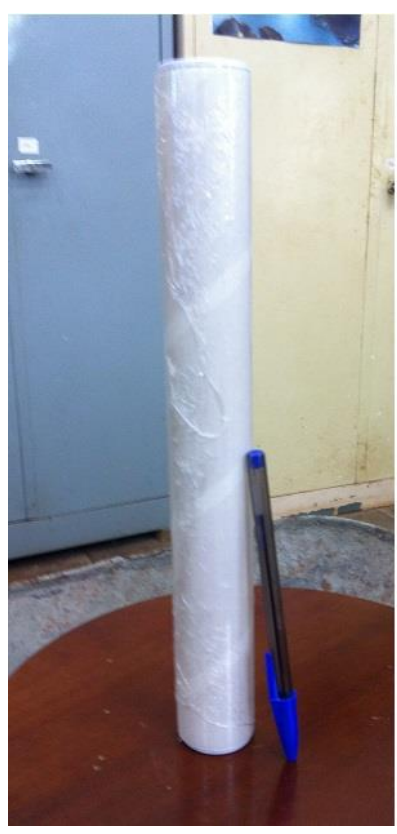

(a)

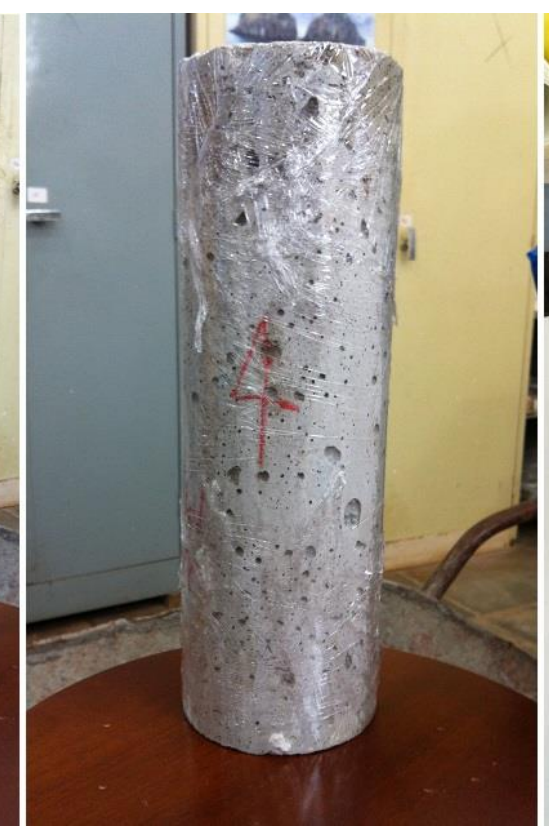

(b)

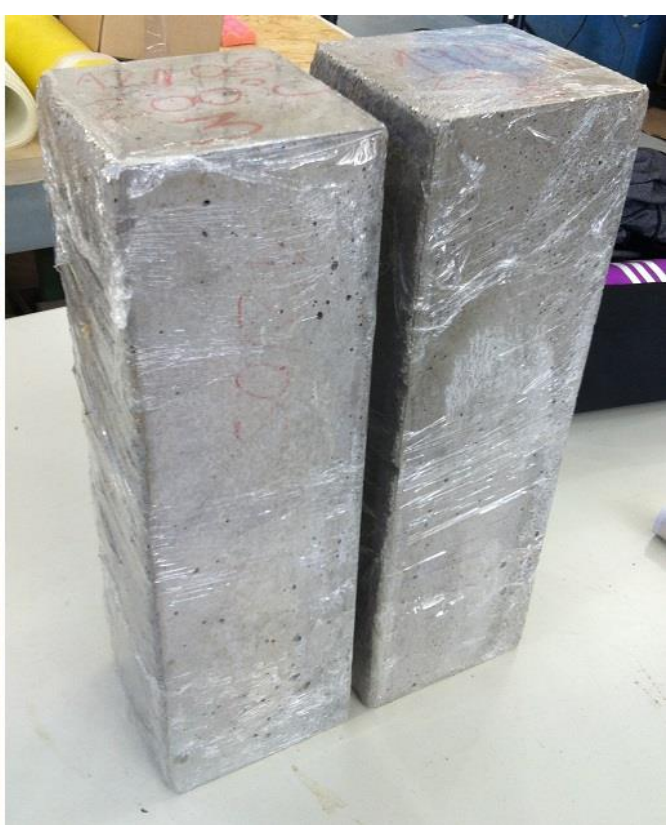

(c)

Figura 5.13. (a) Filme de PVC, (b) cilindro com o filme de PVC e (c) prisma com o filme de PVC. 
Inicialmente, pretendia-se também estudar o aquecimento dos corpos de prova cilíndricos a $800^{\circ} \mathrm{C}$. Porém, por um pequeno problema de excesso de fumaça resultante da queima do EPS, o forno teve de ser desligado no meio do ensaio de $600^{\circ} \mathrm{C}$ e, infelizmente, isso ocasionou na perda de oito corpos de prova cilíndricos.

O problema iniciou no ensaio de $400^{\circ} \mathrm{C}$, em que o forno era completamente fechado. A fumaça começou a sair de dentro do forno quando a temperatura atingiu por volta dos $300^{\circ} \mathrm{C}$, e ficou saindo aos poucos até que se atingiu a temperatura de $400 \stackrel{\circ}{ } \mathrm{C}$, incomodando todos que estavam presentes no laboratório.

Para tentar solucionar esse problema, no ensaio seguinte de $600 \stackrel{\circ}{C}$ foi colocado, na parte superior do forno, um tubo corrugado flexível com $80 \mathrm{~mm}$ de diâmetro, conforme mostrado na figura 5.14. Esse tubo era conectado a um exaustor que levava a fumaça para o telhado. O furo no forno onde o tubo foi encaixado já existia. Ele foi projetado para dar passagem ao dispositivo que iria carregar uma possível viga ensaiada durante o aquecimento. Porém, ocorreu um problema que já se sabia que poderia acontecer. Quando a temperatura atingiu em torno de $300{ }^{\circ} \mathrm{C}$, o tubo derreteu e a fumaça se espalhou por todo o laboratório, sendo necessário desligar o forno, ocasionando a perda desses corpos de prova.

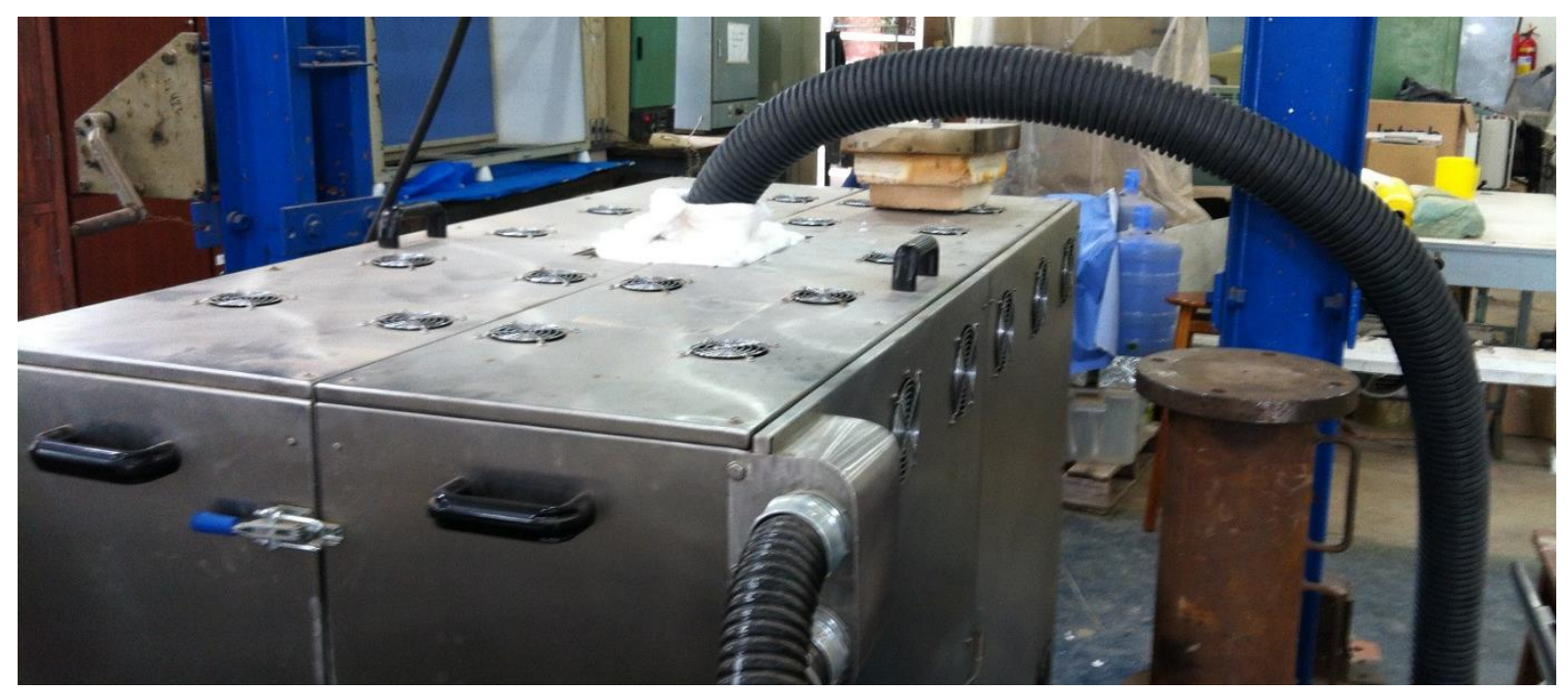

Figura 5.14. Tubo corrugado flexível colocado na parte superior do forno.

Devido ao susto causado por esse problema, não se lembrou de tirar fotos para registrar o fato ocorrido. 
No encontro do tubo corrugado flexível com o forno, foi utilizada lã de vidro, que impede a passagem de calor por ser um excelente isolante térmico. Esse detalhe também pode ser visto na mesma figura 5.14 .

A lã de vidro tem uma textura muito parecida com a do algodão, conforme pode ser visto na figura 5.15 .

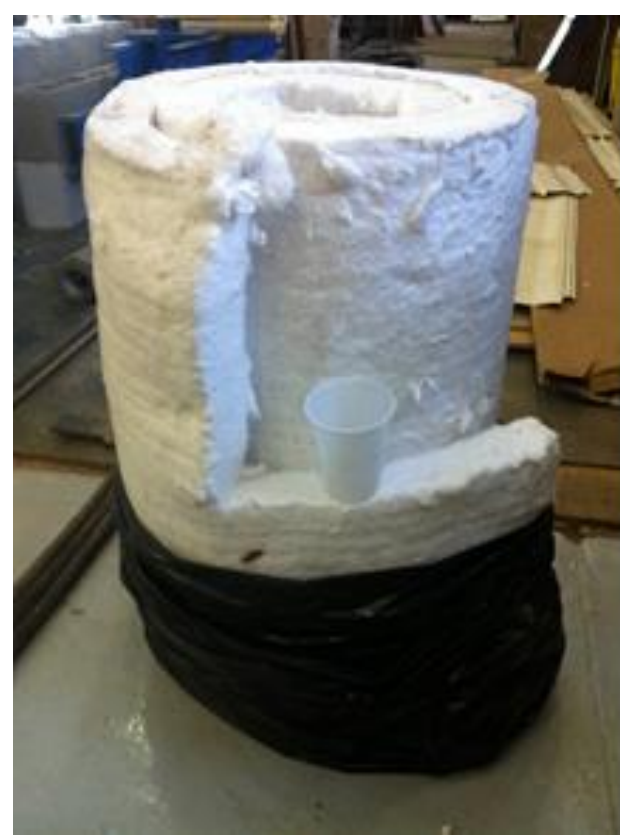

(a)

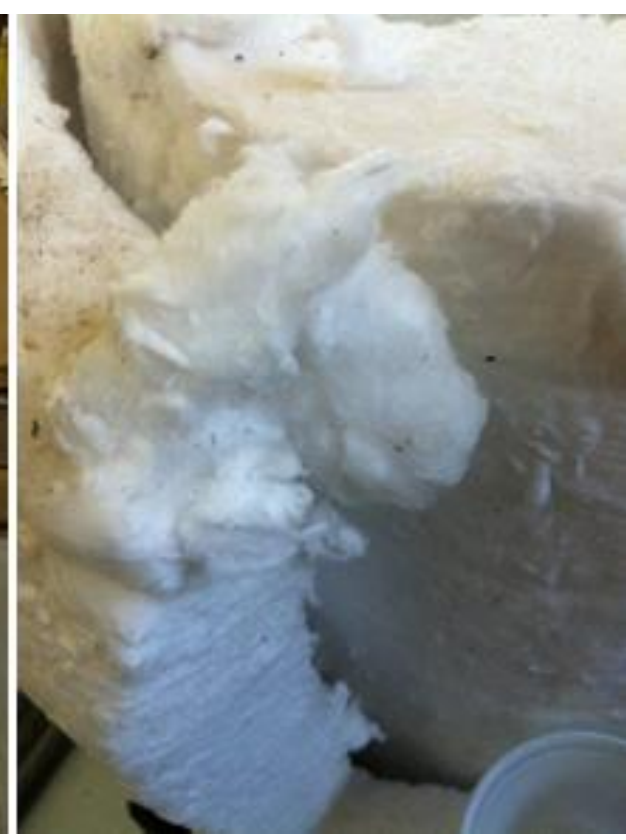

(b)

Figura 5.15. Lã de vidro: (a) rolo; (b) imagem ampliada.

Na sequência, procurou-se um tubo de outro material, e não foi encontrado nenhum que resistisse à temperatura de $600^{\circ} \mathrm{C}$. $\mathrm{O}$ único que chegou mais perto disso foi o duto semidec semiflexível, feito de alumínio, com $76 \mathrm{~mm}$ de diâmetro, em que a temperatura máxima de trabalho era de $250 \stackrel{\circ}{ } \mathrm{C}$. Foi feita uma improvisação, colocando o duto encaixado no tronco de cone do "slump test", conforme mostrado na figura 5.16.

Essa solução improvisada resolveu perfeitamente o problema, e foi possível continuar com todos os outros ensaios.

Para filtrar a fumaça gerada, usou-se, dentro do exaustor, o filtro de carvão ativado FXS Carbo, com as dimensões de $45 \mathrm{~cm} \times 45 \mathrm{~cm} \times 5 \mathrm{~cm}$, conforme mostrado na figura 5.17. 


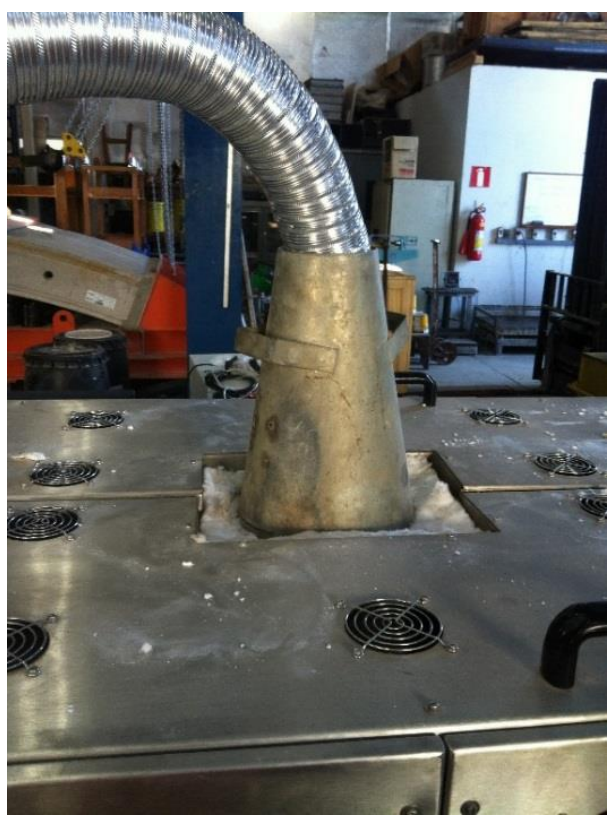

Figura 5.16. Duto semidec $(76 \mathrm{~mm})$ semiflexível feito de alumínio.

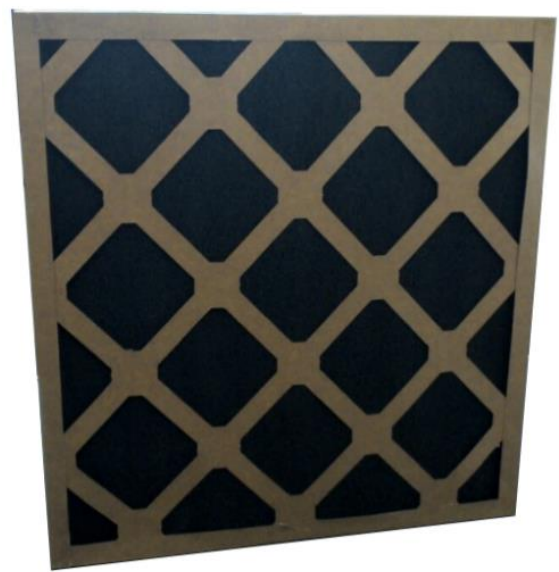

Figura 5.17. Filtro de carvão ativado FXS Carbo.

\subsection{Características dos materiais utilizados}

\subsubsection{Cimento}

O cimento utilizado foi o CP V-ARI, especificado pela ABNT NBR 5733:1191. Pode-se observar a embalagem do cimento na figura 5.18, e as características físicas e químicas na tabela 5.5. 


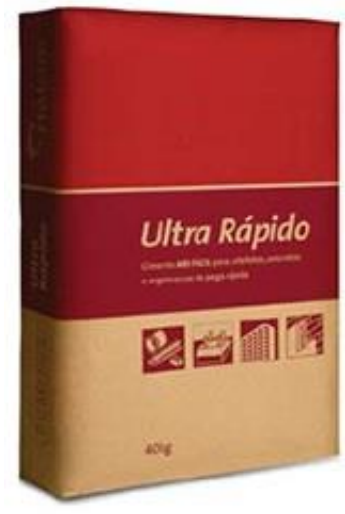

Figura 5.18. Cimento utilizado - CP V-ARI FÁCIL.

Tabela 5.5. Características físicas e químicas do cimento CP V-ARI.

\begin{tabular}{|c|c|c|c|}
\hline CARACTERÍSTICAS & MÉDIA & CARACTERÍSTICAS & MÉDIA \\
\hline \# 400 (\%) & 2,20 & R.I. (\%) & 0,84 \\
\hline Blaine $\left(\mathrm{cm}^{2} / \mathrm{g}\right)$ & 4759 & $\mathrm{Al}_{2} \mathrm{O}_{3}(\%)$ & 4,87 \\
\hline Início Pega (min) & 123 & $\mathrm{Fe}_{2} \mathrm{O}_{3}(\%)$ & 2,96 \\
\hline Fim Pega (min) & 178 & $\mathrm{CaO}(\%)$ & 63,64 \\
\hline R 1 dia (MPa) & 29 & MgO (\%) & 0,72 \\
\hline R 3 dias (MPa) & 41,9 & $\mathrm{SO}_{3}(\%)$ & 3,00 \\
\hline R 7 dias (MPa) & 46,6 & $\mathrm{CO}_{2}(\%)$ & 2,55 \\
\hline R 28 dias (MPa) & 54,8 & $\mathrm{~K}_{2} \mathrm{O}(\%)$ & 0,79 \\
\hline PF $1000^{\circ} \mathrm{C}(\%)$ & 3,61 & PF $500{ }^{\circ} \mathrm{C}(\%)$ & 0,83 \\
\hline $\mathrm{SiO}_{2}(\%)$ & 19,27 & $\mathrm{C}_{3} \mathrm{~A}$ (Teórico) (\%) & 7,66 \\
\hline
\end{tabular}

\subsubsection{Areia}

A areia utilizada neste trabalho foi seca em estufa e apresentou a classificação granulométrica mostrada na tabela 5.6. 
Tabela 5.6. Granulometria da areia média.

\begin{tabular}{c|c|c|c}
\hline Peneira (mm) & Peso retido $(\mathbf{g})$ & \% retido & \% retido acumulado \\
\hline 9,5 & 0 & 0 & 0 \\
\hline 6,3 & 0 & 0 & 0 \\
\hline 4,75 & 0 & 0 & 0 \\
\hline 2,36 & 67,7 & 6,03 & 6,03 \\
\hline 1,18 & 139,7 & 12,44 & 18,47 \\
\hline 0,60 & 307,0 & 27,34 & 45,82 \\
\hline 0,30 & 372,6 & 33,19 & 79,01 \\
\hline 0,15 & 203,4 & 18,12 & 97,12 \\
\hline 0,075 & 25,1 & 2,24 & 99,36 \\
\hline Resíduo & 7,2 & 0,64 & 100 \\
\hline Somatório & $\mathbf{1 . 1 2 2 , 7}$ & $\mathbf{1 0 0}$ & \\
\hline
\end{tabular}

\subsubsection{EPS}

As pérolas de EPS utilizadas são do tipo T5F, retardante à chama, de acordo com a ABNT NBR 11752:2007. Elas podem ser vistas na figura 5.19.

O diâmetro das pérolas era menor que $4,75 \mathrm{~mm}$ e elas apresentaram a classificação granulométrica mostrada na tabela 5.7.

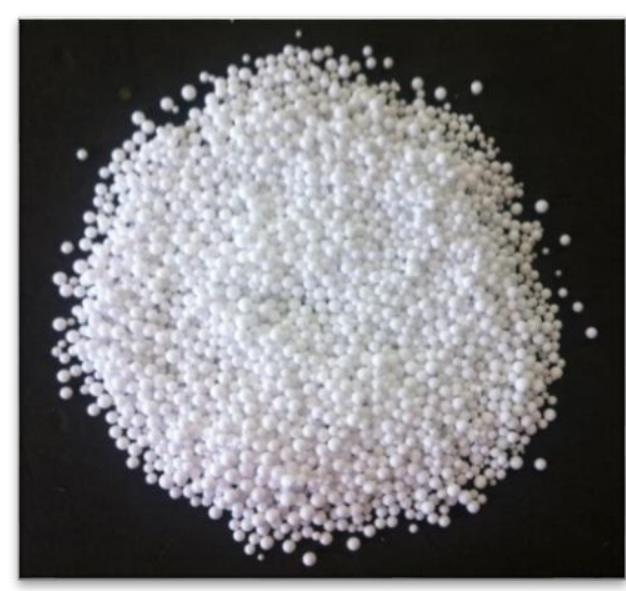

Figura 5.19. Pérolas de EPS. 
Tabela 5.7. Granulometria das pérolas de EPS.

\begin{tabular}{c|c|c|c}
\hline Peneira (mm) & Peso retido $(\mathbf{g})$ & \% retido & \% retido acumulado \\
\hline 4,75 & 0 & 0 & 0 \\
\hline 2,36 & 16,33 & 76,24 & 76,24 \\
\hline 1,18 & 4,90 & 22,88 & 99,11 \\
\hline 0,60 & 0,17 & 0,79 & 99,91 \\
\hline 0,30 & 0,02 & 0,09 & 100 \\
\hline 0,15 & 0,00 & 0 & 100 \\
\hline 0,075 & 0,00 & 0 & 100 \\
\hline Resíduo & 0,00 & 0 & 100 \\
\hline Somatório & $\mathbf{2 1 , 4}$ & $\mathbf{1 0 0}$ & \\
\hline
\end{tabular}

\subsubsection{Superplastificante}

O superplastificante utilizado foi o PLASTOL ${ }^{\circledR} 4685$ do tipo II, da marca Viapol (figura 5.20). É um aditivo para concreto, líquido, pronto para o uso e não contém cloretos. É composto por policarboxilatos de altíssimo desempenho, que possuem grande poder de dispersão, aumentando fortemente a trabalhabilidade. Possui cor amarelada e massa específica aproximadamente igual a $1,1 \mathrm{~g} / \mathrm{cm}^{3}$.

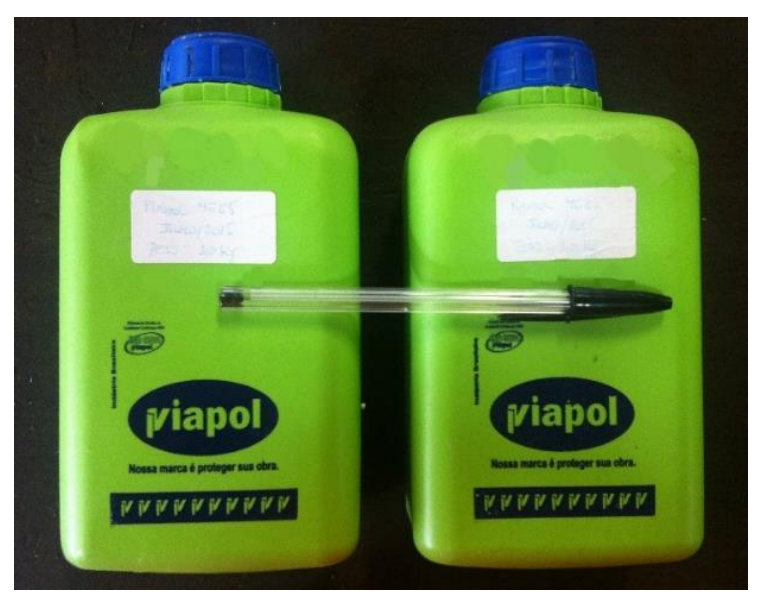

Figura 5.20. Superplastificante da marca Viapol 


\subsubsection{Fibras de aço}

As fibras utilizadas foram do tipo FS8, que são produzidas a partir de aço de baixo teor de carbono, trefilado a frio. Elas podem ser vistas na figura 5.21.

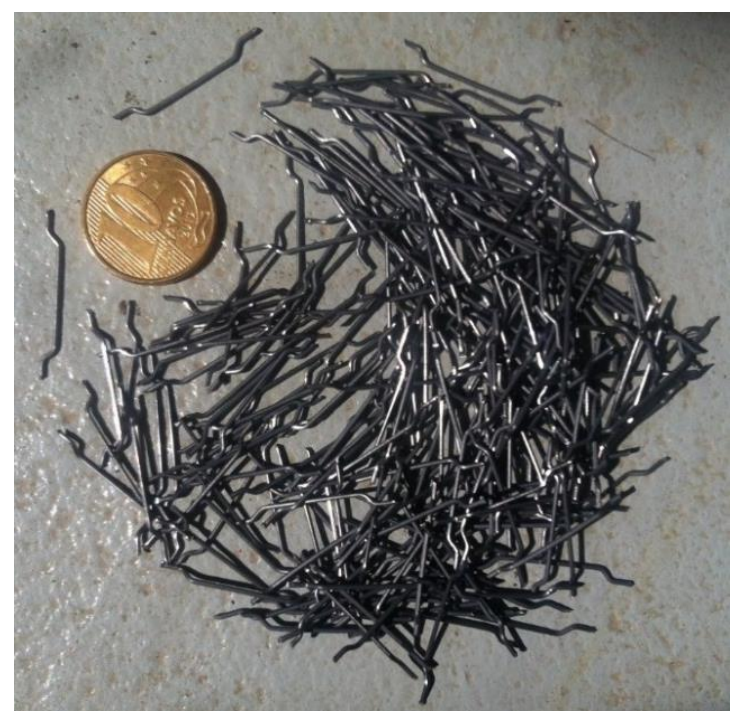

Figura 5.21. Fibras de aço

As características da fibra utilizada encontram-se na tabela 5.8.

Tabela 5.8. Propriedades físicas e mecânicas das fibras FS8 Wirand.

\begin{tabular}{l|c}
\hline \multicolumn{1}{c|}{ Propriedades } & FS8 \\
\hline Fator de forma (comprimento / diâmetro) & 33 \\
\hline Diâmetro & $0,75 \mathrm{~mm}$ \\
\hline Comprimento & $25 \mathrm{~mm}$ \\
\hline Resistência à tração do aço & $>1100 \mathrm{MPa}$ \\
\hline Deformação na ruptura & $<4 \%$ \\
\hline Módulo de elasticidade & $210000 \mathrm{MPa}$ \\
\hline Peso específico & $7850 \mathrm{~kg} / \mathrm{m}^{3}$ \\
\hline
\end{tabular}




\subsection{Corpos de prova}

Foram moldados ao todo 24 corpos de prova cilíndricos com $10 \mathrm{~cm} \times 20 \mathrm{~cm}$, para medir a resistência à compressão aos 28 e aos 100 dias, 40 corpos de prova cilíndricos com $10 \mathrm{~cm} \times 30 \mathrm{~cm}$ e 36 corpos de prova prismáticos com $15 \mathrm{~cm} \times 15 \mathrm{~cm} \times 50 \mathrm{~cm}$, para fazer o estudo específico das propriedades do concreto leve com EPS após situação de incêndio.

Para o controle da temperatura, ao serem inseridos dentro do forno, foram utilizados termopares tipo k (ver figura 5.22), que foram soldados na extremidade que fica em contato com o concreto, com um equipamento elétrico, utilizando uma placa de cobre (ver figura 5.23).

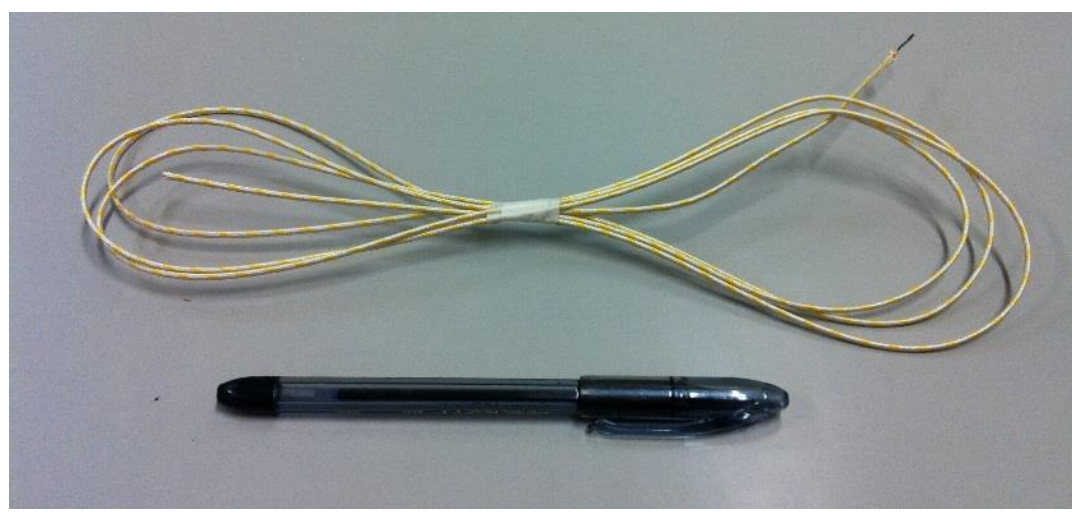

Figura 5.22. Termopar tipo $\mathrm{K}$

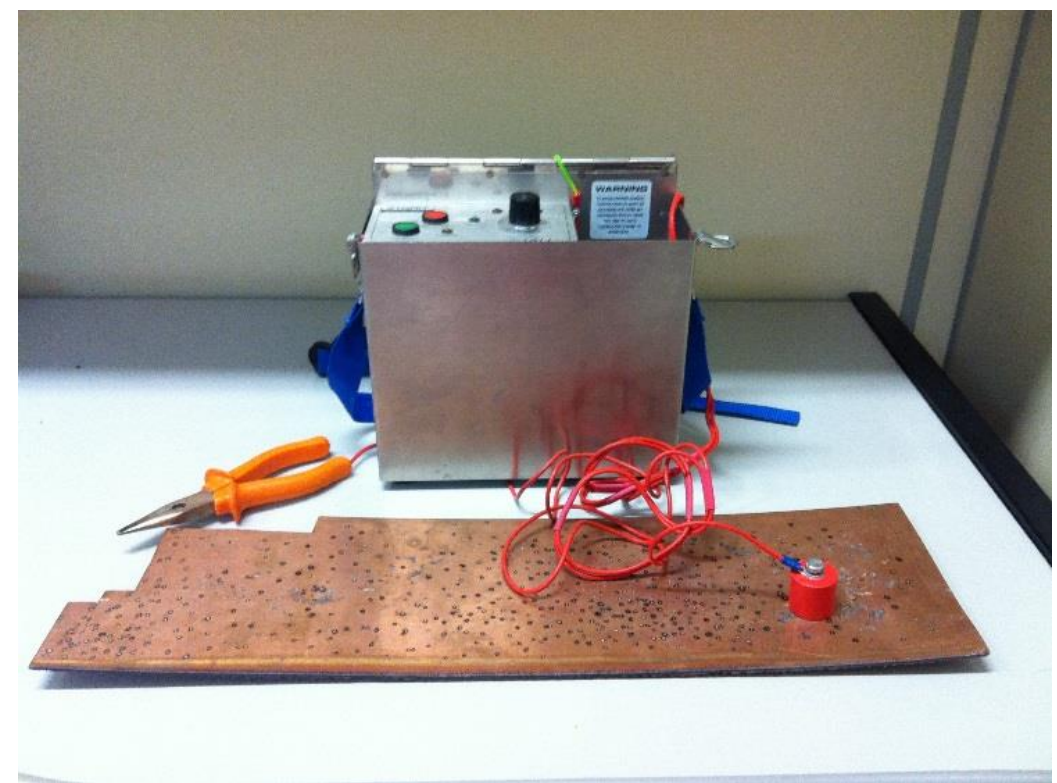

Figura 5.23. Máquina de solda e placa de cobre. 
Os termopares foram inseridos nos corpos de prova durante a concretagem, em posições pré-estabelecidas, conforme podem ser vistas na figura 5.24, para os cilindros, e na figura 5.25, para os prismas. O termopar 1 , no cilindro, foi inserido $5 \mathrm{~cm}$, chegando até o eixo, e o termopar 2 foi inserido apenas $2,5 \mathrm{~cm}$. No caso do prisma, todos os termopares foram inseridos $7,5 \mathrm{~cm}$, chegando até o meio da seção transversal. Eles foram colocados apenas nos corpos de prova que foram ensaiados na temperatura de $600^{\circ} \mathrm{C}$, por ser a maior temperatura considerada neste trabalho. Nas outras temperaturas, foram utilizados apenas os termopares de controle, que ficam na parte interna do forno.

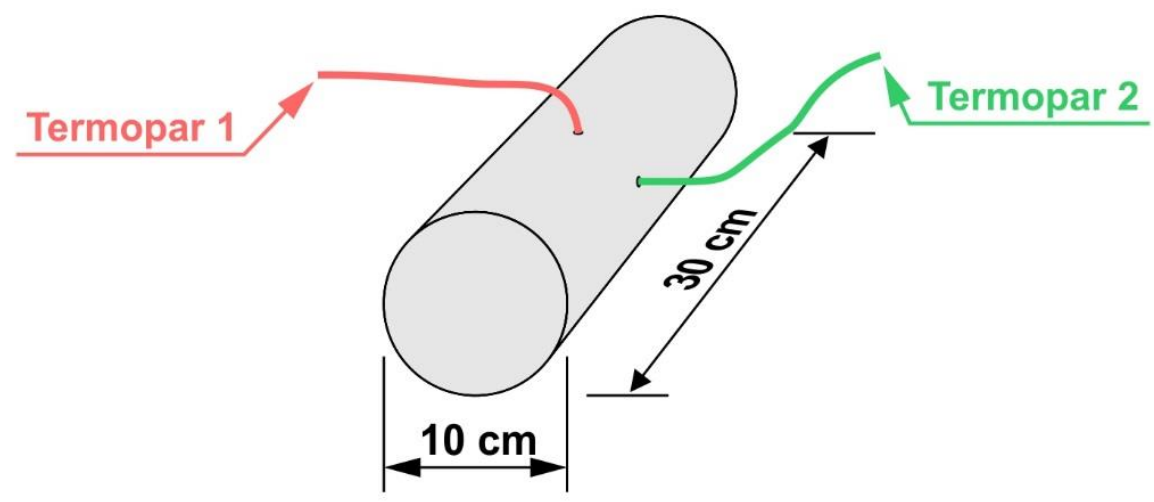

Figura 5.24. Posição dos termopares nos cilindros de concreto.

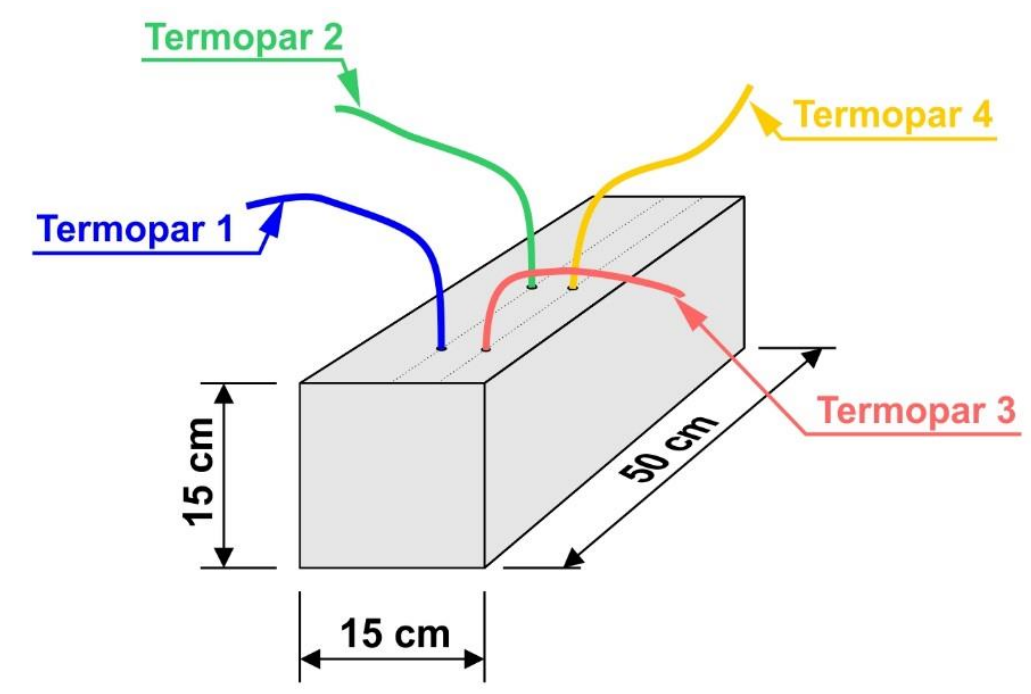

Figura 5.25. Posição dos termopares nos prismas de concreto.

O processo de produção de cada um dos corpos de prova está descrito nos itens a seguir. 


\subsubsection{Produção dos corpos de prova cilíndricos e prismáticos}

Para a produção dos corpos de prova cilíndricos com $10 \mathrm{~cm} \times 20 \mathrm{~cm}$, foram utilizadas formas metálicas, como pode ser visto na figura 5.26-a. Como o Laboratório de Estruturas da EESC-USP não dispunha de formas metálicas cilíndricas nas dimensões de $10 \mathrm{~cm} \times 30 \mathrm{~cm}$, foram confeccionadas formas especiais. Foram comprados três tubos de PVC de diâmetro $100 \mathrm{~mm}$, que foram cortados em pedaços de $30 \mathrm{~cm}$ de comprimento, na Oficina Mecânica da EESC. Para fechar a parte inferior da forma, foram utilizados tampões, também de PVC, como pode ser visto na figura 5.26-b.

Para os corpos de prova prismáticos com $15 \mathrm{~cm} \times 15 \mathrm{~cm} \times 50 \mathrm{~cm}$, foram utilizadas as formas metálicas mostradas na figura 5.27 .

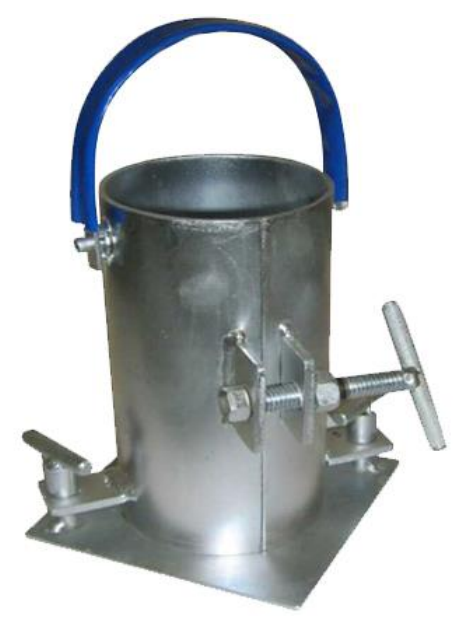

(a)

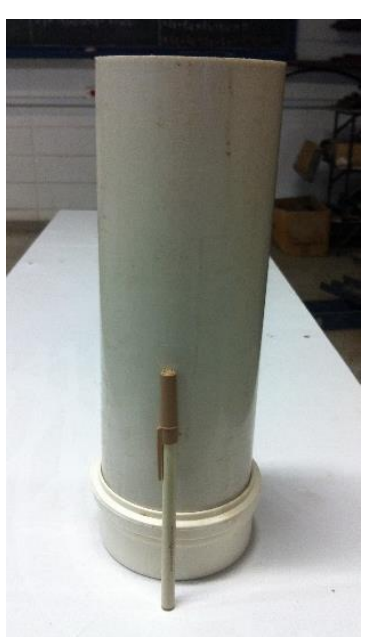

(b)

Figura 5.26. Formas dos corpos de prova cilíndricos (a) com $10 \mathrm{~cm} \times 20 \mathrm{~cm}$ e (b) $\operatorname{com} 10 \mathrm{~cm} \times 30 \mathrm{~cm}$.

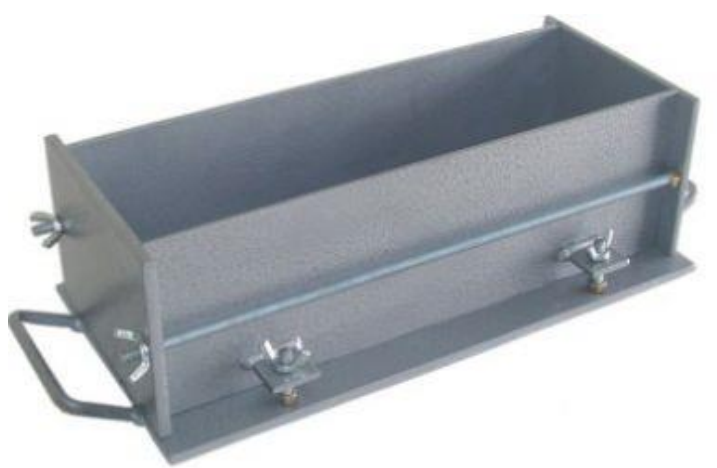

Figura 5.27. Formas dos corpos de prova prismáticos com $15 \mathrm{~cm} \times 15 \mathrm{~cm} \times 50 \mathrm{~cm}$. 
Todos os traços do concreto foram feitos no misturador de 350 litros, mostrado na figura 5.28. Na moldagem de todos os corpos de prova, cilíndricos e prismáticos, foi usada vibração mecânica, em mesa vibratória, com um baixo nível de vibração para evitar segregação, pois o EPS é bastante leve. Dessa maneira, a distribuição do EPS tende a ficar mais homogênea na mistura. Lembra-se que inicialmente foi misturada a areia, o EPS e a água, e logo após foram colocados os outros materiais, sequência que também evita que haja segregação, pelo mesmo motivo já mencionado.

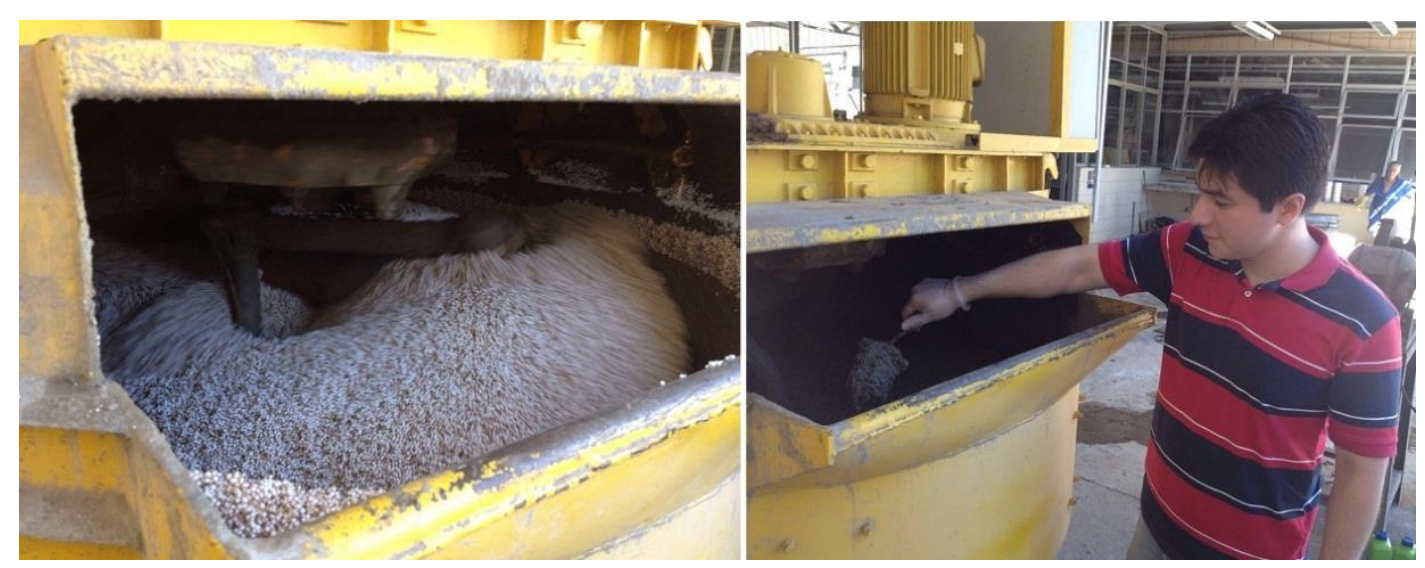

Figura 5.28. Misturador de 350 litros.

Todos os corpos de prova foram desmoldados no dia seguinte ao da concretagem, e colocados em câmara úmida por 100 dias, pois é onde ocorre, praticamente, a estabilização dos incrementos das propriedades mecânicas do concreto em função da idade. E também por recomendação da RILEM TC 200-HTC e da RILEM TC 129-MHT, as quais orientam que todos os ensaios sejam realizados com corpos de prova com pelo menos 90 dias de idade.

A trabalhabilidade dos traços foi avaliada por meio do abatimento do tronco de cone (figura 5.29-a), e em um deles, em que o abatimento teve um valor muito alto, foi feita avaliação também pelo ensaio de espalhamento (figura 5.29-b). 


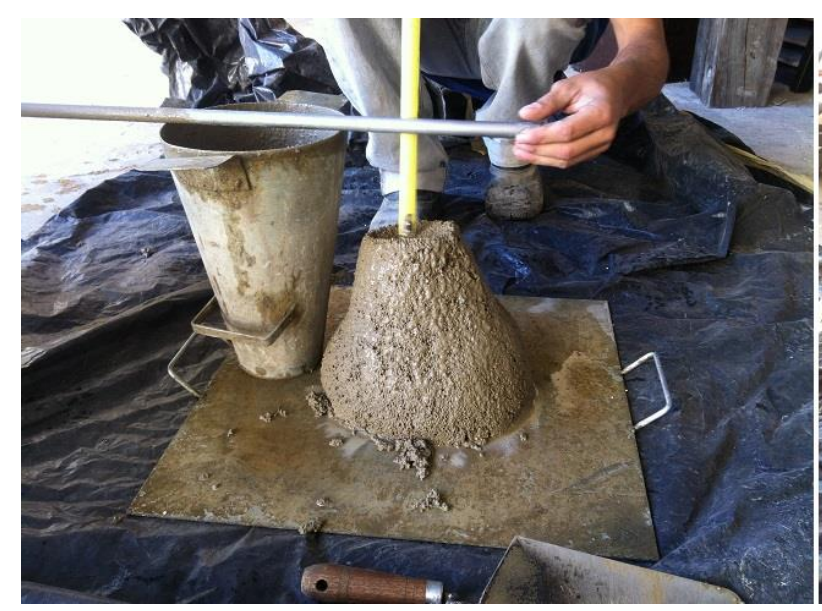

(a)

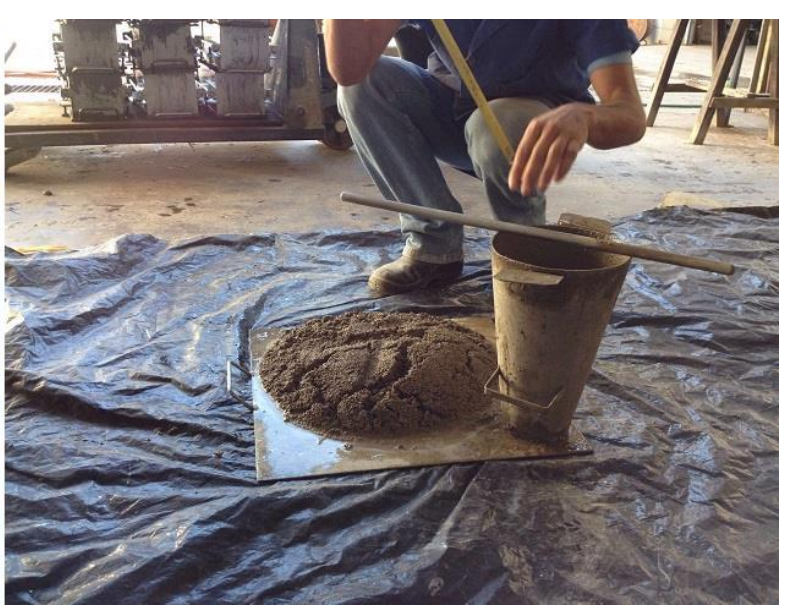

(b)

Figura 5.29. (a) Ensaio do tronco de cone e (b) caso em que se avaliou o espalhamento.

$\mathrm{Na}$ tabela 5.9, pode-se ver algumas propriedades dos quatro traços estudados nesta pesquisa, que são variações do traço padrão (TP).

Tabela 5.9. Propriedades dos traços estudados nesta pesquisa.

\begin{tabular}{c|c|c|c}
\hline Traços & Abatimento $(\mathbf{c m})$ & Espalhamento $(\mathbf{c m})$ & $\begin{array}{c}\text { Consumo de } \\
\text { cimento }\left(\mathbf{k g} / \mathbf{m}^{3}\right)\end{array}$ \\
\hline TP sem fibras & 13,62 & - & 630 \\
\hline TP + 0,3\% fibras & 11,83 & - & 630 \\
\hline TP + 0,6\% fibras & 23,50 & 47 & 630 \\
\hline TP + 0,9\% fibras & 12,25 & - & 630 \\
\hline
\end{tabular}

Nos resultados que serão analisados no capítulo 6, será observado que o traço padrão com $0,6 \%$ de fibras gerou vários resultados incoerentes. Um dos motivos pode ter sido uma pequena falha na dosagem do superplastificante, devido ao grande volume de concretagem, pois foram concretados corpos de prova para duas pesquisas de doutorado.

Nas tabelas 5.10, 5.11, 5.12 e 5.13, encontram-se as cargas máximas (C.M) e as resistências $(R)$ aos 28 e aos 100 dias, dos quatros traços. Para esses ensaios foram utilizados 24 corpos de prova cilíndricos com $10 \mathrm{~cm}$ x $20 \mathrm{~cm}$. 
Vale ressaltar que a massa específica do concreto leve com EPS é algo em torno de $1170 \mathrm{~kg} / \mathrm{m}^{3}$. Por isso a resistência ficou abaixo da informada no ACl 213R-87 (1999), no qual a resistência à compressão aos 28 dias deve ser superior a $17 \mathrm{MPa}$ e a massa específica, menor ou igual a $1850 \mathrm{~kg} / \mathrm{m}^{3}$. Essa resistência mínima de $17 \mathrm{MPa}$ se aplica a concretos em que os agregados têm função resistente, o que não é o caso do concreto com EPS.

Tabela 5.10. Carga máxima $(C M)$ e resistência $(R)$ do traço padrão, aos 28 e 100 dias.

\begin{tabular}{c|c|c|c|c}
\hline CP's & CM 28 (kN) & R28 (MPa) & CM 100 (kN) & R100 (MPa) \\
\hline CP1 & 107,60 & 13,70 & 114,70 & 14,61 \\
\hline CP2 & 107,80 & 13,72 & 116,20 & 14,79 \\
\hline CP3 & 106,70 & 13,59 & 114,60 & 14,59 \\
\hline MÉDIA & $\mathbf{1 0 7 , 3 7}$ & $\mathbf{1 3 , 6 7}$ & $\mathbf{1 1 5 , 1 7}$ & $\mathbf{1 4 , 6 6}$ \\
\hline
\end{tabular}

Tabela 5.11. Carga máxima (CM) e resistência (R) do traço com 0,3\% de fibra, aos 28 e 100 dias.

\begin{tabular}{c|c|c|c|c}
\hline CP's & CM 28 (kN) & R28 (MPa) & CM 100 (kN) & R100 (MPa) \\
\hline CP1 & 113,20 & 14,41 & 112,60 & 14,33 \\
\hline CP2 & 115,00 & 14,65 & 113,60 & 14,47 \\
\hline CP3 & 120,20 & 15,30 & 119,50 & 15,22 \\
\hline MÉDIA & $\mathbf{1 1 6 , 1 3}$ & $\mathbf{1 4 , 7 9}$ & $\mathbf{1 1 5 , 2 3}$ & $\mathbf{1 4 , 6 7}$ \\
\hline
\end{tabular}

Tabela 5.12. Carga máxima $(C M)$ e resistência $(R)$ do traço com $0,6 \%$ de fibra, aos 28 e 100 dias.

\begin{tabular}{c|c|c|c|c}
\hline CP's & CM 28 (kN) & R28 (MPa) & CM 100 (kN) & R100 (MPa) \\
\hline CP1 & 87,90 & 11,19 & 119,40 & 15,20 \\
\hline CP2 & 96,30 & 12,26 & 102,00 & 12,99 \\
\hline CP3 & 90,30 & 11,50 & 106,60 & 13,57 \\
\hline MÉDIA & $\mathbf{9 1 , 5 0}$ & $\mathbf{1 1 , 6 5}$ & $\mathbf{1 0 9 , 3 3}$ & $\mathbf{1 3 , 9 2}$ \\
\hline
\end{tabular}


Tabela 5.13. Carga máxima $(C M)$ e resistência $(R)$ do traço com $0,9 \%$ de fibra, aos 28 e 100 dias.

\begin{tabular}{c|c|c|c|c}
\hline CP's & CM 28 (kN) & R28 (MPa) & CM 100 (kN) & R100 (MPa) \\
\hline CP1 & 115,00 & 14,65 & 129,80 & 16,53 \\
\hline CP2 & 112,90 & 14,38 & 138,90 & 17,69 \\
\hline CP3 & 111,80 & 14,24 & 133,20 & 16,96 \\
\hline MÉDIA & $\mathbf{1 1 3 , 2 3}$ & $\mathbf{1 4 , 4 2}$ & $\mathbf{1 3 3 , 9 7}$ & $\mathbf{1 7 , 0 6}$ \\
\hline
\end{tabular}

\subsubsection{Transporte dos corpos de prova para Unicamp}

Todos os corpos de prova foram transportados de São Carlos para a UNICAMP usando o serviço pago de transporte da Escola de Engenharia de São Carlos - EESC, usando uma caminhonete.

Cada corpo de prova foi embalado de forma individualizada, com três camadas de plástico-bolha, e colocado na caçamba de forma estratégica, para evitar que ficassem espaços entre eles.

Inicialmente, pretendia-se transportar todos os corpos de prova em um caminhão. Porém, percebeu-se que a vibração poderia ser muito grande durante o percurso, pois o caminhão é bem mais instável que a caminhonete. Por isso, todos os corpos de prova foram retirados do caminhão e colocados na caminhonete.

$\mathrm{Na}$ volta, os corpos de prova também foram embalados com três camadas de plástico-bolha e transportados no porta-malas e no banco traseiro de um automóvel, em três viagens, em dias diferentes. Um rolo de $100 \mathrm{~m}$ de plástico-bolha foi o suficiente, para a ida e a volta. 



\section{RESULTADOS E ANÁLISE}

Neste capítulo, serão apresentados os resultados da parte experimental e sua respectiva análise. Todos os ensaios foram realizados no laboratório do departamento de Engenharia de Estruturas da Escola de Engenharia de São Carlos.

Em todos os gráficos apresentados, apenas por simplificação, a temperatura ambiente, em torno de $28^{\circ} \mathrm{C}$, foi representada pelo número 0 (zero).

\subsection{Massa específica ( $\rho)$}

Nas tabelas 6.1, 6.2 e 6.3, pode-se observar o valor da massa específica do concreto leve com EPS, à temperatura ambiente e após ser aquecido a $200{ }^{\circ} \mathrm{C}$, $400^{\circ} \mathrm{C}$ e $600^{\circ} \mathrm{C}$. Todos os corpos de prova utilizados tinham dimensões de $10 \mathrm{~cm} \times 30 \mathrm{~cm}$, porém a altura e a massa foram consideradas após a retífica.

Tabela 6.1. Massa específica após aquecimento a $200 \stackrel{\circ}{C}$.

\begin{tabular}{c|c|c|c|c}
\hline CP's & $\begin{array}{c}\text { Massa à temperatura } \\
\text { ambiente } \mathbf{( g )}\end{array}$ & $\begin{array}{c}\text { Massa após } \\
\text { aquecimento } \mathbf{( g )}\end{array}$ & $\begin{array}{c}\text { Massa específica à } \\
\text { temperatura } \\
\text { ambiente } \mathbf{( k g / \mathbf { m } ^ { 3 } )}\end{array}$ & $\begin{array}{c}\text { Massa específica } \\
\text { após aquecimento } \\
\mathbf{( k g / \mathbf { m } ^ { 3 } )}\end{array}$ \\
\hline CP1 & 2656,60 & 2460,70 & 1138,88 & 1054,90 \\
\hline CP2 & 2831,50 & 2641,90 & 1209,79 & 1128,78 \\
\hline CP3 & 2879,70 & 2704,00 & 1230,39 & 1155,32 \\
\hline CP4 & 2645,60 & 2488,50 & 1130,36 & 1063,24 \\
\hline CP5 & 2572,30 & 2425,50 & 1110,22 & 1046,86 \\
\hline CP6 & 2790,80 & 2630,60 & 1188,41 & 1120,20 \\
\hline CP7 & 2743,60 & 2565,90 & 1184,16 & 1107,46 \\
\hline CP8 & 2689,60 & 2489,70 & 1156,93 & 1070,94 \\
\hline MÉDIA & $\mathbf{2 7 2 6 , 2 1}$ & $\mathbf{2 5 5 0 , 8 5}$ & $\mathbf{1 1 6 8 , 6 4}$ & $\mathbf{1 0 9 3 , 4 6}$ \\
\hline
\end{tabular}


Tabela 6.2. Massa específica após aquecimento a $400{ }^{\circ} \mathrm{C}$.

\begin{tabular}{|c|c|c|c|c|}
\hline CP's & $\begin{array}{c}\text { Massa à temperatura } \\
\text { ambiente }(\mathrm{g})\end{array}$ & $\begin{array}{c}\text { Massa após } \\
\text { aquecimento (g) }\end{array}$ & $\begin{array}{c}\text { Massa específica à } \\
\text { temperatura } \\
\text { ambiente }\left(\mathrm{kg} / \mathrm{m}^{3}\right)\end{array}$ & $\begin{array}{c}\text { Massa específica } \\
\text { após aquecimento } \\
\qquad\left(\mathrm{kg} / \mathrm{m}^{3}\right)\end{array}$ \\
\hline $\mathrm{CP} 1$ & 2705,40 & 2403,70 & 1159,81 & 1030,47 \\
\hline $\mathrm{CP} 2$ & 2819,30 & 2506,30 & 1204,58 & 1070,85 \\
\hline CP3 & 2813,30 & 2499,00 & 1206,06 & 1071,32 \\
\hline CP4 & 2577,00 & 2276,60 & 1104,76 & 975,98 \\
\hline CP5 & 2624,50 & 2331,70 & 1132,75 & 1006,38 \\
\hline CP6 & 2711,40 & 2414,30 & 1166,30 & 1038,51 \\
\hline $\mathrm{CP} 7$ & 2774,60 & 2470,70 & 1193,49 & 1062,77 \\
\hline CP8 & 2612,50 & 2316,80 & 1131,41 & 1003,35 \\
\hline MÉDIA & 2704,75 & 2402,39 & 1162,40 & 1032,45 \\
\hline
\end{tabular}

Tabela 6.3. Massa específica após aquecimento a $600{ }^{\circ} \mathrm{C}$.

\begin{tabular}{|c|c|c|c|c|}
\hline CP's & $\begin{array}{c}\text { Massa à temperatura } \\
\text { ambiente }(\mathrm{g})\end{array}$ & $\begin{array}{c}\text { Massa após } \\
\text { aquecimento (g) }\end{array}$ & $\begin{array}{c}\text { Massa específica à } \\
\text { temperatura } \\
\text { ambiente }\left(\mathrm{kg} / \mathrm{m}^{3}\right)\end{array}$ & $\begin{array}{c}\text { Massa específica } \\
\text { após aquecimento } \\
\left(\mathrm{kg} / \mathrm{m}^{3}\right)\end{array}$ \\
\hline $\mathrm{CP} 1$ & 2884,20 & 2502,50 & 1236,46 & 1072,82 \\
\hline $\mathrm{CP} 2$ & 2799,70 & 2429,20 & 1196,20 & 1037,90 \\
\hline $\mathrm{CP} 3$ & 2594,80 & 2246,80 & 1116,15 & 966,46 \\
\hline CP4 & 2761,60 & 2403,80 & 1191,92 & 1037,50 \\
\hline CP5 & 2638,40 & 2292,20 & 1138,75 & 989,33 \\
\hline CP6 & 2837,70 & 2474,90 & 1224,77 & 1068,18 \\
\hline CP7 & 2863,40 & 2493,50 & 1227,54 & 1068,96 \\
\hline CP8 & 2764,70 & 2400,00 & 1181,25 & 1025,43 \\
\hline MÉDIA & 2768,06 & 2405,36 & 1189,13 & 1033,32 \\
\hline
\end{tabular}

Uma observação importante com relação à massa é que os corpos de prova foram pesados secos à temperatura ambiente, algumas horas após serem retirados da câmara úmida.

Pode-se observar que na temperatura de $200 \stackrel{\circ}{\circ}$, a massa específica teve uma redução de aproximadamente $6,43 \%$, na temperatura de $400 \stackrel{\circ}{\circ}$, a redução foi de $11,18 \%$, e na temperatura de $600{ }^{\circ} \mathrm{C}$, de $13,10 \%$. Essa redução já era esperada, 
uma vez que quanto maior a temperatura, maior a perda de água do concreto, que influencia diretamente na massa específica.

Fazendo uma rápida comparação com o concreto convencional de resistência menor ou igual a $50 \mathrm{MPa}$, usando as equações mostradas no item 3.4.1.a deste trabalho, encontra-se que para $200 \stackrel{\circ}{C}$ a redução da massa específica foi de $2 \%$, para $400 \stackrel{\circ}{\circ}$, foi de $5 \%$, e para $600 \stackrel{\circ}{ } \mathrm{C}$, de $6,75 \%$.

Dessa maneira, conclui-se que o concreto leve com EPS, objeto de estudo desta pesquisa, apresenta uma redução de massa específica bem maior que o concreto convencional, principalmente na temperatura em torno de $200 \stackrel{\circ}{ }$, que foi praticamente três vezes maior.

Na figura 6.1, pode-se ver o gráfico do fator de redução $\left(\mathrm{k}_{\rho, \theta}\right)$ da massa específica em função da temperatura.

O fator de redução pode ser calculado da seguinte maneira:

$$
\mathrm{k}_{\mathrm{c}, \theta}=\frac{\rho_{\mathrm{c}, \theta}}{\rho_{\mathrm{c}}} \cdot 100
$$

$\rho_{c, \theta}$ é a massa específica na temperatura $\theta$;

$\rho_{c}$ é a massa específica em temperatura ambiente.

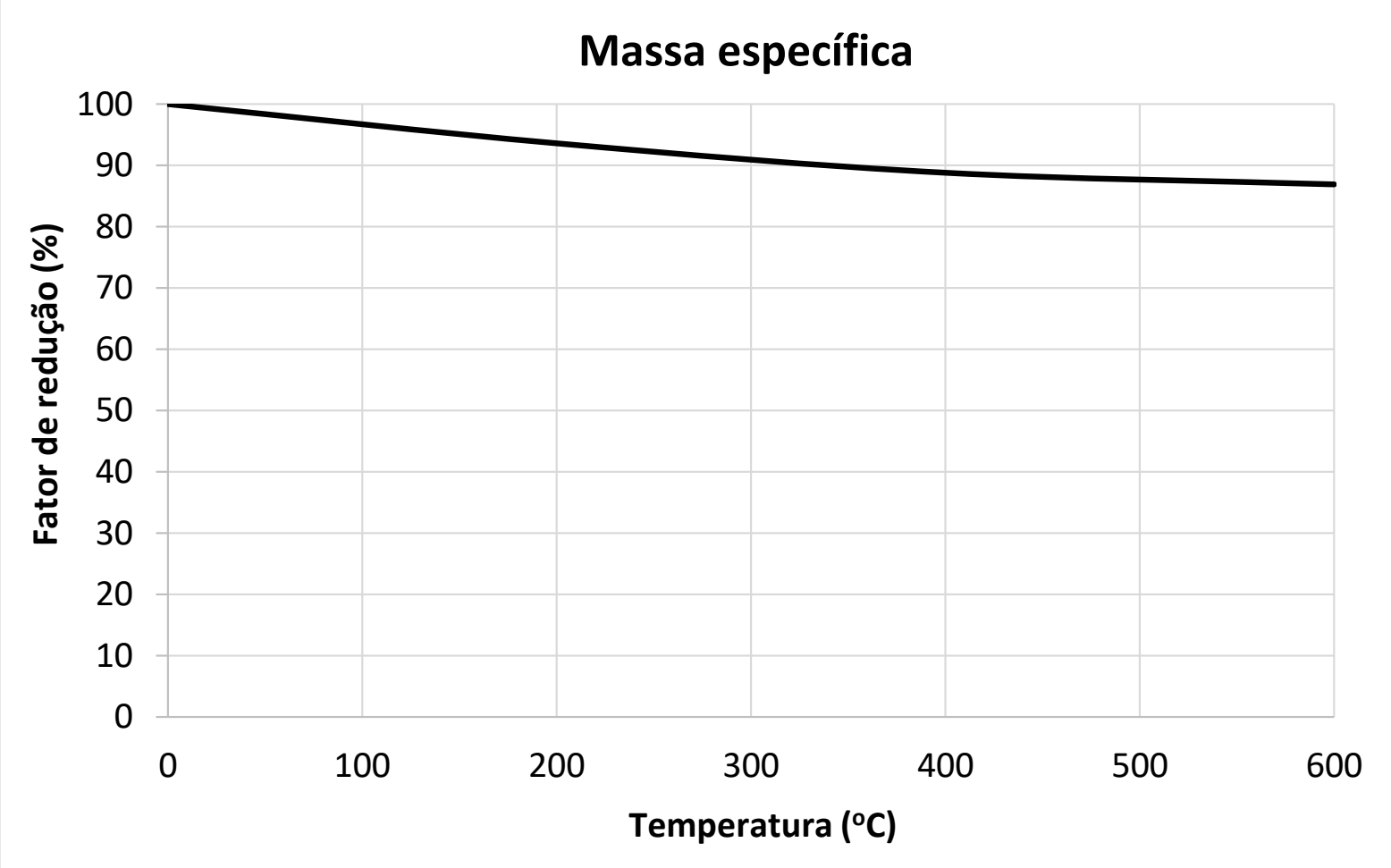

Figura 6.1. Fator de redução da massa específica em função da temperatura. 


\subsection{Resistência à compressão axial $\left(\mathrm{f}_{\mathrm{c}}\right)$}

O ensaio foi realizado na máquina servo-hidráulica da marca INSTRON, modelo $300 \mathrm{HVL}$, cuja capacidade de carga é de 1500 kN (figura 6.2). O ensaio foi por controle de deslocamento, com velocidade de $0,01 \mathrm{~mm} / \mathrm{s}$.

Foram feitos ensaios com corpos de prova à temperatura ambiente e após serem submetidos às temperaturas de $200^{\circ} \mathrm{C}, 400^{\circ} \mathrm{C}$ e $600^{\circ} \mathrm{C}$.

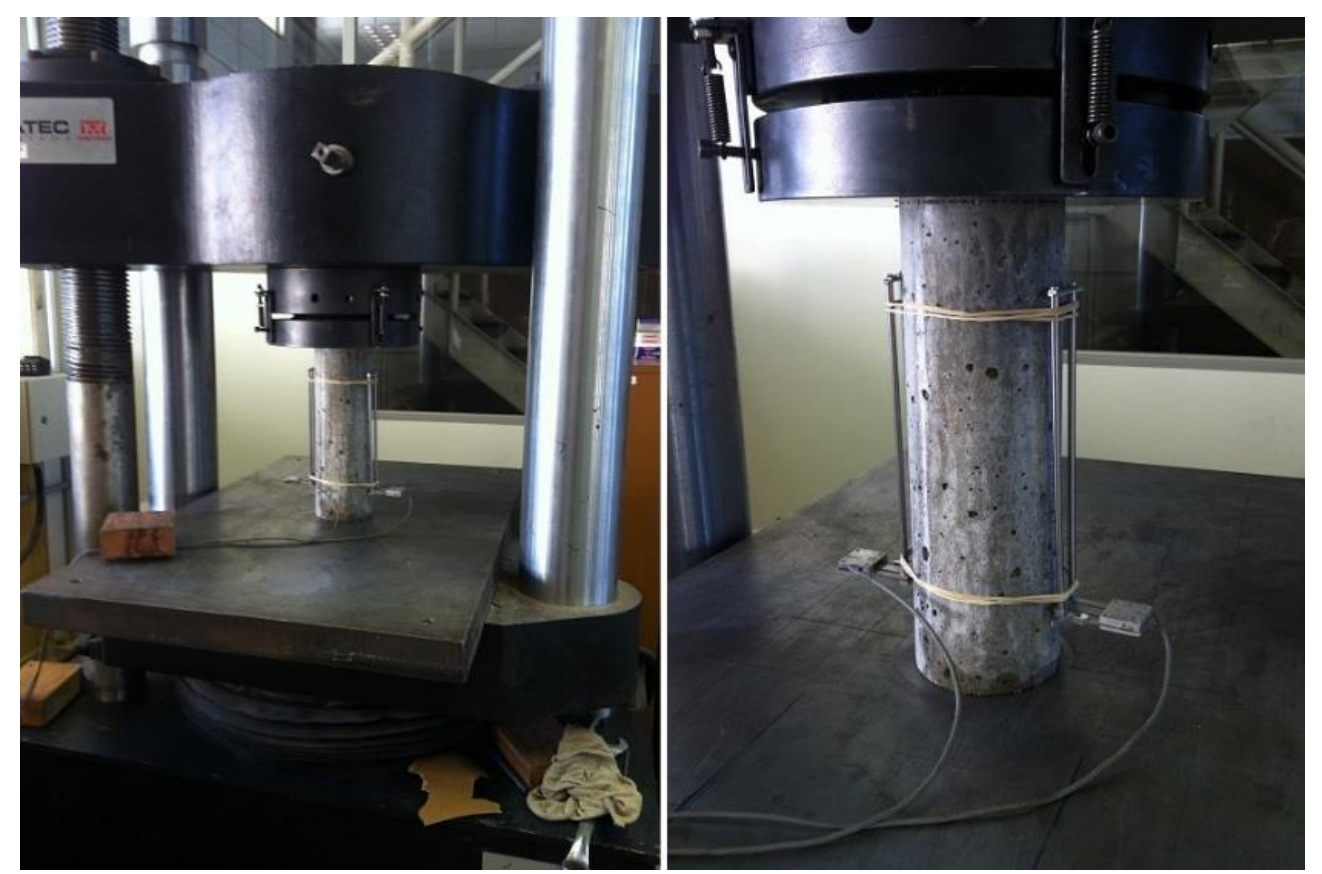

Figura 6.2. Corpo de prova cilíndrico, instrumentado, sendo ensaiado na máquina INSTRON.

\subsubsection{Temperatura ambiente}

$\mathrm{Na}$ figura 6.3, pode-se observar o corpo de prova relativo à temperatura ambiente após a ruptura. Percebe-se que a distribuição do EPS está bem homogênea na seção transversal.

$\mathrm{Na}$ figura 6.4, pode-se observar o gráfico de tensão versus deformação dos quatro corpos de prova cilíndricos, relativos à temperatura ambiente.

De acordo com o gráfico, o CP2 atingiu os maiores valores de tensão normal, enquanto o CP1 atingiu os menores valores. Na tabela 6.4, encontram-se os valores da resistência à compressão de cada corpo de prova e o resultado médio, que é igual a 12,84 MPa. 


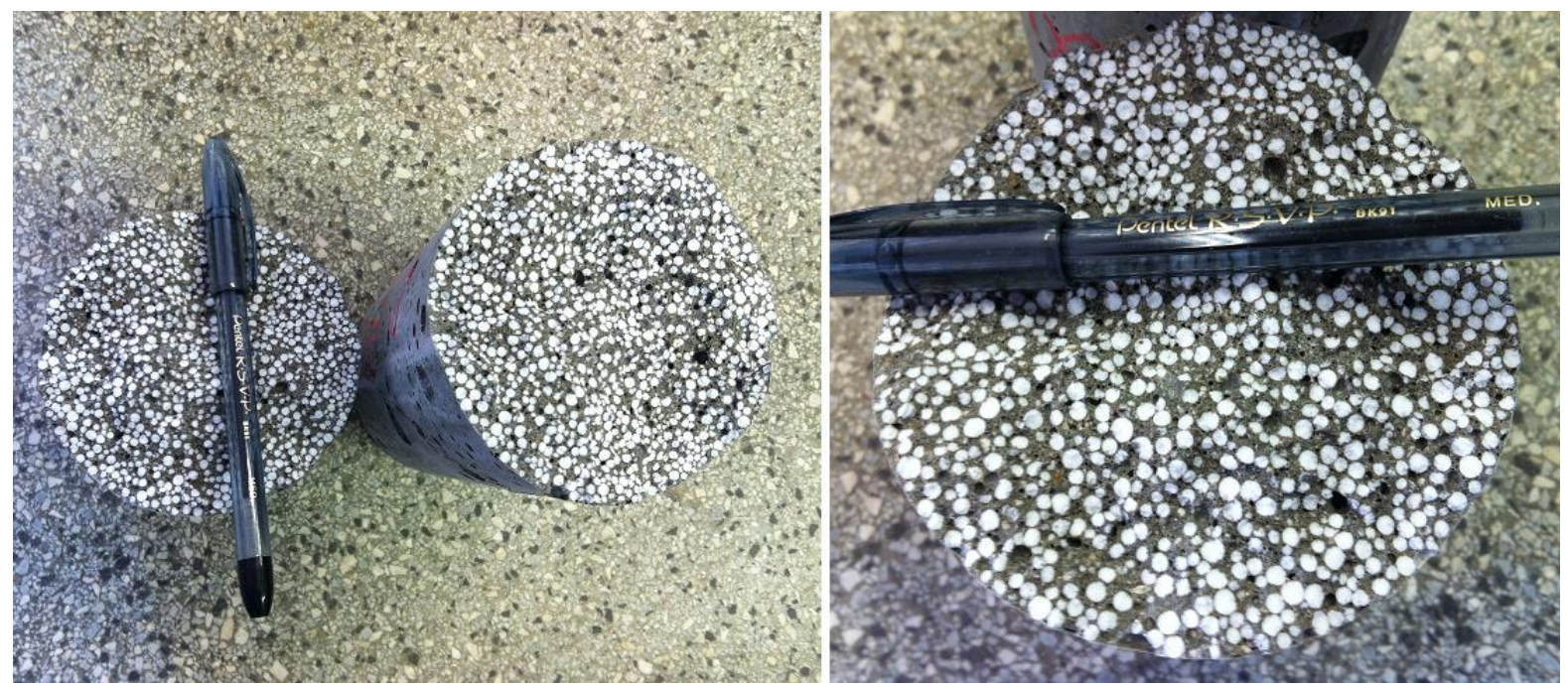

Figura 6.3. Corpo de prova cilíndrico após a ruptura no ensaio de resistência à compressão (temperatura ambiente).

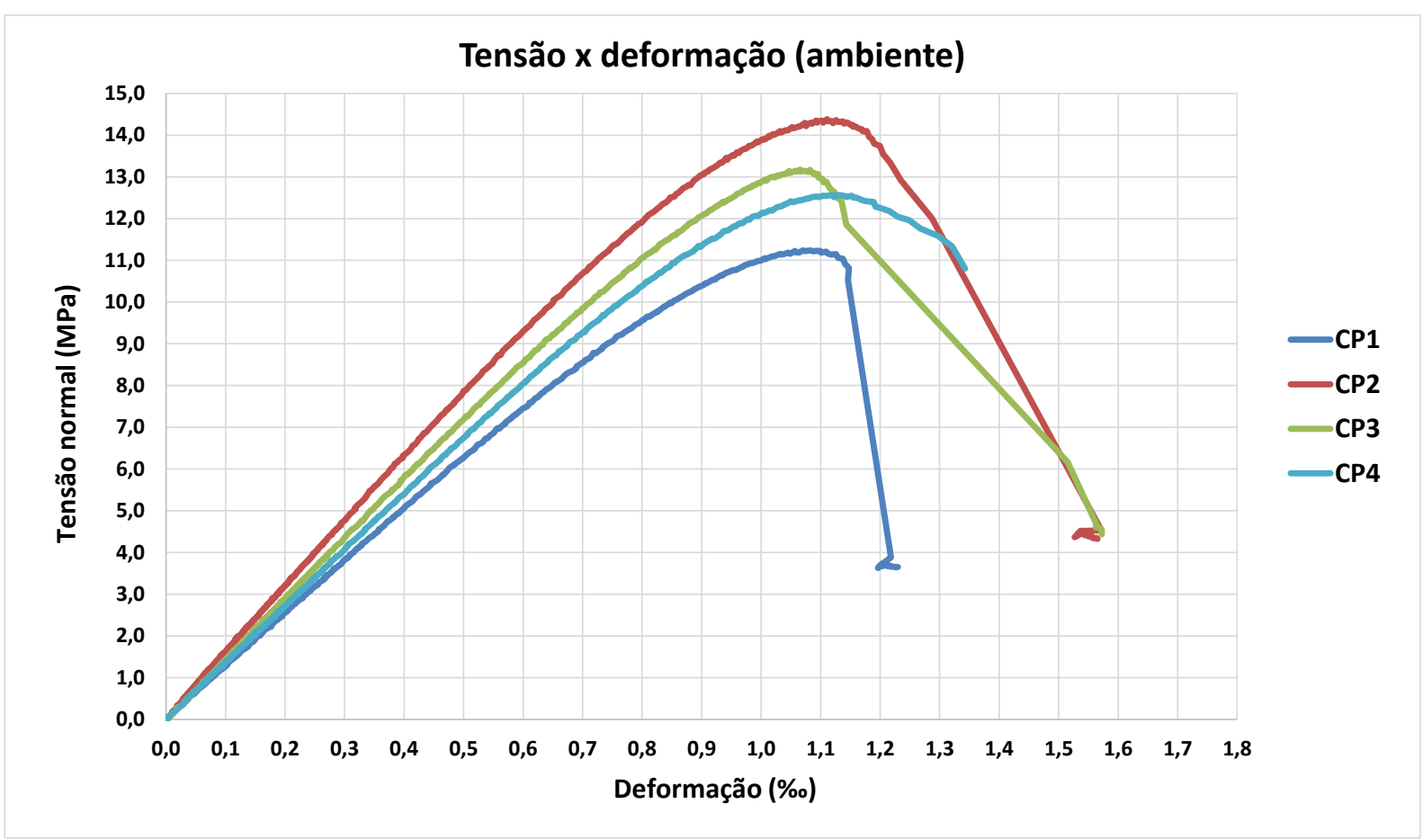

Figura 6.4. Gráfico de tensão versus deformação do ensaio de resistência à compressão dos corpos de prova relativos à temperatura ambiente. 
Tabela 6.4. Resistência à compressão dos corpos de prova relativos à temperatura ambiente.

\begin{tabular}{c|c}
\hline CP's & $\mathbf{f}_{\mathbf{c}}$ (MPa) \\
\hline CP1 & 11,24 \\
\hline CP2 & 14,38 \\
\hline CP3 & 13,17 \\
\hline CP4 & 12,57 \\
\hline MÉDIA & $\mathbf{1 2 , 8 4}$ \\
\hline
\end{tabular}

\subsubsection{Temperatura de $200 \stackrel{\circ}{C}$}

Na figura 6.5, pode-se observar o corpo de prova que foi aquecido a $200{ }^{\circ} \mathrm{C}$, após a ruptura. É bem visível que grande parte do EPS derreteu, porém ainda é possível visualizar algumas pérolas de EPS nessa seção transversal.

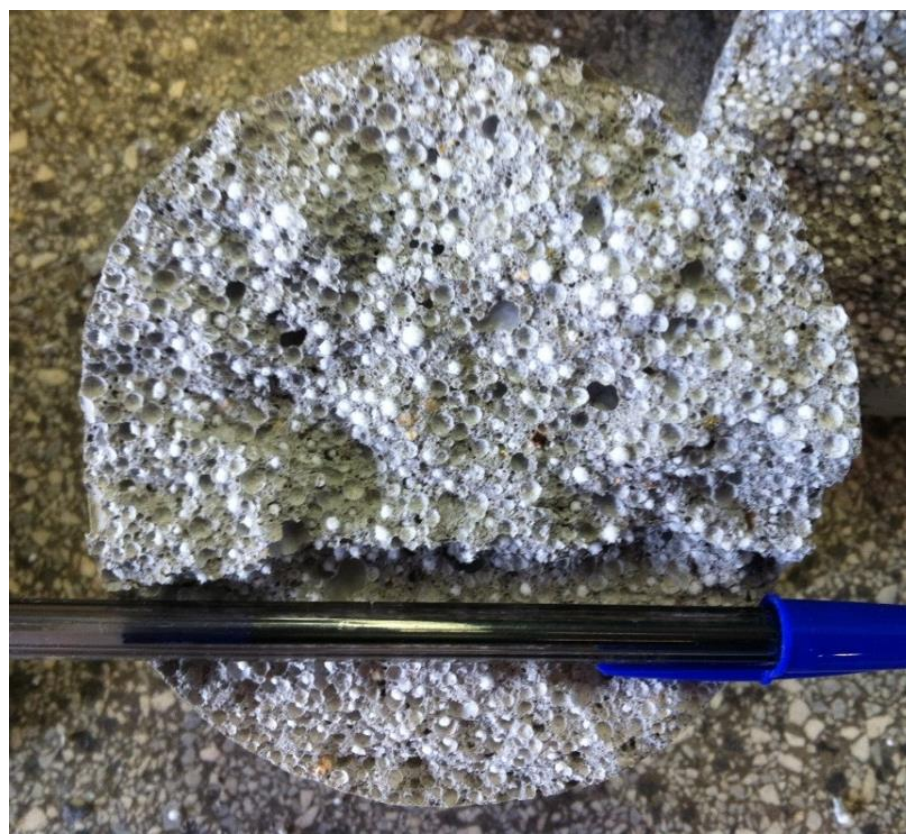

Figura 6.5. Corpo de prova cilíndrico após ruptura no ensaio de resistência à compressão $\left(200{ }^{\circ} \mathrm{C}\right)$. 
Na figura 6.6, pode-se observar o gráfico de tensão versus deformação dos quatro corpos de prova cilíndricos que foram aquecidos a $200^{\circ} \mathrm{C}$.

De acordo com o gráfico, o CP2 e CP4 tiveram praticamente os mesmos resultados de tensão até atingir a tensão máxima, que foi bem próxima para os corpos de prova, exceto para o CP3, que atingiu um valor menor. Porém, todos foram considerados para o cálculo do valor médio.

Na tabela 6.5, têm-se os valores da resistência à compressão de cada corpo de prova e o resultado médio, que é igual a 10,90 $\mathrm{MPa}$, sendo aproximadamente $15 \%$ menor que o valor obtido para os corpos de prova em temperatura ambiente, que é 12,84 MPa.

Outra informação que se pode extrair da figura 6.6 é que, além da resistência à compressão ter reduzido, a deformação aumentou, ou seja, os corpos de prova se tornaram menos resistentes e mais deformáveis. Enquanto que em temperatura ambiente a tensão máxima foi atingida com 1,1\% de deformação, nos corpos de prova aquecidos a $200{ }^{\circ} \mathrm{C}$ a tensão máxima foi atingida com aproximadamente $1,25 \%$ de deformação.

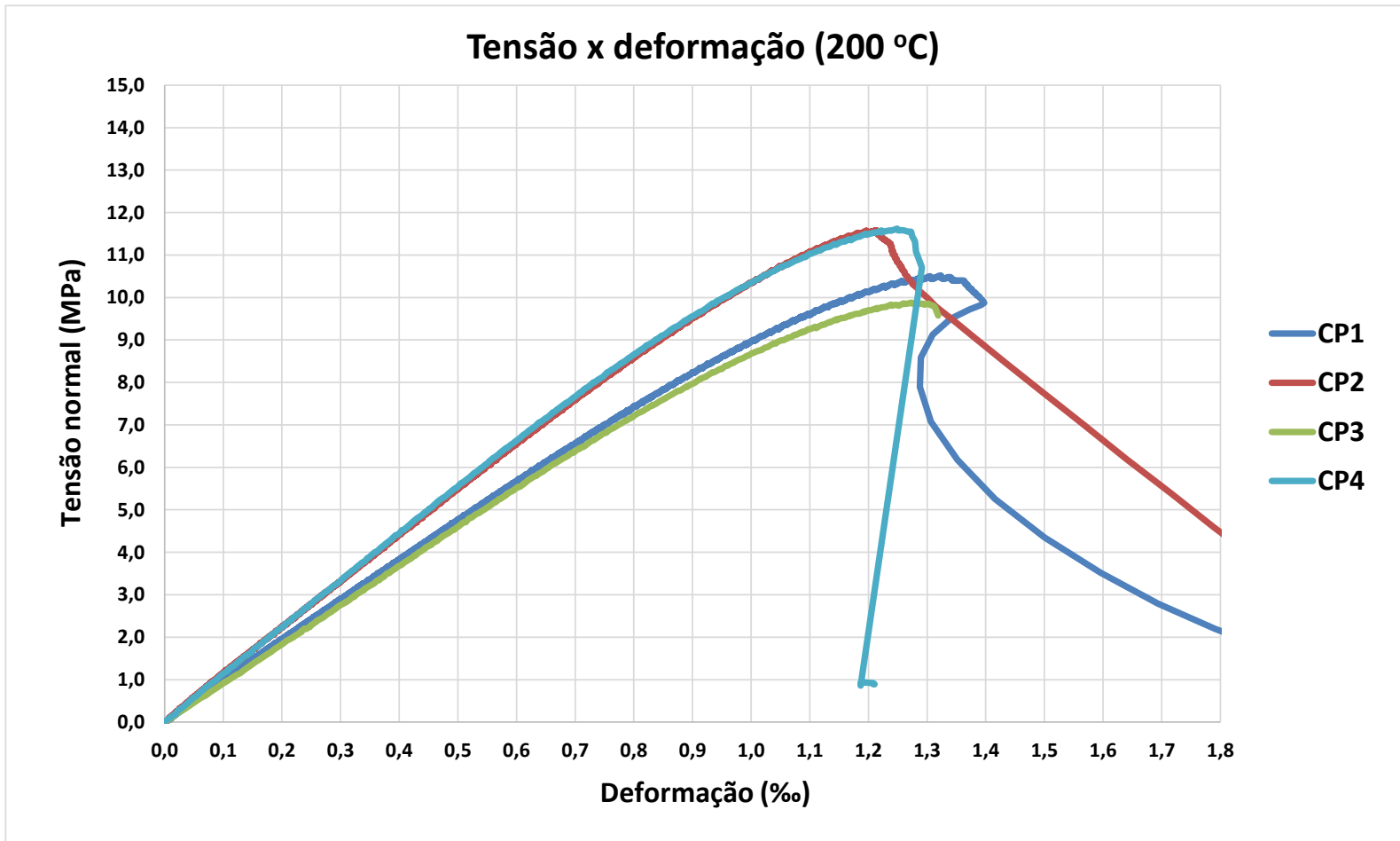

Figura 6.6. Gráfico de tensão versus deformação do ensaio de resistência à compressão dos corpos de prova aquecidos a $200 \stackrel{\circ}{ } \mathrm{C}$. 
Tabela 6.5. Resistência à compressão dos corpos de prova aquecidos a $200{ }^{\circ} \mathrm{C}$.

\begin{tabular}{c|c}
\hline CP's & $\mathbf{f}_{\mathbf{c}}$ (MPa) \\
\hline CP1 & 10,51 \\
\hline CP2 & 11,58 \\
\hline CP3 & 9,88 \\
\hline CP4 & 11,62 \\
\hline MÉDIA & $\mathbf{1 0 , 9 0}$ \\
\hline
\end{tabular}

\subsubsection{Temperatura de $400 \stackrel{\circ}{C}$}

$\mathrm{Na}$ figura 6.7, pode-se observar o corpo de prova, após a ruptura, que foi aquecido a $400 \stackrel{\circ}{\circ}$. Nota-se que derreteram todas as pérolas de EPS, o que permite supor que todo o EPS, no interior do concreto, derrete aproximadamente no intervalo de $250 \stackrel{\circ}{ } \mathrm{C}$ a $350 \stackrel{\circ}{ }$, levando em conta que, na temperatura de $200 \stackrel{\circ}{ } \mathrm{C}$, grande parte já tinha derretido.
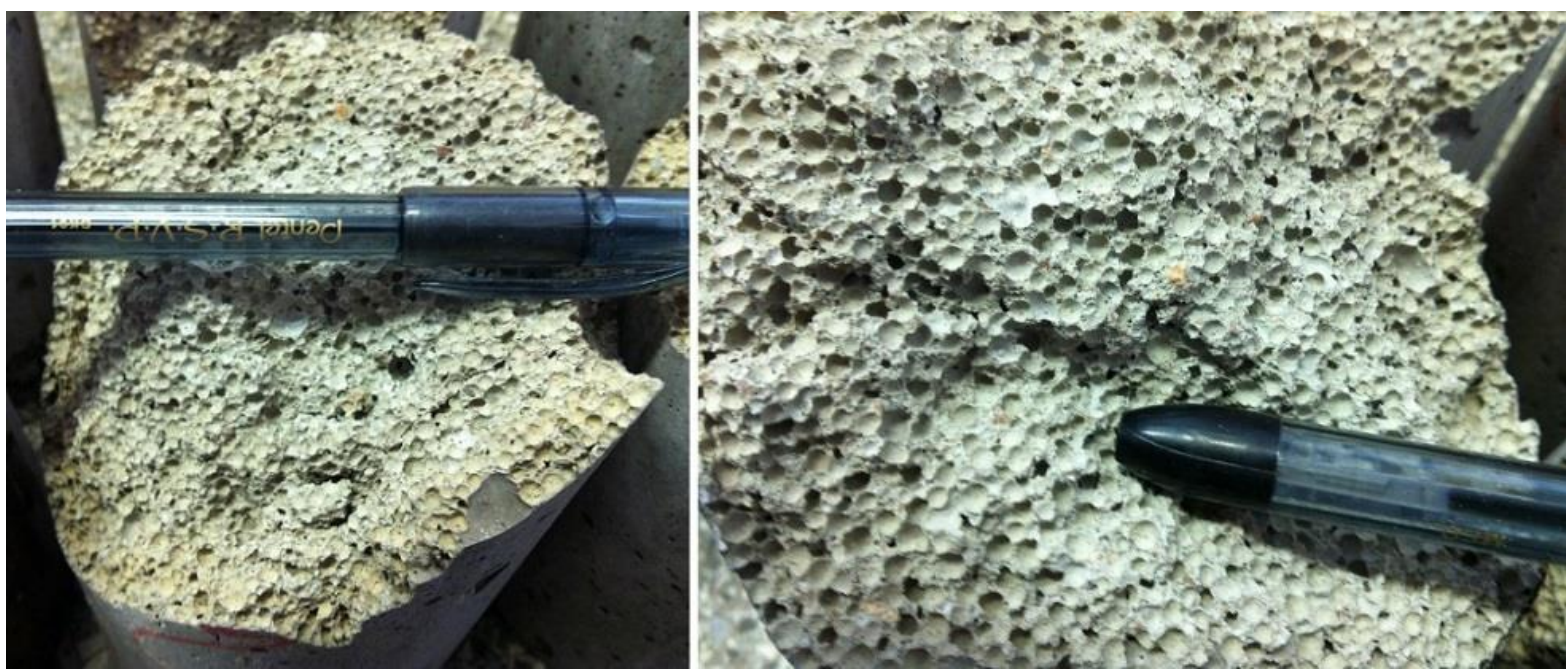

Figura 6.7. Corpo de prova cilíndrico após ruptura no ensaio de resistência à compressão $\left(400^{\circ} \mathrm{C}\right)$. 
Na figura 6.8, pode-se observar o gráfico de tensão versus deformação dos quatro corpos de prova cilíndricos que foram aquecidos a $400^{\circ} \mathrm{C}$.

De acordo com esse gráfico, todos os corpos de prova tiveram praticamente os mesmos resultados de tensão até atingir a tensão máxima, e ela foi bem próxima para os quatro.

Na tabela 6.6, têm-se os valores da resistência à compressão de cada corpo de prova e o resultado médio, que é igual a 4,71 MPa, sendo aproximadamente 57\% menor que o valor obtido para os corpos de prova que foram aquecidos à $200 \stackrel{\circ}{\mathrm{C}}(10,90 \mathrm{MPa})$, e aproximadamente $63 \%$ menor que o valor obtido para os corpos de prova relativos a temperatura ambiente (12,84 MPa).

Para $400 \stackrel{\circ}{\circ}$, também se observa que a deformação aumentou bastante. No caso de $200 \stackrel{\circ}{\circ}$, a tensão máxima foi atingida com aproximadamente $1,25 \%$ de deformação, e neste caso, com aproximadamente $2,2 \%$.

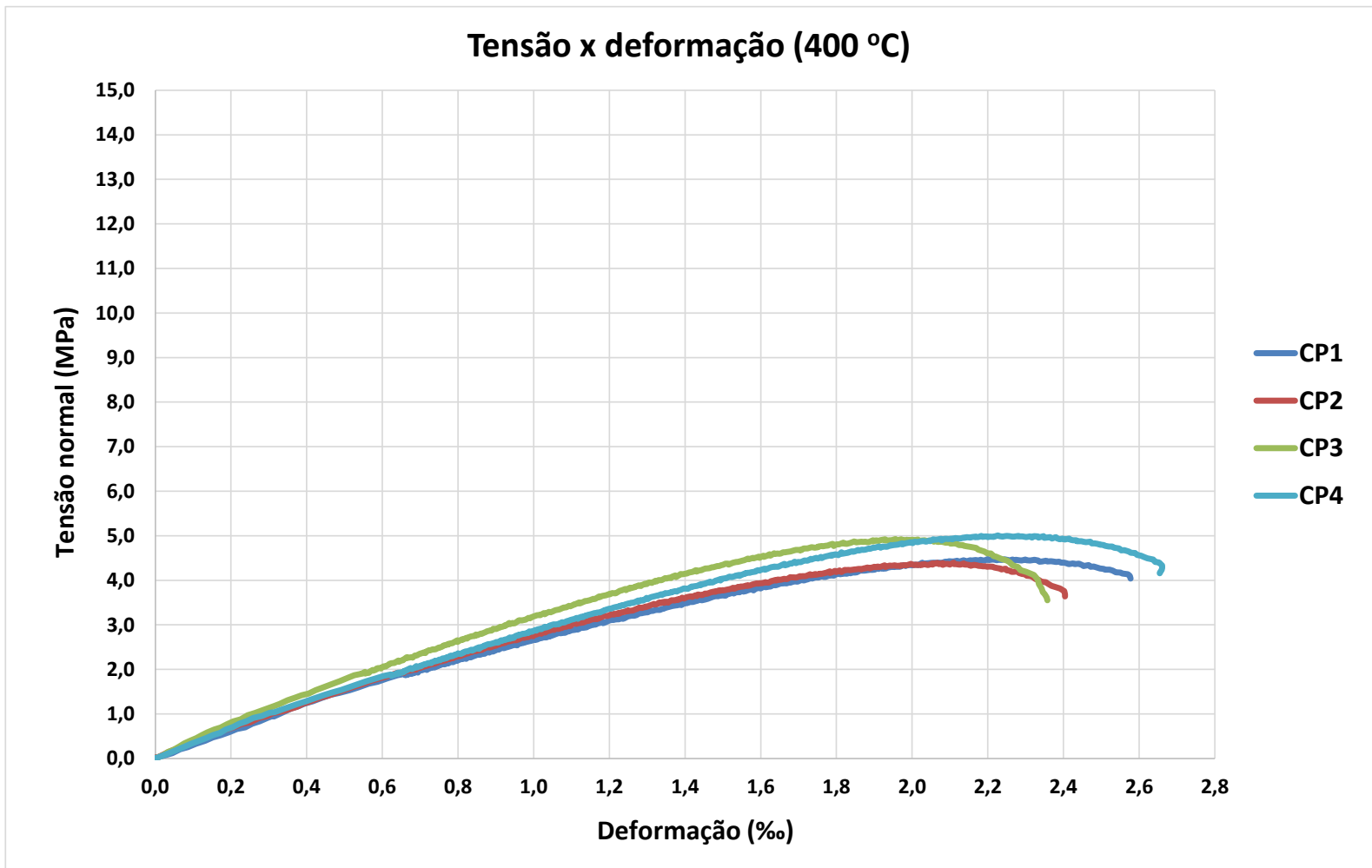

Figura 6.8. Gráfico de tensão versus deformação do ensaio de resistência à compressão dos corpos de prova aquecidos a $400{ }^{\circ} \mathrm{C}$. 
Tabela 6.6. Resistência à compressão dos corpos de prova aquecidos a $400 \stackrel{\circ}{\circ}$.

\begin{tabular}{c|c}
\hline CP's & $\mathbf{f}_{\mathbf{c}}$ (MPa) \\
\hline CP1 & 4,48 \\
\hline CP2 & 4,40 \\
\hline CP3 & 4,93 \\
\hline CP4 & 5,01 \\
\hline MÉDIA & $\mathbf{4 , 7 1}$ \\
\hline
\end{tabular}

\subsubsection{Temperatura de $600 \stackrel{\circ}{C}$}

$\mathrm{Na}$ figura 6.9, pode-se observar o corpo de prova que foi aquecido a $600{ }^{\circ} \mathrm{C}$, após a ruptura. Aqui o aspecto é bem parecido com o que foi visto para $400 \stackrel{\circ}{\mathrm{C}}$ : não teve grandes alterações.

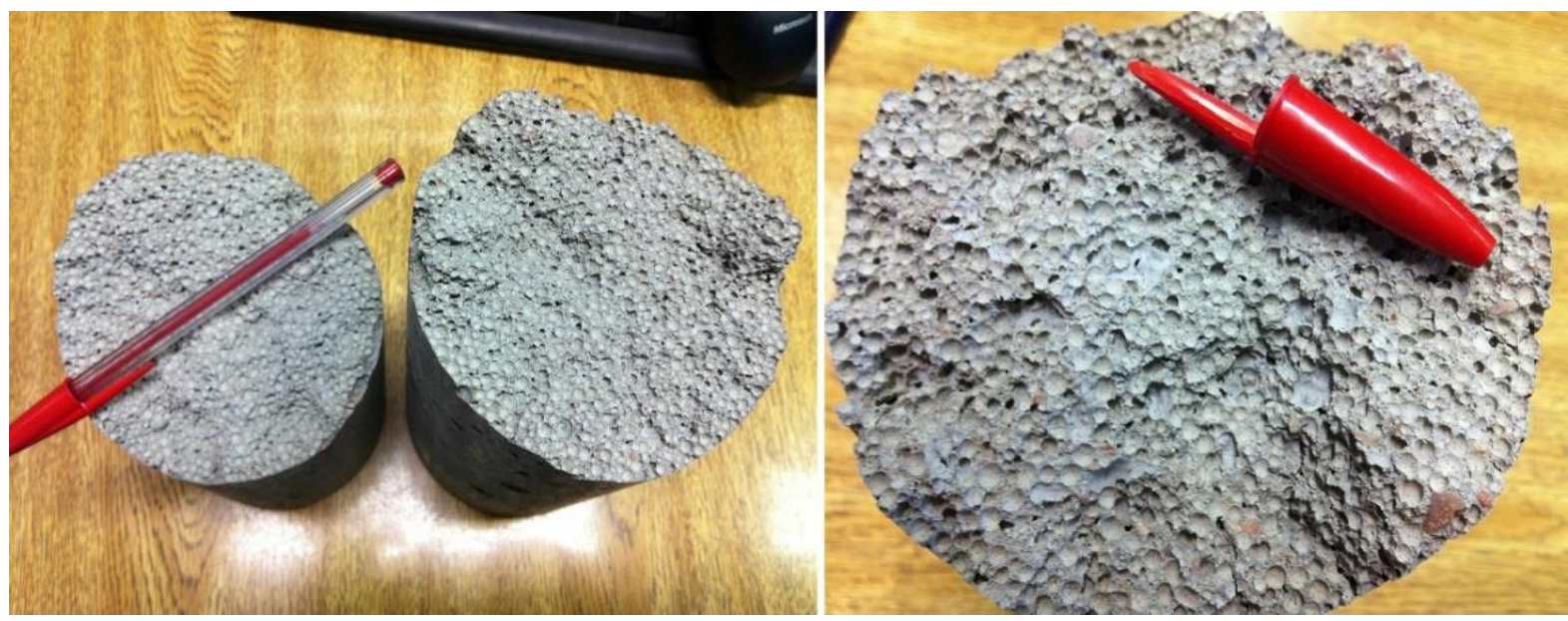

Figura 6.9. Corpo de prova cilíndrico após ruptura no ensaio de resistência à compressão $\left(600{ }^{\circ} \mathrm{C}\right)$.

Na figura 6.10, pode-se observar o gráfico de tensão versus deformação dos quatro corpos de prova cilíndricos que foram aquecidos a $600 \stackrel{\circ}{\circ}$. 
De acordo com o gráfico, todos os corpos de prova tiveram praticamente os mesmos resultados de tensão até atingir a tensão máxima, e ela foi bem próxima, exceto para o CP3, que atingiu um valor um pouco menor.

Na tabela 6.7, têm-se os valores da resistência à compressão de cada corpo de prova e o resultado médio, que é igual a 2,95 MPa, sendo aproximadamente 37\% menor que o valor obtido para os corpos de prova que foram aquecidos a $400 \stackrel{\circ}{\mathrm{C}}(4,71 \mathrm{MPa})$, aproximadamente $73 \%$ menor que o valor obtido para os corpos de prova que foram aquecidos a $200{ }^{\circ} \mathrm{C}(10,90 \mathrm{MPa})$, e aproximadamente $77 \%$ menor que o valor obtido para os corpos de prova relativos a temperatura ambiente $(12,84 \mathrm{MPa})$.

Observa-se mais uma vez que a deformação aumentou bastante. No caso de $400 \stackrel{\circ}{\circ}$, a tensão máxima foi atingida a aproximadamente $2,2 \%$ de deformação, e neste caso, foi atingida a aproximadamente $4,25 \%$ de deformação.

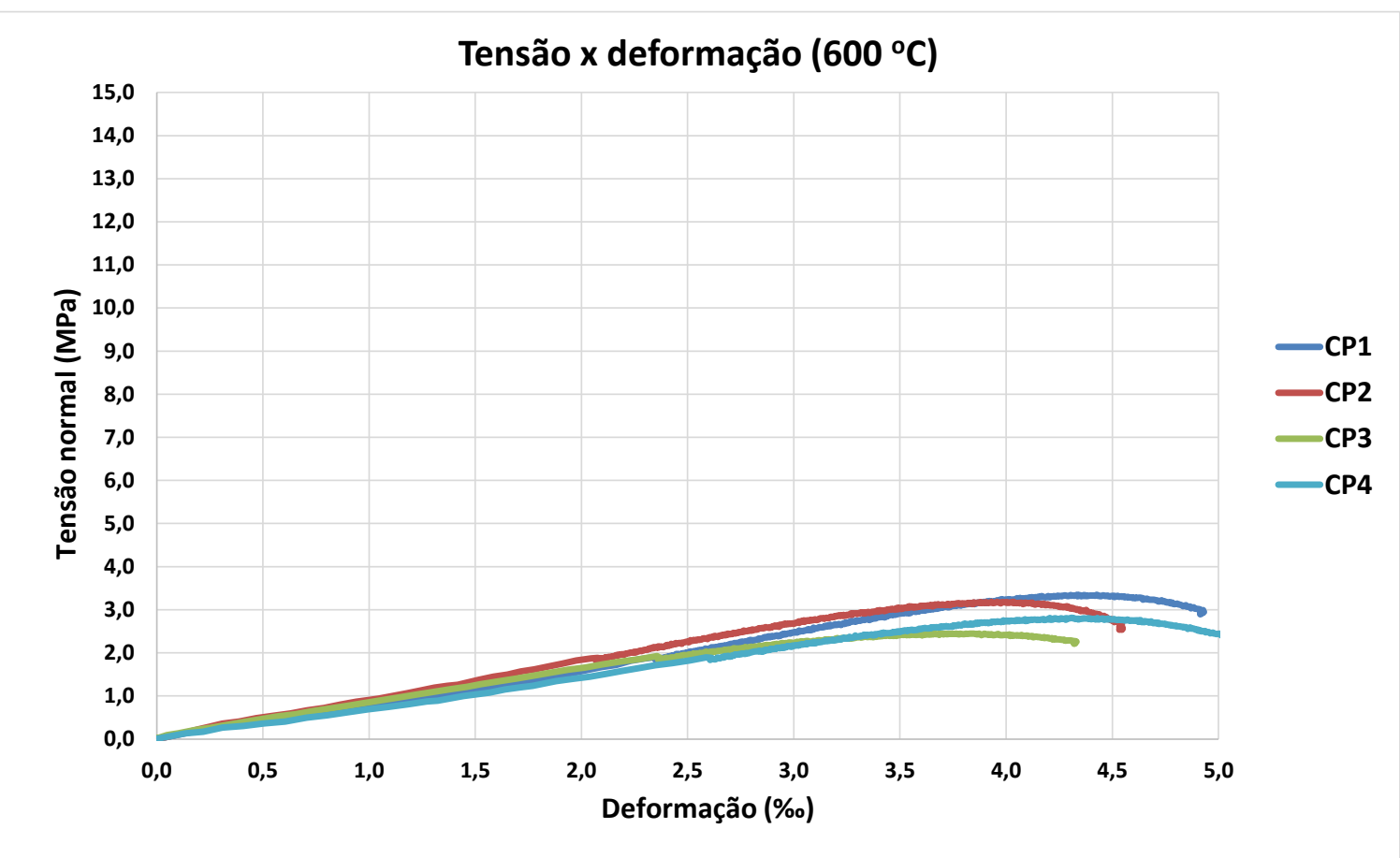

Figura 6.10. Gráfico de tensão versus deformação do ensaio de resistência à compressão dos corpos de prova aquecidos a $600{ }^{\circ} \mathrm{C}$.

Com os quatro casos avaliados, pode-se concluir que quanto maior a temperatura, menor é a tensão máxima atingida, e o concreto com EPS torna-se menos resistente e mais deformável. 
Tabela 6.7. Resistência à compressão dos corpos de prova aquecidos a $600 \stackrel{\circ}{\circ}$.

\begin{tabular}{c|c}
\hline CP's & $\mathbf{f}_{\mathbf{c}}$ (MPa) \\
\hline CP1 & 3,35 \\
\hline CP2 & 3,18 \\
\hline CP3 & 2,45 \\
\hline CP4 & 2,82 \\
\hline MÉDIA & $\mathbf{2 , 9 5}$ \\
\hline
\end{tabular}

\subsubsection{Resistência à compressão axial versus Temperatura}

$\mathrm{Na}$ figura 6.11, pode-se ver a variação da resistência à compressão em função da temperatura.

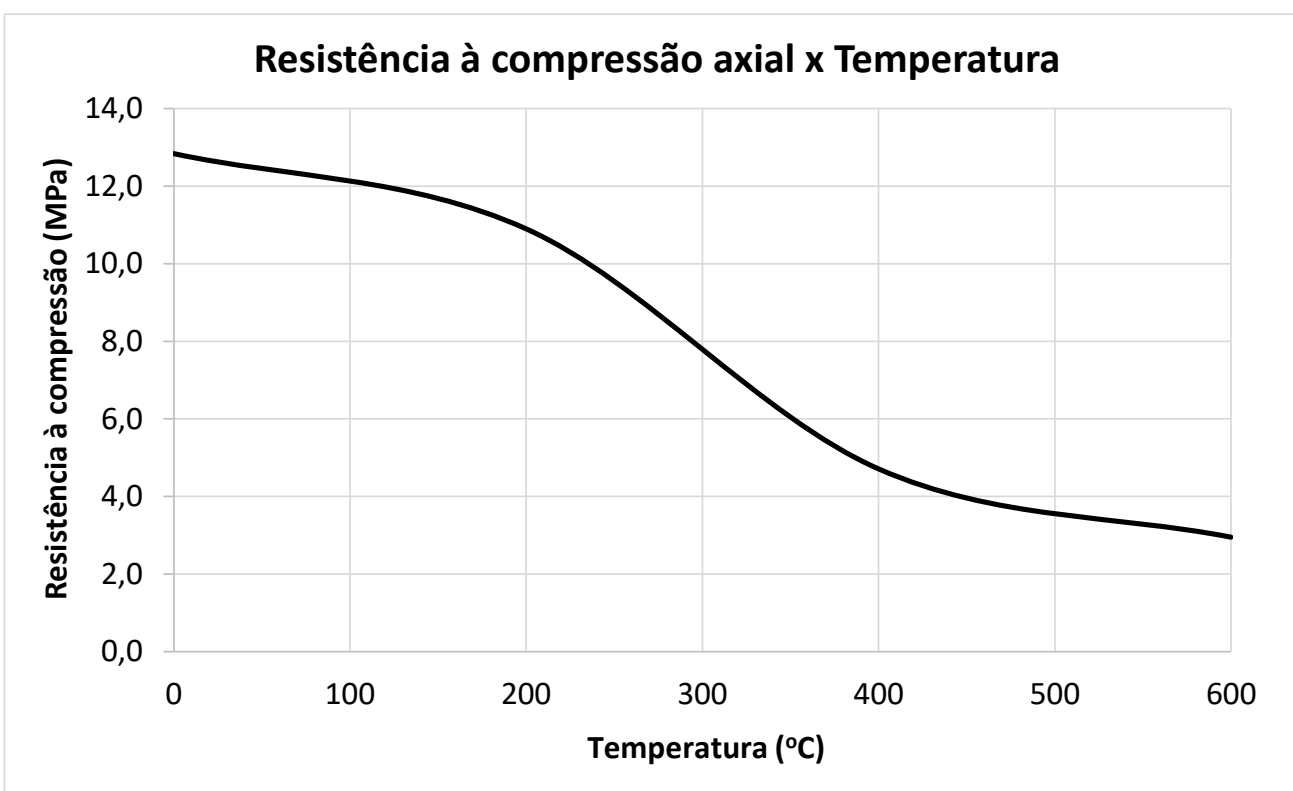

Figura 6.11. Resistência à compressão em função da temperatura.

Pode-se observar que na temperatura de $200 \stackrel{\circ}{\circ}$, a resistência à compressão teve uma redução de aproximadamente $15 \%$, na temperatura de $400 \stackrel{\circ}{\circ}$, a redução 
foi de aproximadamente $63 \%$, e na temperatura de $600 \stackrel{\circ}{\circ}, 77 \%$. Fica claro que a maior variação de resistência ocorre entre as temperaturas de $200{ }^{\circ} \mathrm{C}$ e $400{ }^{\circ} \mathrm{C}$, sendo essa variação mais suave antes de $200{ }^{\circ} \mathrm{C}$ e após $400 \stackrel{\circ}{ } \mathrm{C}$.

Fazendo uma rápida comparação com o concreto convencional de resistência menor ou igual a $50 \mathrm{MPa}$ e com agregado silicoso, usando os resultados mostrados no item 3.4.1.e deste trabalho, encontra-se que para $200{ }^{\circ} \mathrm{C}$, a redução foi de $5 \%$, para $400{ }^{\circ} \mathrm{C}$, foi de $25 \%$, para $600{ }^{\circ} \mathrm{C}$, de $55 \%$, para $800{ }^{\circ} \mathrm{C}$, de $85 \%$, e para $1000{ }^{\circ} \mathrm{C}$, a redução foi de $96 \%$. Neste caso, fica claro que a maior variação de resistência ocorre entre as temperaturas de $200 \stackrel{\circ}{\mathrm{C}}$ e $800 \stackrel{\circ}{\mathrm{C}}$.

Dessa maneira, pode-se concluir que o concreto leve com EPS tem um comportamento bem pior frente a altas temperaturas, com relação à resistência à compressão. Na figura 6.12, pode-se ver o gráfico do fator de redução $\left(\mathrm{k}_{\mathrm{c}, \theta}\right)$ da resistência à compressão em função da temperatura, para o concreto leve com EPS e para o concreto convencional.

O cálculo desse fator de redução é análogo ao já visto para massa específica:

$$
\mathrm{k}_{\mathrm{c}, \theta}=\frac{\mathrm{f}_{\mathrm{c}, \theta}}{\mathrm{f}_{\mathrm{c}}} \cdot 100
$$

$\mathrm{f}_{\mathrm{c}, \theta}$ é a resistência à compressão na temperatura $\theta$;

$\mathrm{f}_{\mathrm{c}}$ é a resistência à compressão em temperatura ambiente.

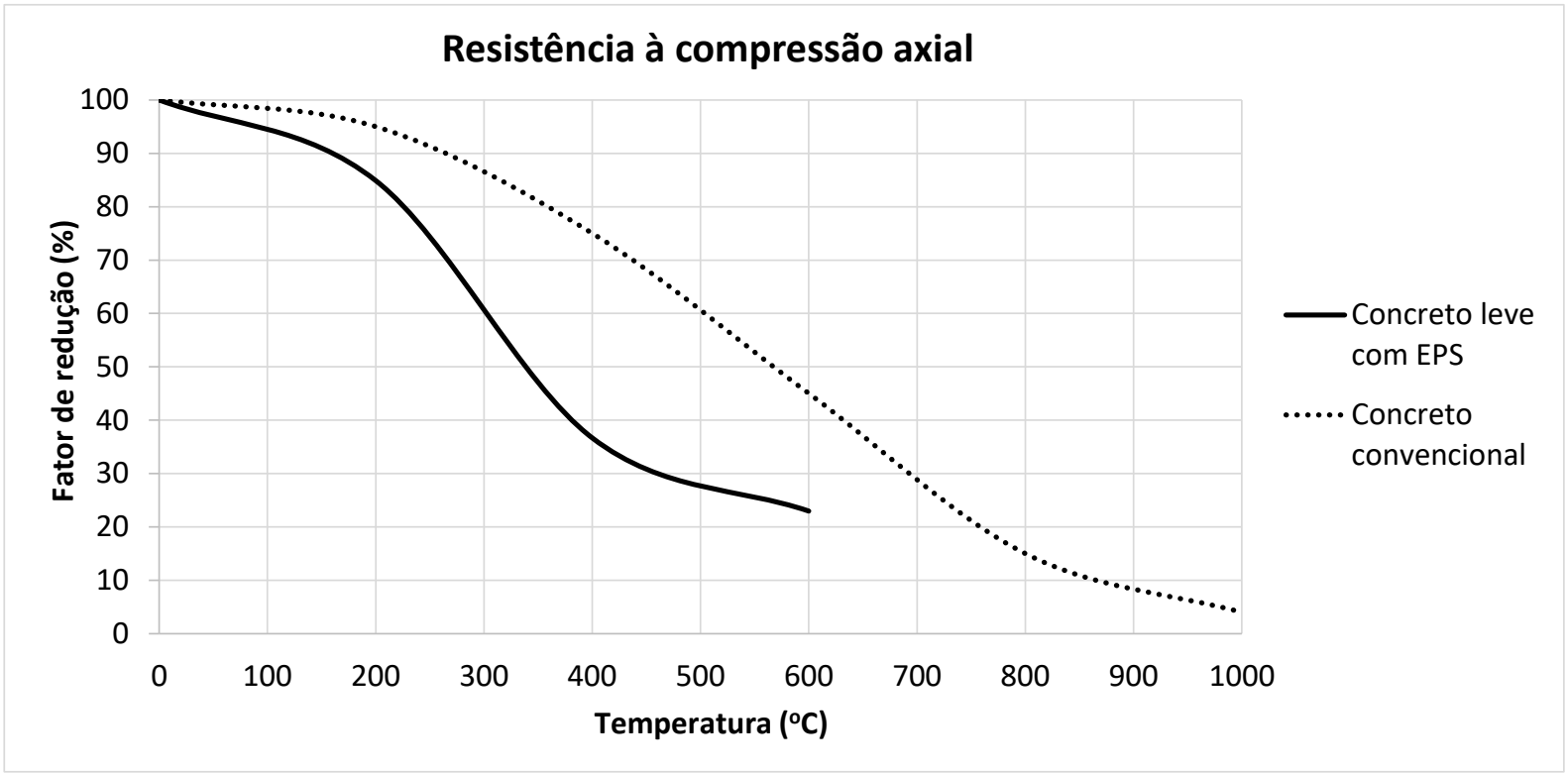

Figura 6.12. Fator de redução da resistência à compressão em função da temperatura. 


\subsection{Módulo de elasticidade estático $\left(E_{c}\right)$}

Para o cálculo do módulo de elasticidade estático, foram utilizados os mesmos gráficos obtidos no ensaio de resistência à compressão, já mostrados nas figuras $6.4,6.6,6.8$ e 6.10 .

O cálculo foi feito de acordo com a ABNT NBR 8522:2008, da seguinte maneira:

$$
E_{c}=\frac{\Delta \sigma}{\Delta \varepsilon} 10^{-3}=\frac{\sigma_{b}-0,5}{\varepsilon_{b}-\varepsilon_{a}} 10^{-3}
$$

$\sigma_{b}$ é igual a $0,30 \mathrm{f}_{c}$;

0,5 é a tensão básica;

$\varepsilon_{b}$ é a deformação específica correspondente a $\sigma_{b}$;

$\varepsilon_{a}$ é a deformação específica correspondente a tensão básica (0,5 $\left.\mathrm{MPa}\right)$.

\subsubsection{Temperatura ambiente}

Na tabela 6.8, podem-se observar todos os dados necessários para o cálculo do módulo de elasticidade segundo a ABNT NBR 8522:2008. Essa tabela apresenta, para os corpos de prova relativos à temperatura ambiente, o valor médio igual a 14,16 GPa.

Tabela 6.8. Módulo de elasticidade estático $\left(\mathrm{E}_{\mathrm{c}}\right)$ dos corpos de prova em temperatura ambiente.

\begin{tabular}{|c|c|c|c|c|c|c|}
\hline CP's & $\mathrm{f}_{\mathrm{c}}(\mathrm{MPa})$ & $\begin{array}{c}\sigma_{\mathrm{b}}=0,30 . \mathrm{fc} \\
(\mathrm{MPa})\end{array}$ & $\begin{array}{c}\text { Tensão } \\
\text { básica (MPa) }\end{array}$ & $\varepsilon_{b}(\% 0)$ & $\varepsilon_{a}(\% o)$ & $\mathrm{E}_{\mathrm{c}}(\mathrm{GPa})$ \\
\hline CP1 & 11,24 & 3,37 & 0,50 & 0,265 & 0,038 & 12,64 \\
\hline CP2 & 14,38 & 4,31 & 0,50 & 0,270 & 0,029 & 15,81 \\
\hline CP3 & 13,17 & 3,95 & 0,50 & 0,271 & 0,037 & 14,74 \\
\hline CP4 & 12,57 & 3,77 & 0,50 & 0,278 & 0,035 & 13,46 \\
\hline & & & & & MÉDIA & 14,16 \\
\hline
\end{tabular}




\subsubsection{Temperatura de $200 \stackrel{\circ}{C}$}

Na tabela 6.9, podem-se observar todos os dados necessários para o cálculo do módulo de elasticidade segundo a ABNT NBR 8522:2008. Essa tabela apresenta, para os corpos de prova que foram aquecidos a $200^{\circ} \mathrm{C}$, o valor médio igual a $10,23 \mathrm{GPa}$, que é $28 \%$ menor que o obtido para os corpos de prova relativos a temperatura ambiente.

Tabela 6.9. Módulo de elasticidade estático $\left(E_{c}\right)$ dos corpos de prova aquecidos a $200 \stackrel{\circ}{ } \mathrm{C}$.

\begin{tabular}{|c|c|c|c|c|c|c|}
\hline CP's & $f_{c}(\mathrm{MPa})$ & $\begin{array}{c}\sigma_{b}=0,30 . f c \\
(\mathrm{MPa})\end{array}$ & $\begin{array}{c}\text { Tensão } \\
\text { básica (MPa) }\end{array}$ & $\varepsilon_{b}(\% 0)$ & $\varepsilon_{\mathrm{a}}(\% 0)$ & $\mathrm{E}_{\mathrm{c}}(\mathrm{GPa})$ \\
\hline CP1 & 10,51 & 3,15 & 0,50 & 0,327 & 0,052 & 9,64 \\
\hline CP2 & 11,58 & 3,47 & 0,50 & 0,312 & 0,042 & 11,00 \\
\hline CP3 & 9,88 & 2,96 & 0,50 & 0,324 & 0,055 & 9,14 \\
\hline CP4 & 11,62 & 3,49 & 0,50 & 0,313 & 0,044 & 11,12 \\
\hline & & & & & MÉDIA & 10,23 \\
\hline
\end{tabular}

\subsubsection{Temperatura de $400 \stackrel{\circ}{C}$}

$\mathrm{Na}$ tabela 6.10, podem-se observar todos os dados necessários para 0 cálculo do módulo de elasticidade segundo a ABNT NBR 8522:2008. Essa tabela apresenta, para os corpos de prova que foram aquecidos a $400^{\circ} \mathrm{C}$, o valor médio igual a 3,09 GPa, que é $70 \%$ menor que o obtido para os corpos de prova que foram aquecidos a $200 \stackrel{\circ}{ } \mathrm{C}$, e $78 \%$ menor que o relativo aos corpos de prova mantidos em temperatura ambiente. 
Tabela 6.10. Módulo de elasticidade estático $\left(\mathrm{E}_{c}\right)$ dos corpos de prova aquecidos a $400{ }^{\circ} \mathrm{C}$.

\begin{tabular}{|c|c|c|c|c|c|c|}
\hline CP's & $\mathrm{f}_{\mathrm{c}}(\mathrm{MPa})$ & $\begin{array}{c}\sigma_{b}=0,30 . f c \\
(\mathrm{MPa})\end{array}$ & $\begin{array}{c}\text { Tensão } \\
\text { básica (MPa) }\end{array}$ & $\varepsilon_{\mathrm{b}}(\% \mathrm{o})$ & $\varepsilon_{\mathrm{a}}(\% 0)$ & $E_{c}(G P a)$ \\
\hline CP1 & 4,48 & 1,34 & 0,50 & 0,439 & 0,164 & 3,05 \\
\hline $\mathrm{CP} 2$ & 4,40 & 1,32 & 0,50 & 0,420 & 0,137 & 2,90 \\
\hline $\mathrm{CP} 3$ & 4,93 & 1,48 & 0,50 & 0,405 & 0,118 & 3,41 \\
\hline CP4 & 5,01 & 1,50 & 0,50 & 0,479 & 0,146 & 3,00 \\
\hline & & & & & MÉDIA & 3,09 \\
\hline
\end{tabular}

\subsubsection{Temperatura de $600 \stackrel{\circ}{C}$}

$\mathrm{Na}$ tabela 6.11, podem-se observar todos os dados necessários para 0 cálculo do módulo de elasticidade segundo a ABNT NBR 8522:2008. Essa tabela apresenta, para os corpos de prova que foram aquecidos a $600^{\circ} \mathrm{C}$, o valor médio igual a $0,73 \mathrm{GPa}$, que é $76 \%$ menor que o obtido para os corpos de prova que foram

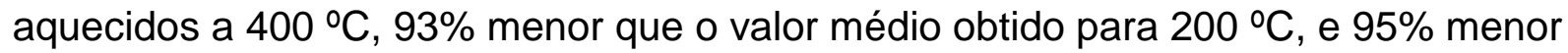
que o relativo à temperatura ambiente.

Tabela 6.11. Módulo de elasticidade estático $\left(E_{c}\right)$ dos corpos de prova aquecidos a $600{ }^{\circ} \mathrm{C}$.

\begin{tabular}{|c|c|c|c|c|c|c|}
\hline CP's & $f_{c}(\mathrm{MPa})$ & $\begin{array}{c}\sigma_{\mathrm{b}}=0,30 . \mathrm{fc} \\
(\mathrm{MPa})\end{array}$ & $\begin{array}{c}\text { Tensão } \\
\text { básica (MPa) } \\
\end{array}$ & $\varepsilon_{b}(\%)$ & $\varepsilon_{\mathrm{a}}(\% 0)$ & $E_{c}(G P a)$ \\
\hline CP1 & 3,35 & 1,01 & 0,50 & 1,382 & 0,641 & 0,69 \\
\hline $\mathrm{CP} 2$ & 3,18 & 0,95 & 0,50 & 1,045 & 0,492 & 0,81 \\
\hline $\mathrm{CP} 3$ & 2,45 & 0,74 & 0,50 & 0,855 & 0,538 & 0,76 \\
\hline CP4 & 2,82 & 0,85 & 0,50 & 1,226 & 0,705 & 0,67 \\
\hline & & & & & MÉDIA & 0,73 \\
\hline
\end{tabular}

\subsubsection{Módulo de elasticidade estático versus Temperatura}

Na figura 6.13, pode-se ver a variação do módulo de elasticidade estático em função da temperatura. 
Pode-se observar que, para a temperatura de $200{ }^{\circ} \mathrm{C}$, o módulo de elasticidade teve uma redução de aproximadamente $28 \%$, para $400{ }^{\circ} \mathrm{C}$, a redução foi de $78 \%$, e para $600 \stackrel{\circ}{\circ}, 95 \%$. Para este caso, a maior variação do módulo de elasticidade ocorreu entre as temperaturas de $200{ }^{\circ} \mathrm{C}$ e $600 \stackrel{\circ}{\mathrm{C}}$, assim como para a resistência à compressão.

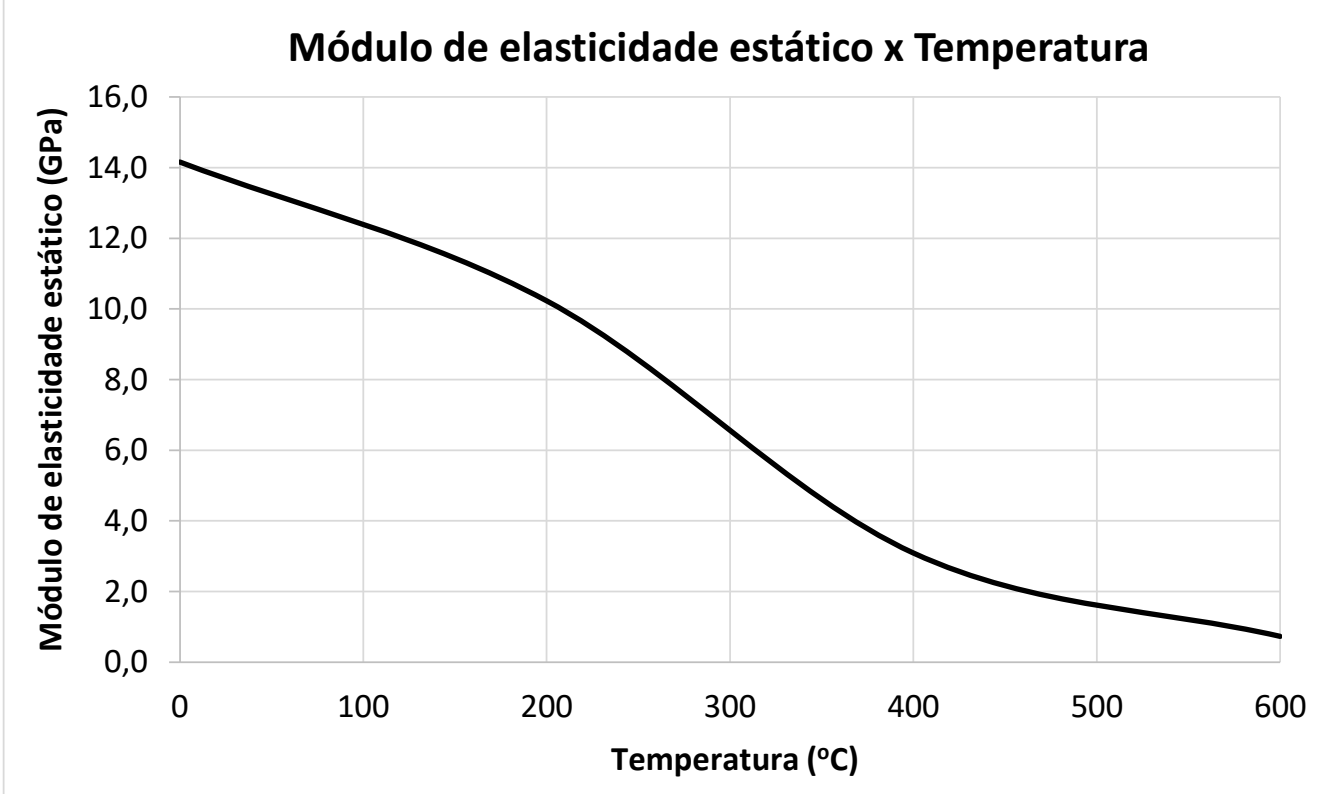

Figura 6.13. Módulo de elasticidade estático $\left(E_{c}\right)$ em função da temperatura.

Fazendo uma comparação com o concreto convencional preparado com agregado silicoso, usando os dados da tabela 1 da ABNT NBR 15200:2004, encontra-se que para $200 \stackrel{\circ}{\mathrm{C}}$ a redução foi de $10 \%$, para $400 \stackrel{\circ}{\mathrm{C}}$, foi de $44 \%$, para $600 \stackrel{\circ}{\circ}$, de $80 \%$, e para $800 \stackrel{\circ}{\circ}$, a redução foi de $98 \%$, conforme pode ser visto na figura 6.14. Neste caso, a maior variação do módulo de elasticidade ocorreu entre as temperaturas de $200^{\circ} \mathrm{C}$ e $800^{\circ} \mathrm{C}$, assim como para a resistência à compressão.

Na mesma figura 6.14, pode-se ver o gráfico do fator de redução $\left(\mathrm{k}_{\mathrm{c}, \theta}\right)$ do módulo de elasticidade estático em função da temperatura, para o concreto leve com EPS.

O cálculo desse fator de redução análogo aos outros já vistos:

$$
\mathrm{k}_{\mathrm{c}, \theta}=\frac{\mathrm{E}_{\mathrm{c}, \theta}}{\mathrm{E}_{\mathrm{c}}} \cdot 100
$$

$\mathrm{E}_{\mathrm{c}, \theta}$ é o módulo de elasticidade estático na temperatura $\theta$;

$\mathrm{E}_{\mathrm{c}}$ é o módulo de elasticidade estático em temperatura ambiente. 


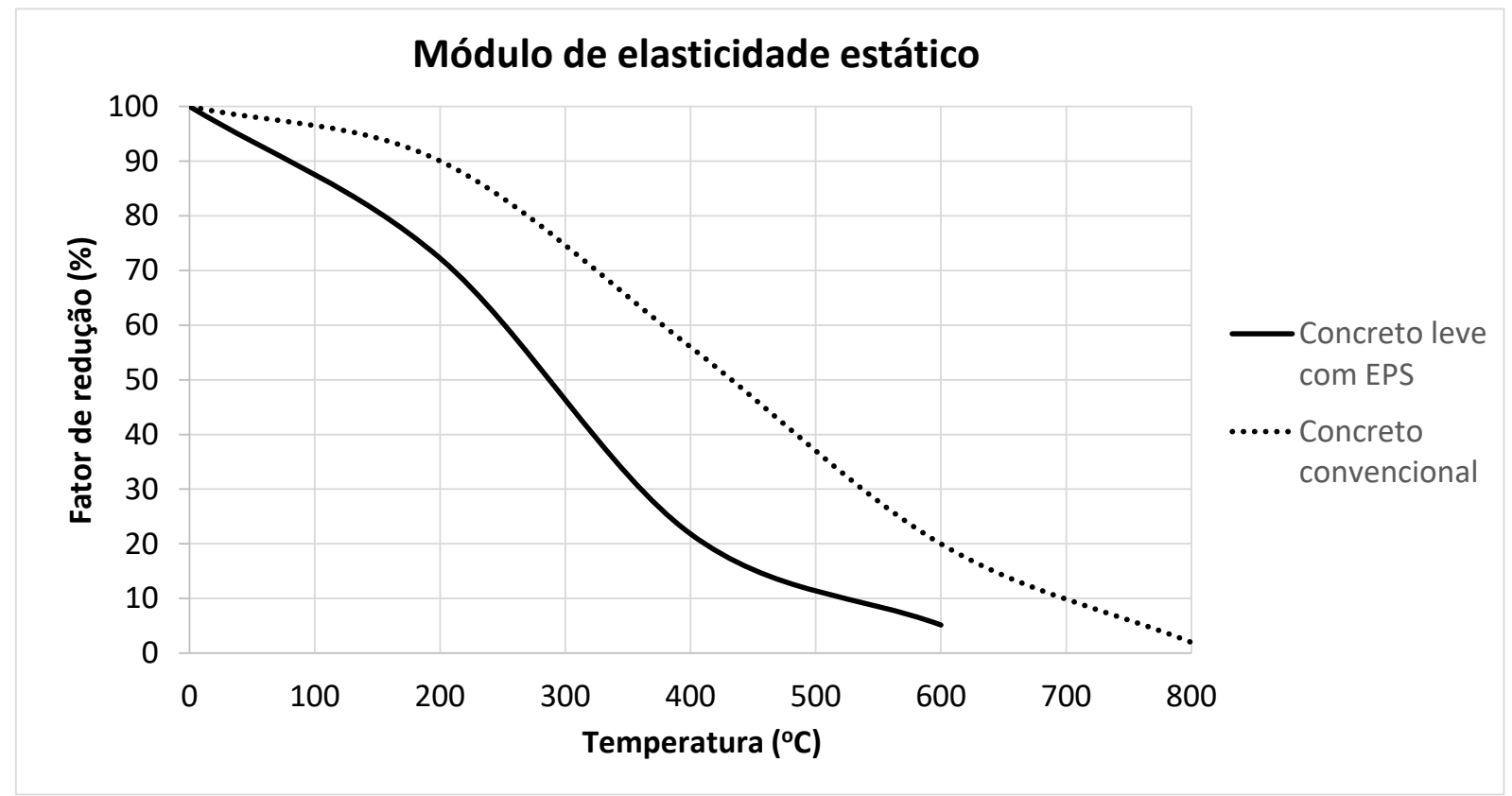

Figura 6.14. Fator de redução do módulo de elasticidade estático $\left(E_{c}\right)$ em função da temperatura.

\subsection{Módulo de elasticidade dinâmico $\left(E_{d}\right)$}

$\mathrm{Na}$ figura 6.15, pode-se ver o equipamento Sonelastic ${ }^{\circledR}$ utilizado para a caracterização não destrutiva do módulo de elasticidade, baseada na técnica de excitação por impulso.

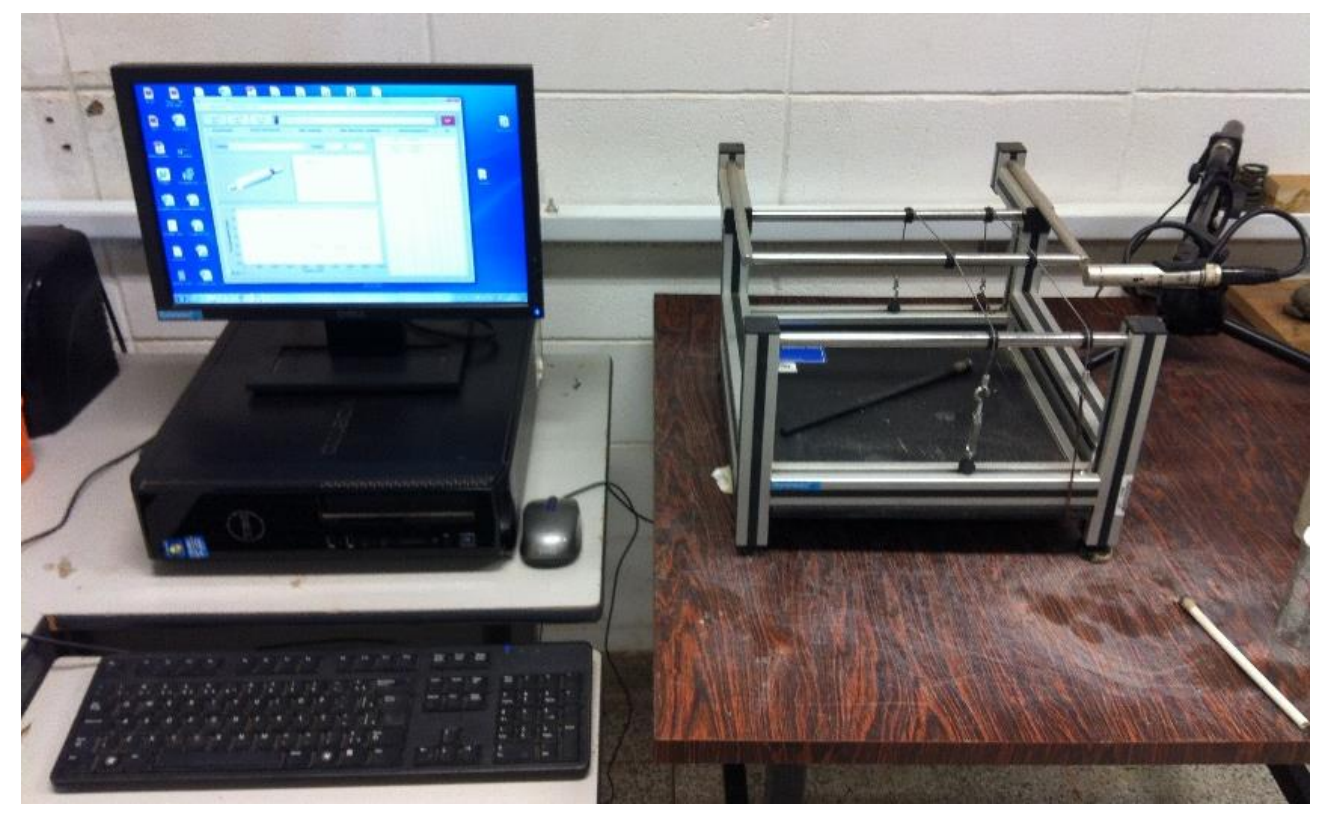

Figura 6.15. Equipamento Sonelastic ${ }^{\circledR}$ 
Por ser um ensaio não destrutivo, foi possível reutilizar o mesmo corpo de prova para os ensaios de compressão axial e de módulo de elasticidade estático. É possível fazer o ensaio com essa tecnologia porque cada material ao ser golpeado emite um som específico, que contém informações que permitem determinar a propriedade elástica.

\subsubsection{Temperatura ambiente}

Na tabela 6.12, têm-se os resultados do módulo de elasticidade dinâmico obtidos com os corpos de prova relativos à temperatura ambiente, em que o valor médio é 10,73 GPa.

Tabela 6.12. Módulo de elasticidade dinâmico $\left(E_{d}\right)$ dos corpos de prova em temperatura ambiente.

\begin{tabular}{c|c}
\hline CP's & $\mathbf{E}_{\mathbf{d}}$ (GPa) \\
\hline CP1 & 9,46 \\
\hline CP2 & 11,90 \\
\hline CP3 & 11,09 \\
\hline CP4 & 10,45 \\
\hline MÉDIA & 10,73 \\
\hline
\end{tabular}

\subsubsection{Temperatura de $200 \stackrel{\circ}{C}$}

Na tabela 6.13, têm-se os resultados para o módulo de elasticidade dinâmico obtidos com os corpos de prova que foram aquecidos a $200^{\circ} \mathrm{C}$, em que o valor médio é $8,02 \mathrm{GPa}, 25 \%$ menor que o obtido para os corpos de prova em temperatura ambiente. 
Tabela 6.13. Módulo de elasticidade dinâmico $\left(E_{d}\right)$ dos corpos de prova aquecidos a $200 \stackrel{\circ}{C}$.

\begin{tabular}{c|c}
\hline CP's & $\mathbf{E}_{\mathbf{d}}$ (GPa) \\
\hline CP1 & 7,42 \\
\hline CP2 & 8,42 \\
\hline CP3 & 8,87 \\
\hline CP4 & 7,35 \\
\hline MÉDIA & $\mathbf{8 , 0 2}$ \\
\hline
\end{tabular}

\subsubsection{Temperatura de $400{ }^{\circ} \mathrm{C}$}

Na tabela 6.14, têm-se os resultados para o módulo de elasticidade dinâmico obtidos com os corpos de prova que foram aquecidos a $400^{\circ} \mathrm{C}$, em que o valor médio é $2,77 \mathrm{GPa}, 65 \%$ menor que o obtido para os corpos de prova que foram aquecidos a $200 \stackrel{\circ}{\circ}$, e $74 \%$ menor que o relativo aos corpos de prova em temperatura ambiente.

Tabela 6.14. Módulo de elasticidade dinâmico $\left(E_{d}\right)$ dos corpos de prova aquecidos a $400{ }^{\circ} \mathrm{C}$.

\begin{tabular}{c|c}
\hline CP's & $\mathbf{E}_{\mathrm{d}}$ (GPa) \\
\hline CP1 & 2,65 \\
\hline CP2 & 2,89 \\
\hline CP3 & 2,87 \\
\hline CP4 & 2,66 \\
\hline MÉDIA & $\mathbf{2 , 7 7}$ \\
\hline
\end{tabular}




\subsubsection{Temperatura de $600 \stackrel{\circ}{C}$}

Na tabela 6.15, têm-se os resultados para o módulo de elasticidade dinâmico obtidos com os corpos de prova que foram aquecidos a $600^{\circ} \mathrm{C}$, em que o valor médio é $0,96 \mathrm{GPa}, 65 \%$ menor que o obtido para os corpos de prova que foram

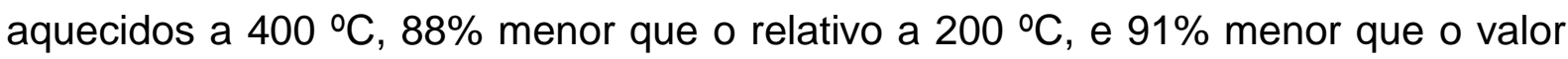
médio para temperatura ambiente.

Tabela 6.15. Módulo de elasticidade dinâmico $\left(E_{d}\right)$ dos corpos de prova aquecidos a $600{ }^{\circ} \mathrm{C}$.

\begin{tabular}{c|c}
\hline CP's & $E_{d}$ (GPa) \\
\hline CP1 & 0,85 \\
\hline CP2 & 0,94 \\
\hline CP3 & 1,05 \\
\hline CP4 & 1,01 \\
\hline MÉDIA & $\mathbf{0 , 9 6}$ \\
\hline
\end{tabular}

\subsubsection{Módulo de elasticidade dinâmico versus Temperatura}

Na figura 6.16, pode-se ver a variação do módulo de elasticidade dinâmico em função da temperatura. E na figura 6.17 , tem-se o fator de redução em função da temperatura.

O cálculo desse fator de redução é análogo aos outros já vistos:

$$
\mathrm{k}_{\mathrm{d}, \theta}=\frac{\mathrm{E}_{\mathrm{d}, \theta}}{\mathrm{E}_{\mathrm{d}}} \cdot 100
$$

$E_{\mathrm{d}, \theta}$ é o módulo de elasticidade dinâmico na temperatura $\theta$;

$\mathrm{E}_{\mathrm{d}}$ é o módulo de elasticidade dinâmico em temperatura ambiente. 


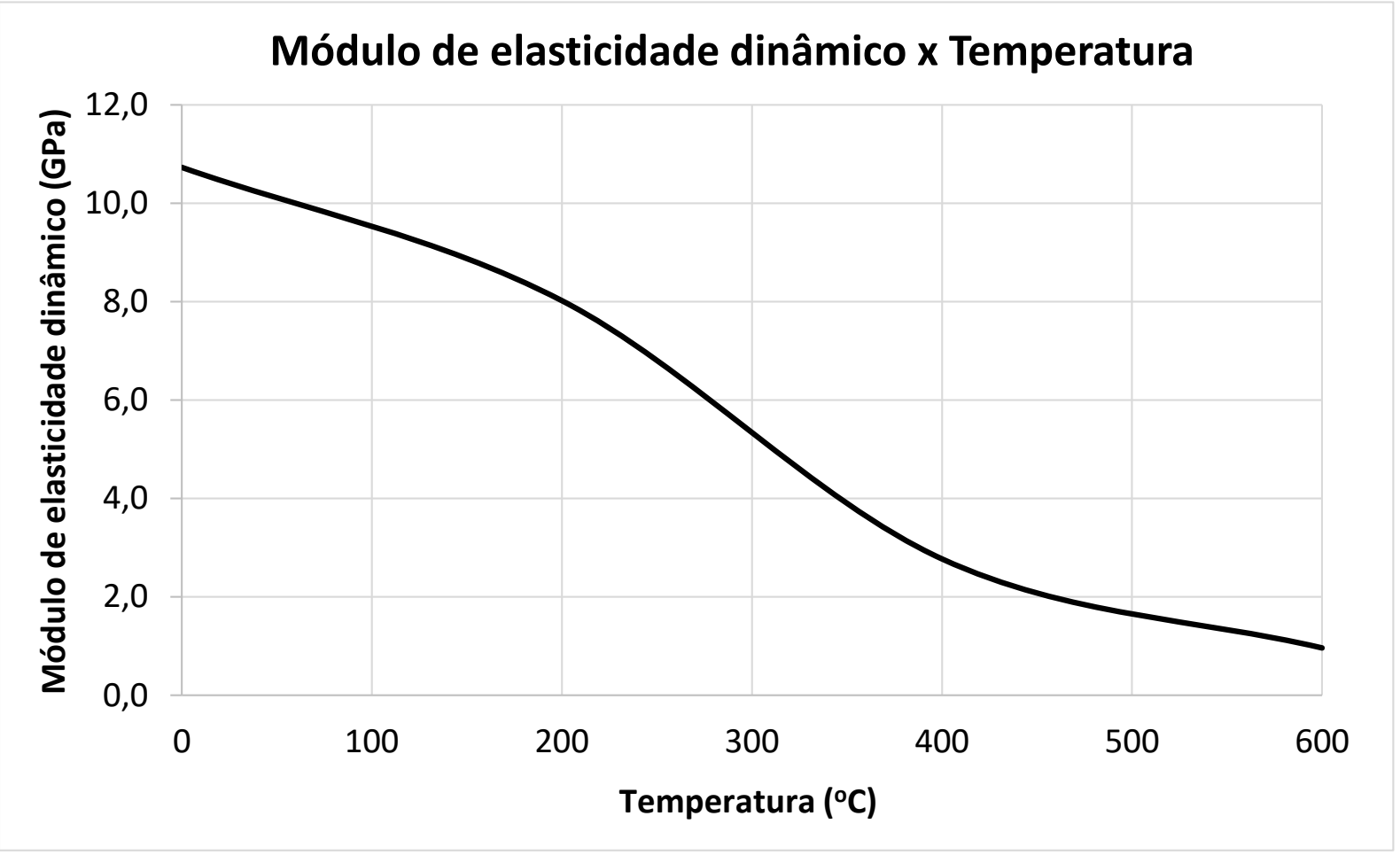

Figura 6.16. Módulo de elasticidade dinâmico $\left(E_{d}\right)$ em função da temperatura.

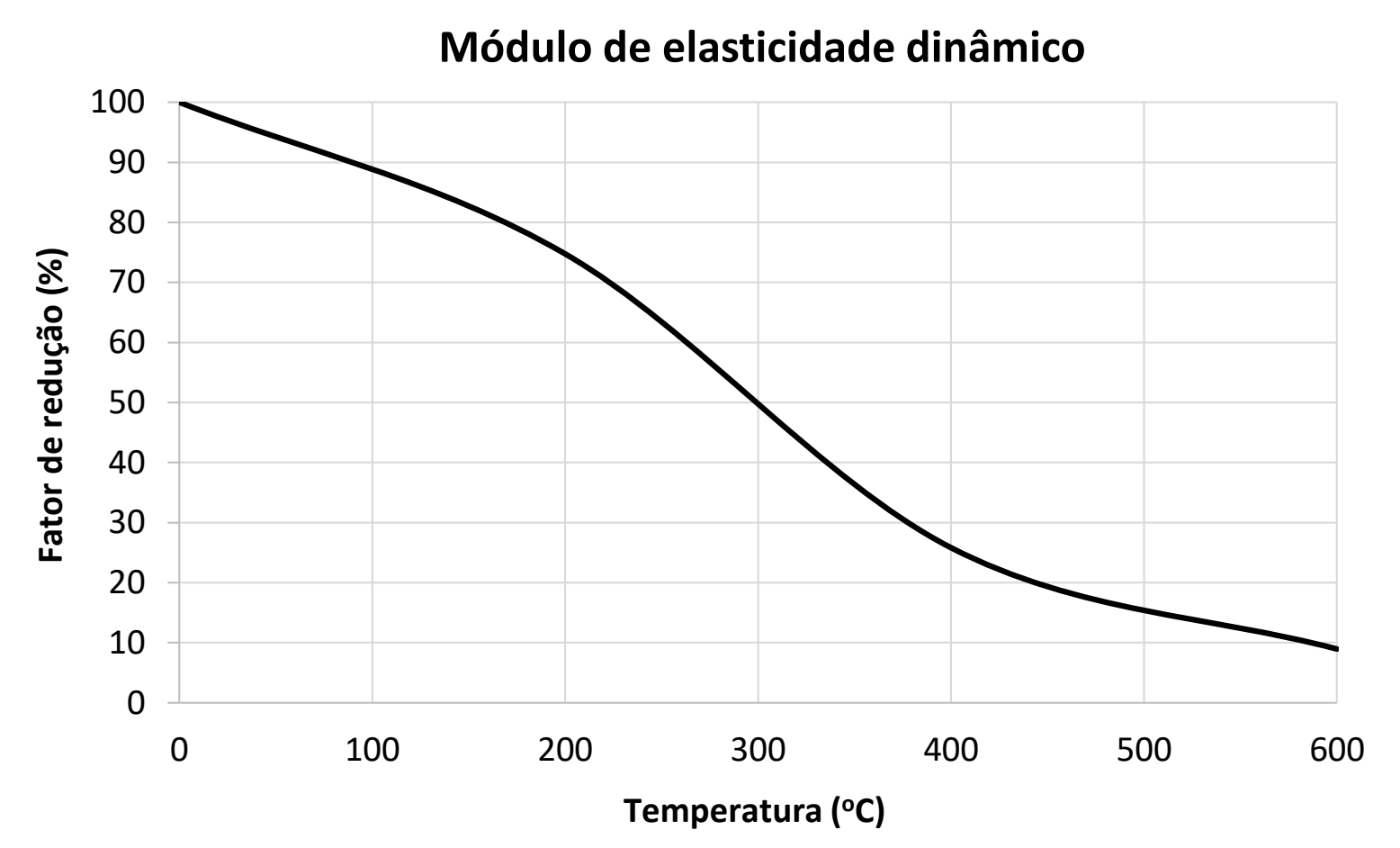

Figura 6.17. Fator de redução do módulo de elasticidade dinâmico $\left(E_{d}\right)$ em função da temperatura. 


\subsection{Resistência à tração por compressão diametral $\left(f_{c t, s p}\right)$}

Na figura 6.18, é mostrado o ensaio de resistência à tração por compressão diametral, de acordo com a ABNT NBR 7222:2011, que foi realizado na máquina hidráulica da marca ELE INTERNATIONAL, modelo autotest 2000, e que possui capacidade de $2000 \mathrm{kN}$.

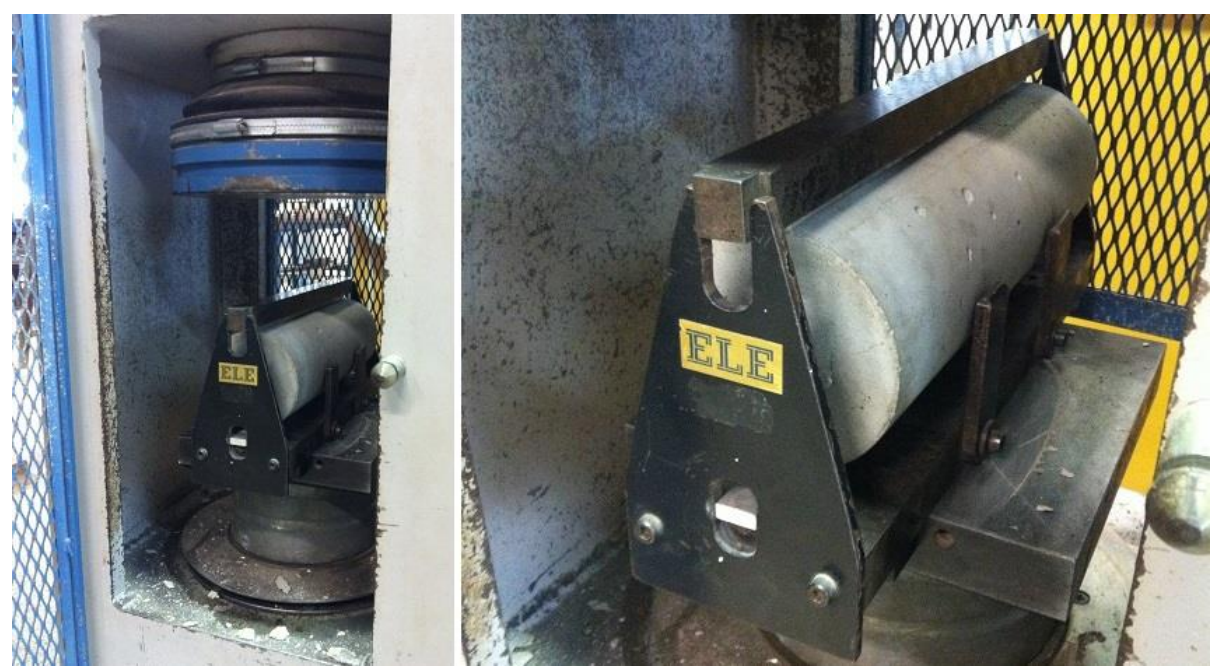

Figura 6.18. Ensaio de resistência à tração por compressão diametral.

\subsubsection{Temperatura ambiente}

$\mathrm{Na}$ tabela 6.16, têm-se os resultados para a resistência à tração por compressão diametral obtidos com os corpos de prova em temperatura ambiente, em que o valor médio é 1,05 MPa.

Tabela 6.16. Resistência à tração por compressão diametral $\left(f_{c t, s p}\right)$ para os corpos de prova em temperatura ambiente.

\begin{tabular}{|c|c|c|c|c|}
\hline CP's & $\begin{array}{c}\text { Carga máxima } \\
(\mathbf{k N})\end{array}$ & Diâmetro (mm) & $\begin{array}{c}\text { Comprimento } \\
(\mathrm{mm})\end{array}$ & $f_{c t, s p}(\mathrm{MPa})$ \\
\hline $\mathrm{CP} 1$ & 46,90 & 100 & 299 & 1,00 \\
\hline $\mathrm{CP} 2$ & 48,60 & 100 & 299 & 1,03 \\
\hline $\mathrm{CP} 3$ & 48,60 & 100 & 298 & 1,04 \\
\hline $\mathrm{CP} 4$ & 53,10 & 100 & 299 & 1,13 \\
\hline & & & MÉDIA & 1,05 \\
\hline
\end{tabular}




\subsubsection{Temperatura de $200 \stackrel{\circ}{C}$}

$\mathrm{Na}$ tabela 6.17, têm-se os resultados para a resistência à tração por compressão diametral obtidos com os corpos de prova que foram aquecidos a $200 \stackrel{\circ}{\circ}$, em que o valor médio é $0,94 \mathrm{GPa}, 10 \%$ menor que o obtido para os corpos de prova em temperatura ambiente.

Tabela 6.17. Resistência à tração por compressão diametral $\left(f_{c t, s p}\right)$ dos corpos de prova aquecidos a $200 \stackrel{\circ}{ } \mathrm{C}$.

\begin{tabular}{|c|c|c|c|c|}
\hline CP's & $\begin{array}{c}\text { Carga máxima } \\
(\mathrm{kN})\end{array}$ & Diâmetro (mm) & $\begin{array}{c}\text { Comprimento } \\
(\mathrm{mm})\end{array}$ & $f_{c t, s p}(\mathrm{MPa})$ \\
\hline CP1 & 46,30 & 100 & 295 & 1,00 \\
\hline $\mathrm{CP} 2$ & 47,10 & 100 & 299 & 1,00 \\
\hline $\mathrm{CP} 3$ & 46,10 & 100 & 295 & 0,99 \\
\hline CP4 & 35,90 & 100 & 296 & 0,77 \\
\hline & & & MÉDIA & 0,94 \\
\hline
\end{tabular}

\subsubsection{Temperatura de $400 \stackrel{\circ}{C}$}

$\mathrm{Na}$ tabela 6.18, têm-se os resultados para a resistência à tração por compressão diametral obtidos com os corpos de prova que foram aquecidos a $400 \stackrel{\circ}{\circ}$, em que o valor médio é $0,37 \mathrm{GPa}, 61 \%$ menor que o obtido para os corpos de prova que foram aquecidos a $200{ }^{\circ} \mathrm{C}$ e $65 \%$ menor que o relativo a temperatura ambiente. 
Tabela 6.18. Resistência à tração por compressão diametral $\left(\mathrm{f}_{\mathrm{ct}, \mathrm{sp}}\right)$ dos corpos de prova aquecidos a $400 \stackrel{\circ}{ } \mathrm{C}$.

\begin{tabular}{|c|c|c|c|c|}
\hline CP's & $\begin{array}{c}\text { Carga máxima } \\
\text { (kN) }\end{array}$ & Diâmetro (mm) & $\begin{array}{c}\text { Comprimento } \\
(\mathrm{mm})\end{array}$ & $f_{c t, s p}(\mathrm{MPa})$ \\
\hline CP1 & 17,10 & 100 & 296 & 0,37 \\
\hline $\mathrm{CP} 2$ & 18,80 & 100 & 296 & 0,40 \\
\hline CP3 & 17,40 & 100 & 294 & 0,38 \\
\hline CP4 & 15,00 & 100 & 299 & 0,32 \\
\hline & & & MÉDIA & 0,37 \\
\hline
\end{tabular}

\subsubsection{Temperatura de $600 \stackrel{\circ}{C}$}

$\mathrm{Na}$ tabela 6.19, têm-se os resultados para a resistência à tração por compressão diametral obtidos com os corpos de prova que foram aquecidos a $600^{\circ} \mathrm{C}$, em que o valor médio é $0,30 \mathrm{GPa}, 19 \%$ menor que o obtido para os corpos de prova que foram aquecidos a $400 \stackrel{\circ}{\circ}$, $68 \%$ menor que o relativo a $200{ }^{\circ} \mathrm{C}$ e $71 \%$ menor que o obtido para temperatura ambiente.

Tabela 6.19. Resistência à tração por compressão diametral $\left(f_{c t, s p}\right)$ dos corpos de prova aquecidos a $600 \stackrel{\circ}{\circ}$.

\begin{tabular}{|c|c|c|c|c|}
\hline CP's & $\begin{array}{c}\text { Carga máxima } \\
\text { (kN) }\end{array}$ & Diâmetro (mm) & $\begin{array}{c}\text { Comprimento } \\
(\mathrm{mm})\end{array}$ & $f_{c t, s p}(\mathrm{MPa})$ \\
\hline CP1 & 13,70 & 100 & 295 & 0,30 \\
\hline $\mathrm{CP} 2$ & 14,70 & 100 & 295 & 0,32 \\
\hline CP3 & 14,70 & 100 & 297 & 0,32 \\
\hline $\mathrm{CP} 4$ & 12,60 & 100 & 298 & 0,27 \\
\hline & & & MÉDIA & 0,30 \\
\hline
\end{tabular}




\subsubsection{Resistência à tração por compressão diametral versus Temperatura}

Na figura 6.19, pode-se ver a variação da resistência à tração por compressão diametral em função da temperatura.

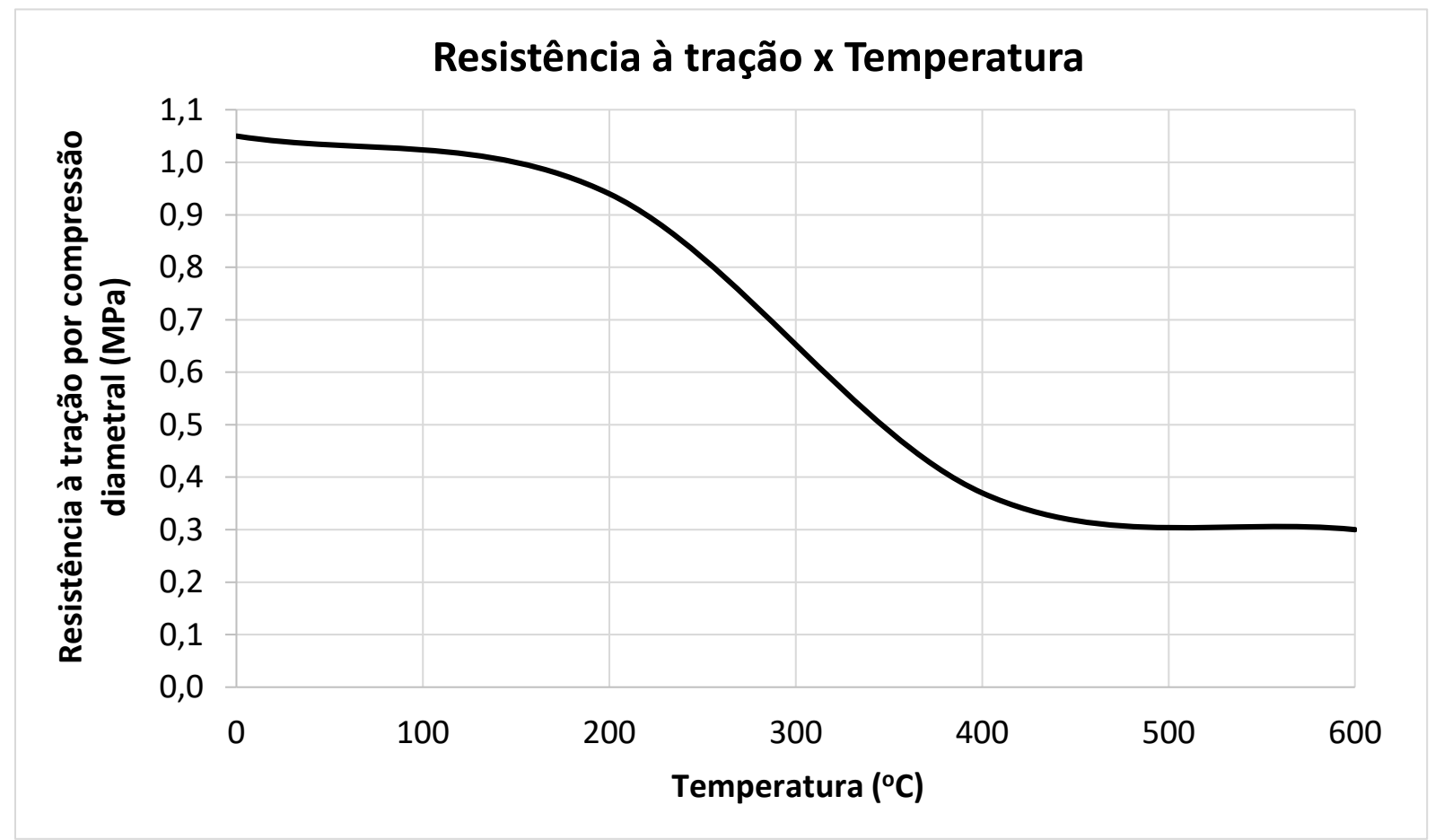

Figura 6.19. Resistência à tração por compressão diametral ( $\left.f_{c t, s p}\right)$ em função da temperatura.

$\mathrm{Na}$ figura 6.20, tem-se $\mathrm{o}$ fator de redução em função da temperatura. $\mathrm{O}$ cálculo desse fator de redução é análogo aos outros já vistos:

$$
\mathrm{k}_{\mathrm{ct}, \mathrm{sp}, \theta}=\frac{\mathrm{f}_{\mathrm{ct}, \mathrm{sp}, \theta}}{\mathrm{f}_{\mathrm{ct}, \mathrm{sp}}} \cdot 100
$$

$\mathrm{f}_{\mathrm{ct}, \mathrm{sp}, \theta}$ é a resistência à tração por compressão diametral na temperatura $\theta$;

$\mathrm{f}_{\mathrm{ct}, \mathrm{sp}}$ é a resistência à tração por compressão diametral em temperatura ambiente. 


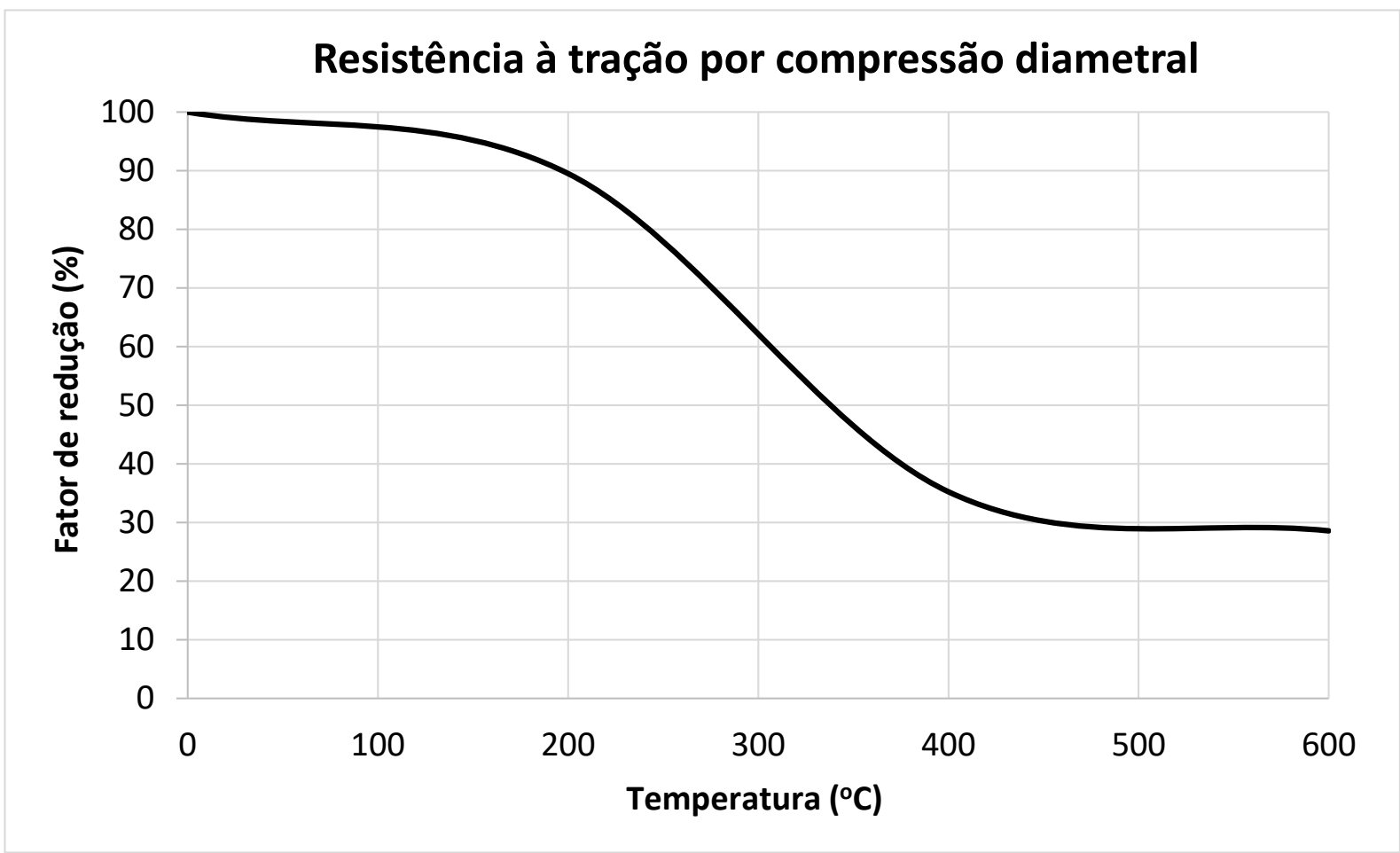

Figura 6.20. Fator de redução da resistência à tração por compressão diametral $\left(f_{c t, s p}\right)$ em função da temperatura.

\subsection{Resistência à tração na flexão $\left(f_{c t, f}\right)$ e fator de tenacidade (FT)}

O ensaio foi realizado na máquina servo-hidráulica da marca INSTRON, modelo $300 \mathrm{HVL}$, que tem capacidade de carga de $1500 \mathrm{kN}$. Essa máquina pode ser vista na figura 6.21. O ensaio foi por controle de deslocamento, com velocidade de $0,005 \mathrm{~mm} / \mathrm{s}$.

Foram feitos ensaios de quatro pontos com corpos de prova em temperatura ambiente e com corpos de prova após serem submetidos às temperaturas de $200{ }^{\circ} \mathrm{C}$ e $600{ }^{\circ} \mathrm{C}$. Foram avaliados a resistência à tração na flexão, segundo a ABNT NBR 12142:2010, e o fator de tenacidade, de acordo com a norma japonesa JSCESF4:1984, que é o procedimento mais utilizado no Brasil.

Vale destacar que, em todos os ensaios realizados, o vão foi $450 \mathrm{~mm}$, e os prismas apresentaram a ruptura em seu terço central. 

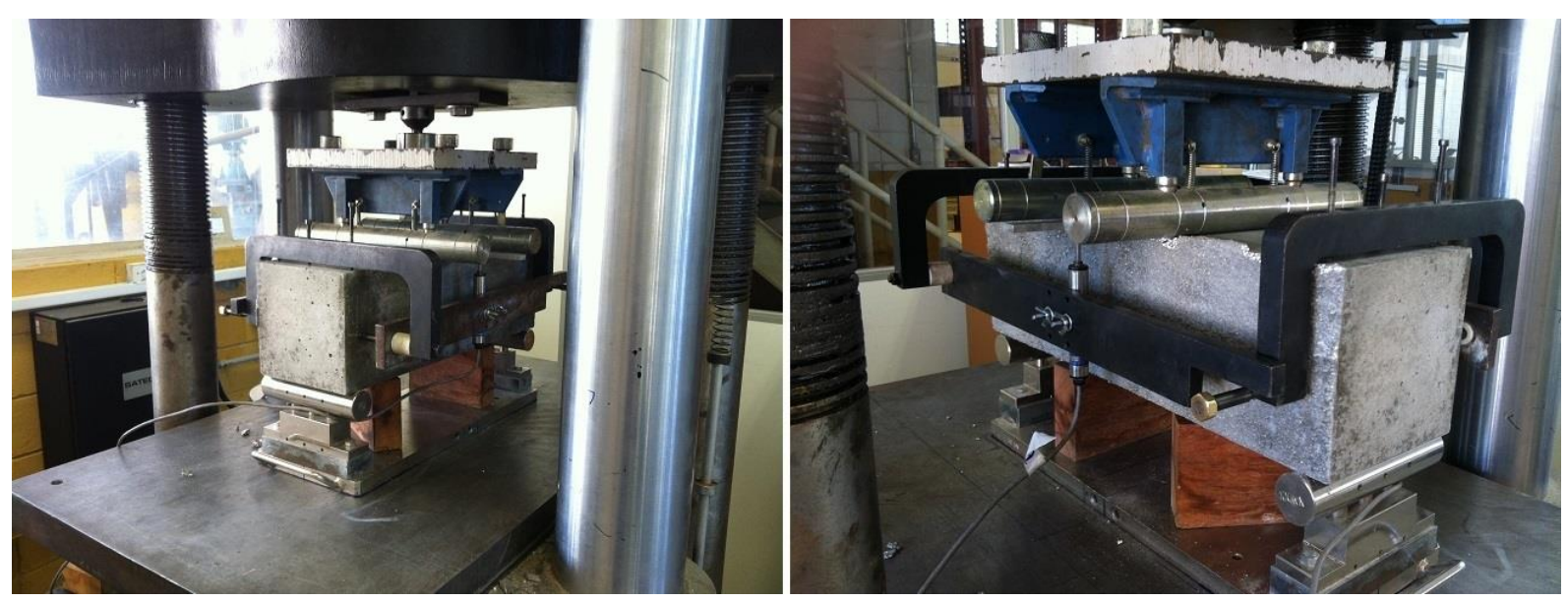

Figura 6.21. Corpo de prova prismático, instrumentado, sendo ensaiado na máquina INSTRON.

Sendo $F$ a carga máxima, a resistência à tração na flexão foi calculada pela seguinte expressão:

$$
f_{c t, f}=\frac{F \cdot L}{b \cdot d^{2}}=\frac{F \cdot 450}{150 \cdot 150^{2}}=\frac{F \cdot 450}{150^{3}} \rightarrow \boldsymbol{f}_{c t, f}=\frac{\boldsymbol{F}}{\mathbf{7 5 0 0}}
$$

Sendo $T_{b}$ a tenacidade na flexão, o fator de tenacidade foi calculado usando a equação 4.1, indicada no item 4.4 deste trabalho, como mostrado a seguir:

$$
F T=\frac{T_{b}}{\delta_{t b}} \cdot \frac{L}{b \cdot h^{2}}=\frac{T_{b}}{\frac{L}{150}} \cdot \frac{L}{b \cdot h^{2}}=\frac{T_{b}}{\frac{450}{150}} \cdot \frac{450}{150 \cdot 150^{2}} \rightarrow \boldsymbol{F T}=\frac{\boldsymbol{T}_{\boldsymbol{b}}}{\mathbf{2 2 5 0 0}}
$$

Para o cálculo de $T_{b}$, foi considerada a área sob a curva até o deslocamento de $3 \mathrm{~mm}$, conforme especifica a norma JSCE-SF4:1984, e nos casos em que o deslocamento máximo foi menor que $3 \mathrm{~mm}$, a área sob a curva foi calculada até o respectivo deslocamento máximo. A área foi calculada usando-se o Excel.

\subsubsection{Traço padrão}

Na figura 6.22, pode-se observar o corpo de prova mantido em temperatura ambiente após a ruptura. Percebe-se que a distribuição do EPS está bem homogênea na seção transversal, assim como na seção transversal do corpo de prova cilíndrico. 


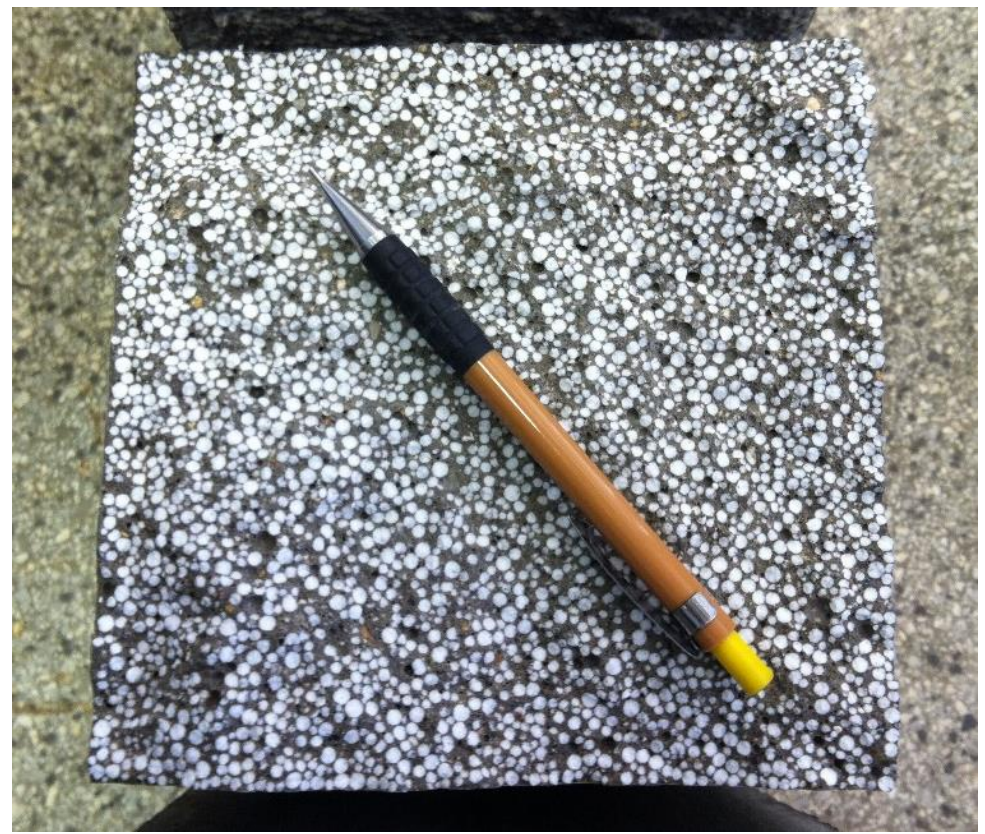

Figura 6.22. Corpo de prova prismático, sem fibras, após a ruptura no ensaio de resistência à tração na flexão (temperatura ambiente).

$\mathrm{Na}$ figura 6.23, pode-se observar o gráfico carga versus deslocamento dos três corpos de prova prismáticos, mantidos à temperatura ambiente.

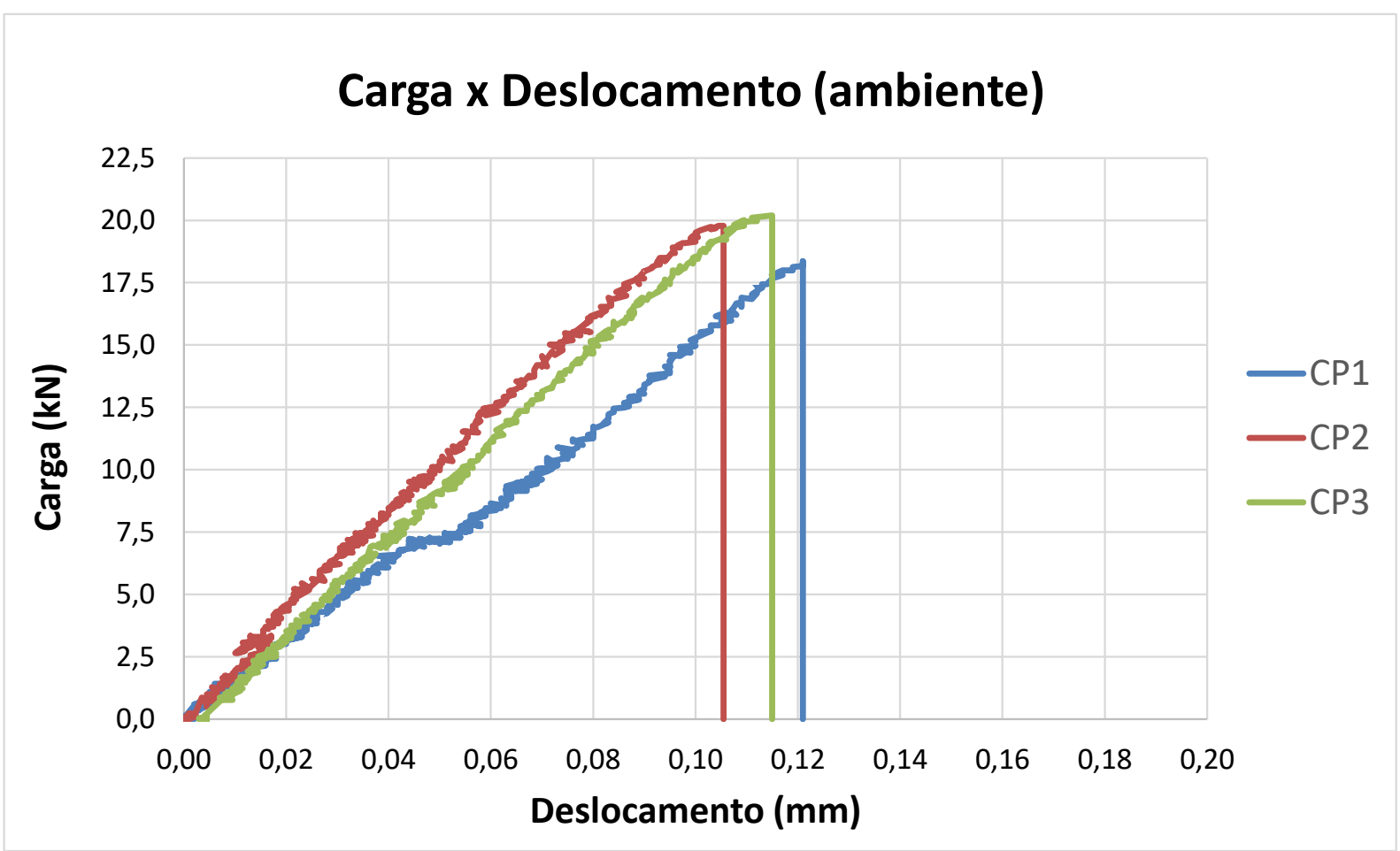

Figura 6.23. Gráfico carga versus deslocamento do ensaio de resistência à tração na flexão dos corpos de prova com o traço padrão, em temperatura ambiente. 
De acordo com o gráfico, apenas o CP1 teve um comportamento um pouco diferente, em comparação aos CP2 e CP3. Vale destacar que o deslocamento máximo não atingiu os $3 \mathrm{~mm}$, chegou apenas a $0,12 \mathrm{~mm}$, o que ocorreu pelo fato do concreto ter uma baixa resistência à tração e estar sem fibras.

$\mathrm{Na}$ tabela 6.20, têm-se os valores médios da resistência à tração na flexão e do fator de tenacidade, que são 2,59 e 0,17 , respectivamente.

Tabela 6.20. Resistência à tração na flexão $\left(f_{c t, f}\right)$ e fator de tenacidade $(F T)$ dos corpos de prova com o traço padrão, mantidos em temperatura ambiente.

\begin{tabular}{c|c|c|c|c}
\hline CP's & $\begin{array}{c}\text { Carga máxima } \\
(\mathbf{k N})\end{array}$ & $\mathbf{f}_{\mathrm{ct}, \mathrm{f}}$ (MPa) & $\mathbf{T}_{\mathbf{b}}$ (N.mm) & $\mathbf{F T}$ (MPa) \\
\hline $\mathrm{CP} 1$ & 18,36 & 2,45 & 4162,82 & 0,19 \\
\hline $\mathrm{CP} 2$ & 19,78 & 2,64 & 3871,40 & 0,17 \\
\hline $\mathrm{CP} 3$ & 20,19 & 2,69 & 3696,99 & 0,16 \\
\hline MÉDIA & $\mathbf{1 9 , 4 4}$ & $\mathbf{2 , 5 9}$ & $\mathbf{3 9 1 0 , 4 0}$ & $\mathbf{0 , 1 7}$ \\
\hline
\end{tabular}

Na figura 6.24, pode-se observar o corpo de prova que foi aquecido a $200{ }^{\circ} \mathrm{C}$, após a ruptura, e é bem visível que o EPS derreteu por completo, enquanto que para o cilindro submetido a $200^{\circ} \mathrm{C}$, ainda existiam traços de EPS.
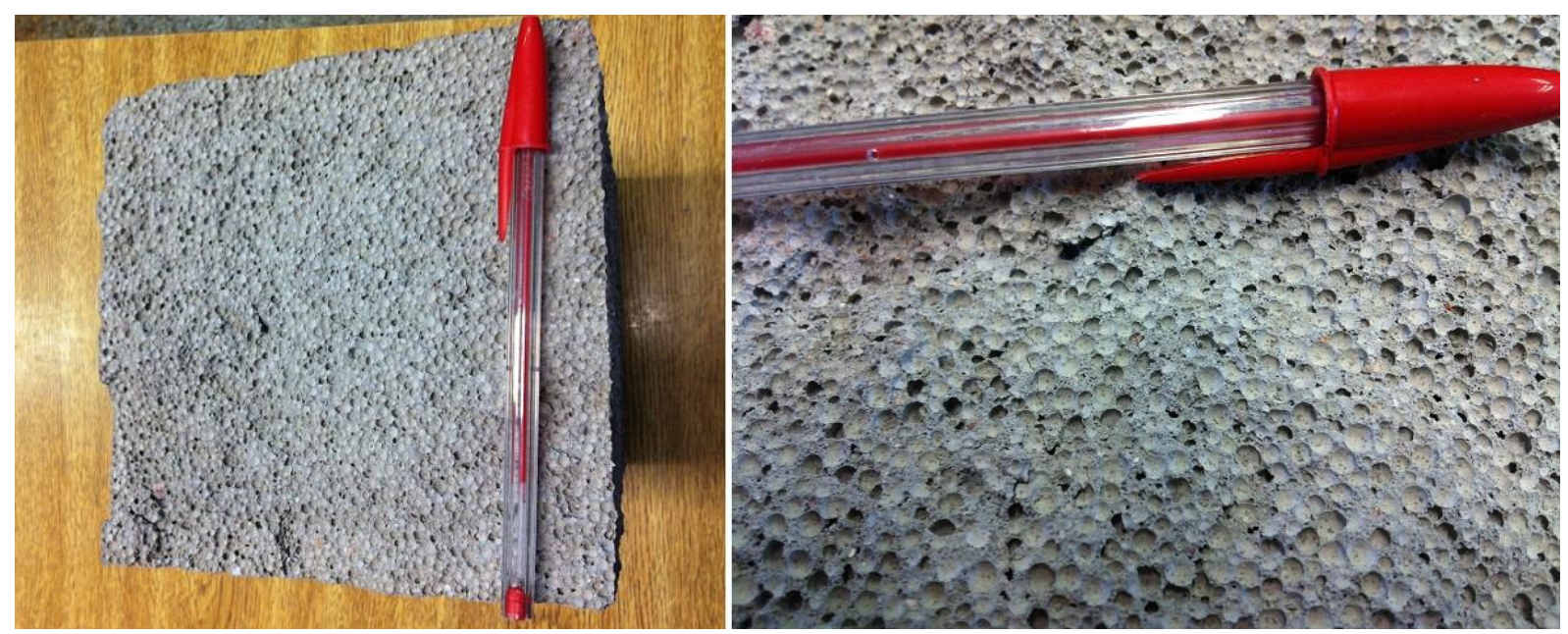

Figura 6.24. Corpo de prova prismático, sem fibras, após a ruptura no ensaio de resistência à tração na flexão $\left(200^{\circ} \mathrm{C}\right)$. 
O fato de o EPS ter derretido nos prismas pode ser explicado pela taxa de aquecimento ser igual à metade $\left(0,5^{\circ} \mathrm{C} / \mathrm{min}\right)$ da utilizada nos cilindros, e isso fez com que o tempo dentro do forno fosse praticamente o dobro. Lembra-se que para os cilindros a $200^{\circ} \mathrm{C}$, o tempo foi de 7 horas, e para os prismas, foi de 13 horas.

$\mathrm{Na}$ figura 6.25, pode-se observar o gráfico carga versus deslocamento dos três corpos de prova prismáticos que foram aquecidos a $200{ }^{\circ} \mathrm{C}$.

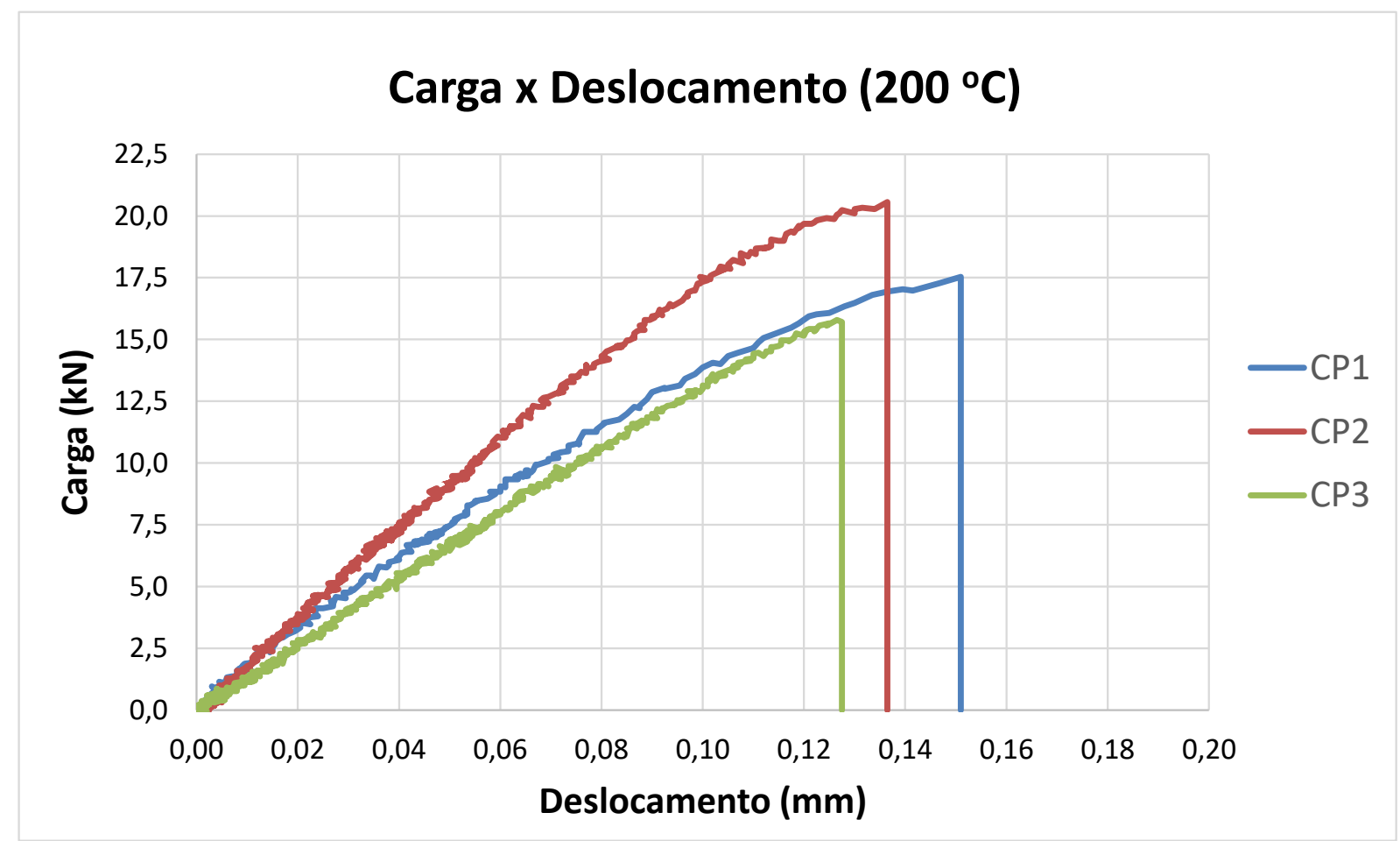

Figura 6.25. Gráfico carga versus deslocamento do ensaio de resistência à tração na flexão dos corpos de prova com o traço padrão, aquecidos a $200^{\circ} \mathrm{C}$.

De acordo com o gráfico, os três apresentaram comportamentos um pouco diferentes entre si. Vale destacar que o deslocamento máximo também não atingiu os $3 \mathrm{~mm}$, chegando apenas até aproximadamente $0,15 \mathrm{~mm}$, o que ocorreu pelo mesmo motivo do caso anterior.

Na tabela 6.21, têm-se os valores médios da resistência à tração na flexão e do fator de tenacidade, que são 2,40 (7\% menor) e 0,14 (18\% menor), respectivamente. Os valores foram comparados aos do caso relativo a temperatura ambiente. 
Tabela 6.21. Resistência à tração na flexão $\left(f_{c t, f}\right)$ e fator de tenacidade $(F T)$ dos corpos de prova com o traço padrão, aquecidos a $200 \stackrel{\circ}{\circ}$.

\begin{tabular}{c|c|c|c|c}
\hline CP's & $\begin{array}{c}\text { Carga máxima } \\
(\mathbf{k N})\end{array}$ & $\mathbf{f}_{\mathrm{ct,f}} \mathbf{( M P a )}$ & $\mathbf{T}_{\mathbf{b}}$ (N.mm) & $\mathbf{F T}$ (MPa) \\
\hline $\mathrm{CP} 1$ & 17,53 & 2,34 & 1955,67 & 0,09 \\
\hline $\mathrm{CP} 2$ & 20,56 & 2,74 & 4063,16 & 0,18 \\
\hline CP3 & 15,80 & 2,11 & 3646,94 & 0,16 \\
\hline MÉDIA & $\mathbf{1 7 , 9 6}$ & $\mathbf{2 , 4 0}$ & $\mathbf{3 2 2 1 , 9 2}$ & $\mathbf{0 , 1 4}$ \\
\hline
\end{tabular}

A aparência da parte interna do corpo de prova que foi aquecido a $600 \stackrel{\circ}{\mathrm{C}}$, após a ruptura, é muito semelhante à do que foi aquecido a $200 \stackrel{\circ}{\circ}$, conforme foi mostrado na figura 6.24 .

$\mathrm{Na}$ figura 6.26, pode-se observar o gráfico carga versus deslocamento dos três corpos de prova prismáticos que foram aquecidos a $600{ }^{\circ} \mathrm{C}$.

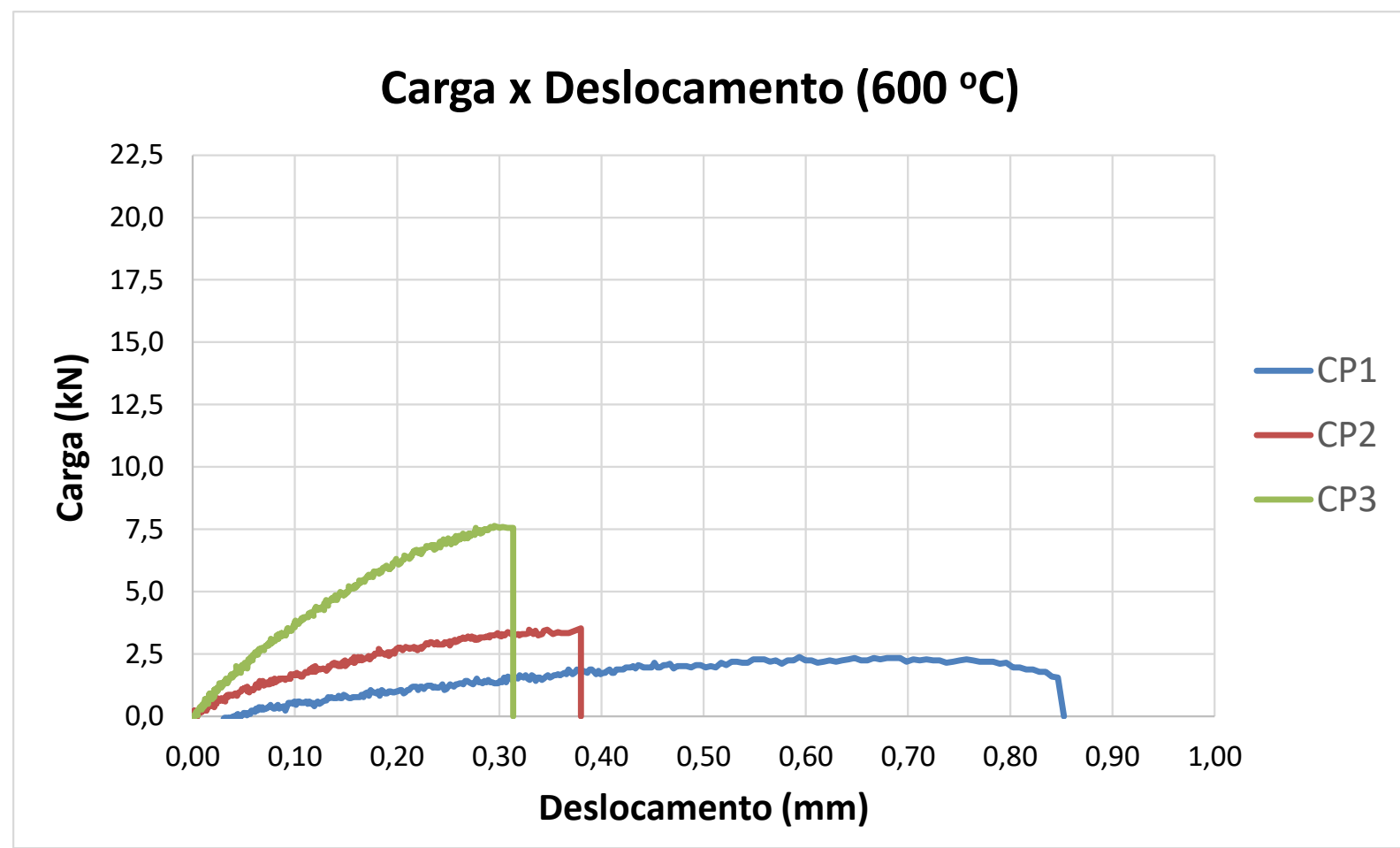

Figura 6.26. Gráfico carga versus deslocamento do ensaio de resistência à tração na flexão dos corpos de prova com o traço padrão, aquecidos a $600{ }^{\circ} \mathrm{C}$. 
De acordo com o gráfico, o CP1 teve um deslocamento bem maior que o CP2 e o CP3, porém também foi menor que $3 \mathrm{~mm}$. Chegou apenas até aproximadamente $0,85 \mathrm{~mm}$, e isso ocorreu também pelo mesmo motivo dos casos anteriores.

Na tabela 6.22, têm-se os valores médios da resistência à tração na flexão e do fator de tenacidade, 0,60 e 0,07, respectivamente, que comparados ao caso com corpos de prova aquecidos a $200 \stackrel{\circ}{\circ}$ são $75 \%$ menor e $50 \%$ menor, respectivamente. E quando comparados ao caso com corpos de prova em temperatura ambiente, são $77 \%$ menor e 59\% menor, respectivamente.

Tabela 6.22. Resistência à tração na flexão $\left(f_{c t, f}\right)$ e fator de tenacidade $(F T)$ dos corpos de prova com o traço padrão, aquecidos a $600 \stackrel{\circ}{\circ}$.

\begin{tabular}{c|c|c|c|c}
\hline CP's & $\begin{array}{c}\text { Carga máxima } \\
(\mathbf{k N})\end{array}$ & $\mathbf{f}_{\mathrm{ct}, \mathrm{f}}(\mathbf{M P a})$ & $\mathbf{T}_{\mathbf{b}}$ (N.mm) & $\mathbf{F T}(\mathbf{M P a})$ \\
\hline $\mathrm{CP} 1$ & 2,38 & 0,32 & 1641,26 & 0,07 \\
\hline CP2 & 3,53 & 0,47 & 958,01 & 0,04 \\
\hline CP3 & $\mathbf{7 , 6 5}$ & 1,02 & 2308,71 & 0,10 \\
\hline MÉDIA & $\mathbf{4 , 5 2}$ & $\mathbf{0 , 6 0}$ & $\mathbf{1 6 3 5 , 9 9}$ & $\mathbf{0 , 0 7}$ \\
\hline
\end{tabular}

\subsubsection{Traço padrão com $0,3 \%$ de fibras de aço}

Na figura 6.27, pode-se observar o corpo de prova relativo à temperatura ambiente, após a ruptura. Percebe-se que a distribuição do EPS também está bem homogênea na seção transversal, assim como na seção transversal do corpo de prova cilíndrico. Também é possível ver as fibras de aço, principalmente na parte superior direita da imagem.

$\mathrm{Na}$ figura 6.28, pode-se observar o gráfico carga versus deslocamento dos três corpos de prova prismáticos, em temperatura ambiente, porém desta vez com 0,3\% de fibras de aço. De acordo com o gráfico, todos tiveram um comportamento bem parecido e ultrapassaram os $3 \mathrm{~mm}$ de deslocamento, o que aconteceu devido à presença das fibras. 


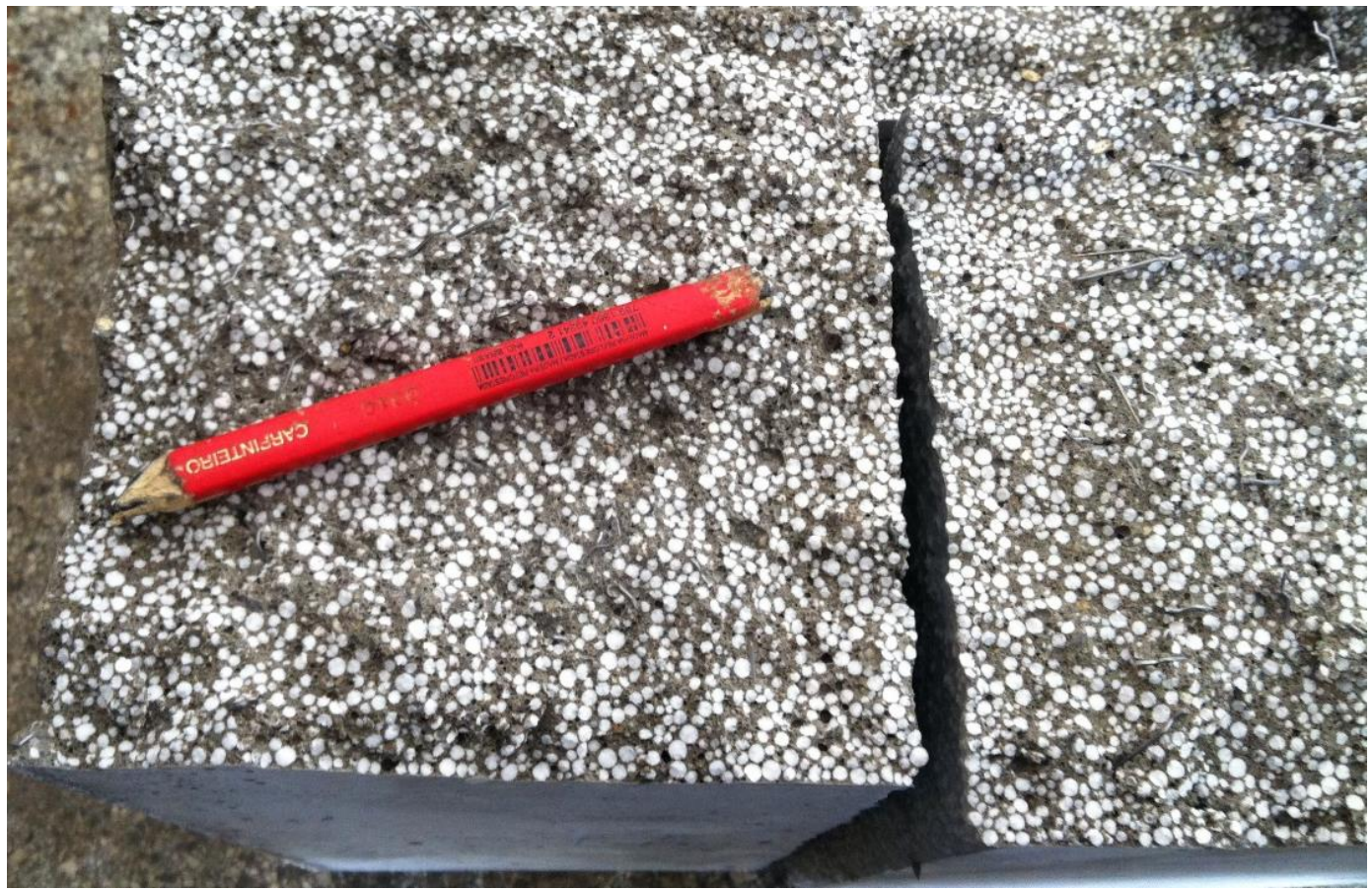

Figura 6.27. Corpo de prova prismático com $0,3 \%$ de fibras, após a ruptura no ensaio de resistência à tração na flexão (temperatura ambiente).

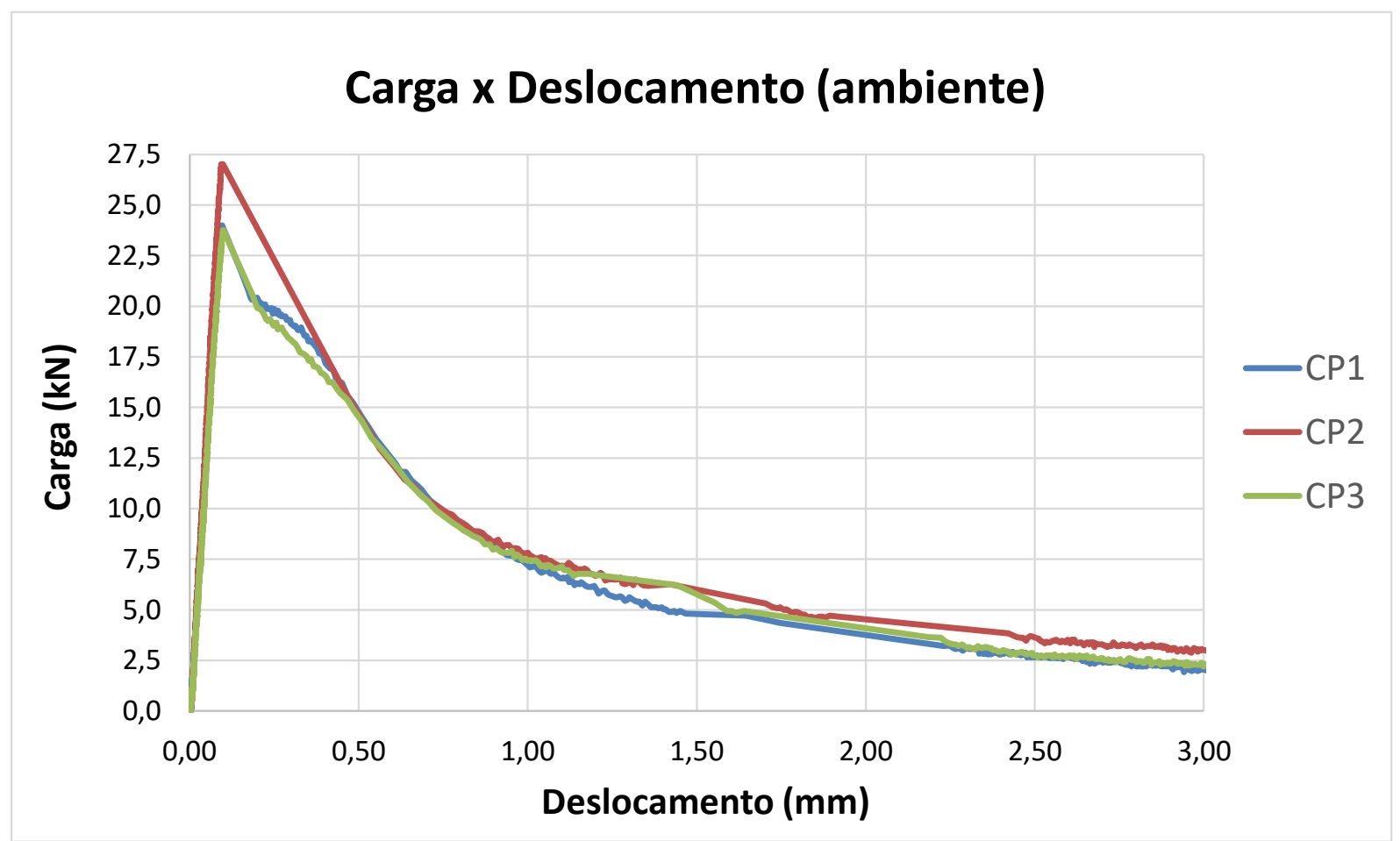

Figura 6.28. Gráfico carga versus deslocamento do ensaio de resistência à tração na flexão dos corpos de prova com $0,3 \%$ de fibras de aço, para temperatura ambiente. 
Na tabela 6.23, têm-se os valores médios da resistência à tração na flexão e do fator de tenacidade, 3,32 e 1,20, respectivamente, desta vez com 0,3\% de fibras.

Tabela 6.23. Resistência à tração na flexão $\left(\mathrm{f}_{\mathrm{ct}, \mathrm{f}}\right)$ e fator de tenacidade $(\mathrm{FT})$ dos corpos de prova com $0,3 \%$ de fibras de aço, para temperatura ambiente.

\begin{tabular}{c|c|c|c|c}
\hline CP's & $\begin{array}{c}\text { Carga máxima } \\
(\mathbf{k N})\end{array}$ & $\mathbf{f}_{\mathrm{ct}, \mathbf{f}}(\mathbf{M P a})$ & $\mathbf{T}_{\mathbf{b}}$ (N.mm) & $\mathbf{F T}(\mathbf{M P a})$ \\
\hline $\mathrm{CP} 1$ & 23,99 & 3,20 & 25475,74 & 1,13 \\
\hline $\mathrm{CP} 2$ & 27,01 & 3,60 & 29136,41 & 1,29 \\
\hline CP3 & 23,76 & 3,17 & 26437,30 & 1,17 \\
\hline MÉDIA & $\mathbf{2 4 , 9 2}$ & $\mathbf{3 , 3 2}$ & $\mathbf{2 7 0 1 6 , 4 8}$ & $\mathbf{1 , 2 0}$ \\
\hline
\end{tabular}

Na figura 6.29, pode-se observar o corpo de prova que foi aquecido a $200{ }^{\circ} \mathrm{C}$, com $0,3 \%$ de fibras, após a ruptura, e percebe-se que todo o EPS derreteu, o que se deve ao mesmo motivo já explicado anteriormente. Também é possível ver algumas fibras de aço.

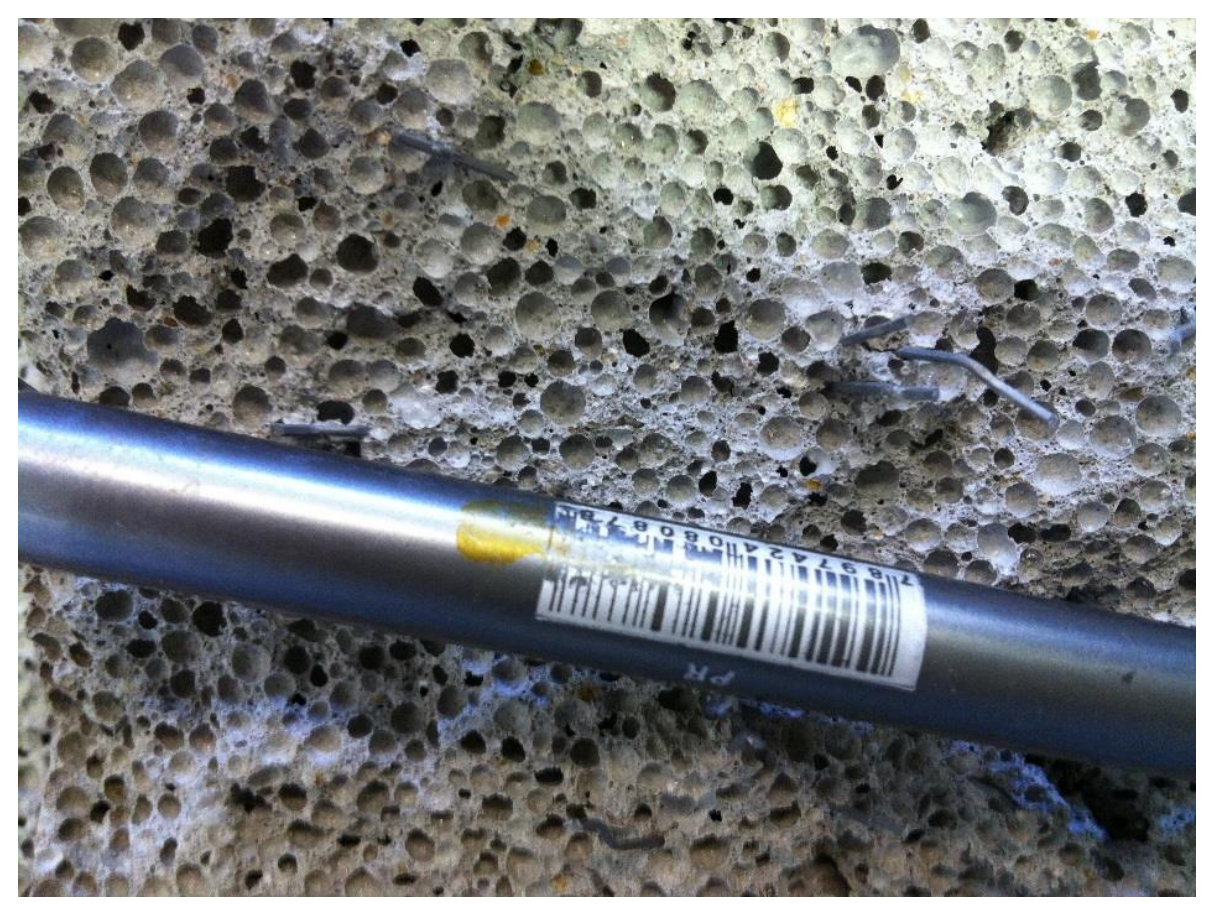

Figura 6.29. Corpo de prova prismático com $0,3 \%$ de fibras, após a ruptura no ensaio de resistência à tração na flexão $(200 \stackrel{\circ}{\circ})$. 
$\mathrm{Na}$ figura 6.30, pode-se observar o gráfico carga versus deslocamento dos três corpos de prova prismáticos que foram aquecidos a $200 \stackrel{\circ}{\circ}$, porém desta vez com $0,3 \%$ de fibras de aço.

De acordo com o gráfico, o CP3 teve uma carga máxima bem abaixo dos outros, porém todos ultrapassaram os $3 \mathrm{~mm}$ de deslocamento.

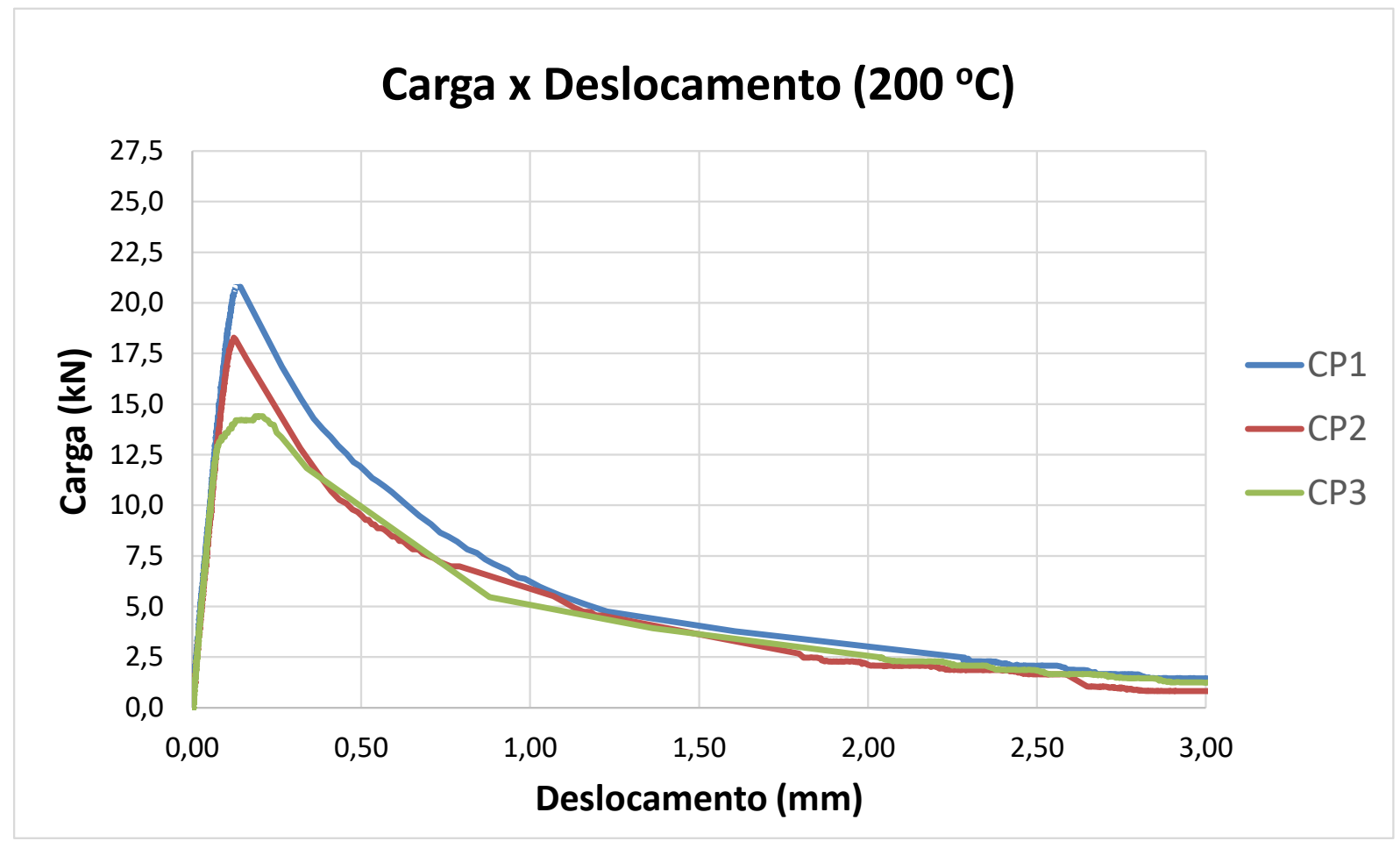

Figura 6.30. Gráfico carga versus deslocamento do ensaio de resistência à tração na flexão dos corpos de prova com $0,3 \%$ de fibras de aço, aquecidos a $200 \stackrel{\circ}{\circ}$.

Na tabela 6.24, têm-se os valores médios da resistência à tração na flexão e do fator de tenacidade, 2,38 e 0,84, respectivamente, que comparados ao caso com temperatura ambiente são $28 \%$ menor e $30 \%$ menor, respectivamente.

A parte interna do corpo de prova que foi aquecido a $600{ }^{\circ} \mathrm{C}$, com $0,3 \%$ de fibras, após a ruptura, é muito parecida com a da parte interna do corpo de prova que foi aquecido a $200{ }^{\circ} \mathrm{C}$, também com $0,3 \%$ de fibras, conforme foi mostrado na figura 6.29.

$\mathrm{Na}$ figura 6.31, pode-se observar o gráfico carga versus deslocamento dos três corpos de prova prismáticos que foram aquecidos a $600 \stackrel{\circ}{\mathrm{C}}$. 
Tabela 6.24. Resistência à tração na flexão $\left(\mathrm{f}_{\mathrm{ct}, \mathrm{f}}\right)$ e fator de tenacidade $(\mathrm{FT})$ dos corpos de prova com $0,3 \%$ de fibras de aço, aquecidos a $200 \stackrel{\circ}{\circ}$.

\begin{tabular}{c|c|c|c|c}
\hline CP's & $\begin{array}{c}\text { Carga máxima } \\
(\mathbf{k N})\end{array}$ & $\mathbf{f}_{\mathrm{ct}, \mathrm{f}}$ (MPa) & $\mathbf{T}_{\mathbf{b}}$ (N.mm) & $\mathbf{F T}$ (MPa) \\
\hline $\mathrm{CP} 1$ & 20,79 & 2,77 & 21240,37 & 0,94 \\
\hline CP2 & 18,28 & 2,44 & 18026,35 & 0,80 \\
\hline CP3 & 14,41 & 1,92 & 17156,08 & 0,76 \\
\hline MÉDIA & $\mathbf{1 7 , 8 3}$ & $\mathbf{2 , 3 8}$ & $\mathbf{1 8 8 0 7 , 6 0}$ & $\mathbf{0 , 8 4}$ \\
\hline
\end{tabular}

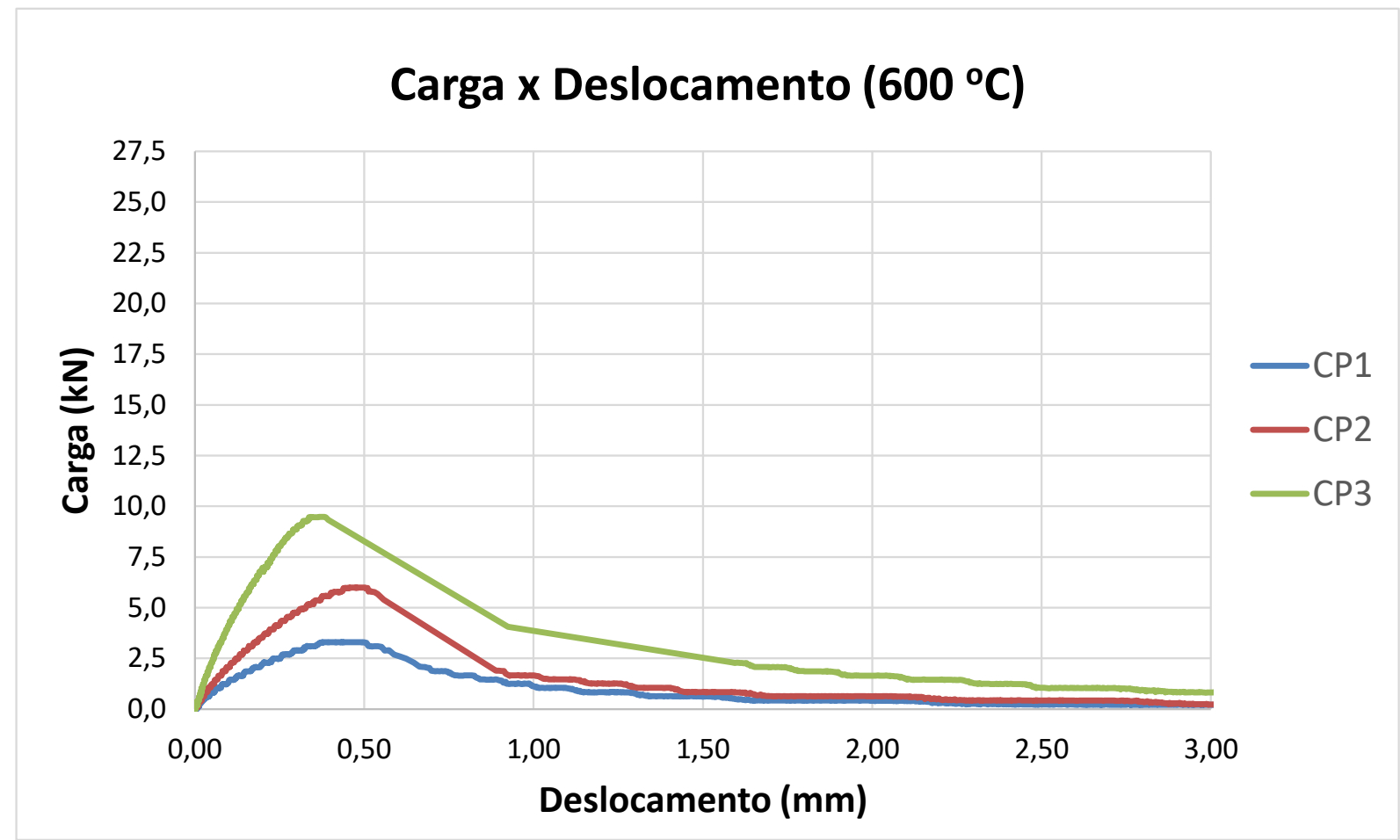

Figura 6.31. Gráfico carga versus deslocamento do ensaio de resistência à tração na flexão dos corpos de prova com $0,3 \%$ de fibras de aço, aquecidos a $600 \stackrel{\circ}{\circ}$.

De acordo com o gráfico, o CP1 teve uma carga máxima bem abaixo da dos outros, porém todos ultrapassaram os $3 \mathrm{~mm}$ de deslocamento.

$\mathrm{Na}$ tabela 6.25, têm-se os valores médios da resistência à tração na flexão e do fator de tenacidade, 0,83 e 0,29, respectivamente, que comparados ao caso com $200 \stackrel{\circ}{\circ}$ são $65,1 \%$ e $65,5 \%$ menores, respectivamente. E quando comparados ao caso com temperatura ambiente, são $75 \%$ e $75,8 \%$ menores, respectivamente. 
Tabela 6.25. Resistência à tração na flexão $\left(f_{c t, f}\right)$ e fator de tenacidade (FT) dos corpos de prova com $0,3 \%$ de fibras de aço, aquecidos a $600 \stackrel{\circ}{ } \mathrm{C}$.

\begin{tabular}{c|c|c|c|c}
\hline CP's & $\begin{array}{c}\text { Carga máxima } \\
(\mathbf{k N})\end{array}$ & $\mathbf{f}_{\mathrm{ct}, \mathbf{f}}$ (MPa) & $\mathbf{T}_{\mathbf{b}}$ (N.mm) & $\mathbf{F T}$ (MPa) \\
\hline $\mathrm{CP} 1$ & 3,31 & 0,44 & 3099,01 & 0,14 \\
\hline $\mathrm{CP} 2$ & 5,99 & 0,80 & 5177,08 & 0,23 \\
\hline CP3 & 9,48 & 1,26 & 11013,67 & 0,49 \\
\hline MÉDIA & $\mathbf{6 , 2 6}$ & $\mathbf{0 , 8 3}$ & $\mathbf{6 4 2 9 , 9 2}$ & $\mathbf{0 , 2 9}$ \\
\hline
\end{tabular}

\subsubsection{Casos com $0,6 \%$ de fibras de aço}

Na figura 6.32, pode-se observar o corpo de prova mantido em temperatura ambiente, com $0,6 \%$ de fibras, após a ruptura, e percebe-se que a distribuição do EPS também está bem homogênea na seção transversal, assim como na seção transversal do corpo de prova cilíndrico. Também é possível ver algumas fibras de aço.

$\mathrm{Na}$ figura 6.33, pode-se observar o gráfico carga versus deslocamento dos três corpos de prova prismáticos, para temperatura ambiente, porém desta vez com $0,6 \%$ de fibras de aço.

De acordo com o gráfico, todos tiveram um comportamento bem parecido, e também ultrapassaram os $3 \mathrm{~mm}$ de deslocamento. 


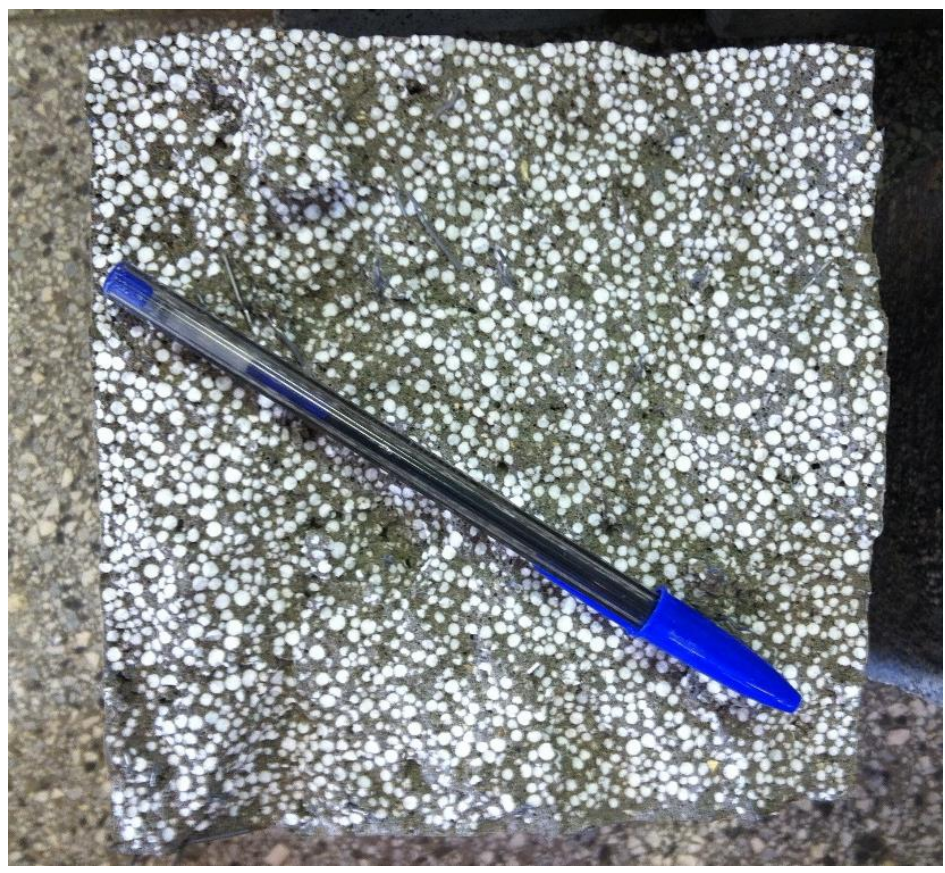

Figura 6.32. Corpo de prova prismático com $0,6 \%$ de fibras, após a ruptura no ensaio de resistência à tração na flexão (temperatura ambiente).

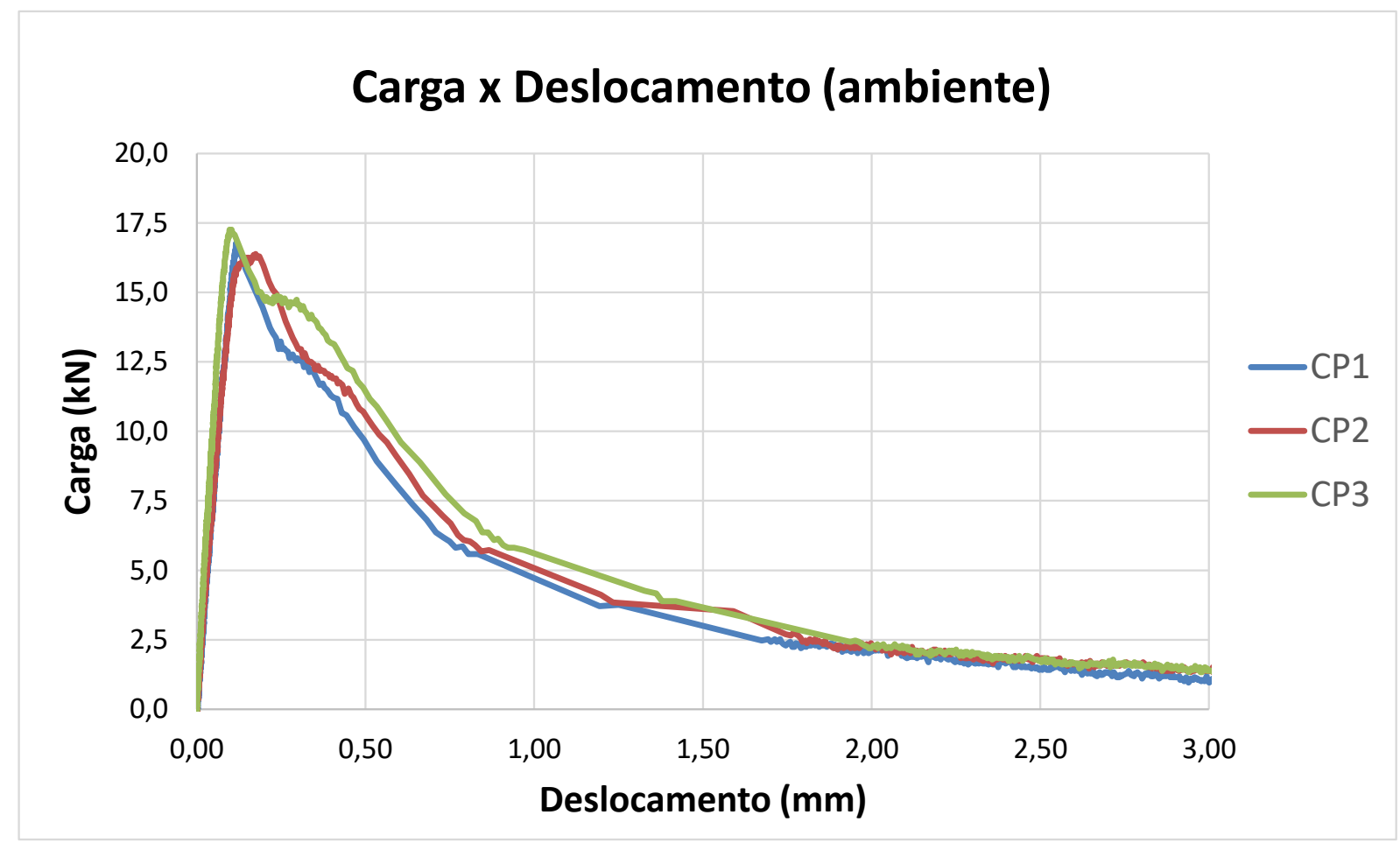

Figura 6.33. Gráfico carga versus deslocamento do ensaio de resistência à tração na flexão dos corpos de prova com $0,6 \%$ de fibras de aço, para temperatura ambiente. 
Na tabela 6.26, têm-se os valores médios da resistência à tração na flexão e do fator de tenacidade, 2,24 e 0,78 , respectivamente, relativos a $0,6 \%$ de fibras.

Tabela 6.26. Resistência à tração na flexão $\left(f_{c t, f}\right)$ e fator de tenacidade $(F T)$ dos corpos de prova com $0,6 \%$ de fibras de aço, para temperatura ambiente.

\begin{tabular}{c|c|c|c|c}
\hline CP's & $\begin{array}{c}\text { Carga máxima } \\
(\mathbf{k N})\end{array}$ & $\mathbf{f}_{\mathrm{ct}, \mathbf{f}} \mathbf{( M P a )}$ & $\mathbf{T}_{\mathbf{b}}$ (N.mm) & $\mathbf{F T}$ (MPa) \\
\hline $\mathrm{CP} 1$ & 16,80 & 2,24 & 16571,64 & 0,74 \\
\hline $\mathrm{CP} 2$ & 16,39 & 2,19 & 17272,32 & 0,77 \\
\hline $\mathrm{CP} 3$ & 17,26 & 2,30 & 18711,41 & 0,83 \\
\hline MÉDIA & $\mathbf{1 6 , 8 2}$ & $\mathbf{2 , 2 4}$ & $\mathbf{1 7 5 1 8 , 4 6}$ & $\mathbf{0 , 7 8}$ \\
\hline
\end{tabular}

A parte interna do corpo de prova que foi aquecido a $200{ }^{\circ} \mathrm{C}$, com $0,6 \%$ de fibras, após a ruptura, é muito parecida com a do corpo de prova que foi aquecido a $200 \stackrel{\circ}{ } \mathrm{C}$, com $0,3 \%$ de fibras, conforme foi mostrado na figura 6.29.

$\mathrm{Na}$ figura 6.34, pode-se observar o gráfico carga versus deslocamento dos três corpos de prova prismáticos que foram aquecidos a $200{ }^{\circ} \mathrm{C}$.

De acordo com o gráfico, todos tiveram um comportamento bem parecido, e também ultrapassaram os $3 \mathrm{~mm}$ de deslocamento.

Na tabela 6.27, têm-se os valores médios da resistência à tração na flexão e do fator de tenacidade, 2,16 e 0,83 , respectivamente, que comparados ao caso com temperatura ambiente são 3,6\% menor e 6,4\% maior, respectivamente.

Nesse caso específico, houve um resultado inesperado, levando em conta todos os outros já analisados até aqui, que apresentavam resultados menores à medida que se aumentava a temperatura do ensaio, porém aqui o fator de tenacidade apresentou um resultado $6,4 \%$ maior.

Mais à frente, serão analisados a resistência à tração na flexão e o fator de tenacidade em função da quantidade de fibras, e haverá mais dados para fazer uma análise mais fundamentada. 


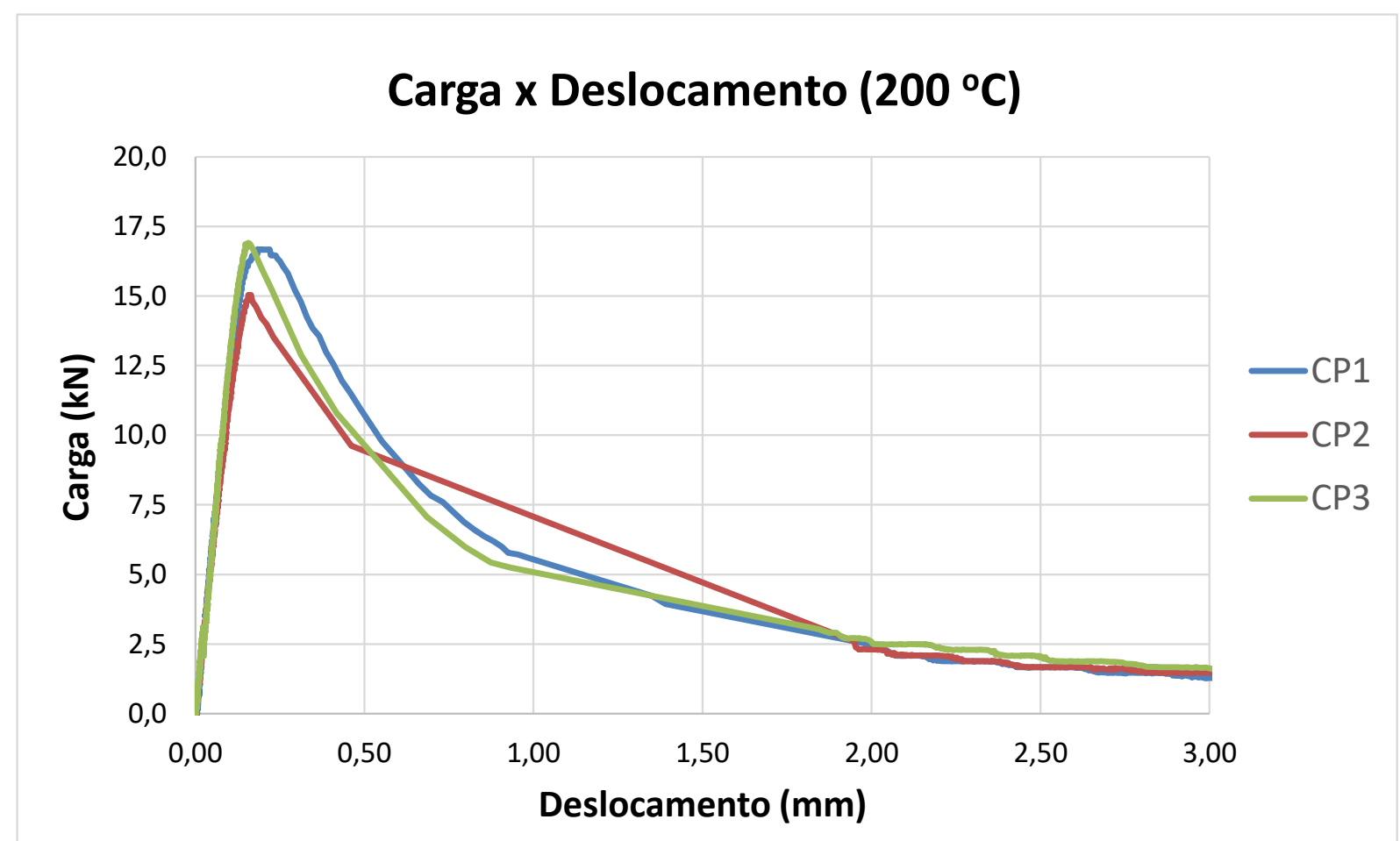

Figura 6.34. Gráfico carga versus deslocamento do ensaio de resistência à tração na flexão dos corpos de prova com $0,6 \%$ de fibras de aço, aquecidos a $200 \stackrel{\circ}{\mathrm{C}}$.

Tabela 6.27. Resistência à tração na flexão $\left(\mathrm{f}_{\mathrm{ct}, \mathrm{f}}\right)$ e fator de tenacidade $(\mathrm{FT})$ dos corpos de prova com $0,6 \%$ de fibras de aço, aquecidos a $200 \stackrel{\circ}{ } \mathrm{C}$.

\begin{tabular}{c|c|c|c|c}
\hline CP's & $\begin{array}{c}\text { Carga máxima } \\
(\mathbf{k N})\end{array}$ & $\mathbf{f}_{\mathrm{ct}, \mathrm{f}}(\mathbf{M P a})$ & $\mathbf{T}_{\mathbf{b}}$ (N.mm) & $\mathbf{F T}$ (MPa) \\
\hline $\mathrm{CP} 1$ & 16,68 & 2,22 & 18533,73 & 0,82 \\
\hline $\mathrm{CP} 2$ & 15,04 & 2,01 & 18434,94 & 0,82 \\
\hline CP3 & 16,92 & 2,26 & 18735,70 & 0,83 \\
\hline MÉDIA & $\mathbf{1 6 , 2 1}$ & $\mathbf{2 , 1 6}$ & $\mathbf{1 8 5 6 8 , 1 2}$ & $\mathbf{0 , 8 3}$ \\
\hline
\end{tabular}

A parte interna do corpo de prova que foi aquecido a $600{ }^{\circ} \mathrm{C}$, com $0,6 \%$ de fibras, após a ruptura, é muito parecida com a do corpo de prova que foi aquecido a $200^{\circ} \mathrm{C}$, com $0,3 \%$ de fibras, conforme foi mostrado na figura 6.29 .

Na figura 6.35, pode-se observar o gráfico carga versus deslocamento dos três corpos de prova prismáticos que foram aquecidos a $600^{\circ} \mathrm{C}$. 
De acordo com o gráfico, o CP1 apresentou uma carga máxima um pouco abaixo em comparação aos outros, e todos também ultrapassaram os $3 \mathrm{~mm}$ de deslocamento.

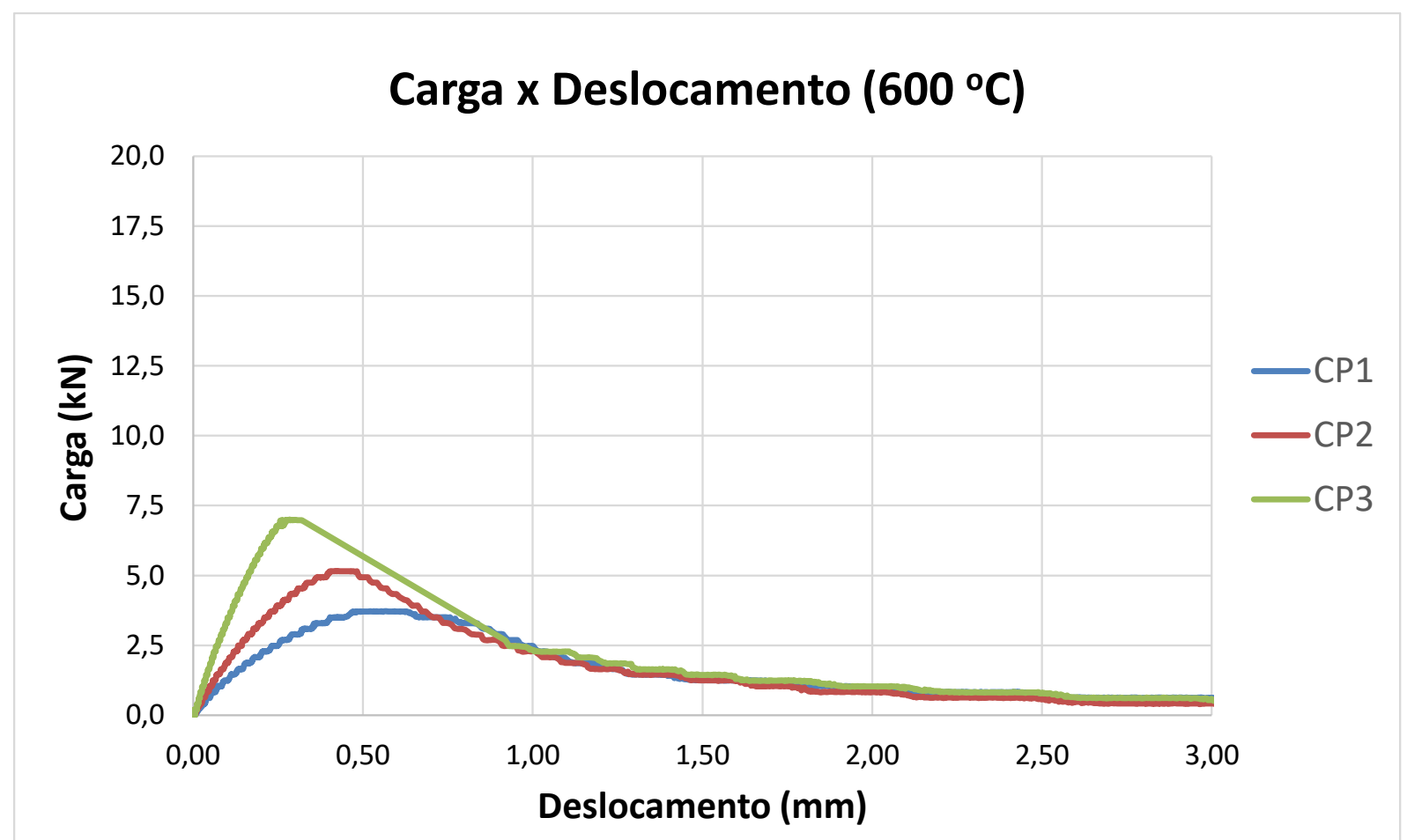

Figura 6.35. Gráfico carga versus deslocamento do ensaio de resistência à tração na flexão dos corpos de prova com $0,6 \%$ de fibras de aço, aquecidos a $600 \stackrel{\circ}{\mathrm{C}}$.

Na tabela 6.28, têm-se os valores médios da resistência à tração na flexão e do fator de tenacidade, 0,71 e 0,26, respectivamente, que comparados ao caso com $200 \stackrel{\circ}{\circ}$ são $67,1 \%$ menor e $68,7 \%$ menor, respectivamente. E quando comparados ao caso para temperatura ambiente, são $68,3 \%$ menor e $66,7 \%$ menor, respectivamente.

Aqui a redução, em comparação com o caso de temperatura ambiente, foi menor que para o caso de aquecimento a $200 \stackrel{\circ}{\circ}$, devido ao pequeno aumento que teve na situação anterior. 
Tabela 6.28. Resistência à tração na flexão $\left(f_{c t, f}\right)$ e fator de tenacidade $(F T)$ dos corpos de prova com $0,6 \%$ de fibras de aço, aquecidos a $600^{\circ} \mathrm{C}$.

\begin{tabular}{c|c|c|c|c}
\hline CP's & $\begin{array}{c}\text { Carga máxima } \\
(\mathbf{k N})\end{array}$ & $\mathbf{f}_{\mathrm{ct}, \mathrm{f}}$ (MPa) & $\mathbf{T}_{\mathbf{b}}$ (N.mm) & $\mathbf{F T}$ (MPa) \\
\hline CP1 & 3,72 & 0,50 & 5041,25 & 0,22 \\
\hline CP2 & 5,16 & 0,69 & 5470,13 & 0,24 \\
\hline CP3 & 7,00 & 0,93 & 7373,93 & 0,33 \\
\hline MÉDIA & $\mathbf{5 , 2 9}$ & $\mathbf{0 , 7 1}$ & $\mathbf{5 9 6 1 , 7 7}$ & $\mathbf{0 , 2 6}$ \\
\hline
\end{tabular}

\subsubsection{Casos com $0,9 \%$ de fibras de aço}

$\mathrm{Na}$ figura 6.36, pode-se observar o corpo de prova para temperatura ambiente, com 0,9\% de fibras, após a ruptura, e percebe-se que a distribuição do EPS também está bem homogênea, assim como nos casos anteriores. Também é possível ver uma quantidade um pouco maior de fibras de aço.

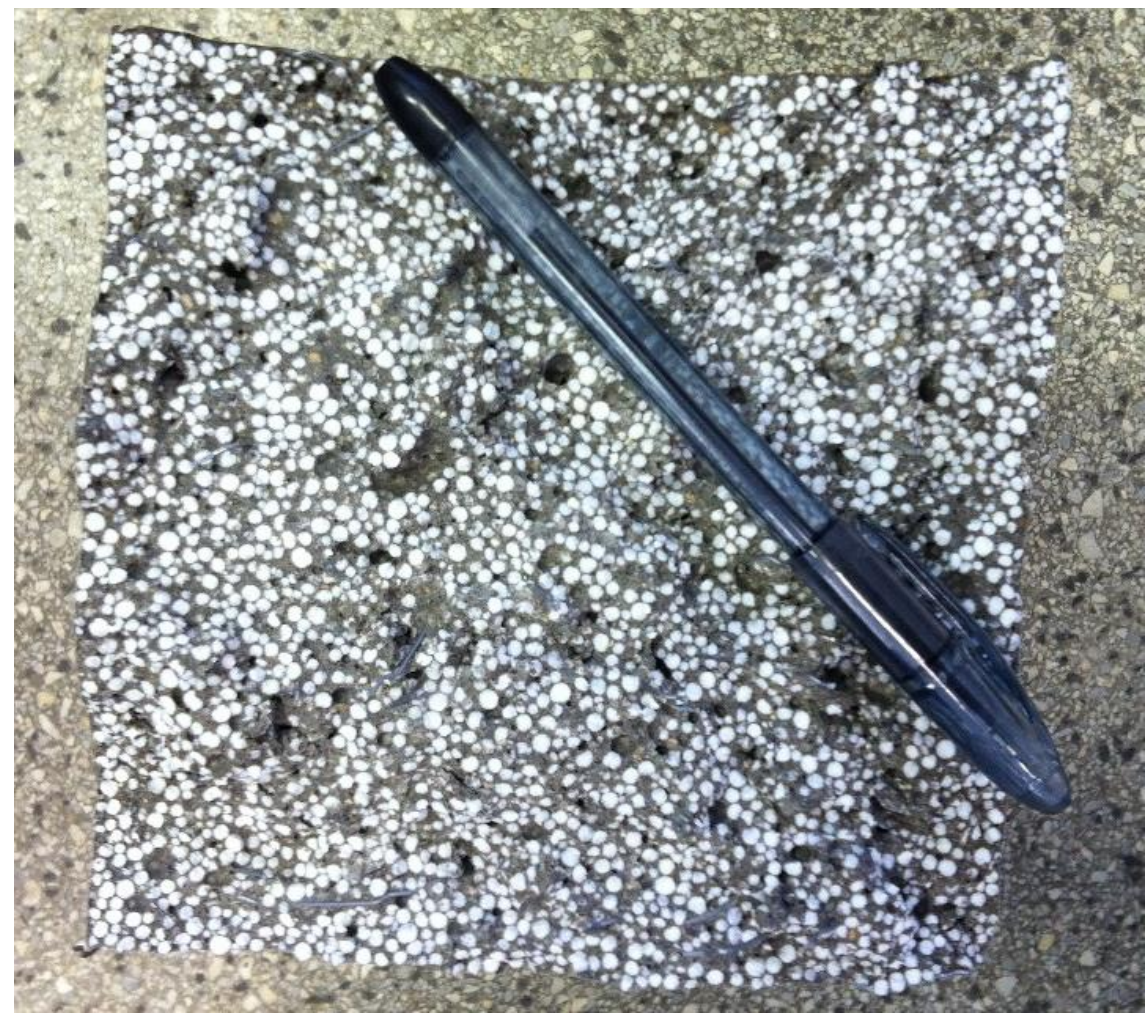

Figura 6.36. Corpo de prova prismático com $0,9 \%$ de fibras, após a ruptura no ensaio de resistência à tração na flexão (temperatura ambiente). 
$\mathrm{Na}$ figura 6.37, pode-se observar o gráfico carga versus deslocamento dos três corpos de prova prismáticos, para temperatura ambiente, porém desta vez com 0,9\% de fibras de aço. De acordo com o gráfico, todos tiveram um comportamento bem parecido, e também ultrapassaram os $3 \mathrm{~mm}$ de deslocamento.

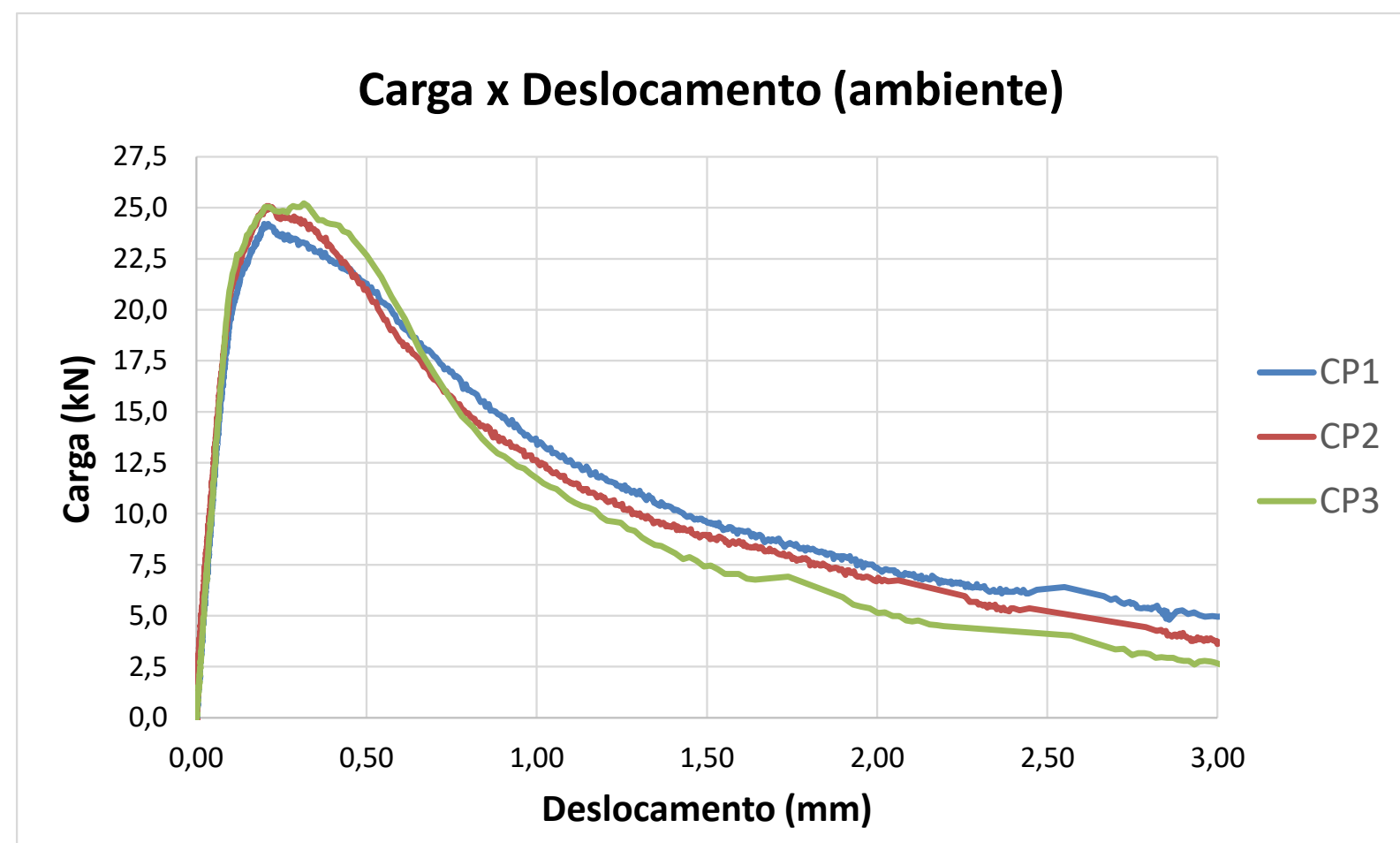

Figura 6.37. Gráfico carga versus deslocamento do ensaio de resistência à tração na flexão dos corpos de prova com $0,9 \%$ de fibras de aço, para temperatura ambiente.

Na tabela 6.29, têm-se os valores médios da resistência à tração na flexão e do fator de tenacidade, 3,31 e 1,54, respectivamente, relativos a 0,9\% de fibras.

Tabela 6.29. Resistência à tração na flexão $\left(f_{c t, f}\right)$ e fator de tenacidade $(F T)$ dos corpos de prova com $0,9 \%$ de fibras de aço, para temperatura ambiente.

\begin{tabular}{c|c|c|c|c}
\hline CP's & $\begin{array}{c}\text { Carga máxima } \\
(\mathbf{k N})\end{array}$ & $\mathbf{f}_{\mathbf{c t , f}} \mathbf{( M P a )}$ & $\mathbf{T}_{\mathbf{b}}$ (N.mm) & $\mathbf{F T}(\mathbf{M P a})$ \\
\hline $\mathrm{CP} 1$ & 24,22 & 3,23 & 37065,65 & 1,65 \\
\hline $\mathrm{CP} 2$ & 25,09 & 3,35 & 35560,99 & 1,58 \\
\hline $\mathrm{CP} 3$ & 25,23 & 3,36 & 31034,02 & 1,38 \\
\hline MÉDIA & $\mathbf{2 4 , 8 5}$ & $\mathbf{3 , 3 1}$ & $\mathbf{3 4 5 5 3 , 5 5}$ & $\mathbf{1 , 5 4}$ \\
\hline
\end{tabular}


Na figura 6.38, pode-se observar o corpo de prova, que foi aquecido a $200{ }^{\circ} \mathrm{C}$, com $0,9 \%$ de fibras, após a ruptura, e percebe-se que todo o EPS também derreteu, e isso se deve pelo mesmo motivo já explicado anteriormente. Também é possível ver uma quantidade maior de fibras de aço.

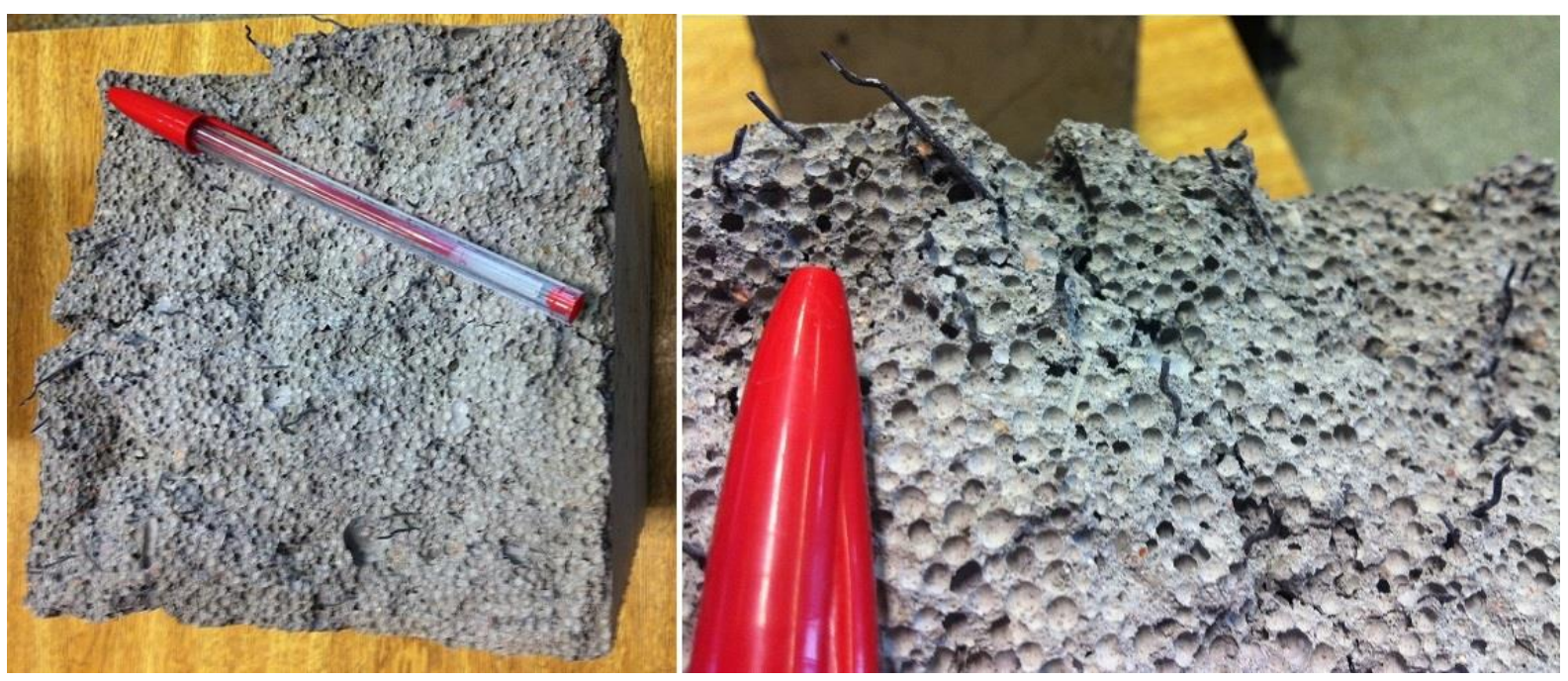

Figura 6.38. Corpo de prova prismático com $0,9 \%$ de fibras, após a ruptura no ensaio de resistência à tração na flexão $(200 \stackrel{\circ}{\circ})$.

$\mathrm{Na}$ figura 6.39, pode-se observar o gráfico carga versus deslocamento dos três corpos de prova prismáticos que foram aquecidos a $200 \stackrel{\circ}{\circ}$, porém desta vez com $0,9 \%$ de fibras de aço. De acordo com o gráfico, apenas o CP1 teve um comportamento um pouco diferente, e todos ultrapassaram os $3 \mathrm{~mm}$ de deslocamento.

$\mathrm{Na}$ tabela 6.30, têm-se os valores médios da resistência à tração na flexão e do fator de tenacidade, 2,80 e 1,36, respectivamente, que comparados ao caso com temperatura ambiente, são 15,4\% menor e 11,7\% menor, respectivamente.

$\mathrm{Na}$ figura 6.40, pode-se observar o gráfico carga versus deslocamento dos três corpos de prova prismáticos que foram aquecidos a $600 \stackrel{\circ}{\circ}$, porém desta vez com $0,9 \%$ de fibras de aço. De acordo com o gráfico, apenas o CP3 teve um comportamento mais diferente, com carga máxima maior que a dos outros, porém todos ultrapassaram os $3 \mathrm{~mm}$ de deslocamento. 


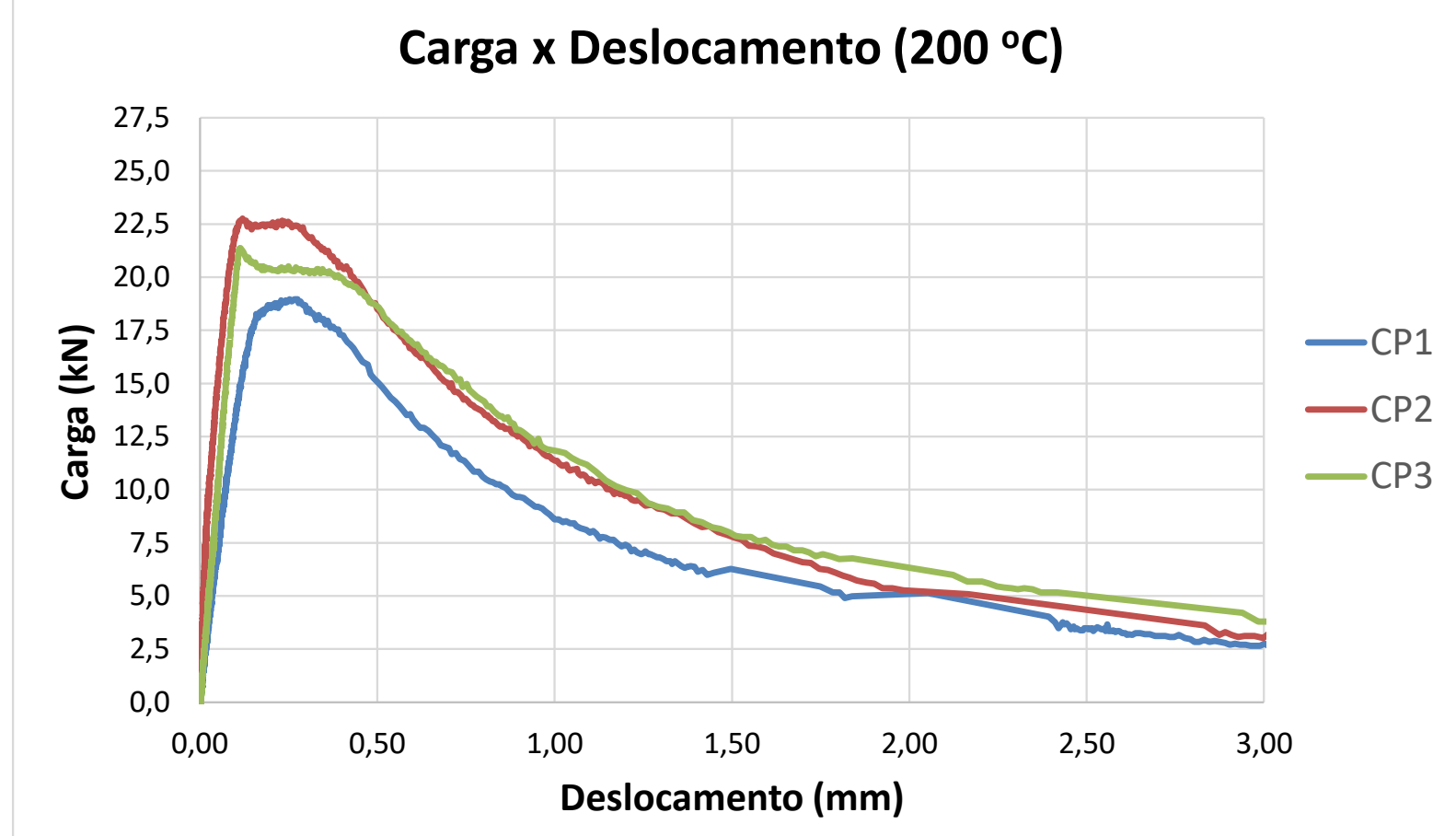

Figura 6.39. Gráfico carga versus deslocamento do ensaio de resistência à tração na flexão dos corpos de prova com $0,9 \%$ de fibras de aço, aquecidos a $200 \stackrel{\circ}{ } \mathrm{C}$.

Tabela 6.30. Resistência à tração na flexão $\left(f_{c t, f}\right)$ e fator de tenacidade $(F T)$ dos corpos de prova com $0,9 \%$ de fibras de aço, aquecidos a $200 \stackrel{\circ}{\circ}$.

\begin{tabular}{c|c|c|c|c}
\hline CP's & $\begin{array}{c}\text { Carga máxima } \\
(\mathbf{k N})\end{array}$ & $\mathbf{f}_{\mathrm{ct,f}} \mathbf{( M P a )}$ & $\mathbf{T}_{\mathbf{b}}$ (N.mm) & $\mathbf{F T}$ (MPa) \\
\hline $\mathrm{CP} 1$ & 18,95 & 2,53 & 26045,17 & 1,16 \\
\hline $\mathrm{CP} 2$ & 22,75 & 3,03 & 32968,52 & 1,47 \\
\hline $\mathrm{CP} 3$ & 21,38 & 2,85 & 33031,81 & 1,47 \\
\hline MÉDIA & $\mathbf{2 1 , 0 3}$ & $\mathbf{2 , 8 0}$ & $\mathbf{3 0 6 8 1 , 8 3}$ & $\mathbf{1 , 3 6}$ \\
\hline
\end{tabular}

A parte interna do corpo de prova que foi aquecido a $600{ }^{\circ} \mathrm{C}$, com $0,9 \%$ de fibras, após a ruptura, é muito parecida com a do corpo de prova aquecido a $200 \stackrel{\circ}{ }$, com $0,9 \%$ de fibras, conforme foi mostrado na figura 6.38 . 


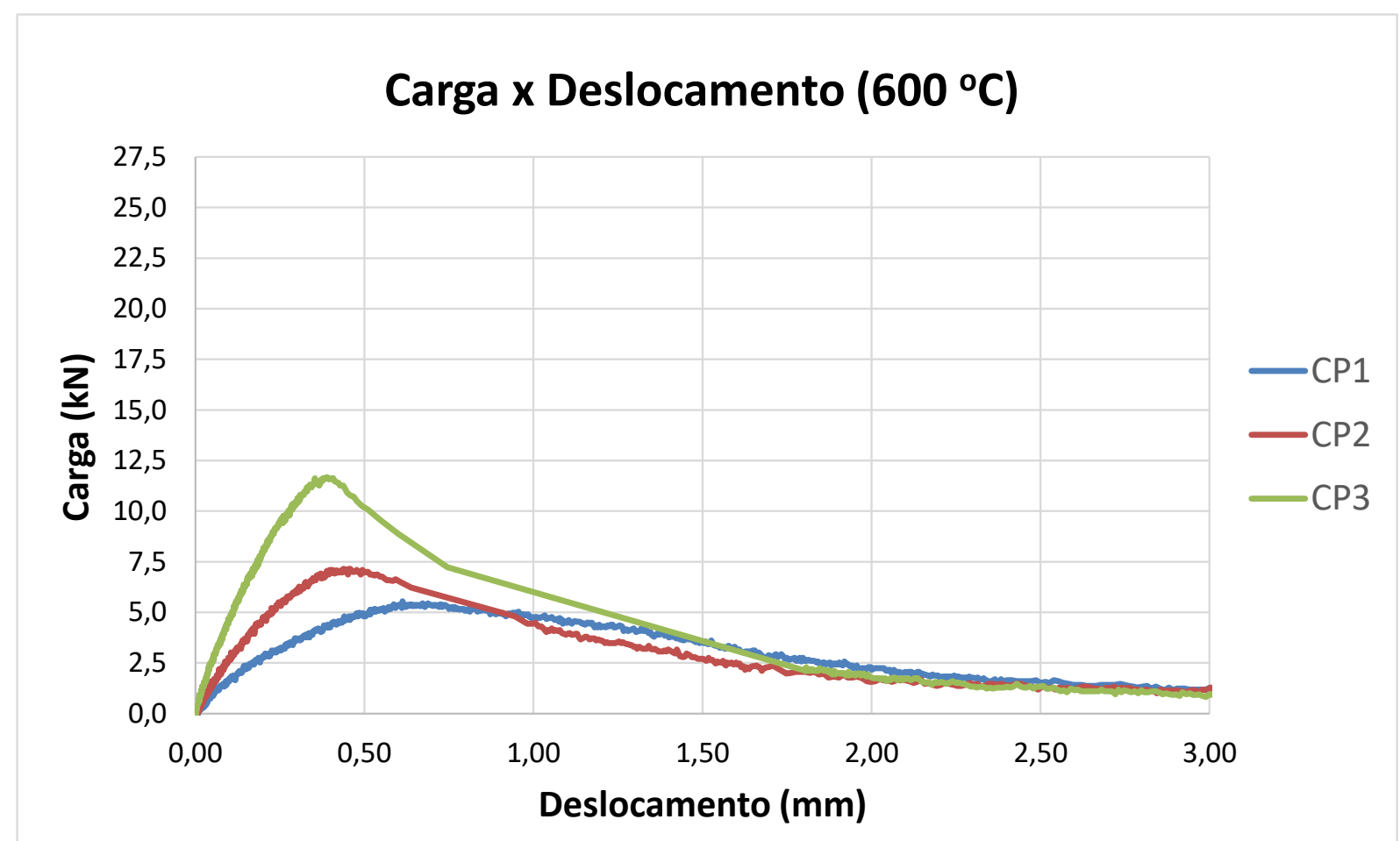

Figura 6.40. Gráfico carga versus deslocamento do ensaio de resistência à tração na flexão dos corpos de prova com $0,9 \%$ de fibras de aço, aquecidos a $600 \stackrel{\circ}{\mathrm{C}}$.

$\mathrm{Na}$ tabela 6.31, têm-se os valores médios da resistência à tração na flexão e do fator de tenacidade, 1,08 e 0,50, respectivamente, que comparados ao caso com $200 \stackrel{\circ}{\circ}$ são $61,4 \%$ menor e 63,2\% menor, respectivamente. E quando comparados ao caso com temperatura ambiente, são 67,4\% menor e 67,5\% menor, respectivamente.

Tabela 6.31. Resistência à tração na flexão $\left(f_{c t, f}\right)$ e fator de tenacidade $(F T)$ dos corpos de prova com $0,9 \%$ de fibras de aço, aquecidos a $600 \stackrel{\circ}{\circ}$.

\begin{tabular}{c|c|c|c|c}
\hline CP's & $\begin{array}{c}\text { Carga máxima } \\
(\mathbf{k N})\end{array}$ & $\mathbf{f}_{\mathrm{ct}, \mathrm{f}}(\mathbf{M P a})$ & $\mathbf{T}_{\mathbf{b}}$ (N.mm) & $\mathbf{F T}$ (MPa) \\
\hline $\mathrm{CP} 1$ & 5,54 & 0,74 & 9251,17 & 0,41 \\
\hline $\mathrm{CP} 2$ & 7,14 & 0,95 & 9908,52 & 0,44 \\
\hline CP3 & 11,67 & 1,56 & 14416,00 & 0,64 \\
\hline MÉDIA & $\mathbf{8 , 1 2}$ & $\mathbf{1 , 0 8}$ & $\mathbf{1 1 1 9 1 , 9 0}$ & $\mathbf{0 , 5 0}$ \\
\hline
\end{tabular}


Na figura 6.41, pode-se ver um comparativo da resistência à tração na flexão em função da temperatura, e nota-se que o traço com 0,9\% de fibras apresenta os maiores valores de resistência à tração para todas as temperaturas em estudo, o que já era esperado.

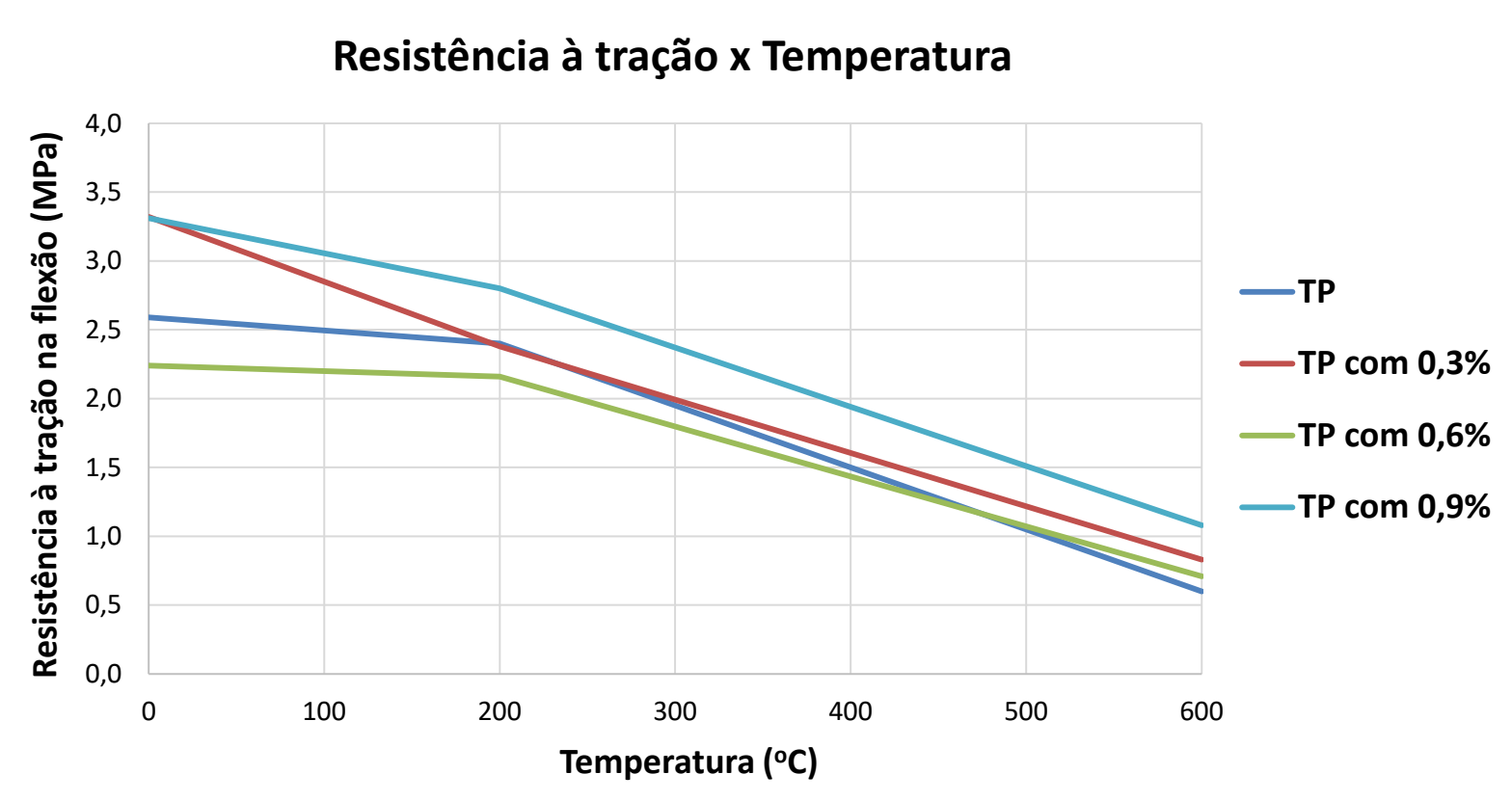

Figura 6.41. Comparativo da resistência à tração na flexão em função da temperatura.

Esperava-se que o traço que teria os menores valores de resistência seria o sem fibras, porém o que teve os menores resultados foi o traço com $0,6 \%$ de fibras, - mesmo que apresentou resultados inesperados na comparação vista anteriormente.

O que pode explicar esses resultados ruins para o traço com 0,6\% de fibras, que teoricamente deveria ficar entre os resultados de $0,3 \%$ e $0,9 \%$, é o volume no misturador, que foi bem grande, pois foram produzidos corpos de provas cilíndricos e prismáticos para duas pesquisas de doutorado, a fim de aproveitar a mesma concretagem.

O traço com $0,3 \%$ de fibras apresentou resultados de resistência à tração maiores que o traço sem fibras, e menores que o traço com 0,9\%, o que é bem coerente e já era esperado. Pode-se observar também que, para temperatura ambiente, a eficiência das fibras foi um pouco maior em relação às outras 
temperaturas, fazendo-se a comparação com o traço sem fibras. Isso não vale para a taxa de $0,6 \%$.

Se não forem considerados os resultados obtidos para o traço com $0,6 \%$, todos os outros estão coerentes. Dessa forma, pode-se concluir que a utilização de fibras de aço no concreto leve com EPS vale muito a pena, para que haja acréscimo de resistência à tração na flexão, principalmente para os casos em elevadas temperaturas.

Na figura 6.42, pode-se ver um comparativo da resistência à tração na flexão em função da taxa de fibras, e nota-se que o traço com 0,6\% de fibras apresenta resultados incoerentes, assim como já foi visto em outras análises.

Se não forem considerados os resultados para o traço com $0,6 \%$ de fibras, fica-se com o gráfico mostrado na figura 6.43, e pode-se concluir que para temperatura ambiente, a partir de $0,3 \%$ de fibras, não faz diferença, pois foi obtida a mesma resistência à tração para as taxas de 0,6\% e 0,9\%. Porém, analisando os casos com aquecimento a $200^{\circ} \mathrm{C}$ e $600 \stackrel{\circ}{ } \mathrm{C}$, verifica-se que há um ganho de resistência com o acréscimo de fibras, conforme já foi mencionado.

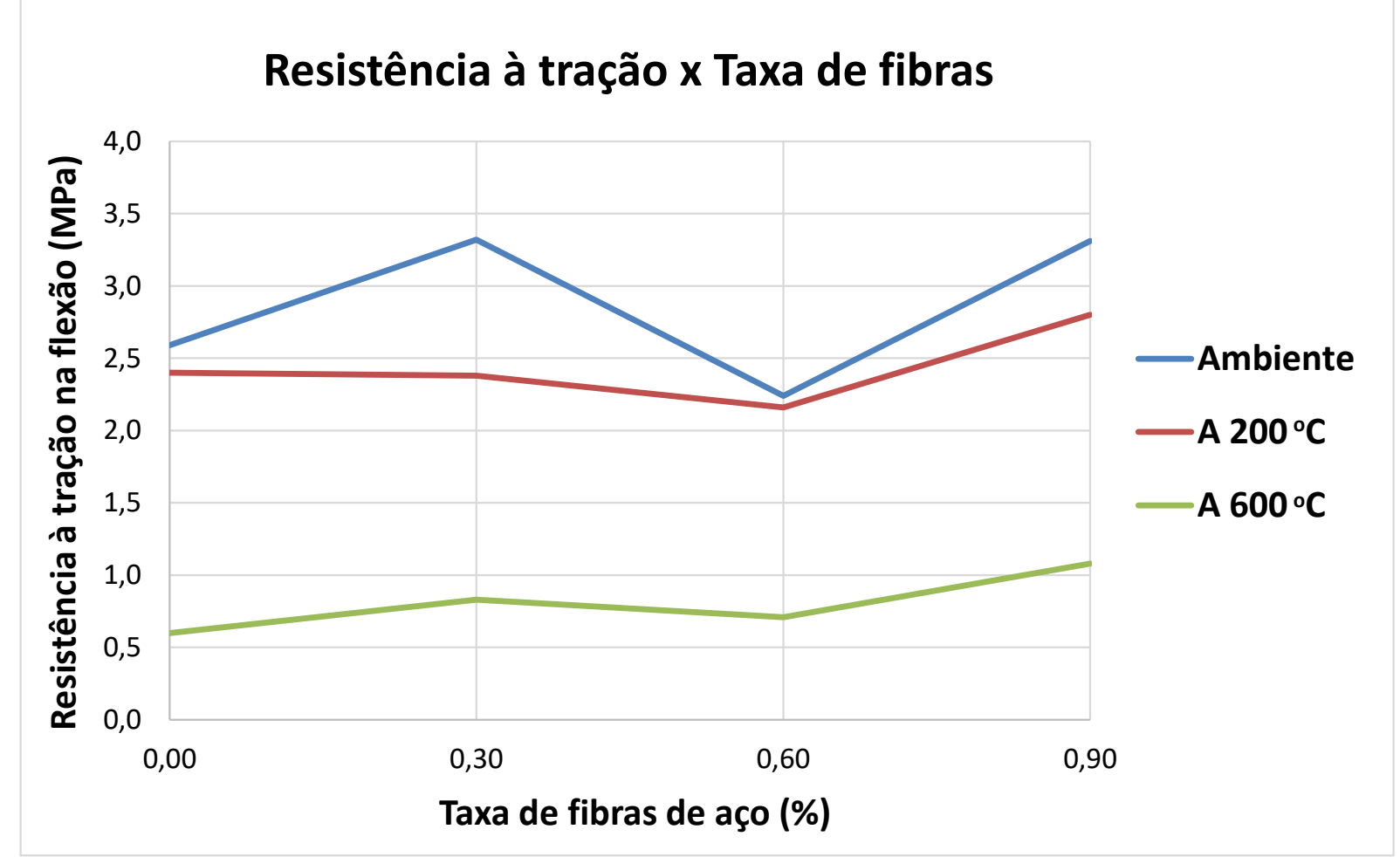

Figura 6.42. Comparativo da resistência à tração na flexão em função da taxa de fibras. 


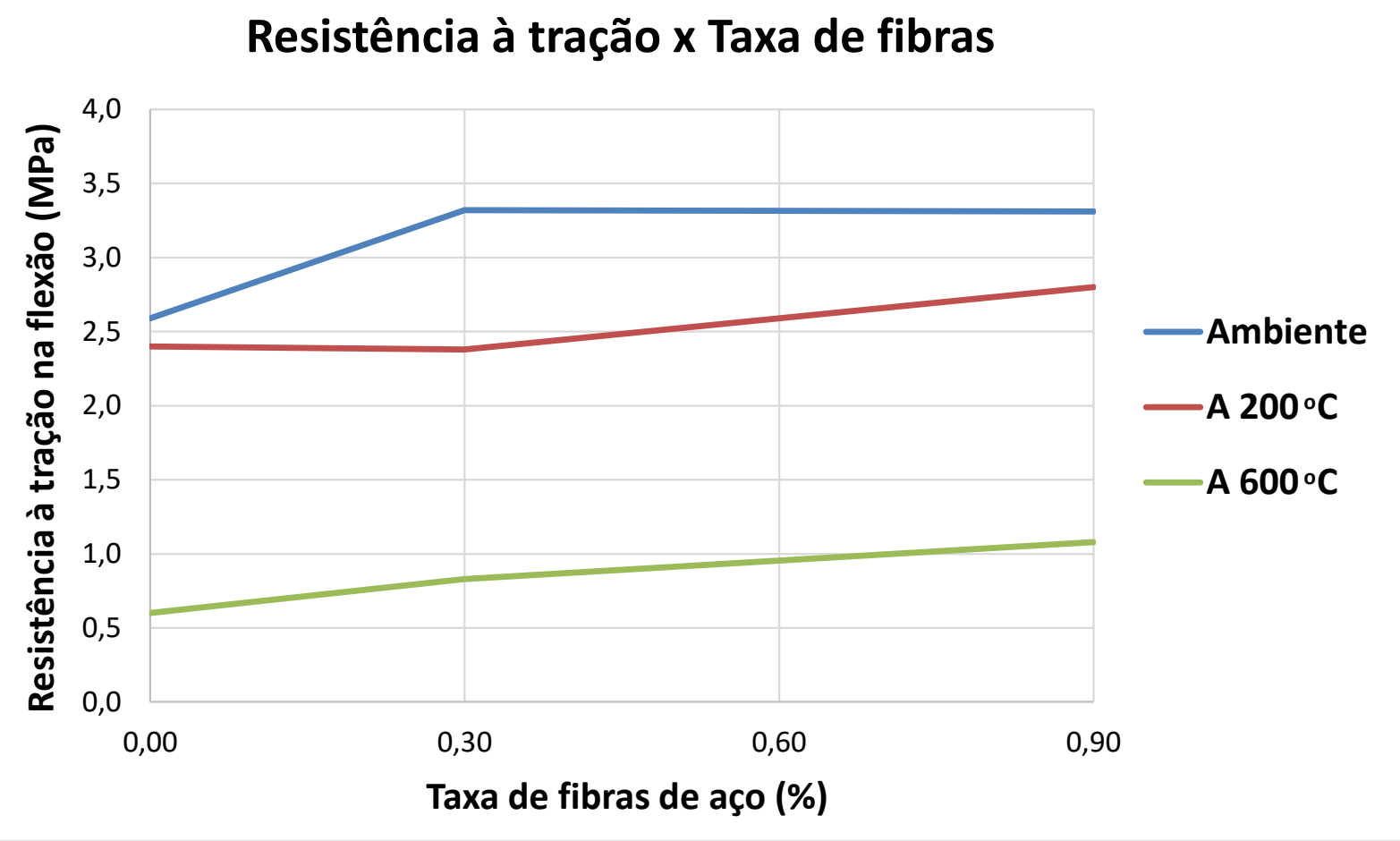

Figura 6.43. Comparativo da resistência à tração na flexão em função da taxa de fibras, retirando os pontos referentes a $0,6 \%$ de fibras.

Na figura 6.44, pode-se ver um comparativo do fator de tenacidade em função da temperatura, e nota-se que o traço com $0,9 \%$ de fibras apresenta os maiores valores de tenacidade para todas as temperaturas em estudo, o que já era esperado. Observa-se também que $0,9 \%$ de fibras geraram excelentes resultados, pois para temperatura ambiente levaram a aproximadamente $700 \%$ de eficiência, e

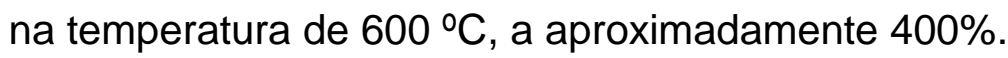

Para temperatura ambiente, o traço com 0,3\% de fibras apresentou melhores resultados de tenacidade em comparação com o traço com $0,6 \%$ de fibras, e após $200 \stackrel{\circ}{ } \mathrm{C}$, apresentou praticamente os mesmos resultados. Em relação à tenacidade, observa-se que o traço com $0,6 \%$ também apresenta resultados incoerentes, mas também se pode concluir que a utilização das fibras vale muito a pena, quando se quer aumentar a tenacidade de possíveis elementos estruturais com o concreto leve com EPS. 


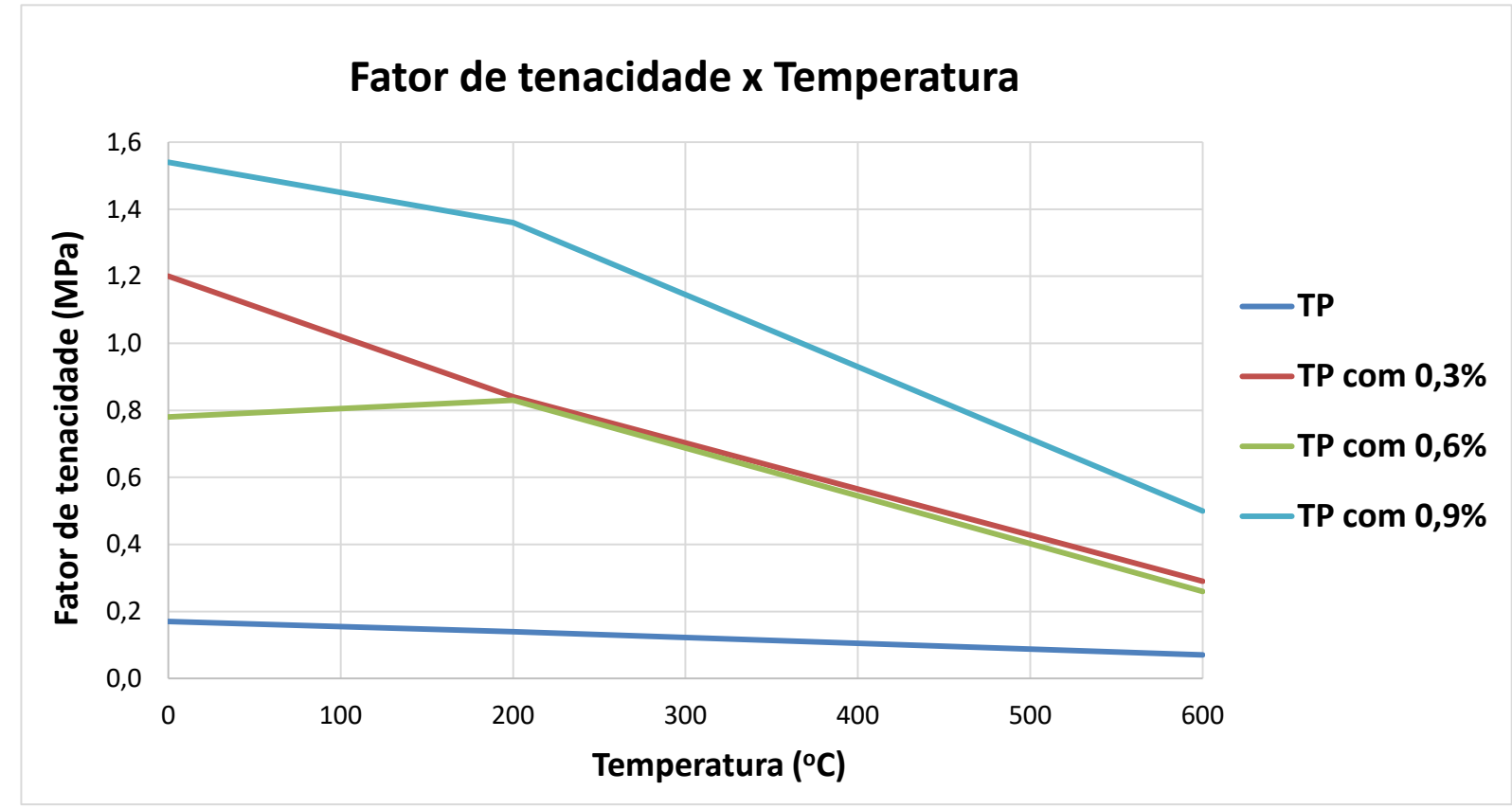

Figura 6.44. Comparativo do fator de tenacidade em função da temperatura.

Na figura 6.45, pode-se ver um comparativo do fator de tenacidade em função da taxa de fibras, e nota-se que o traço com $0,6 \%$ de fibras apresenta resultados incoerentes, assim como já foi visto em outras análises.

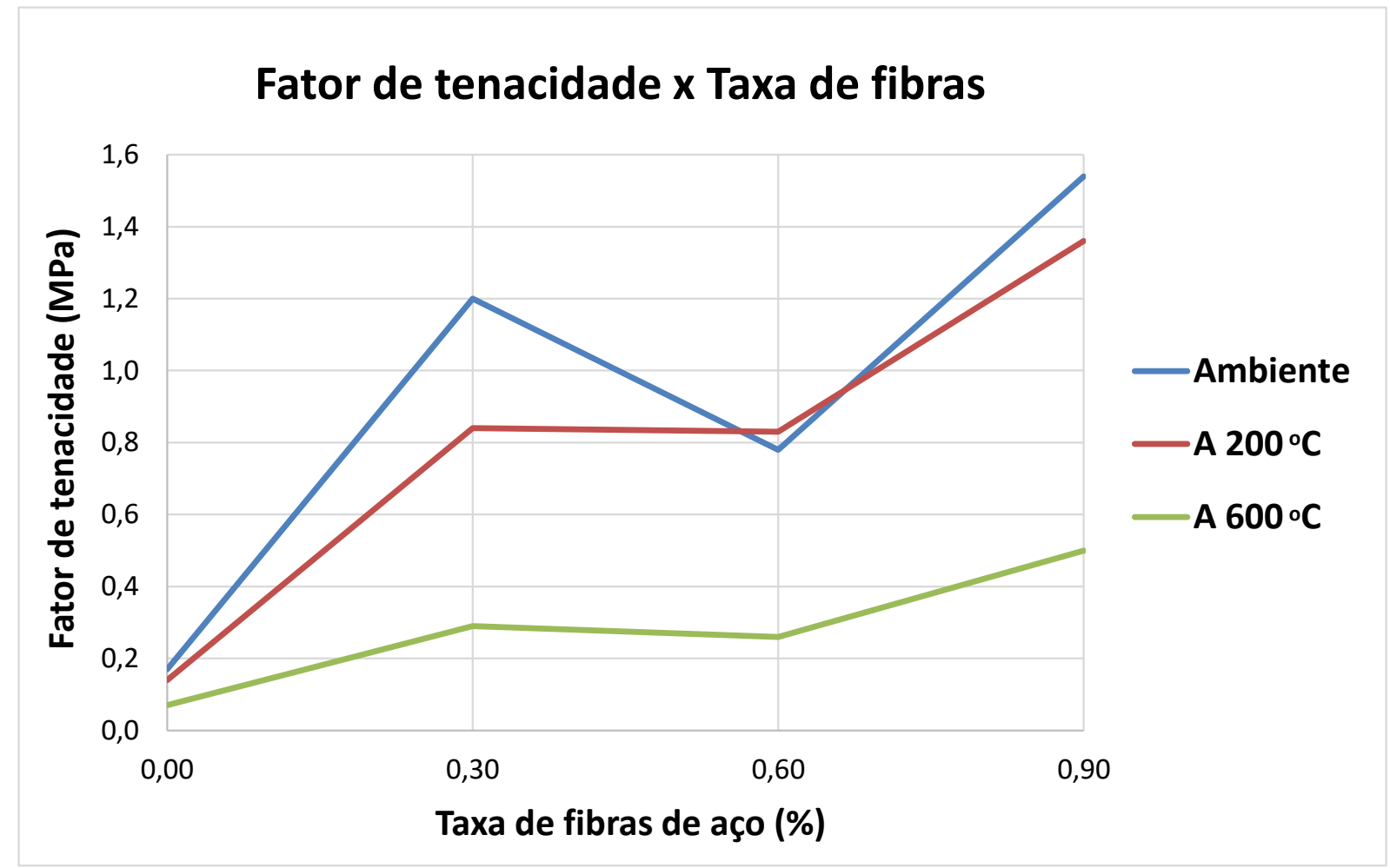

Figura 6.45. Comparativo do fator de tenacidade em função da taxa de fibras. 
Se não forem considerados os resultados para o traço com $0,6 \%$ de fibras, obtém-se o gráfico mostrado na figura 6.46.

Pode-se concluir que o acréscimo de fibras é altamente efetivo para o aumento da tenacidade, para temperatura ambiente, pois a tenacidade apresenta um aumento de aproximadamente $500 \%$ para a taxa de $0,3 \%$ de fibras. Esse aumento é um pouco menor para $200^{\circ} \mathrm{C}$, e bem menor para $600^{\circ} \mathrm{C}$, e para as taxas seguintes, 0,6\% e 0,9\%, o aumento já não é mais tão significativo. Porém, todo acréscimo de taxa de fibras leva a um aumento na tenacidade. $E$ dependendo da utilidade do elemento estrutural, pode valer a pena considerar uma taxa maior de fibras.

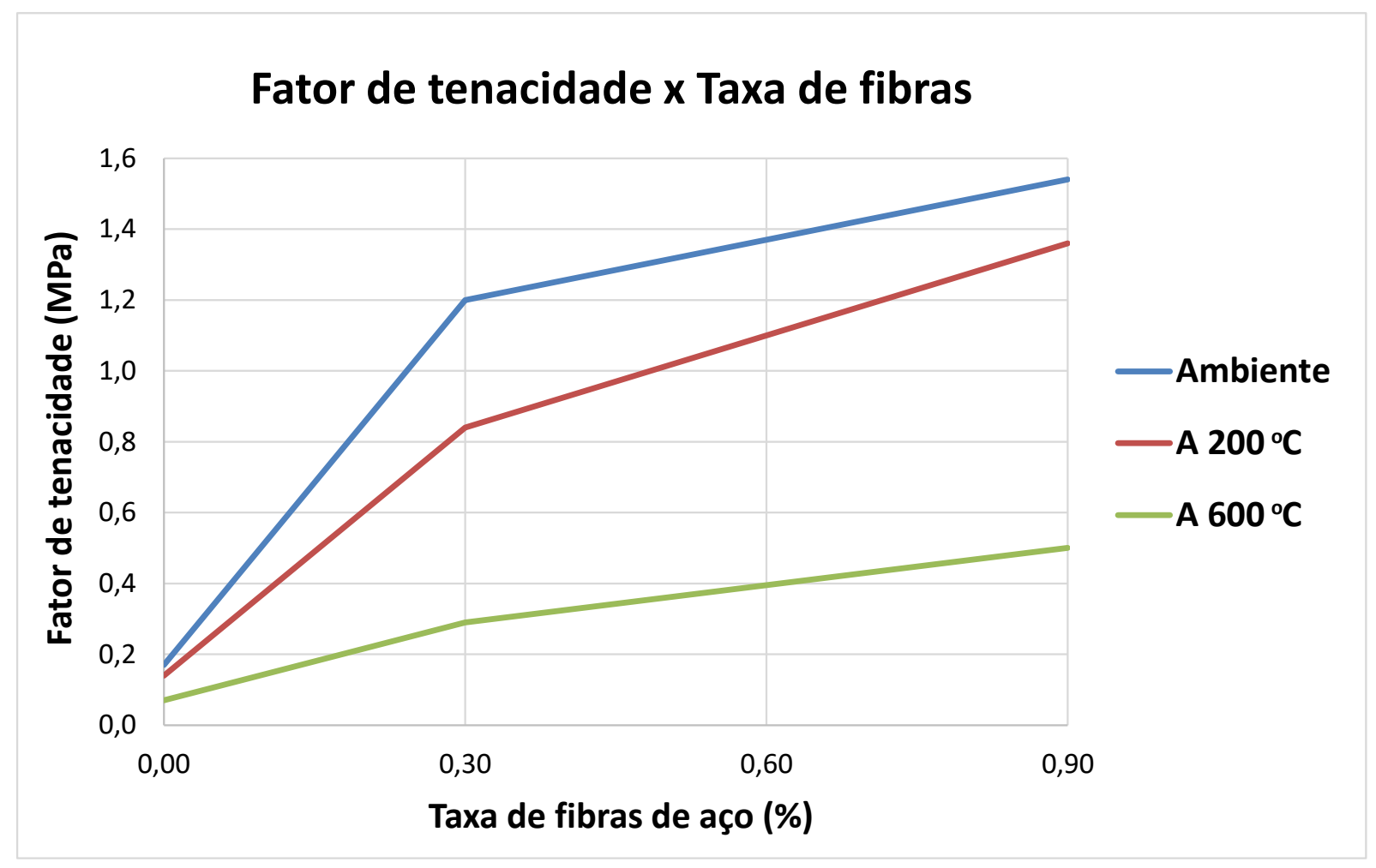

Figura 6.46. Comparativo do fator de tenacidade em função da taxa de fibras, retirando os pontos referentes a $0,6 \%$ de fibras. 


\section{ANÁLISE NUMÉRICA}

Neste capítulo será tratado o modelo numérico utilizado no trabalho, para as análises térmicas dos corpos de prova estudados. Devido à complexidade de se considerarem fibras de aço no modelo numérico, deixou-se esta análise para trabalhos futuros. Neste trabalho considerou-se apenas o traço padrão.

\subsection{Considerações gerais}

Para a análise térmica numérica foi utilizado o ABAQUS versão 14, software fundamentado em elementos finitos. A análise foi realizada apenas para o traço padrão sem fibras, e utilizou-se um modelo numérico tridimensional, para os corpos de prova cilíndricos (Figura 7.1-a) e prismáticos (Figura 7.1-b), com elementos lineares de oito nós, DC3D8.

O computador utilizado possuía as seguintes configurações:

> Processador Intel Core i5 - 2400 CPU 3.10 GHz;

> Memória RAM: 4 GB;

$>$ Sistema operacional de 64 Bits - Windows 7 Professional.

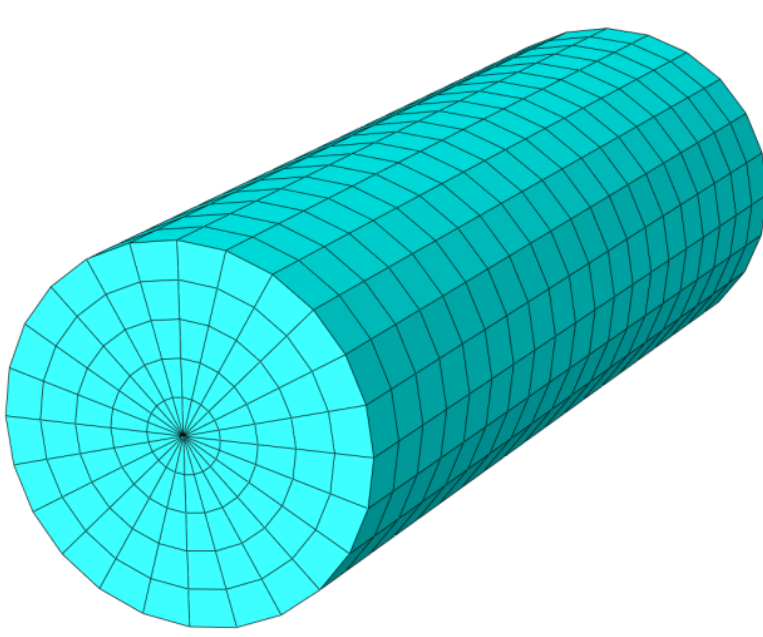

(a)

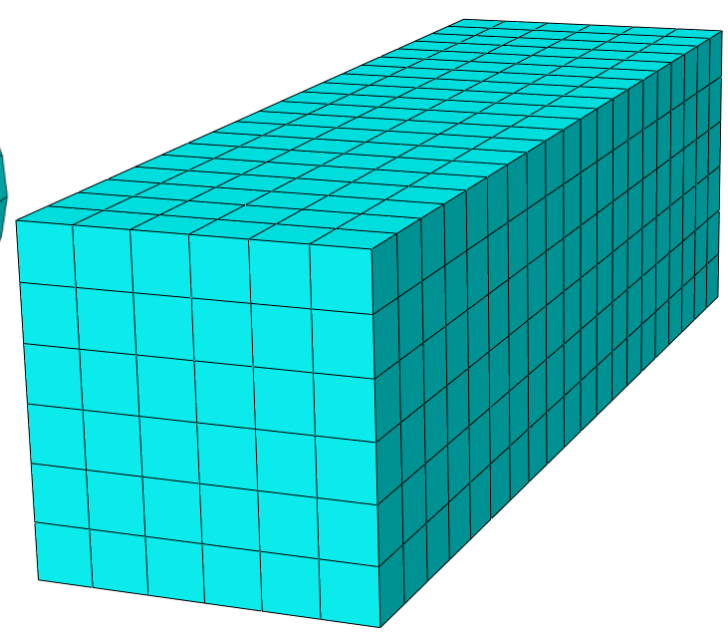

(b)

Figura 7.1. Modelo numérico dos corpos de prova (a) cilíndricos e (b) prismáticos 
Para a discretização do modelo cilíndrico, dividiu-se cada quadrante da seção transversal em seis fatias radiais, ou seja, dividiu-se o comprimento da circunferência em 24 partes de aproximadamente $1,31 \mathrm{~cm}$. Para a discretização do modelo prismático, consideraram-se pequenos elementos cúbicos com aresta igual a $2,5 \mathrm{~cm}$.

Para os dois modelos tentou-se um refinamento da malha, porém apenas se obteve um aumento do tempo de processamento, sem alteração dos resultados.

\subsection{Modelo térmico}

Foram consideradas as trocas de calor por radiação e por convecção, apenas para as faces expostas ao calor. Como os dois corpos de prova ficaram na posição vertical dentro do forno, a face que ficou apoiada na fibra de vidro foi considerada sem aquecimento.

As taxas de aquecimento adotadas foram as mesmas já mencionadas na análise experimental, $1^{\circ} \mathrm{C} / \mathrm{min}$ para os cilindros e $0,5^{\circ} \mathrm{C} / \mathrm{min}$ para os prismas.

Para a emissividade utilizou-se 0,8 e para o coeficiente de convecção, $25 \mathrm{Wm}^{2} /{ }^{\circ} \mathrm{C}$.

Para o calor específico, por falta de resultados experimentais, utilizou-se de forma simplificada, para todas as temperaturas (28 ${ }^{\circ} \mathrm{C}$ a $600^{\circ} \mathrm{C}$ ), valor igual a $500 \mathrm{~J} / \mathrm{kg} \stackrel{\circ}{ } \mathrm{C}$, tomando-se como valor de pico $850 \mathrm{~J} / \mathrm{kg} \stackrel{\circ}{\circ}(70 \%$ maior), entre $100 \stackrel{\circ}{\mathrm{C} \text { e }}$ $115^{\circ} \mathrm{C}$. Para a adoção desses valores, foram tomados como base os valores que constam no Eurocode EN 1994-1-2:2005, no qual o calor específico para concreto convencional com massa específica igual a $2300 \mathrm{~kg} / \mathrm{m}^{3}$, de forma simplificada, pode ser tomado como igual a $1000 \mathrm{~J} / \mathrm{kg}{ }^{\circ} \mathrm{C}$, e para concreto leve com massa específica em torno de $1800 \mathrm{~kg} / \mathrm{m}^{3}$, pode ser adotado $840 \mathrm{~J} / \mathrm{kg} \stackrel{\circ}{\circ} \mathrm{C}$. Como o concreto objeto de estudo desta tese possui massa específica em torno de $1170 \mathrm{~kg} / \mathrm{m}^{3}$, estimou-se os valores já mencionados, conforme pode ser visto na tabela 7.1.

A massa específica considerada para a temperatura ambiente foi a média das encontradas na parte experimental, igual a $1173,40 \mathrm{~kg} / \mathrm{m}^{3}$, e para as demais temperaturas, foi utilizada a curva do fator de redução, também encontrada na parte experimental deste trabalho, conforme mostra a mesma tabela 7.1. 
Tabela 7.1. Calor específico e massa especifica utilizados na análise numérica

\begin{tabular}{c|c|c}
\hline Temperatura $\left({ }^{\circ} \mathrm{C}\right)$ & Calor específico $\left(\mathrm{J} / \mathbf{k g}{ }^{\circ} \mathrm{C}\right)$ & Massa específica $\left(\mathrm{kg} / \mathrm{m}^{\mathbf{3}}\right)$ \\
\hline 28 & 500 & 1173,40 \\
\hline 100 & 850 & 1138,26 \\
\hline 115 & 850 & 1131,73 \\
\hline 150 & 675 & 1117,16 \\
\hline 200 & 500 & 1095,12 \\
\hline 250 & 500 & 1080,68 \\
\hline 300 & 500 & 1065,39 \\
\hline 350 & 500 & 1052,12 \\
\hline 400 & 500 & 1038,96 \\
\hline 450 & 500 & 1031,84 \\
\hline 500 & 500 & 1024,91 \\
\hline 550 & 500 & 1020,18 \\
\hline 600 & 500 & 1016,73 \\
\hline
\end{tabular}

\subsection{Resultados e análise}

Cada análise realizada para a calibração da condutividade térmica demorou em torno de 18 minutos de processamento para os cilindros e 34 minutos para os prismas.

Nas figuras 7.2 e 7.3, são mostrados a variação de calor para o cilindro e para o prisma, respectivamente. Observa-se que na extremidade da direita os corpos de prova estão totalmente aquecidos, enquanto na extremidade da esquerda, não. Isso se deve ao fato da extremidade esquerda ter sido a face que estava apoiada na base do forno, que é feito de fibra de vidro, e por esse motivo não ter ficado exposta ao aquecimento. 


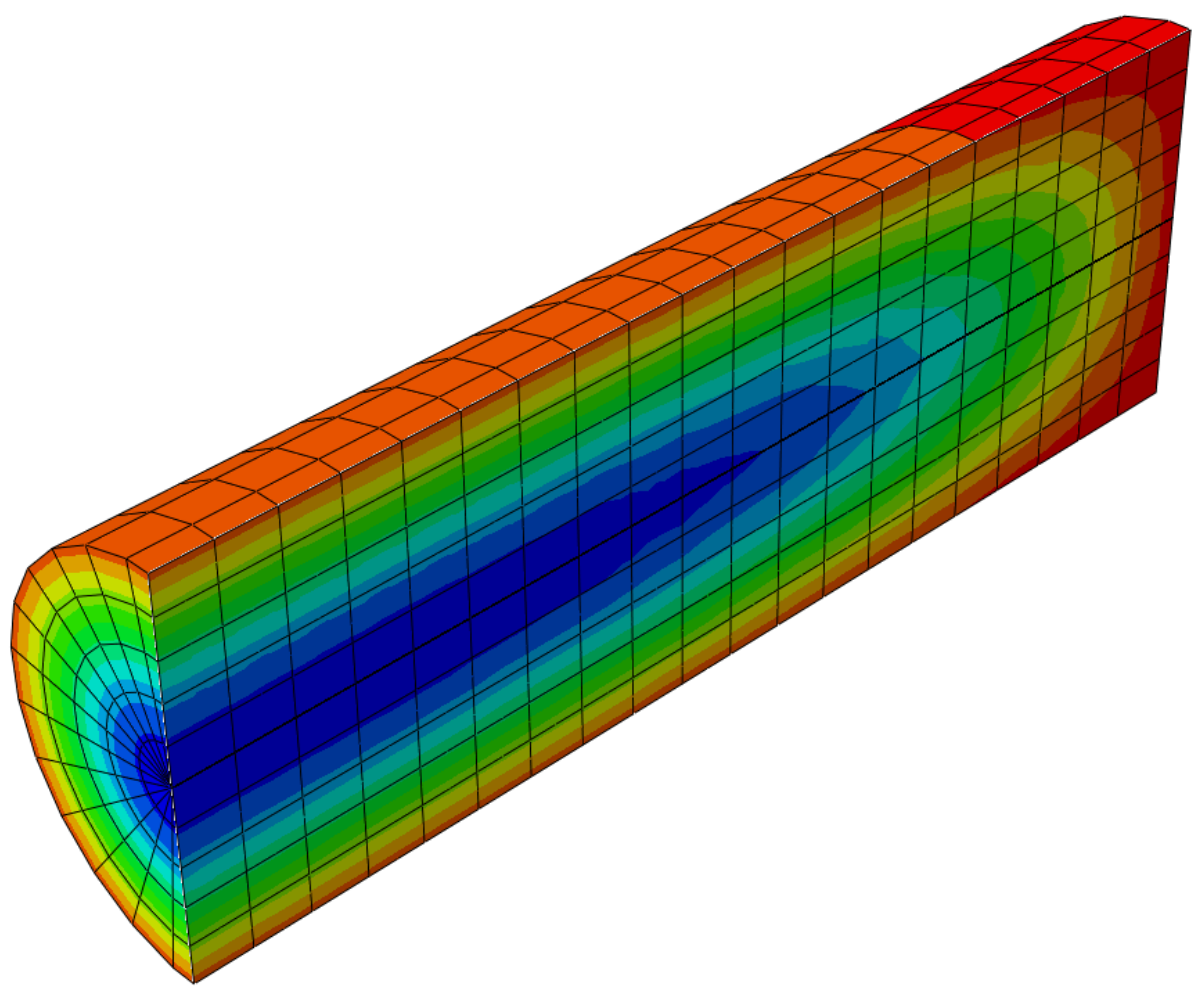

Figura 7.2. Variação do calor no cilindro

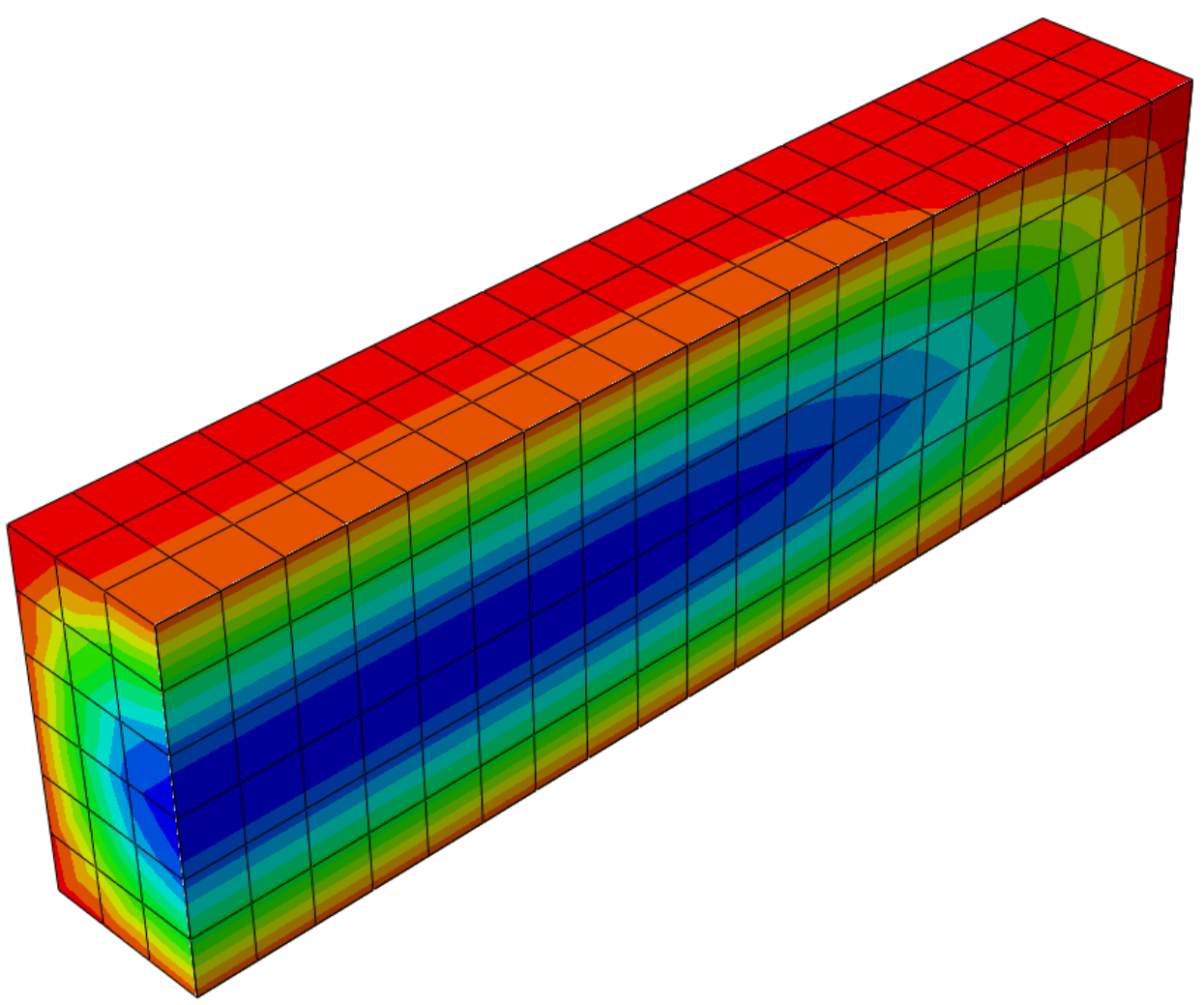

Figura 7.3. Variação do calor no prisma 
Neste estudo fez-se a calibragem da condutividade térmica usando os resultados da parte experimental. Para fazer essa calibragem, utilizaram-se as temperaturas obtidas no interior dos corpos de prova, que foram captadas por meio dos termopares. Para os cilindros, utilizaram-se os dois termopares, que apresentaram resultados quase idênticos. A fim de simplificar a análise para o prisma, foi utilizada apenas a temperatura do termopar no centro do corpo de prova.

A análise foi iniciada com os valores de condutividade térmica para concreto convencional, retirados do item C.3 da ABNT NBR 15200:2012, e todos esses valores, no intervalo de $28{ }^{\circ} \mathrm{C}$ a $600 \stackrel{\circ}{\circ}$, foram sendo ajustados um a um, até que a curva do resultado numérico ficasse sobre a curva da parte experimental. Foram feitas várias análises, até que se chegou aos resultados mostrados nas figuras $7.4 \mathrm{e}$ 7.5 , para os cilindros e prismas, respectivamente.

Observa-se na figura 7.4 a reta azul, que representa a taxa de aquecimento igual a $1^{\circ} \mathrm{O} / \mathrm{min}$, e as curvas laranja e cinza, relativas às temperaturas captadas pelos termopares 1 e 2 , respectivamente, que são muito próximas, mesmo estando os termopares em posições um pouco diferentes. E por último, indica-se a curva tracejada, que representa o resultado obtido na análise numérica. Percebe-se que ela ficou praticamente sobre a curva resultante da análise experimental.

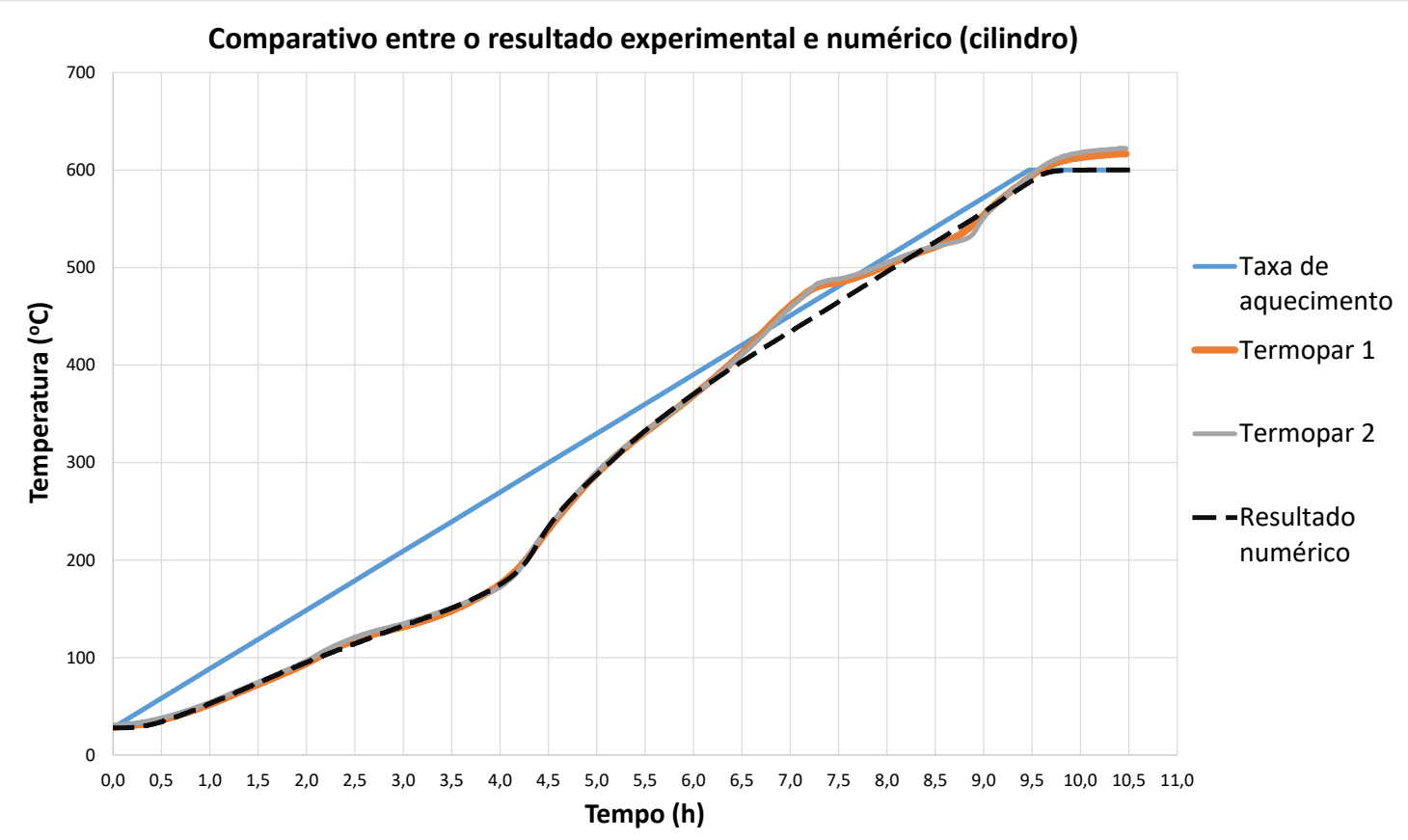

Figura 7.4. Gráfico comparativo entre o resultado experimental e o numérico para o cilindro. 
Na figura 7.5, observa-se a reta azul, que neste caso corresponde à taxa de aquecimento igual a $0,5^{\circ} \mathrm{C} / \mathrm{min}$, a curva verde, relativa ao termopar 2 , e a curva tracejada, que indica os resultados da análise numérica, e que também ficou praticamente sobre a curva obtida na análise experimental.

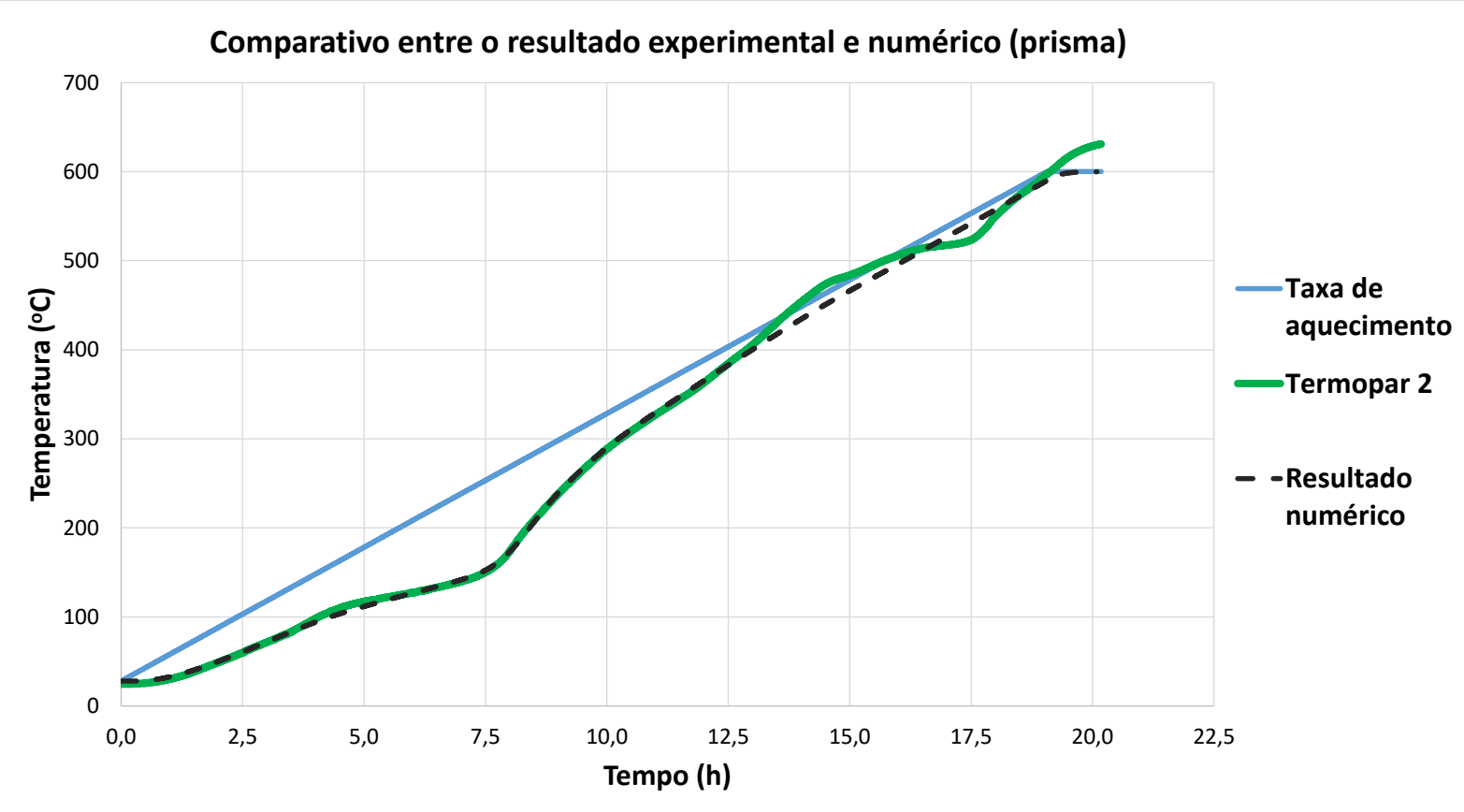

Figura 7.5. Gráfico comparativo entre o resultado experimental e o numérico para o prisma.

Os resultados obtidos de condutividade térmica estão mostrados na tabela 7.2 e na figura 7.6, nas quais podem ser comparados com os valores de condutividade do concreto convencional. Observa-se que o concreto com EPS possui uma grande diferença com relação ao concreto convencional, sendo a condutividade térmica aproximadamente $80 \%$ menor. Acredita-se que isso se deve ao fato do EPS ser um excelente isolante térmico, e por esse motivo, possuir condutividade térmica tão baixa, no início do ensaio.

Uma observação importante é que, mesmo o concreto do corpo de prova cilíndrico e o do prismático sendo do mesmo lote, eles apresentam resultados um tanto diferentes. Acredita-se que essa diferença também se deve ao EPS, porém, desta vez, também está relacionada com a taxa de aquecimento. 
Tabela 7.2. Resultados de condutividade térmica $\left(W / m{ }^{\circ} \mathrm{C}\right)$

\begin{tabular}{c|c|c|c}
\hline Temperatura $\left({ }^{\circ} \mathrm{C}\right)$ & $\begin{array}{c}\text { Corpo de prova } \\
\text { cilíndrico }\end{array}$ & $\begin{array}{c}\text { Corpo de prova } \\
\text { prismático }\end{array}$ & Concreto Convencional \\
\hline 28 & 0,25 & 0,25 & 1,32 \\
\hline 100 & 0,20 & 0,25 & 1,23 \\
\hline 150 & 0,09 & 0,08 & 1,17 \\
\hline 200 & 0,05 & 0,12 & 1,11 \\
\hline 250 & 0,10 & 0,20 & 1,06 \\
\hline 300 & 0,20 & 0,28 & 1,00 \\
\hline 350 & 0,35 & 0,35 & 0,95 \\
\hline 400 & 0,50 & 0,50 & 0,91 \\
\hline 450 & 0,50 & 0,75 & 0,86 \\
\hline 500 & 0,52 & 0,75 & 0,82 \\
\hline 550 & 0,55 & 0,80 & 0,78 \\
\hline 600 & 0,80 & 0,93 & 0,75 \\
\hline
\end{tabular}

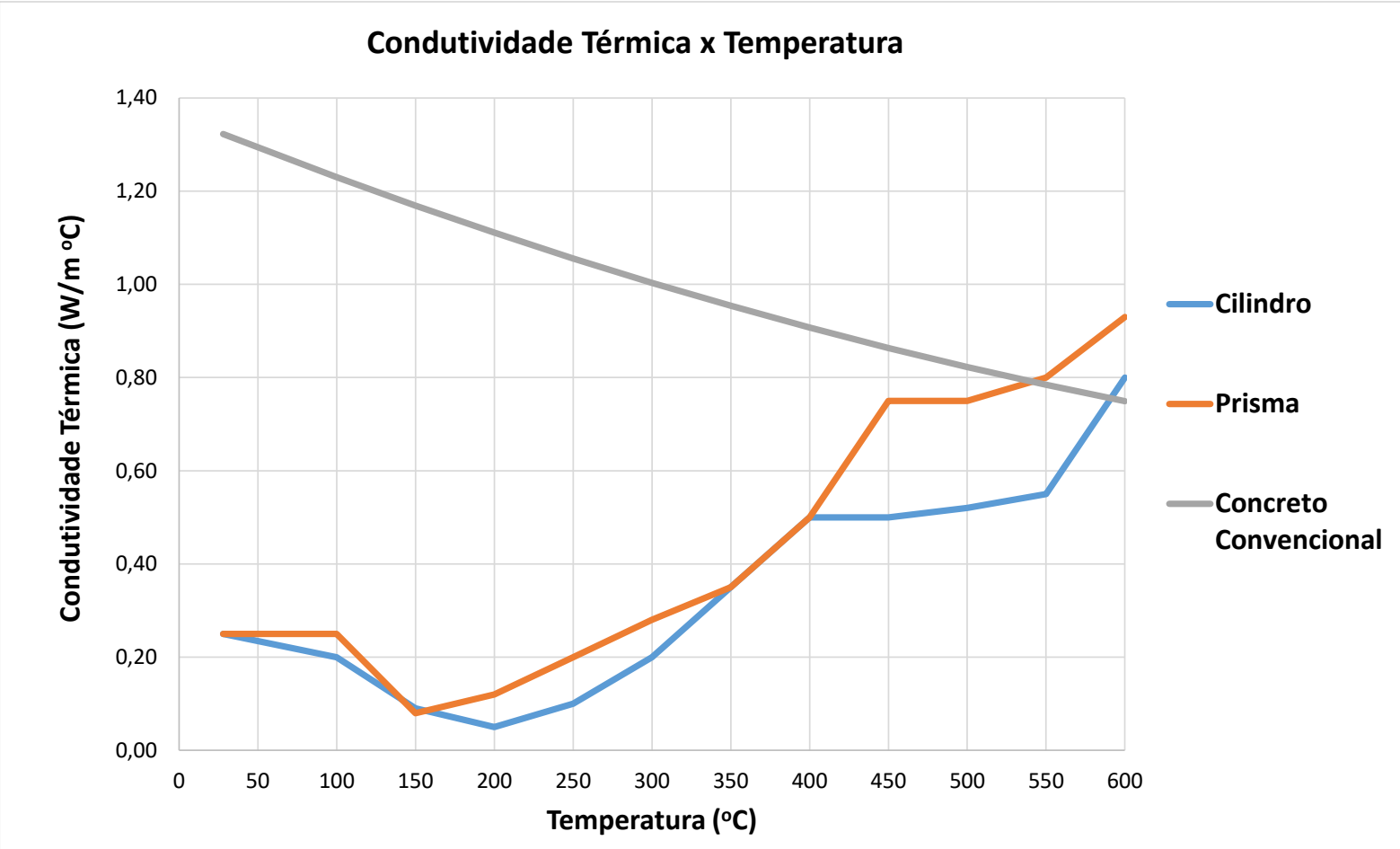

Figura 7.6. Condutividade térmica versus temperatura 
Pode-se explicar essa diferença lembrando-se do que foi comentado na análise dos resultados experimentais: os cilindros que foram aquecidos a $200{ }^{\circ} \mathrm{C}$ ainda possuíam um pouco de EPS após a ruptura, conforme foi mostrado na figura 6.5; já os prismas não possuíam mais EPS nessa temperatura, conforme foi mostrado na figura 6.24.

Agora, analisando o gráfico da figura 7.6, a condutividade térmica é decrescente até $200 \stackrel{\circ}{\mathrm{C}}$ para os cilindros, e passa a ser crescente com uma grande variação até os $400{ }^{\circ} \mathrm{C}$. Fica claro que esse trecho teve esse aumento de condutividade porque o EPS derreteu com o calor. E a mesma análise pode ser feita para o prisma, em que a condutividade é decrescente até $150^{\circ} \mathrm{C}$, e passa a ser crescente até os $450 \stackrel{\circ}{\circ}$, pelo mesmo motivo anterior.

Acredita-se que esse grande aumento da condutividade entre $500 \stackrel{\circ}{\mathrm{C}}$ e $600 \stackrel{\circ}{\circ} \mathrm{C}$ se deve ao fato do concreto possuir uma grande parte de vazios, devido ao derretimento do EPS. 


\section{CONCLUSÕES}

Neste capítulo, apresentam-se as conclusões da análise experimental dos corpos de prova cilíndricos, dos prismáticos e da análise numérica. Apresentam-se, também, sugestões para futuras pesquisas.

\subsection{Análise experimental dos corpos de prova cilíndricos}

$\mathrm{Na}$ figura 8.1, tem-se um comparativo de todas as propriedades estudadas com os corpos de prova cilíndricos, que embasam as seguintes conclusões:

$>$ Todas as propriedades tiveram uma redução significativa com o aumento da temperatura, exceto a massa específica, pois ela nunca será igual a zero após aquecimento a qualquer temperatura;

$>$ Exceto a massa específica, todas tiveram a maior variação de redução entre $200^{\circ} \mathrm{C}$ e $400^{\circ} \mathrm{C}$;

$>$ A resistência à compressão axial teve um fator de redução bem próximo ao da resistência à tração por compressão diametral, o que mostra que as duas grandezas podem ser relacionadas. Usando os valores encontrados nos ensaios, chega-se à seguinte relação aproximada:

$$
f_{c t, s p}=8,54 \% \cdot f_{c}
$$

$>$ O módulo de elasticidade dinâmico teve um fator de redução bem próximo ao do módulo de elasticidade estático, o que comprova que, mesmo para corpos de prova previamente aquecidos, a técnica de excitação por impulso gera resultados coerentes;

> O módulo de elasticidade estático apresentou o pior comportamento sob elevadas temperaturas, em comparação com as outras propriedades estudadas. Esse módulo é praticamente nulo na temperatura de $600{ }^{\circ} \mathrm{C}$;

$>$ A resistência à compressão diminuiu 50\% para uma temperatura aproximada de $340 \stackrel{\circ}{\circ}$, que é atingida com facilidade em um incêndio, o que indica ser muito importante a consideração de proteção ativa. 


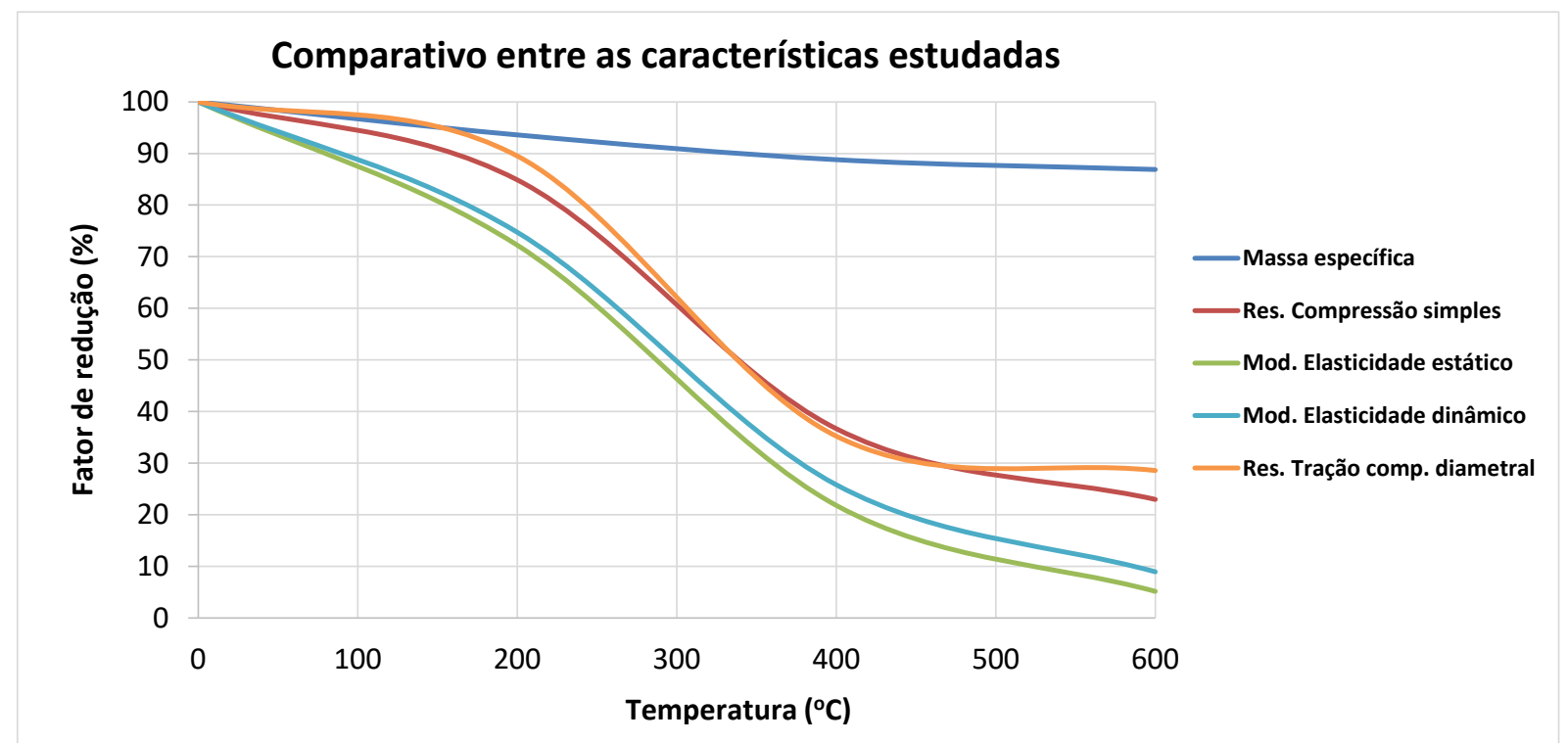

Figura 8.1. Comparativo entre as características estudadas com os corpos de prova cilíndricos

\subsection{Análise experimental com os corpos de prova prismáticos}

Sobre a análise experimental realizada com os corpos de prova prismáticos, pode-se concluir que:

> A consideração de fibras de aço no concreto leve com EPS é benéfica para que haja acréscimo de resistência à tração na flexão, principalmente para os casos com elevadas temperaturas.

Para temperatura ambiente, a partir de 0,3\% de fibras, não há diferença na resistência à tração, pois foram obtidos os mesmos resultados para as taxas de $0,6 \%$ e $0,9 \%$. Porém, analisando os casos com aquecimento a $200{ }^{\circ} \mathrm{C}$ e $600{ }^{\circ} \mathrm{C}$, verifica-se que há um aumento de resistência com $\mathrm{O}$ acréscimo de fibras, conforme já foi mencionado.

$>$ O traço com $0,6 \%$ de fibra apresentou resultados incoerentes em todas as análises, pois se acredita que houve erro na dosagem do superplastificante. $O$ volume no misturador foi muito grande, pois foram produzidos corpos de provas cilíndricos e prismáticos para duas pesquisas de doutorado, a fim de aproveitar a mesma concretagem.

Há grande vantagem na utilização de fibras de aço para aumentar a tenacidade de possíveis elementos estruturais com o concreto leve com EPS. 
$>$ O acréscimo de fibras é altamente efetivo para o aumento da tenacidade para temperatura ambiente, pois a tenacidade apresenta um aumento de aproximadamente $500 \%$ para a taxa de 0,3\% de fibras. Esse aumento é um pouco menor para $200^{\circ} \mathrm{C}$, e bem menor para $600^{\circ} \mathrm{C}$, e para as taxas seguintes, $0,6 \%$ e 0,9\%, o aumento já não é mais tão significativo. Porém, todo acréscimo de taxa de fibras leva a um aumento na tenacidade. $E$ dependendo da utilidade do elemento estrutural, pode valer a pena considerar uma taxa maior de fibras.

\subsection{Análise numérica}

Após todos os resultados obtidos e análises realizadas, pode-se concluir que a condutividade térmica do concreto leve com EPS varia de acordo com a existência do EPS e com a taxa de aquecimento considerada, pois como o EPS é um excelente isolante térmico com baixa condutividade, enquanto ele estiver inserido no concreto, a condutividade do conjunto também será baixa.

E a condutividade térmica depende também da taxa de aquecimento, pois, como pôde ser visto no capítulo 6 , os cilindros que foram ensaiados após serem aquecidos a $200^{\circ} \mathrm{C}$, com a taxa de $1^{\circ} \mathrm{C} / \mathrm{min}$, ainda possuíam EPS em sua seção transversal, e estima-se que o EPS derreta por volta dos $300^{\circ} \mathrm{C}$. Já no caso do prisma, a taxa é de $0,5^{\circ} \mathrm{C} / \mathrm{min}$, e ele é mantido praticamente o dobro do tempo dentro do forno, e viu-se, após a ruptura, que o prisma relativo a $200{ }^{\circ} \mathrm{C}$ já não possuía mais EPS em sua seção transversal.

Sendo assim, acredita-se que se fosse utilizada uma taxa de aquecimento de $0,25{ }^{\circ} \mathrm{C} / \mathrm{min}$, seria possível que o EPS derretesse por completo na faixa dos $150{ }^{\circ} \mathrm{C}$, pois o EPS isolado, submetido a altas temperatura, começa a amolecer e a se

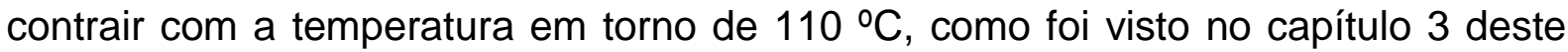
trabalho.

Vale ressaltar que neste trabalho foram feitos estudos iniciais com esse material, e somente após algumas outras pesquisas que precisam ser realizadas é que se poderá chegar a uma conclusão mais definitiva sobre o comportamento do concreto com EPS após situação de incêndio. 


\subsection{Sugestões para futuras pesquisas}

Para dar continuidade a este trabalho, sugerem-se as seguintes pesquisas sobre concreto leve com EPS submetido a elevadas temperaturas:

Avaliar a possibilidade de lascamento;

> Avaliar as propriedades após incêndio, ensaiando aquecido e com resfriamento rápido;

> Estudar o comportamento de estruturas mistas de concreto leve com EPS e aço;

> Estudar o comportamento de blocos de alvenaria estrutural.

> Estudar o comportamento de vigas armadas, com pequenos vãos.

> Fazer uma simulação numérica considerando fibras de aço em temperatura ambiente e em altas temperaturas. 


\section{REFERÊNCIAS BIBLIOGRÁFICAS}

AMERICAN CONCRETE INSTITUTE (ACI). ACI 213R-87. Guide for structural lightweight aggregate concrete, 1999.

AMERICAN CONCRETE INSTITUTE. Manual of concrete practice: part 5. ACI. Report on fiber-reinforced concrete (ACI 544.1R-96). ACI Committee 544. Detroit, USA, 2002.

AMERICAN SOCIETY FOR TESTING AND MATERIALS (ASTM). ASTM C330: Standard specification for lightweight aggregates for structural concrete. Philadelphia, 1989.

AMERICAN SOCIETY FOR TESTING AND MATERIALS (ASTM). E-119-00: Standard test methods for fire tests of building constructions and material. West Conshohocken (USA), 2000.

ANBIO: banco de dados. (2008). Disponível em:

<http://www.anbio.org.br/biodiver_art102.htm>. Acesso em: 25 mar. 2014.

ANDERSSON, A. Apropos a Swedish Library on Fire: the Salamander and the Parrot. The Art Bin, Sept. Articles and Essays. 1996. Disponível em:

<http://artbin.com/art/abooksonfire.html>. Acesso em: 15 jul. 2014.

ASSOCIAÇÃO BRASILEIRA DE NORMAS TÉCNICAS. Cargas para o cálculo de estruturas de edificações, NBR 6120, Rio de Janeiro, RJ, 1980.

ASSOCIAÇÃO BRASILEIRA DE NORMAS TÉCNICAS. Exigências de resistência ao fogo de elementos construtivos de edificações - Procedimento, NBR 14432, Rio de Janeiro, RJ, 2001.

ASSOCIAÇÃO BRASILEIRA DE NORMAS TÉCNICAS. Dimensionamento de estruturas de aço e de estruturas mistas aço-concreto de edifícios em situação de incêndio - Procedimento, NBR 14323, Rio de Janeiro, RJ, 2003.

ASSOCIAÇÃO BRASILEIRA DE NORMAS TÉCNICAS. Fibras de aço para concreto - Especificação. NBR 15530, ABNT, Rio de Janeiro, 2007.

ASSOCIAÇÃO BRASILEIRA DE NORMAS TÉCNICAS. Concreto - Determinação do módulo estático de elasticidade à compressão. NBR 8522, ABNT, Rio de Janeiro, 2008.

ASSOCIAÇÃO BRASILEIRA DE NORMAS TÉCNICAS. Concreto e argamassa Determinação da resistência à tração por compressão diametral de corpos de prova cilíndricos. NBR 7222, ABNT, Rio de Janeiro, 2011. 
ASSOCIAÇÃO BRASILEIRA DE NORMAS TÉCNICAS. Projeto de estruturas de concreto em situação de incêndio, NBR 15200, Rio de Janeiro, RJ, 2012.

ASSOCIAÇÃO BRASILEIRA DE NORMAS TÉCNICAS. Projeto de estruturas de concreto - Procedimento, NBR 6118, Rio de Janeiro, RJ, 2014.

BACARJI, E. Análise de estruturas de edifícios: projeto de pilares. 1993. Dissertação (Mestrado) - Escola de Engenharia de São Carlos, Universidade de São Paulo, São Carlos, 1993.

BATTISTA, R.; BATISTA, E.; CARVALHO, E. Reabilitação estrutural do prédio do Aeroporto Santos Dumont após danos causados por incêndio. Revista Internacional de Desastres Naturales: acidentes e infraestructura civil. v.1, n.1, p. 51-60.

BAUER, L. A. F.; TOLEDO, E. Características do concreto leve de styropor. São Paulo: IBRACON, 1973.

BENTUR, A.; MINDESS, D. Fibre reinforced cementitious composites. United Kingdom: Elsevier, 2007.

BUCHANAN, A. H. Structural for Design Safety. John Wiley \&Sons Ltd. Chichester (UK), 2001.

Cairo building collapse kills five. CHINAdaily.com.cn, Jan. 27, 2004.

News/International News. Disponível em:

<http://www.chinadaily.com.cn/en/doc/2004- 01/27/content_301145.htm>. Acesso em 15 jul. 2014.

CARNIO, M. A. Análise em regime plástico de placas de concreto reforçado com fibras de aço sobre base elástica. 1998. 103p. Dissertação (Mestrado) Faculdade de Engenharia Civil, Universidade Estadual de Campinas, Campinas, 1998.

CATOIA, T. Concreto Ultraleve ${ }^{\circledR}$ estrutural com pérolas de EPS: caracterização do material e estudo de sua aplicação em lajes. 2012. Tese (Doutorado). Escola de Engenharia de São Carlos, Universidade de São Paulo, São Carlos, 2012.

CORPO DE BOMBEIROS - POLÍCIA MILITAR DO ESTADO DE SÃO PAULO (CVPMESP). Segurança estrutural nas edificações - resistência ao fogo dos elementos de construção. São Paulo: Secretaria de Estado dos Negócios da Segurança Pública. 2001. [Decreto Lei $n^{\circ} 46.076$ do Estado de São Paulo, 31 de Agosto de 2001].

COSTA, C. N. Dimensionamento de elementos de concreto armado em situação de incêndio. 2008. Tese (Doutorado). Escola Politécnica da Universidade de São Paulo, São Paulo, 2008. 
COSTA, C. N.; FIGUEIREDO, A. D.; SILVA, V. P. O fenômeno do lascamento ("spalling") nas estruturas de concreto armado submetidas a incêndio - uma revisão crítica. In: Instituto Brasileiro do Concreto - 44ํㅡㄹ Congresso Brasileiro - Belo Horizonte, MG, 2002.

EUROPEAN COMMITTEE FOR STANDARDIZATION. EN 1992-1-2: Eurocode 2: design of concrete structures - part 1.2: general rules - structural fire design. Brussels: CEN. 2004. 97p.

EUROPEAN COMMITTEE FOR STANDARDIZATION. EN 1994-1-2: Eurocode 4: design of composite steel and concrete structures - part 1.2: general rules structural fire design. Brussels: 2005.

FERREIRA, C. N. G.; RIBEIRO, M. C. F. Reutilização de resíduos de EPS na produção de concreto leve. 2008. 43p. Trabalho de conclusão de curso (Graduação) - Centro Universitário da Fundação Educacional de Barretos, Barretos, 2008.

FIGUEIREDO, A. D. Dosagem e controle do concreto projetado com fibras. 1999. 26p. Anais. In: Simpósio tendência da engenharia estrutural empregando concreto de alto desempenho e concreto reforçado com fibras. Escola Politécnica da Universidade de São Paulo, São Paulo, 1999.

FIGUEIREDO, A. D. Concreto com fibras de aço. Boletim Técnico (BT/PCC/260). São Paulo: Escola Politécnica da Universidade de São Paulo, São Paulo, 2000.

FIGUEIREDO, A. D. Concreto com fibras. In: ISAIA, G.C. Concreto: ensino, pesquisa e realizações. São Paulo: Instituto Brasileiro do Concreto (IBRACON), 2005. v.2, Capítulo 39, p.1195-1225, 2005.

FIGUEIREDO, A. D. A nova especificação brasileira das fibras de aço para concreto. In: $50^{\circ}$ Congresso Brasileiro do Concreto, Salvador, 2008 Anais. Instituto Brasileiro do Concreto (IBRACON). São Paulo, 2008.

FIGUEIREDO, A. D. Concreto reforçado com fibras. 2011. 248p. Tese (LivreDocência) - Escola Politécnica da Universidade de São Paulo, São Paulo, 2011.

FIGUEIREDO, A. D.; NUNES, N. L; TANESI, J. Mix design analysis on steel fiber reinforced concrete. 2000. In: Fifth International RILEM Symposium on FibreReinforced Concretes (FRC), Fibre-Reinforced Concretes (FRC) - BEFIB'2000. Proceedings. RILEM Publications S.A.R.L., Lyon, 2000.

FIGUEIREDO, A. D.; TORNERI, P. Efeitos da ancoragem em gancho de fibras na tenacidade dos concretos. In: VI Simpósio EPUSP sobre Estruturas de Concreto, Anais, p.1173-1184. São Paulo, 2006. 
FIGUEIREDO, A. D.; CHAMA NETO, P. J.; FARIA, H. M. A nova normalização brasileira sobre fibras de aço. Concreto \& Construções, São Paulo, v. 36, n. 50, p.67-76, 2008.

Fünf der siebenvermisstenFeuerwehrmännersindtot. FeuerwehrvereinHinwil.

27 nov. 2004. Disponível em:

<http://www.feuerwehrschweiz.ch/index.php?module=News\&func=display\&sid=434>.

Acesso em: 14 jul. 2014.

HARMATHY, T. Z. Fire Safety Design \& Concrete. Concrete Design \& Construction Series. Longman Scientific \& Technical. London, 1993.

HERTZ, K. D. Limits of Spalling of Fire-exposed Concrete. Fire Safety Journal. V.38, 2003. p. 103-116.

INTERNATIONAL ORGANIZATION FOR STANDARDIZATION. Fire-Resistance Tests - Elements of Building Construction. Part 1: General Requirements. ISO 834. Geneva. Revision of first edition (ISO 834:1975), 1999.

ISOFÉRES (2012). Comportamento do Poliestireno Expandido EPS ao fogo. Disponível em:

<http://www.isoferes.com.br/imagens/ARQUIVOS\%20PDF\%20SITE/Comportamento \%20do\%20EPS\%20ao\%20fogo.pdf>. Acesso em: 12 dez. 2014.

JAPAN SOCIETY OF CIVIL ENGINEERS. Method of tests for flexural strength and flexural toughness of steel fiber reinforced concrete. JSCE-SF4. Concrete Library of JSCE. Part III-2 Method of tests for steel fiber reinforced concrete. №3 June 1984b. p. 58-61.

KALIFA, P.; MENNETEAU, F. D.; QUENARD, D. Spalling and Pore Pressure in HPC at High Temperatures. Cement and Concrete Research, n. 30. Elsevier Science Ltd., Amsterdam, 2000.

KHOURY, G. A. Effect of fire on concrete and concrete structures. Progress in Structural Engineering and Materials, London, v. 2, n. 4, 2000. p. 429-447.

KIRCHHOF, L. D. Estudo teórico-experimental da influência do teor de umidade no fenômeno de spalling explosivo em concretos expostos a elevadas temperaturas. 2010. 237p. Tese (Doutorado) - Programa de Pós-graduação em Engenharia Civil, Universidade do Rio Grande do Sul, Porto Alegre, 2010.

LANDI, F. R. Ação do incêndio sobre as estruturas de concreto armado. Boletim Técnico BT (PCC - 86 / 001). São Paulo: EPUSP, 1986.

LARANJEIRAS, A. C. R. Colapso progressivo dos edifícios. TQS News, Edição 33, 2011. 
Lembranças do Andraus e do Joelma. Blog Memória Viva. Fev. 28, 2011. Disponível em: http://novoblog.memoriaviva.com.br/2011/02/28/lembrancas-doandraus-e-do-joelma. Acesso em: 15 jul. 2014.

MAIDL, B. Stahlfaserbeton. Berlin. Ernst \& Sohn Verlag für Architektur und technische Wissenschaften, 1991.

MEHTA, P. K.; MONTEIRO, P. J. M. Concreto: microestrutura, propriedades e materiais. 3. ed. 674p. São Paulo: IBRACON, 2008.

MORRISON, R. T.; BOYD, R. N. Organic Chemistry. USA: Prentice Hall, 2002.

NAAMAN, A. E. Development and evolution of tensile strain-hardening FRC composites. In: 7th International RILEM Symposium on Fiber Reinforced Concrete: Design and Applications, 2008, Chennai, India. Fiber Reinforced Concrete: Design and Applications. Babneux - France: RILEM Publications S. A. R. L., Lyon, 2008.

NEVILLE, A. M. Propriedades do concreto. Pini, 2. ed. São Paulo, 1997.

NINCE, A. A. Lascamento do concreto exposto a altas temperaturas. 2006. 300p. Tese (Doutorado) - Escola politécnica, Universidade de São Paulo, São Paulo, 2006.

NUNES, N. L. Contribuição para a aplicação do concreto reforçado com fibras de aço em elementos de superfície restringidos. 2006. 253p. Tese (Doutorado) Escola Politécnica da Universidade de São Paulo. São Paulo, 2006.

NUNES, N. L.; TANESE, J.; FIGUEIREDO, A. D. Aplicação do concreto reforçado com fibras de aço na recuperação de estruturas e pavimentos. In: Congresso lberoamericano de Patologia das Construções, 1997, Porto Alegre RS: Anais, 1997. v.2, p.41-48. Porto Alegre, 1997.

Olhar sobre o Mundo. Jornal Estado de São Paulo. Dez. 07, 2010. Foto: Antônio Lúcio. Disponível em:

http://blogs.estadao.com.br/olhar-sobre-o-mundo/?attachment_id=8408\#.

Acesso em: 18 jul. 2014.

OLIVEIRA JUNIOR, L. A. Ligação viga-pilar em elementos pré-moldados de concreto solidarizados por concreto reforçado com fibras de aço: análises estática e dinâmica. 2012. 255p. Tese (Doutorado) - Escola de Engenharia de São Carlos, Universidade de São Paulo, São Carlos, 2012.

OZÓRIO, B. P. M. Concreto leve com pérolas de EPS: estudo de dosagens e de características mecânicas. 2016. 151p. Tese (Doutorado) - Escola de Engenharia de São Carlos, Universidade de São Paulo, São Carlos, 2016 
PHAN, L. T.; CARINO, N. J. Review of Mechanical Properties of HSC at Elevated Temperature. Journal of Materials in Civil Engineering. v.10, n.1. ASCE Publications, 1998.

PURKISS, J. A. Fire Safety Engineering Design of Structures. Butterworth Heinemann. Oxford, 1996.

RAMOS, A. L. Análise numérica de pisos mistos aço-concreto de pequena altura. 2010. 138p. Dissertação (Mestrado) - Escola de Engenharia de São Carlos, Universidade de São Paulo, São Carlos, 2010.

RAMOS, M. F. Análise experimental de tubos de concreto reforçado com fibras de aço. 2002. 140p. Dissertação (Mestrado) - Faculdade de Engenharia Civil, Universidade Estadual de Campinas, Campinas, 2002.

REUTERS. Governo pede esforço de Cuiabá para terminar estádio, que terá novas inspeções. Disponível em: http://esportes.terra.com.br/governo-pedeesforco-de-cuiaba-para-terminar-estadio-que-tera-novas-

inspecoes,c71adcd122144410VgnCLD2000000 ec6eb0aRCRD.html. Acesso em: 20 out. 2014.

ROCHA, F. M. Modelos numéricos de vigas mistas de aço e concreto pertencentes a sistemas de pisos mistos de pequena altura em situação de incêndio. 2012. 267p. Dissertação (Mestrado) - Departamento de Engenharia de Estruturas, Escola de Engenharia de São Carlos, Universidade de São Paulo, São Carlos, 2012.

ROSSIGNOLO, J. A.; AGNESINI, M. V. C. Concreto estrutural leve. In: ISAIA, G. C. Concreto: ensino, pesquisa e realizações. São Paulo: IBRACON, 2005. Cap.43, v.2, p.1333-1362.

ROSSO, T. Concretos leves na construção civil. São Paulo: IBRACON, 1973.

Russian apartment block collapses. BBC News. Jun. 3, 2002. Europe. Disponível em: <http://news.bbc.co.uk/2/hi/europe/2023544.stm>. Acesso em: 16 jul. 2014.

RUIZ, M. F.; MUTTONI, A.; KUNZ, J. Strengthening of Flat Slabs against Punching Shear Using Post-Installed Shear Reinforcement. ACI Structural Journal, v. 107, n. 4, p. 434-442, Julho, 2010.

SANTOS, D. B. R. Modelagem numérica de lajes mistas de aço e concreto em situação de incêndio. 2014. 243p. Dissertação (Mestrado) - Departamento de Engenharia de Estruturas, Escola de Engenharia de São Carlos, Universidade de São Paulo, São Carlos, 2014.

SILVA, V. P. Projeto de estruturas de concreto em situação de incêndio. Editora Blücher, São Paulo, SP, 2012. 
SILVA, V. P. Projeto de estruturas de concreto em situação de incêndio Proposta de revisão da NBR 15200:2004. Associação Brasileira de Engenharia e Consultoria Estrutural (ABECE), São Paulo, 2010.

SIQUEIRA, L. V. M.; STRAMARI, M. R.; FOLGUERAS, M. V. Adição de Poliuretano Expandido para a Confecção de Blocos de Concreto Leve. Revista Matéria, 2004. v.9, n.4, pp.399-410.

SOUZA, A. A. A. Influência do tipo de agregado nas propriedades mecânicas do concreto submetido ao fogo. 2005. Dissertação (Mestrado) - Faculdade de Engenharia Civil, Arquitetura e Urbanismo, Universidade Estadual de Campinas, Campinas, SP, 2005.

SOUZA, A. A. A. Procedimento de ensaio para verificação da tendência em laboratório do lascamento do concreto em situação de incêndio. 2010. Tese (Doutorado) - Faculdade de Engenharia Civil, Arquitetura e Urbanismo, Universidade Estadual de Campinas, Campinas, São Paulo, 2010.

SOUZA, L. M.; SANTOS, R. D.; MELO, A. V.; MENDES, J. U. L.; NASCIMENTO, C. M. Compósito a base de gesso e EPS para fabricação de casas populares - 17은 CBECIMat - Congresso Brasileiro de Engenharia e Ciência dos Materiais, Foz do Iguaçu, PR, 2006.

STOCCO, W. RODRIGUES, D.; CASTRO, A. P. A. S. Concreto Leve com Uso de EPS. Recife: COBENGE, 2009. 



\section{APÊNDICE A - Roteiro da análise numérica}

A seguir, apresenta-se um roteiro resumido dos procedimentos realizados dentro do software, para a concretização da análise numérica.

Editar Model-1

- Inserir o zero absoluto: - $273.15 \stackrel{\circ}{\circ}$

- Inserir a constante de Stefan-Boltzmann: $5.67 \times 10^{-8} \mathrm{~W} \cdot \mathrm{m}^{-2} \cdot \mathrm{k}^{-4}$

Clicar em Parts (dentro de Model-1)

- Inserir Name: Cilindro ou Prisma

- Modeling Space 3D

- Type Deformable

- Shape Solid - Extrusion

- Approximate size: 1

$>$ Fazer o desenho

- Para a análise do cilindro, fazer o desenho de um círculo com diâmetro igual a $0.1 \mathrm{~m}$, confirmar e colocar Depth igual $0.3 \mathrm{~m}$. Quando realizar a análise do prisma, desenhar um quadrado com lado $0.15 \mathrm{~m}$, confirmar e colocar Depth igual a $0.5 \mathrm{~m}$.

Clicar em Materials

- Inserir Name: Concreto

- General Density

- Thermal Conductivity

- Thermal Specific Heat

- Em todos, marcar Use temperature-dependent data

Clicar em Surfaces (dentro de cilindro ou prisma)

- Inserir Name: face exposta

- Type Geometry

- Selecionar a face exposta e clicar em Done 
Clicar em Sections

- Inserir Name

- Solid e Homogeneous

- Selecionar Material criado

Clicar em Section Assignments (dentro de cilindro ou prisma)

- Selecionar todo o elemento e confirmar

- Escolher a Section criada, e o elemento muda de cor

Clicar em Instances (dentro de Assembly)

- Marcar Parts e Dependent (mesh on part)

Clicar em Mesh (dentro de cilindro ou prisma)

- Clicar na barra de ferramentas Seed, e logo depois em Edges, e escolher o tamanho ou a quantidade dos elementos finitos que irá formar a malha do corpo de prova. Clicar em Mesh na barra de ferramentas, e logo depois em Part e Yes, para confirmar. Clicar em Mesh novamente, Element Type, selecionar o corpo de prova todo, clicar em Done, e escolher Family Heat Transfer, deixar Standard e Linear.

Clicar em Amplitude (dentro de Model-1)

- Inserir Name: Taxa de aquecimento

- Type Tabular

- Time span Step time

- Inserir uma planilha com a taxa de aquecimento já preenchida

Clicar em Predefined Fields (dentro de Initial que fica dentro de Steps)

- Inserir Name

- Step Initial

- Category Other

- Types for Selectec Step: Temperature

- Selecionar todo o corpo de prova e clicar em Done

- Distribution: Direct specification

- Section variation: constant through region

- Magnitude (temperature ambiente): $28 \stackrel{\circ}{C}$ 
Clicar em Steps (dentro de Model-1)

- Inserir Name: aquecimento

- Procedure type: General

- Heat Transfer

Aba Basic

- Response: Transient

- Time period: tempo final da amplitude

Aba Incrementation

- Maximum number of increments: quantidade suficiente para realizar a análise

- Increment size - Initial: 0.1 - Minimum: 0.001 - Maximum: 1 ou 20 ou 60 (quanto maior este número, mais rápido o processamento encerra).

- Max. Allowable temperature change per increment: 5

- Max. Allowable emissivity change per increment: 1

Clicar em Interection (dentro de aquecimento que fica dentro de Steps)

- Inserir Name: conveccao

- Step: aquecimento

- Types for Selected Step: Surface film condition

- Clicar em Surfaces... (botão do canto inferior direito da tela)

- Selecionar Cilindro-1. Face exposta e continuar

- Definition: Embedded Coefficient

- Film Coefficient: $25 \mathrm{Wm}^{2} /{ }^{\circ} \mathrm{C}$

- Film coefficient amplitude: Instantaneous

- Sink definition: 1 (fator de multiplicação)

- Sink amplitude: Taxa de aquecimento

Clicar em Interection (dentro de aquecimento que fica dentro de Steps)

- Inserir Name: radiacao

- Step: aquecimento

- Types for Selected Step: Surface radiation

- Clicar em Surfaces... (botão do canto inferior direito da tela)

- Selecionar Cilindro-1. Face exposta e continuar 
- Radiation type: To ambient

- Emissivity distribution: Uniform

- Emissivity: 0.8

- Ambient temperature: 1 (fator de multiplicação)

- Ambiente temperature amplitude: Taxa de aquecimento

Clicar em aquecimento created (dentro de States que fica dentro de Field Output Request)

- Domain: Whole model

- Frequency: Every $\mathrm{n}$ increments - n:1

- Output Variables: select from list below, NT, HFL (dentro de Thermal)

Clicar em History output request (dentro de Model-1)

- Inserir Name

- Step: aquecimento

- Domain: Set: cilindro-1.Set-1

- Frequency: Every $\mathrm{n}$ increments - n:1

- Output Variables: select from list below, NT (dentro de Thermal)

Clicar Job (dentro de Analysis)

- Inserir Name: Job-1

- Source: Model e ok.

- Clicar em Job-1 com o botão direito do mouse: Submit (irá fazer a análise)

- Clicar em Job-1 com o botão direito do mouse: Monitor (para acompanhar a análise)

- Clicar em Job-1 com o botão direito do mouse: Results (para ver os resultados, assim que a análise for concluída) 